\title{
Platelet procoagulant acitivity: focus on calcium entry and phospholipid scrambling
}

Citation for published version (APA):

van Kruchten, R. (2014). Platelet procoagulant acitivity: focus on calcium entry and phospholipid scrambling. [Doctoral Thesis, Maastricht University]. Uitgeverij BOXPress. https://doi.org/10.26481/dis.20140117rk

Document status and date:

Published: 01/01/2014

DOI:

10.26481/dis.20140117rk

Document Version:

Publisher's PDF, also known as Version of record

\section{Please check the document version of this publication:}

- A submitted manuscript is the version of the article upon submission and before peer-review. There can be important differences between the submitted version and the official published version of record.

People interested in the research are advised to contact the author for the final version of the publication, or visit the DOI to the publisher's website.

- The final author version and the galley proof are versions of the publication after peer review.

- The final published version features the final layout of the paper including the volume, issue and page numbers.

Link to publication

\footnotetext{
General rights rights.

- You may freely distribute the URL identifying the publication in the public portal. please follow below link for the End User Agreement:

www.umlib.nl/taverne-license

Take down policy

If you believe that this document breaches copyright please contact us at:

repository@maastrichtuniversity.nl

providing details and we will investigate your claim.
}

Copyright and moral rights for the publications made accessible in the public portal are retained by the authors and/or other copyright owners and it is a condition of accessing publications that users recognise and abide by the legal requirements associated with these

- Users may download and print one copy of any publication from the public portal for the purpose of private study or research.

- You may not further distribute the material or use it for any profit-making activity or commercial gain

If the publication is distributed under the terms of Article $25 \mathrm{fa}$ of the Dutch Copyright Act, indicated by the "Taverne" license above, 
Platelet procoagulant activity: focus on calcium entry and phospholipid scrambling 
Platelet procoagulant activity: focus on calcium entry and phospholipid scrambling Thesis Universiteit Maastricht ISBN: 978-90-8891-775-2

Cover design: Roger van Kruchten

Printed by: Proefschriftmaken.nl || Uitgeverij BOXPress

(C) 2013 Roger van Kruchten, Nootdorp 


\title{
Platelet procoagulant activity: focus on calcium entry and phospholipid scrambling
}

\author{
PROEFSCHRIFT \\ ter verkrijging van de graad van doctor \\ aan de Universiteit Maastricht, \\ op gezag van de Rector Magnificus, \\ Prof. dr. L.L.G. Soete, \\ volgens het besluit van het College van Decanen, \\ in het openbaar te verdedigen op
}

vrijdag 17 januari 2014 om 12.00 uur

door

Roger van Kruchten

Geboren op 13 februari 1985 te Sittard 


\section{Promotor}

Prof. Dr. J.W.M. Heemskerk

Department of Biochemistry, CARIM, Maastricht University

\section{Copromotor}

Dr. E.M. Bevers

Department of Biochemistry, CARIM, Maastricht University

\section{Beoordelingscommissie}

Prof. Dr. J.F.C. Glatz (voorzitter)

Prof. Dr. U. Schotten

Prof. Dr. H. Struijker-Boudier

Dr. M.M.P.C. Donners

Dr. M. Roest (Universitair Medisch Centrum Utrecht)

Financial support by the Dutch Heart Foundation for the publication of this thesis is gratefully acknowledged.

Project supported by the Center for Translational Molecular Medicine (INCOAG). 


\section{Contents}

$\begin{array}{lll}\text { Chapter } 1 & \text { General introduction } & 7\end{array}$

Chapter $2 \quad$ Measurement of whole blood thrombus formation using 19 parallel-plate flow chambers - a practical guide.

Chapter 3 Roles of platelet STIM1 and Orai1 in glycoprotein VI- and thrombin-dependent procoagulant activity and thrombus formation.

Chapter $4 \quad$ Antithrombotic potential of blockers of store-operated calcium channels in platelets.

Chapter $5 \quad$ Both TMEM16F-dependent and TMEM16F-independent 79 pathways contribute to phosphatidylserine exposure in platelet apoptosis and platelet activation.

Chapter 6 Role of murine TMEM16F in agonist- and apoptosis-induced 95 phospholipid scrambling in platelets and erythrocytes.

Chapter 7

Calcium-activated and apoptotic phospholipid scrambling induced by Ano6 can occur independently of Ano6 ion currents.

Chapter $8 \quad$ General discussion

Summary

Samenvatting

Curriculum Vitae

Publications

Dankwoord 

Chapter 1

General introduction 
Blood platelets play important roles in hemostasis and arterial thrombosis. When a blood vessel is ruptured, platelets rapidly interact with components of the extracellular matrix, then become activated and aggregate to form a plug, which is a first response to stop the bleeding ${ }^{1}$. Similarly, platelets contribute to the pathologic process of arterial thrombosis through formation of occlusive thrombi in atherosclerotic arteries, thus preventing sufficient blood supply to downstream tissues. Such an occlusive thrombus may result in coronary heart disease or stroke, both of which are major causes of death globally ${ }^{2}$. Besides platelets, also the process of blood coagulation is of key importance for both hemostasis and thrombosis. An important product of the coagulation cascade is thrombin, which acts as a potent platelet-activating agent and leads to the formation of a fibrin network, thus stabilizing the platelet plug or thrombus ${ }^{3}$.

In contrast to arterial thrombosis, where platelets play a pivotal role, the process of venous thrombosis is more critically dependent on the coagulation process. Therefore, arterial thrombosis is commonly treated with anti-thrombotics directed against platelet function (e.g., aspirin, clopidogrel), while venous thrombosis is targeted by inhibiting the coagulation process (e.g., with heparin or vitamin $\mathrm{K}$ antagonists). Although antithrombotic strategies are reasonably successful, a major concern is that most current forms of antithrombotic therapy (against platelets and coagulation) also cause an increased risk of bleeding. Therefore, considerable effort is put into the search for safer anti-thrombotic strategies, which combine successful prevention of thrombosis, with a limited risk of bleeding. In this introduction, as far as relevant for the present thesis, a general overview of the pathways of platelet activation and thrombus formation are described, including a brief description of the mechanisms of $\mathrm{Ca}^{2+}$ mobilization and phospholipid scrambling in platelets.

\section{Platelet adhesion, activation and thrombus formation}

Upon vessel wall damage or rupture of an atherosclerotic plaque, extracellular matrix components are exposed to the blood stream. Platelets express adhesive receptors that can interact with several of these components. One of the most thrombogenic components is collagen, in particular collagen types I and III, which are abundantly present in the vessel wall and in atherosclerotic plaques ${ }^{4}$. At high, arterial shear conditions, the primary adhesion of platelets to collagen is mediated by von Willebrand factor (vWF), which avidly binds to collagen fibers. Under shear stress, the collagen-bound vWF provides a highaffinity interaction site for glycoprotein lb (GPIb) on the platelet surface ${ }^{5-7}$. As platelets slow down by adhering to $\mathrm{VWF}$, they can directly interact with the collagen fibers through the collagen receptors, glycoprotein VI (GPVI) and integrin $\alpha_{2} \beta_{1}$. Besides collagen, also other components present in the vessel wall support platelet adhesion, such as fibronectin ${ }^{8,9}$ and laminin ${ }^{10}$. Once a platelet binds to collagen, signaling through GPVI induces platelet activation ${ }^{11-14}$. This activation causes release of secondary agonists such as ADP and thromboxane $A_{2}$, which enhance platelet activation in an autocrine or paracrine fashion by stimulating the $\mathrm{P} 2 \mathrm{Y}_{1} / \mathrm{P}_{2} \mathrm{Y}_{12}{ }^{15}$ and $\mathrm{TP}^{16,17}$ receptors, respectively. As a result of initial activation of the coagulation system, traces of locally produced thrombin further stimulate platelet activation through proteolytic cleavage of the protease-activated receptors, PAR-1 and PAR-4 ${ }^{18}$. 
The integrin $\alpha_{111} \beta_{3}$, highly expressed at the platelet surface, plays and important role in platelet aggregation. In an activated platelet, $\alpha_{11 b} \beta_{3}$ changes in conformational state in such a way, that fibrinogen can interact with this receptor, which then further facilitates platelet-platelet interactions through platelet-fibrinogen bridges ${ }^{1}$. While integrin activation leads to aggregation of a main population of the platelets, another subset of platelets is more directly involved in the coagulation process. These so-called procoagulant platelets expose phosphatidylserine (PS) on their outer cell surface, which acts as a platform for the $\mathrm{Ca}^{2+}$-dependent assembly of coagulation factor complexes, implicated in thrombin generation (Figure 1). Thus, the tenase complex, consisting of coagulation factors IXa and VIIla, forms activated factor $\mathrm{X}$, while the prothrombinase complex, consisting of factors $\mathrm{Xa}$ and $\mathrm{Va}$, converts prothrombin into thrombin. The result is an increase in the rate of thrombin formation on PS-exposing lipid membranes by 5 to 6 orders of magnitude ${ }^{19}$. Thrombin, apart from stimulating platelets through the receptors PAR-1 and PAR-4, accelerates coagulation through positive feedback on several other coagulation factors, and is responsible for the cleavage of fibrinogen, thus triggering the formation of a fibrin network, which stabilizes the thrombus.

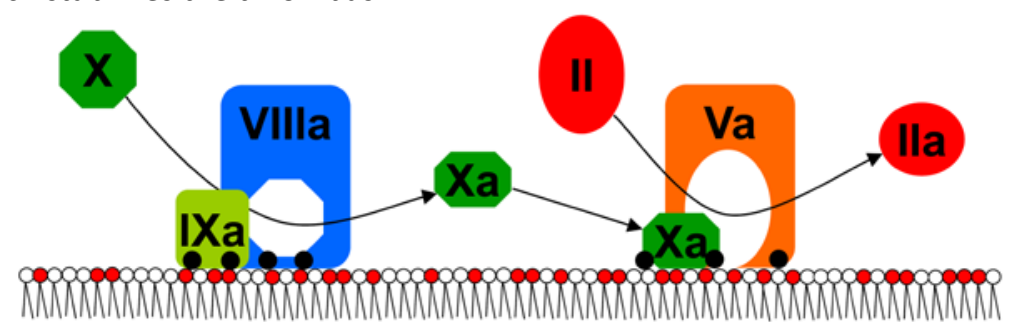

Figure 1. Schematic presentation of the tenase and prothrombinase complexes in thrombin generation. Factors IXa and co-factor VIIIla bind in a $\mathrm{Ca}^{2+}$-dependent way to a surface of negatively charged phospholipids (red bullets) to form the tenase complex, which cleaves factor $\mathrm{X}$ to its active form factor Xa. Subsequently, factor Xa together with co-factor Va forms a prothrombinase complex on the same phospholipid surface. This prothrombinase complex converts prothrombin (factor II) into the active thrombin (factor Ila).

\section{Flow chamber models}

Fluid dynamics play an important role in thrombus formation, as they determine plateletmatrix interactions, the kinetics of coagulation, margination of platelets to the vessel wall, folding of proteins like vWF, and shear-dependent platelet activation ${ }^{20}$. Steady interest into better understanding the role of flow in platelet activation has led to the development of flow-based devices, where many of the events in thrombus formation can be studied. In a parallel-plate flow chamber, the rheological conditions present in the vessel wall, can be mimicked in a well-controlled way. Baumgartner and colleagues developed such a device already in $1970^{21}$. While this flow chamber consumed multiple milliliters of blood per experiment, in later years flow devices were gradually down-scaled, so that nowadays only a few hundred microliters of blood are necessary for a typical blood perfusion experiment.

A usual procedure is to coat a thrombogenic substrate like collagen on a glass cover slip of the flow chamber, which is transparent in order to visualize the thrombus buildup during 
blood flow in real time. To study platelet function, most flow chamber experiments are performed with anticoagulated blood, i.e. by inhibiting the coagulation system. However, suppression of coagulation does only limitedly reflect the actual situation in vivo. Alternatively, by allowing coagulation in a controlled way, it is possible to investigate thrombus formation under conditions where also thrombin and fibrin are formed ${ }^{22}$. Currently, numerous laboratories around the world are using flow chambers to study the process of thrombus formation ${ }^{23}$. However, there is a huge variation in type of flow chamber used, in coating with thrombogenic substrates, and in type of anticoagulation employed. This variation needs to be reduced, especially for use in future clinical studies, where the potency of this technique to assess thrombosis and bleeding risks will be evaluated. Given that many research laboratories study in vitro thrombus formation, there is a strong need for guidelines to standardize flow chamber experiments. These will be provided in the present thesis, which also reviews the numerous variables and readouts that can be used to assay thrombus formation under flow.

\section{Platelet calcium signaling}

Increase in the intracellular $\mathrm{Ca}^{2+}$ concentration plays an important role in platelet activation, since this mediates platelet shape change and pseudopod formation, integrin activation, secretion of secondary mediators, and the platelet procoagulant response. In platelets, the dense tubular system, which is the equivalent of the endoplasmic reticulum in other cell types, serves as the main intracellular $\mathrm{Ca}^{2+}$ store ${ }^{24}$. As there is a continuous leakage of $\mathrm{Ca}^{2+}$ from this store, it needs to be refilled by the action of sarco/endoplasmatic reticulum $\mathrm{Ca}^{2+}$-ATPases (SERCA). In platelets, the isoform SERCA2b is a key $\mathrm{Ca}^{2+}$-ATPase involved in store refilling. It is sensitive to inhibition by thapsigargin which, accordingly, provokes cytosolic $\mathrm{Ca}^{2+}$ elevation. Quantitatively less important may be the isoform SERCA3, which is considered to regulate $\mathrm{Ca}^{2+}$ transport into 2,5-di-(t-butyl)-1,4hydroquinone-sensitive acidic stores ${ }^{25-28}$. Homeostasis of $\mathrm{Ca}^{2+}$ in the platelet is further maintained by the action of plasma membrane $\mathrm{Ca}^{2+}$-ATPases, which function by transporting $\mathrm{Ca}^{2+}$ out of the platelet ${ }^{29}$.

Besides the $\mathrm{Ca}^{2+}$-ATPases, platelets also possess mechanisms to actively elevate $\mathrm{Ca}^{2+}$, both via $\mathrm{Ca}^{2+}$ entry over the plasma membrane and via $\mathrm{Ca}^{2+}$ release from the internal stores. The main pathway for $\mathrm{Ca}^{2+}$ entry is the so-called store-operated $\mathrm{Ca}^{2+}$ entry (SOCE). However, also receptor-coupled and -operated $\mathrm{Ca}^{2+}$ entry mechanisms exist, e.g., involving $\mathrm{P}_{2} \mathrm{X}_{1}$ receptors and TRPC channels ${ }^{30-33}$.

The term SOCE refers to a mechanism, in which the release of $\mathrm{Ca}^{2+}$ from internal stores primes for subsequent $\mathrm{Ca}^{2+}$ entry from the extracellular environment. Inositol triphosphate, generated by the action of phospholipase $C \beta /$ phospholipase $C \gamma 2$ upon collagen or thrombin stimulation, activates the inositol triphosphate receptor, which is a $\mathrm{Ca}^{2+}$ permeable ion channel present in the endoplasmic reticulum membrane. This mediates influx of $\mathrm{Ca}^{2+}$ from the reticular compartment into the cytosol, thereby reducing the $\mathrm{Ca}^{2+}$ store content. In SOCE, the $\mathrm{Ca}^{2+}$ store depletion triggers activation of plasma membrane $\mathrm{Ca}^{2+}$ channels, which then mediate influx of $\mathrm{Ca}^{2+}$ over the plasma membrane.

For long, the molecular identity of the SOCE channels has remained a mystery. This changed with the identification of $\mathrm{Ca}^{2+}$-sensing stromal interacting molecule 1 (STIM1) and 
the Orai type of plasma membrane $\mathrm{Ca}^{2+}$ channels ${ }^{34-39}$. The transmembrane protein STIM1 is located in the endoplasmic reticulum membrane and contains $\mathrm{Ca}^{2+}$-binding EF-hand domains, which stretch into the lumen of the endoplasmic reticulum. Following $\mathrm{Ca}^{2+}$ store depletion, this ion no longer binds to the $\mathrm{Ca}^{2+}$-binding domains of STIM1, causing this protein to redistribute towards so-called punctae near the plasma membrane (Figure 2). At these sites, STIM1 can activate the store-operated $\mathrm{Ca}^{2+}$ channels ${ }^{40}$. This mechanism was discovered by the finding that an EF-hand mutated STIM1 protein, which was unable to bind $\mathrm{Ca}^{2+}$, permanently opened the SOCE channels ${ }^{35,36,41}$.

Later, Orai1 was identified as the SOCE channel involved, when a mutated variant of Orai1 was characterized as the cause of a hereditary form of severe combined immunodeficiency due to defective T-cell function ${ }^{39}$. Expression of wildtype Orai1 restored the defective SOCE function in the affected T-cells. In mouse platelets, it was established that genetic deletion of STIM1 or Orai1 abrogated essentially all $\mathrm{Ca}^{2+}$ entry via SOCE. Importantly, in murine thrombosis models, the lack of STIM1 or Orai1 appeared to be protective in platelet-mediated, collagen-dependent arterial thrombus formation and ischemic brain infarction $^{38,42}$.

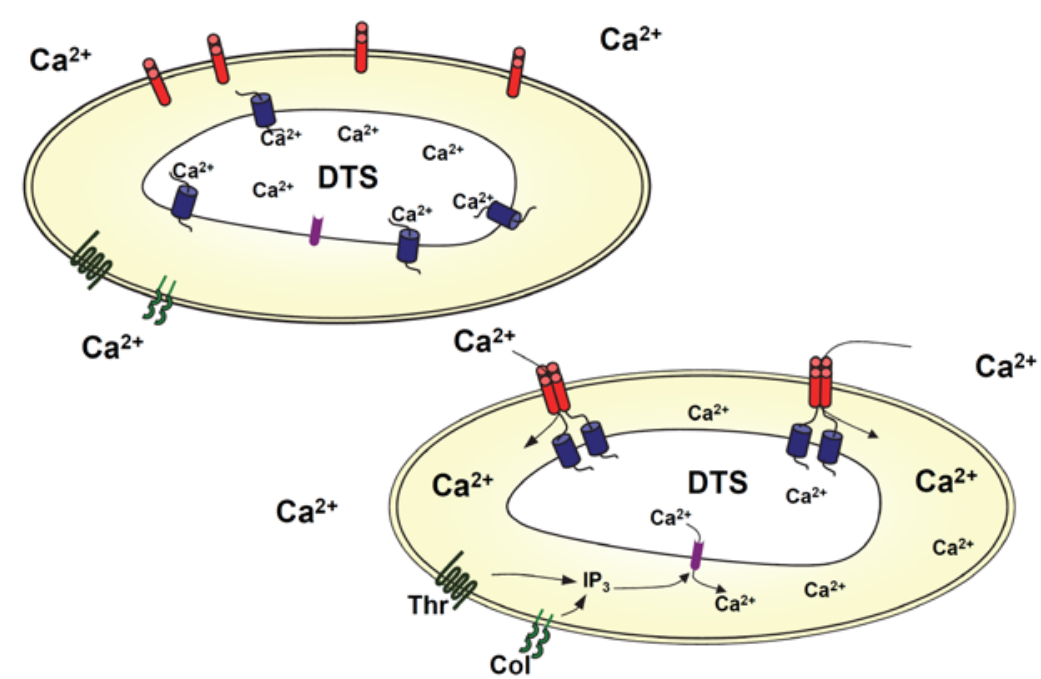

Orai1 subunits $\mathrm{STIM1}$ lo0 PAR-1/4 33 GPVI IP ${ }_{3}$ Receptor

Figure 2. Schematic model of STIM1- and Orai1-mediated store-operated $\mathrm{Ca}^{2+}$ entry. In the resting state, platelet $\mathrm{Ca}^{2+}$-stores are filled with $\mathrm{Ca}^{2+}$. This high $\mathrm{Ca}^{2+}$ content ensures binding to the $\mathrm{EF}$-hand in the $\mathrm{N}$-terminus of STIM1. Upon stimulation with platelet agonists such as thrombin or collagen, inositol triphosphate $\left(\mathrm{IP}_{3}\right)$ is generated, which activates the $\mathrm{IP}_{3}$ receptor in the endoplasmic reticulum membrane, enabling $\mathrm{Ca}^{2+}$ mobilization through its $\mathrm{Ca}^{2+}$ channel pore. Due to a lowered luminal $\mathrm{Ca}^{2+}$ concentration, $\mathrm{Ca}^{2+}$ dissociates from the EF-hand of STIM1, triggering migration of STIM1 to socalled punctae near the plasma membrane. Following this, STIM1 interacts with Orai1 dimers, creating a functional Orai1 tetramer allowing $\mathrm{Ca}^{2+}$ influx into the platelet. Modified after Ref. 68. 
It has been recognized for long, that a potent and prolonged elevation in cytosolic $\mathrm{Ca}^{2+}$ is required for platelet procoagulant activity ${ }^{19}$. However, whether SOCE in general, and $\mathrm{Ca}^{2+}$ entry via STIM1 and Orai1 in particular, is required for this platelet property in thrombus formation remains to be elucidated. In the present thesis, this is investigated under both coagulating and non-coagulating conditions. For this purpose, blood was used from bonemarrow chimeric mice, which lack expression of STIM1 or Orai1 in all hematologic cells, including platelets. Previously, blockers of $\mathrm{Ca}^{2+}$ entry were found to suppress platelet aggregation ${ }^{43}$. However, their efficacy has not been studied in more advanced models of thrombus formation. To answer the question whether Orai1 could be a drug target in thrombosis, we therefore decided to study the potential of several proposed $\mathrm{Ca}^{2+}$ entry blockers in arterial thrombus formation, both in vitro and in vivo.

\section{Phospholipid scrambling}

The catalytic activity of platelets to support blood coagulation particularly relies on the appearance of negatively charged PS in the outer leaflet of the plasma membrane (Figure 1). In resting platelets, the aminophospholipids $P S$ and phosphatidylethanolamine (PE) are kept in the cytoplasmic leaflet of the plasma membrane bilayer, while phosphatidylcholine and sphingomyelin are the major lipids of the outer leaflet ${ }^{44}$. This asymmetric distribution is maintained by the activity of an aminophospholipid translocase ${ }^{45}$, which continuously transports PS and PE from the outer leaflet to the inner leaflet at the expense of ATP. Upon strong platelet activation, lipid asymmetry dissipates due to inhibition of the aminophospholipid translocase and simultaneous activation of a phospholipid scramblase, catalyzing a rapid bidirectional transbilayer movement of all phospholipids ${ }^{46}$.

Whereas the identity of the aminophospholipid translocase has been resolved, the exact (molecular) identity of the scramblase is unclear. There is an important role for intracellular $\mathrm{Ca}^{2+}$ in phospholipid scrambling, taken from the observation that scramblase activity is induced, and translocase activity is inhibited by a high and sustained rise in cytosolic $\mathrm{Ca}^{2+}$ level ${ }^{47,48}$. Collagen or thrombin, separately, induce a modest $\mathrm{Ca}^{2+}$ response in platelets, thereby causing PS exposure in only a minor fraction of the platelets. However, the combined action of these two agonists is responsible for a sustained high $\mathrm{Ca}^{2+}$ level, which stimulates phospholipid scrambling resulting in PS exposure in a substantial fraction of the platelets. In vitro, elevation of cytosolic $\mathrm{Ca}^{2+}$ by ionomycin induces PS exposure in virtually all platelets ${ }^{49}$.

Recently, the TMEM16F gene has been identified to be critically involved in $\mathrm{Ca}^{2+}$-induced phospholipid scrambling ${ }^{50}$. The TMEM16F protein belongs to a family of $\mathrm{Ca}^{2+}$-activated chloride channels, the so-called anoctamins. This name is derived from their anion selectivity and the characteristic 8 membrane-spanning domains ${ }^{51,52}$. Knockdown of TMEM16F (anoctamin 6) was found to strongly decrease PS and PE externalization in a Ba/F3 cell line ${ }^{50}$. Moreover, a constitutively active mutant of TMEM16F was identified, in which a point mutation (Asp409Gly) resulted in a strongly decreased $\mathrm{Ca}^{2+}$ sensitivity of the phospholipid scramblase activity ${ }^{50}$.

Interestingly, defective expression of TMEM16F was demonstrated in two unrelated female patients with Scott syndrome, a rare congenital bleeding disorder linked with impaired $\mathrm{Ca}^{2+}$-induced phospholipid scrambling in hematopoietic cells ${ }^{50,53}$. Clinically these 
patients can be identified by a reduced prothrombin consumption, which can be restored by platelet transfusion ${ }^{54,55}$. Despite deficient platelet procoagulant activity, however, these patients do not bruise easily nor bleed excessively after superficial cuts. A bleeding tendency is though demonstrated by a high susceptibility for trauma-related hematoma, nose bleeds, and bleeding after tooth extraction, while there is also a risk for severe postpartum bleeding ${ }^{54}$. Although TMEM16F apparently seems crucial in externalizing PS, it remains unclear whether it is (part of) the scrambling machinery or whether it acts as a regulatory protein of a distinct scramblase.

In 2008, three independent laboratories demonstrated that two members of the anoctamin family, TMEM16A and TMEM16B (anoctamins 1 and 2), can serve as $\mathrm{Ca}^{2+}$-activated chloride channels ${ }^{56-59}$. However, whether other members of this gene family also have the capacity to function as $\mathrm{Ca}^{2+}$-activated chloride channels, is not yet clear. In Jurkat T-cells, TMEM16F has been demonstrated to account for outwardly rectifying chloride currents ${ }^{60}$. This raises the question to the relation of these apparently dual functions of TMEM16F: $\mathrm{Ca}^{2+}$-dependent phospholipid scrambling and $\mathrm{Ca}^{2+}$-dependent chloride channel activity. To investigate this, we used immortalized B-lymphocytes derived from the two Scott patients and from healthy subjects.

\section{Platelet apoptosis}

Platelets in the circulation have a life-span of 7-10 days. While some platelets are consumed as a result of their hemostatic function, most platelets become senescent and will be cleared in the liver or spleen. The mechanism behind platelet clearance is still mainly unknown. For the clearance of transfused platelets, glycan-lectin mediated mechanisms were found to be important ${ }^{61}$, but whether these also act on native, non-transfused platelets is questionable. Recent findings indicate that, similarly to nucleated cells, platelets can go into apoptosis, i.e. the process of programmed cell death executed through proteolytic caspases. This contrasts to the process of necrosis, in which a pronounced role of ATP depletion and $\mathrm{Ca}^{2+}$-dependent calpains has been recognized ${ }^{62}$.

In platelets, caspases appear to become active after initiating the so-called intrinsic, mitochondrial, pathway of apoptosis (Figure 3). This pathway is triggered when the proapoptotic proteins Bax and Bak are no longer suppressed by their anti-apoptotic counter parts like $\mathrm{BCl}-\mathrm{x}_{\mathrm{L}}{ }^{63,64}$. In many cell types, unrestrained Bax and Bak form a pore in the outer mitochondrial membrane, which results in the release of cytochrome c. Cytochrome $c$ is able to activate pro-caspase-9, which activates effector proteases like caspase-3, responsible for the cleavage of several cytoskeletal proteins such as filamin and gelsolin. In many cells, including platelets, this ultimately results in membrane blebbing and exposure of PS at the cell surface ${ }^{64}$. The exposed PS serves as a ligand for macrophage-produced lactadherin, which then facilitates the clearance of apoptotic cells from the circulation ${ }^{65}$.

In mice, it has been shown that dysfunctional mutations in $\mathrm{Bcl}-\mathrm{x}_{\mathrm{L}}$ result in thrombocytopenia due to a reduced platelet life span, while the genetic deletion of Bak effectively counteracted this phenotype ${ }^{63}$. Further support for the anti-apoptotic role of $B C l-x_{L}$ in platelets comes from the observation that, in vitro, $\mathrm{BH} 3$ mimetics inhibiting $\mathrm{Bcl}-\mathrm{x}_{\mathrm{L}}$ (such as ABT-737 and ABT-263 or Navitoclax) trigger platelet apoptosis ${ }^{64,66}$, while these compounds induce an acute thrombocytopenia in vivo ${ }^{67}$. The involvement of caspases in the 
apoptotic process is illustrated by the fact the ABT-737-induced apoptosis and PS exposure in platelets are completely abrogated by general caspase inhibition ${ }^{64}$. This suggests that apoptosis-mediated PS exposure likely contributes to the clearance of ageing platelets from the circulation.

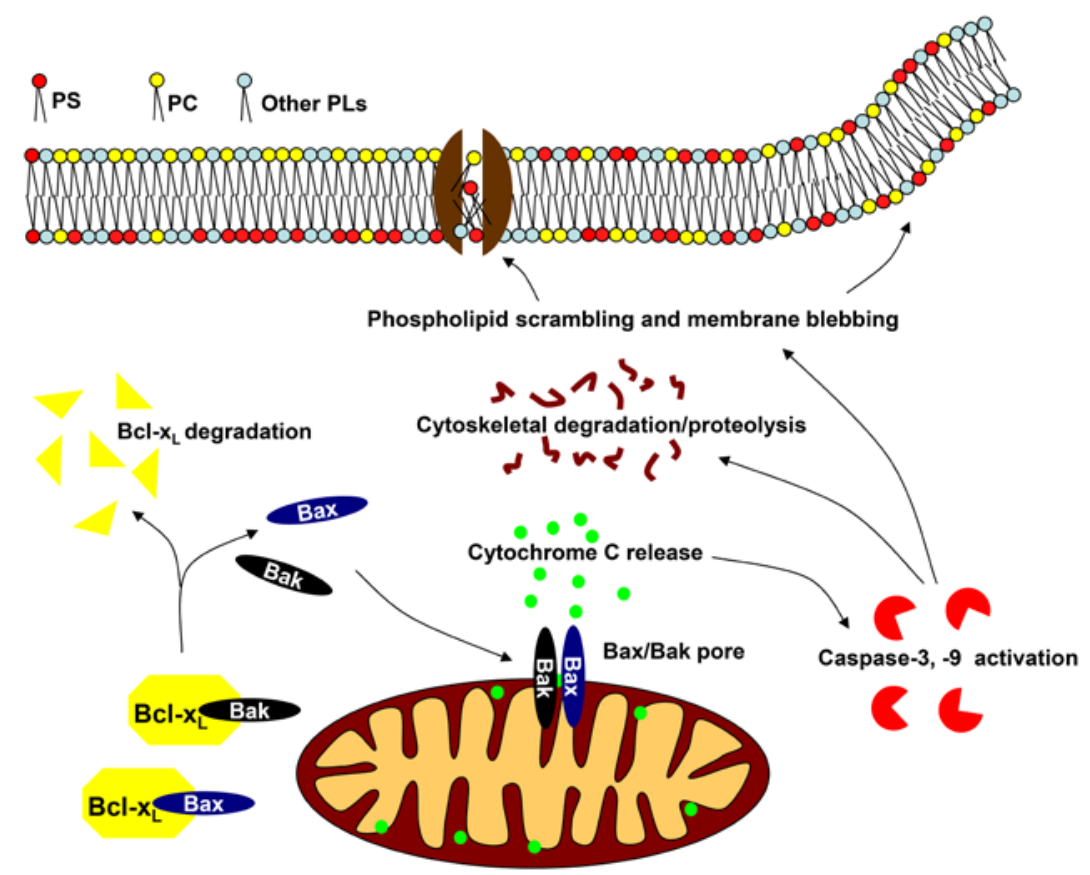

Figure 3. Schematic overview of processes in platelet apoptosis. Bcl- $x_{L}$ degradation drives Bax/Bakmediated mitochondrial cytochrome-c release. Cytochrome $C$ released into the cytosol, activates several downstream caspases. These proteolytic enzymes degrade the actin membrane cytoskeleton, resulting in a loss of cell integrity. Furthermore, phospholipid scrambling is induced, resulting in the exposure of PS at the cell surface along with membrane blebbing. Abbreviation: PLs: phospholipids.

Taken together, as well summarized by the Jackson group ${ }^{62}$, apparently two distinct processes in platelets lead to PS exposure; activation with strong agonists like collagen/ thrombin and apoptosis upon ageing. Yet, the phospholipid scrambling in platelet activation and apoptosis must be differently regulated, since caspase inhibition does not suppress PS exposure after collagen/thrombin stimulation whereas, conversely, platelet inhibition by cyclic AMP elevation does not affect platelet PS exposure after ABT-737 stimulation ${ }^{64}$. Whether and how TMEM16F is implicated in ageing- or ABT-737-induced PS exposure in apoptosis is yet unknown. This is also investigated in the present thesis.

\section{Aims and outline of the thesis}

The studies described in this thesis aim to better understand the mechanisms of platelet $\mathrm{Ca}^{2+}$ entry and phospholipid scrambling in relation to platelet function. Another goal is to 
determine the functional consequences of diminished $\mathrm{Ca}^{2+}$ entry in platelets. The general introduction, Chapter 1, gives a brief background on the mechanism of thrombus formation and provides information on key proteins and signaling pathways involved in platelet $\mathrm{Ca}^{2+}$ entry and phospholipid scrambling. The purpose of Chapter $\mathbf{2}$ is to give improved guidelines for the in vitro assessment of thrombus formation by flow chamber technology and to give a detailed overview of the various parameters that can be measured with this technique. Several practical issues concerning flow chamber experiments are also discussed in this chapter, which includes flow chamber assembly, substrate use and parameter readouts. Because residual coagulation is a major source of variation in this type of experiments, it is emphasized how to suppress or allow coagulation in a well controlled way in such flow chambers.

Chapter $\mathbf{3}$ concerns studies on two platelet proteins that are critically involved in storeoperated $\mathrm{Ca}^{2+}$ entry. This chapter determines the relative contributions of the endoplasmic reticulum $\mathrm{Ca}^{2+}$ sensor STIM1 and the $\mathrm{Ca}^{2+}$ entry channel Orai1 to platelet procoagulant activity and thrombus formation under flow, either in the presence or absence of coagulation. Given the protective effect of Orai1 deficiency in murine experimental thrombosis models, it was reasoned that $\mathrm{Ca}^{2+}$ entry blockade might be a suitable strategy to suppress thrombosis. To test this in detail, the antithrombotic potential of several proposed $\mathrm{Ca}^{2+}$ channel blockers was studied in vitro and in vivo, the results of which are described in Chapter 4.

As described above, TMEM16F (anoctamin 6) is supposed to be critically involved in $\mathrm{Ca}^{2+}$ dependent phospholipid scrambling and is a defective protein in patients with Scott syndrome. The contribution of TMEM16F to PS exposure in platelets upon apoptosis and agonist stimulation is described in Chapter 5. In the subsequent Chapter 6, the role of TMEM16F in platelet activation and apoptosis is shown with TMEM16F-deficient mice. Further studies were conducted to study the role of TMEM16F in mediating $\mathrm{Ca}^{2+}$-activated chloride currents. Whether suppression of TMEM16F-dependent $\mathrm{Cl}^{-}$currents affects PS exposure is examined in Chapter 7, by comparing immortalized B-cells from healthy control subjects and Scott syndrome patients. In addition, this chapter describes the effect of either $\mathrm{Cl}^{-}$removal or $\mathrm{Cl}^{-}$channel blockade on PS exposure. In the general discussion of Chapter 8 the principal findings of this thesis are discussed in relation to the current literature.

\section{References}

1. Broos K, Feys HB, De Meyer SF, Vanhoorelbeke K, Deckmyn H. Platelets at work in primary hemostasis. Blood Rev. 2011;25:155-167.

2. World health organization. Cardiovascular diseases. Fact sheet no: 317. 2011:http://www.who.int/ mediacentre/factsheets/fs317/en/index.html.

3. Furie B, Furie BC. Mechanisms of thrombus formation. N Engl J Med. 2008;359:938-949

4. Ruggeri ZM. Platelets in atherothrombosis. Nat Med. 2002;8:1227-1234.

5. Jackson SP, Mistry N, Yuan Y. Platelets and the injured vessel wall: "rolling into action": focus on glycoprotein Ib/V/IX and the platelet cytoskeleton. Trends Cardiovasc Med. 2000;10:192-197.

6. Kuijpers MJ, Schulte V, Oury C, Lindhout T, Broers J, Hoylaerts MF, Nieswandt B, Heemskerk JW. Facilitating roles of murine platelet glycoprotein $\mathrm{lb}$ and $\alpha_{\| \mathrm{lb}} \beta_{3}$ in phosphatidylserine exposure during VWFcollagen-induced thrombus formation. J Physiol. 2004;558:403-415.

7. Savage B, Saldivar E, Ruggeri ZM. Initiation of platelet adhesion by arrest onto fibrinogen or translocation on von Willebrand factor. Cell. 1996;84:289-297. 
8. Beumer S, IJsseldijk MJ, de Groot PG, Sixma JJ. Platelet adhesion to fibronectin in flow: Dependence on surface concentration and shear rate, role of platelet membrane glycoproteins GPIIb/IIIa and VLA5, and inhibition by heparin. Blood. 1994;84:3724-3733.

9. Piotrowicz RS, Orchekowski RP, Nugent DJ, Yamada KY, Kunicki TJ. Glycoprotein Ic-lla functions as an activation-independent fibronectin receptor on human platelets. J Cell Biol. 1988;106:1359-1364.

10. Inoue O, Suzuki-Inoue K, Ozaki Y. Redundant mechanism of platelet adhesion to laminin and collagen under flow: involvement of von Willebrand factor and glycoprotein Ib-IX-V. J Biol Chem. 2008;283: 16279-16282.

11. Nieswandt B, Watson SP. Platelet-collagen interaction: is GPVI the central receptor? Blood. 2003;102:449-461.

12. Goto S, Tamura N, Handa S, Arai M, Kodama K, Takayama H. Involvement of glycoprotein VI in platelet thrombus formation on both collagen and von Willebrand factor surfaces under flow conditions. Circulation. 2002;106:266-272.

13. Nieswandt B, Brakebusch C, Bergmeier W, Schulte V, Bouvard D, Mokhtari-Nejad R, Lindhout T, Heemskerk JW, Zirngibl H, Fässler R. Glycoprotein VI but not $\alpha_{2} \beta_{1}$ integrin is essential for platelet interaction with collagen. Embo J. 2001;20:2120-2130.

14. Massberg S, Gawaz M, Gruner S, Schulte V, Konrad I, Zohlnhofer D, Heinzmann U, Nieswandt B. A crucial role of glycoprotein VI for platelet recruitment to the injured arterial wall in vivo. J Exp Med. 2003;197:41-49.

15. Hollopeter G, Jantzen HM, Vincent D, Li G, England L, Ramakrishnan V, Yang RB, Nurden P, Nurden A, Julius $\mathrm{D}$, Conley PB. Identification of the platelet ADP receptor targeted by antithrombotic drugs. Nature. 2001;409:202-207.

16. Li Z, Zhang G, Le Breton GC, Gao X, Malik AB, Du X. Two waves of platelet secretion induced by thromboxane $A_{2}$ receptor and a critical role for phosphoinositide 3-kinases. J Biol Chem. 2003;278:30725-30731.

17. Kim SO, Lim CT, Lam SC, Hall SE, Komiotis D, Venton DL, Le Breton GC. Purification of the human blood platelet thromboxane $\mathrm{A}_{2}$ /prostaglandin $\mathrm{H}_{2}$ receptor protein. Biochem Pharmacol. 1992;43:313-322.

18. Kahn ML, Nakanishi-Matsui M, Shapiro MJ, Ishihara H, Coughlin SR. Protease-activated receptors 1 and 4 mediate activation of human platelets by thrombin. J Clin Invest. 1999;103:879-887.

19. Heemskerk JW, Bevers EM, Lindhout T. Platelet activation and blood coagulation. Thromb Haemost. 2002;88:186-193.

20. Zwaginga JJ, Nash G, King MR, Heemskerk JW, Frojmovic M, Hoylaerts MF, Sakariassen KS. Flow-based assays for global assessment of hemostasis. Part 1: biorheologic considerations. J Thromb Haemost. 2006;4:2486-2487.

21. Baumgartner HR, Haudenschild C. Adhesion of platelets to subendothelium. Ann New York Acad Sci. 1972;201:22-36.

22. Berny MA, Munnix IC, Auger JM, Schols SE, Cosemans JM, Panizzi P, Bock PE, Watson SP, McCarty OJ, Heemskerk JW. Spatial distribution of factor Xa, thrombin, and fibrin(ogen) on thrombi at venous shear. Plos One. 2010;5:e10415.

23. Roest M, Reininger A, Zwaginga JJ, King MR, Heemskerk JW. Flow chamber-based assays to measure thrombus formation in vitro: requirements for standardization. J Thromb Haemost. 2011;9:23222324.

24. Varga-Szabo D, Braun A, Nieswandt B. Calcium signaling in platelets. J Thromb Haemost. 2009;7:10571066.

25. Cavallini L, Coassin M, Alexandre A. Two classes of agonist-sensitive $\mathrm{Ca}^{2+}$ stores in platelets, as identified by their differential sensitivity to 2,5-di-(tert-butyl)-1,4-benzohydroquinone and thapsigargin. Biochem J. 1995;310:449-452.

26. Papp B, Enyedi A, Kovacs T, Sarkadi B, Wuytack F, Thastrup O, Gardos G, Bredoux R, Levy-Toledano S, Enouf J. Demonstration of two forms of calcium pumps by thapsigargin inhibition and radioimmunoblotting in platelet membrane vesicles. J Biol Chem. 1991;266:14593-14596.

27. Wuytack F, Papp B, Verboomen H, Raeymaekers L, Dode L, Bobe R, Enouf J, Bokkala S, Authi KS, Casteels R. A sarco/endoplasmic reticulum $\mathrm{Ca}^{2+}$-ATPase 3-type $\mathrm{Ca}^{2+}$ pump is expressed in platelets, in lymphoid cells, and in mast cells. J Biol Chem. 1994;269:1410-1416. 
28. Enouf J, Bredoux R, Papp B, Djaffar I, Lompre AM, Kieffer N, Gayet O, Clemetson K, Wuytack F, Rosa JP. Human platelets express the SERCA2b isoform of $\mathrm{Ca}^{2+}$-transport ATPase. Biochem J. 1992;286:135140.

29. Redondo PC, Rosado JA, Pariente JA, Salido GM. Collaborative effect of SERCA and PMCA in cytosolic calcium homeostasis in human platelets. J Physiol Biochem. 2005;61:507-516.

30. Fung $\mathrm{CY}$, Brearley CA, Farndale RW, Mahaut-Smith MP. A major role for $\mathrm{P} 2 \mathrm{X}_{1}$ receptors in the early collagen-evoked intracellular $\mathrm{Ca}^{2+}$ responses of human platelets. Thromb Haemost. 2005;94:37-40

31. MacKenzie AB, Mahaut-Smith MP, Sage SO. Activation of receptor-operated cation channels via $P 2 X_{1}$ not P2T purinoceptors in human platelets. J Biol Chem. 1996;271:2879-2881.

32. Hassock SR, Zhu MX, Trost C, Flockerzi V, Authi KS. Expression and role of TRPC proteins in human platelets: evidence that TRPC6 forms the store-independent calcium entry channel. Blood. 2002;100:2801-2811.

33. Harper MT, Poole AW. Store-operated calcium entry and non-capacitative calcium entry have distinct roles in thrombin-induced calcium signalling in human platelets. Cell Calcium. 2011;50:351-358.

34. Roos J, DiGregorio PJ, Yeromin AV, Ohlsen K, Lioudyno M, Zhang S, Safrina O, Kozak JA, Wagner SL, Cahalan MD, Velicelebi G, Stauderman KA. STIM1, an essential and conserved component of storeoperated $\mathrm{Ca}^{2+}$ channel function. J Cell Biol. 2005;169:435-445.

35. Zhang SL, Yu Y, Roos J, Kozak JA, Deerinck TJ, Ellisman MH, Stauderman KA, Cahalan MD. STIM1 is a $\mathrm{Ca}^{2+}$ sensor that activates CRAC channels and migrates from the $\mathrm{Ca}^{2+}$ store to the plasma membrane. Nature. 2005;437:902-905.

36. Liou J, Kim ML, Heo WD, Jones JT, Myers JW, Ferrell JE, Meyer T. STIM is a Ca ${ }^{2+}$ sensor essential for $\mathrm{Ca}^{2+}$-store-depletion-triggered $\mathrm{Ca}^{2+}$ influx. Curr Biol. 2005;15:1235-1241.

37. Bergmeier W, Oh-Hora M, McCarl CA, Roden RC, Bray PF, Feske S. R93W mutation in Orai1 causes impaired calcium influx in platelets. Blood. 2009;113:675-678.

38. Braun A, Varga-Szabo D, Kleinschnitz C, Pleines I, Bender M, Austinat M, BosI M, Stoll G, Nieswandt B. Orai1 (CRACM1) is the platelet SOC channel and essential for pathological thrombus formation. Blood. 2009;113:2056-2063.

39. Feske S, Prakriya M, Rao A, Lewis RS. A severe defect in CRAC Ca ${ }^{2+}$ channel activation and altered $\mathrm{K}^{+}$ channel gating in T cells from immunodeficient patients. J Exp Med. 2005;202:651-662.

40. Stathopulos PB, Zheng L, Li GY, Plevin MJ, Ikura M. Structural and mechanistic insights into STIM1mediated initiation of store-operated calcium entry. Cell. 2008;135:110-122.

41. Grosse J, Braun A, Varga-Szabo D, Beyersdorf N, Schneider B, Zeitlmann L, Hanke P, Schropp P, Muhlstedt S, Zorn C, Huber M, Schmittwolf C, Jagla W, Yu P, Kerkau T, Schulze H, Nehls M, Nieswandt B. An EF hand mutation in STIM1 causes premature platelet activation and bleeding in mice. J Clin Invest. 2007;117:3540-3550.

42. Varga-Szabo D, Braun A, Kleinschnitz C, Bender M, Pleines I, Pham M, Renne T, Stoll G, Nieswandt B. The calcium sensor STIM1 is an essential mediator of arterial thrombosis and ischemic brain infarction. J Exp Med. 2008;205:1583-1591.

43. Merritt JE, Armstrong WP, Benham CD, Hallam TJ, Jacob R, Jaxa-Chamiec A, Leigh BK, McCarthy SA, Moores KE, Rink TJ. SK\&F96365, a novel inhibitor of receptor-mediated calcium entry. Biochem J. 1990;271:515-522.

44. Bevers EM, Williamson PL. Phospholipid scramblase: an update. FEBS Lett. 2010;584:2724-2730.

45. Tang X, Halleck MS, Schlegel RA, Williamson P. A subfamily of P-type ATPases with aminophospholipid transporting activity. Science. 1996;272:1495-1497.

46. Lhermusier T, Chap H, Payrastre B. Platelet membrane phospholipid asymmetry: from the characterization of a scramblase activity to the identification of an essential protein mutated in Scott syndrome. J Thromb Haemost. 2011;9:1883-1891.

47. Williamson P, Bevers EM, Smeets EF, Comfurius P, Schlegel RA, Zwaal RF. Continuous analysis of the mechanism of activated transbilayer lipid movement in platelets. Biochemistry. 1995;34:1044810455.

48. Bitbol M, Fellmann P, Zachowski A, Devaux PF. Ion regulation of phosphatidylserine and phosphatidylethanolamine outside-inside translocation in human erythrocytes. Biochim Biophys Acta. 1987;904:268-282. 
49. Wolfs JL, Comfurius P, Rasmussen JT, Keuren JF, Lindhout T, Zwaal RF, Bevers EM. Activated scramblase and inhibited aminophospholipid translocase cause phosphatidylserine exposure in a distinct platelet fraction. Cell Mol Life Sci. 2005;62:1514-1525.

50. Suzuki J, Umeda M, Sims PJ, Nagata S. Calcium-dependent phospholipid scrambling by TMEM16F. Nature. 2010;468:834-838.

51. Galietta LJ. The TMEM16 protein family: A new class of chloride channels? Biophys J. 2009;97:30473053.

52. Tian Y, Schreiber R, Kunzelmann K. Anoctamins are a family of $\mathrm{Ca}^{2+}$-activated $\mathrm{Cl}^{-}$channels. J Cell Sci. 2012;125:4991-4998.

53. Castoldi E, Collins PW, Williamson PL, Bevers EM. Compound heterozygosity for 2 novel TMEM16F mutations in a patient with Scott syndrome. Blood. 2011;117:4399-4400.

54. Zwaal RF, Comfurius P, Bevers EM. Scott syndrome, a bleeding disorder caused by defective scrambling of membrane phospholipids. Biochim Biophys Acta. 2004;1636:119-128.

55. Weiss HJ, Vicic WJ, Lages BA, Rogers J. Isolated deficiency of platelet procoagulant activity. Am J Med. 1979;67:206-213.

56. Schroeder BC, Cheng T, Jan YN, Jan LY. Expression cloning of TMEM16A as a calcium-activated chloride channel subunit. Cell. 2008;134:1019-1029.

57. Caputo A, Caci E, Ferrera L, Pedemonte N, Barsanti C, Sondo E, Pfeffer U, Ravazzolo R, Zegarra-Moran $\mathrm{O}$, Galietta LJ. TMEM16A, a membrane protein associated with calcium-dependent chloride channel activity. Science. 2008;322:590-594.

58. Yang YD, Cho H, Koo JY, Tak MH, Cho Y, Shim WS, Park SP, Lee J, Lee B, Kim BM, Raouf R, Shin YK, Oh U. TMEM16A confers receptor-activated calcium-dependent chloride conductance. Nature. 2008;455:1210-1215.

59. Stohr H, Heisig JB, Benz PM, Schoberl S, Milenkovic VM, Strauss O, Aartsen WM, Wijnholds J, Weber $\mathrm{BH}$, Schulz HL. TMEM16B, a novel protein with calcium-dependent chloride channel activity, associates with a presynaptic protein complex in photoreceptor terminals. J Neurosci. 2009;29:6809-6818.

60. Martins JR, Faria D, Kongsuphol P, Reisch B, Schreiber R, Kunzelmann K. Anoctamin 6 is an essential component of the outwardly rectifying chloride channel. Proc Natl Acad Sci U S A. 2011;108:1816818172.

61. Hoffmeister KM. The role of lectins and glycans in platelet clearance. J Thromb Haemost. 2011;9 Suppl 1:35-43.

62. Jackson SP, Schoenwaelder SM. Procoagulant platelets: Are they necrotic? Blood. 2010;116:20112018.

63. Mason KD, Carpinelli MR, Fletcher JI, Collinge JE, Hilton AA, Ellis S, Kelly PN, Ekert PG, Metcalf D, Roberts AW, Huang DC, Kile BT. Programmed anuclear cell death delimits platelet life span. Cell. 2007;128:1173-1186.

64. Schoenwaelder SM, Yuan Y, Josefsson EC, White MJ, Yao Y, Mason KD, O'Reilly LA, Henley KJ, Ono A, Hsiao S, Willcox A, Roberts AW, Huang DC, Salem HH, Kile BT, Jackson SP. Two distinct pathways regulate platelet phosphatidylserine exposure and procoagulant function. Blood. 2009;114:663-666.

65. Fadok VA, Voelker DR, Campbell PA, Cohen JJ, Bratton DL, Henson PM. Exposure of phosphatidylserine on the surface of apoptotic lymphocytes triggers specific recognition and removal by macrophages. J Immunol. 1992;148:2207-2216.

66. Vogler M, Hamali HA, Sun XM, Bampton ET, Dinsdale D, Snowden RT, Dyer MJ, Goodall AH, Cohen $\mathrm{GM}$. Bcl2/Bcl- $\mathrm{x}_{\mathrm{L}}$ inhibition induces apoptosis, disrupts cellular calcium homeostasis, and prevents platelet activation. Blood. 2011;117:7145-7154.

67. Schoenwaelder SM, Jarman KE, Gardiner EE, Hua M, Qiao J, White MJ, Josefsson EC, Alwis I, Ono A, Willcox A, Andrews RK, Mason KD, Salem HH, Huang DC, Kile BT, Roberts AW, Jackson SP. Bcl- $\mathrm{x}_{\mathrm{L}^{-}}$ inhibitory $\mathrm{BH} 3$ mimetics can induce a transient thrombocytopathy that undermines the hemostatic function of platelets. Blood. 2011;118:1663-1674.

68. Penna A, Demuro A, Yeromin AV, Zhang SL, Safrina O, Parker I, Cahalan MD. The CRAC channel consists of a tetramer formed by STIM-induced dimerization of Orai dimers. Nature. 2008;456:116-120. 
Chapter 2

Measurement of whole blood thrombus formation using parallel-plate flow chambers -

a practical guide.

van Kruchten R, Cosemans JM, Heemskerk JW.

Platelets. 2012;23:229-242

Reprinted with permission 


\begin{abstract}
Custom-made and commercial parallel-plate flow chambers are widely used for studies of platelet activation and thrombus formation in whole blood at defined shear rates. When used in a reproducible way, such flow chamber devices give valuable information on the thrombogenic potential of human, mouse, or rat blood. This article aims to provide a practical guide for the use of parallel-plate flow chambers in combination with routine microscopic imaging techniques. The following methodological aspects are addressed; preparation of surface coatings, calculation of blood flow and shear rate, control of preanalytical variables, protocols for routine performing of flow chamber tests with noncoagulating or coagulating blood, and procedures for real-time and end-point analysis of thrombus formation. Frequently encountered experimental problems and artifacts are discussed, as well as possibilities for using flow chamber devices as a diagnostic tool to test antithrombotic medication.
\end{abstract}

\title{
Introduction
}

The formation of a platelet thrombus at sites of vascular damage is critical to normal hemostasis. In arteries at risk, however, uncontrolled formation of a thrombus can result in vessel occlusion and provoke ischemia in heart or brain. Understanding and measurement of the process of thrombus formation is thus of key importance for research into hemostasis and thrombosis. Studies so far have distinguished three phases in thrombus formation under flow: initiation by adhesion of platelets to extracellular matrix components (e.g., platelet-collagen interaction); extension through autocrine signaling (e.g., via adenosine diphosphate (ADP) and thromboxane) and platelet co-aggregation (via the fibrinogen receptor, integrin $\alpha_{11 b} \beta_{3}$ ); and perpetuation by thrombus contraction (via thrombin) and formation of a fibrin network ${ }^{1-3}$.

Especially, in the past decade, custom-made and commercial flow devices are widely used to study the process of thrombus formation in vitro ${ }^{4,5}$. The most versatile devices consist of a small parallel-plate flow chamber with technology to perfuse whole blood through the chamber at well-defined shear conditions. These flow chambers allow measurements of platelet adhesion, platelet aggregation, and coagulation within one experiment, and hence are attractive as capacity test for determining the thrombogenic activity of human or animal blood ${ }^{6-9}$. Flow studies using these chambers have also been quite valuable in identifying the roles of numerous platelet receptors and signaling proteins in thrombus formation. The possibilities and limitations of the most common flow chamber devices for standardized assaying of whole-blood thrombus formation have been listed in a recent paper of the Scientific and Standardization Committee (SSC) of the International Society on Thrombosis and Haemostasis (ISTH) ${ }^{10}$.

The present methods article aims to provide a practical guide for the reproducible use of parallel-plate flow chambers in combination with microscopic imaging techniques. In separate text boxes, we describe protocols on how to perform blood flow experiments, and how to record and analyze microscopic images. Where appropriate, we explain differences in the use of human, mouse, or rat blood. In addition, we discuss frequent experimental problems and artifacts, and we describe the use of flow chambers for monitoring the effects of antiplatelet drugs. 
Table 1. Surface coatings for the measurement of thrombus formation with parallel-plate flow chambers at indicated shear rates. Indicated materials can be used with custom-made or commercial flow devices.

\begin{tabular}{|c|c|c|c|c|c|}
\hline Coating material & $\begin{array}{l}\text { Concentration } \\
\text { applied } \\
(\mu \mathrm{g} / \mathrm{mL})\end{array}$ & $\begin{array}{l}\text { Platelet } \\
\text { receptors }\end{array}$ & $\begin{array}{l}\text { Shear rate } \\
\left(s^{-1}\right)\end{array}$ & $\begin{array}{l}\text { Flow } \\
\text { time } \\
\text { (min) }\end{array}$ & Refs. \\
\hline Collagen type $I^{\mathrm{a}}$ & $50-200$ & $\begin{array}{l}\text { GPIb, } \alpha_{111} \beta_{3} \\
\text { GPVI, } \alpha_{2} \beta_{1}\end{array}$ & $300-1700$ & $4-5$ & $9,11-15$ \\
\hline Collagen type III & $50-200$ & $\begin{array}{l}\text { GPIb, } \alpha_{11 b} \beta_{3} \\
\text { GPVI, } \alpha_{2} \beta_{1}\end{array}$ & $300-1700$ & $4-5$ & $8,16-18$ \\
\hline $\begin{array}{l}\text { GFOGER-(GPO) and } \\
\text { vWF-BP }\end{array}$ & $100-1000$ & $\begin{array}{l}\text { GPIb, } \alpha_{11 b} \beta_{3}, \\
\text { GPVI, } \alpha_{2} \beta_{1}\end{array}$ & $150-3000$ & $4-10$ & $19-21$ \\
\hline VWF, anti-VWF mAb & $100-1000$ & GPIb, $\alpha_{\| b} \beta_{3}$, & $300-3000$ & $4-5$ & $2,16,22-24$ \\
\hline Fibronectin & 300 & $\alpha_{5} \beta_{1}$ & $150-800$ & $4-10$ & 16,25 \\
\hline Fibrinogen & $100-1000$ & $\alpha_{11 b} \beta_{3}$ & $150-800$ & $4-5$ & $16,22,26-28$ \\
\hline Fibrin & 1000 & GPIb & $150-1700$ & $4-10$ & $22,28-30$ \\
\hline Laminin & 100 & $\alpha_{6} \beta_{1}$ & $300-800$ & $4-5$ & $16,31,32$ \\
\hline $\begin{array}{l}\text { Atherosclerotic } \\
\text { plaque preparation }^{a}\end{array}$ & $\begin{array}{l}50-160 \mathrm{mg} \\
\text { wet weight } / \mathrm{mL}\end{array}$ & $\begin{array}{l}\text { GPIb, GPVI, } \\
\alpha_{2} \beta_{1}\end{array}$ & $300-1700$ & $4-5$ & $17,33-35$ \\
\hline Extracellular matrix & n.d. & n.d. & $300-1700$ & $4-5$ & $6,16,36$ \\
\hline
\end{tabular}

Note: ${ }^{a}$ Platelet GPIb and $\alpha_{\| 1 b} \beta_{3}$ indirectly bind to collagen via vWF.

bWF-binding peptide

\section{Thrombogenic surfaces in flow chamber assays}

Both custom-made and commercial flow devices need to be pre-coated with thrombogenic components to achieve platelet adhesion and aggregation under flow conditions. In Table 1, an overview is given of substrates available for coating and the corresponding platelet receptors, while Box 1 provides a guide for preparing coated flow chambers.

\section{Collagens and related surfaces}

The fibrillar collagens, types I and III, are highly platelet-adhesive and thus can act as suitable substrates in whole-blood flow assays (Table 1). Both collagens bind von Willebrand factor (VWF) from blood plasma, and serve as ligand for the two platelet collagen receptors, glycoprotein (GP)VI, and integrin $\alpha_{2} \beta_{1}{ }^{11,37,38}$. The collagen-bound vWF captures platelets at high-shear flow, via initially GPIb-V-IX and subsequently integrin $\alpha_{11 b} \beta_{3}^{22,39,40}$. Since platelet-collagen interaction via GPVI causes secretion, integrin activation, and procoagulant activity, coated collagens are capable to induce the whole process of thrombus formation within a time period of several minutes ${ }^{3,12,41}$. Most active in promoting thrombus formation are those preparations of type I collagen, which form large fibers and thereby strongly activate GPVI. In general, type III collagens have a lower thrombogenic activity. Precise recommendations on the use of collagen surfaces for flow assays have been given in an SSC communication ${ }^{42}$.

When coated alone, VWF again interacts with platelets via GPIb-V-IX and $\alpha_{11 b} \beta_{3}$ at high shear rate $\left(>800 \mathrm{~s}^{-1}\right)$, and establishes membrane tether formation and platelet arrest ${ }^{23,39}$. 
However, large thrombi with platelet aggregates are not formed on vWF surfaces, unless experiments are carried out at very high shear rates $\left(>10000 \mathrm{~s}^{-1}\right)^{41}$. Surfaces coated with anti-vWF mAb bind vWF from plasma, and are similarly effective as coated vWF ${ }^{24}$.

Immobilized synthetic collagen-like peptides provide a recent alternative for the use of native fibrillar collagens in flow assays, allowing studying platelet adhesion under flow via specific collagen receptors (Table 1). Peptides containing the amino acid motif GPRGQOGVMGFO bind VWF, peptides with the sequence GFOGER interact with platelet integrin $\alpha_{2} \beta_{1}$, while peptides containing multiple GPO residues interact with platelet GPVI ${ }^{19,20}$. Interestingly, these collagen-like peptides can also be used in combinations, or together with vWF.

Box 1. Protocol for preparation of custom-made and commercial flow chamber devices.

- Use devices with parallel-plate flow chambers, which are appropriately cleaned and blocked.

- Preferably coat one side of the chamber with thrombogenic material of interest. Note: precise control is possible by coating a glass cover slip that can be mounted onto the chamber. In this case, the following procedure can be used;

0 degrease coverslips with $2 \mathrm{M} \mathrm{HCl}$ in $50 \%$ ethanol, then wash with Milli-Q water;

0 apply the coating at the cover slip in a humid atmosphere. Note: pipetting of $2 \mu \mathrm{l}$ solution (e.g. collagen $50 \mu \mathrm{g} / \mathrm{mL}$ ) gives coated spots of $>2 \mathrm{~mm}$ in diameter;

o allow the coating material to adhere for 30-60 min. Prevent drying out of coated proteins. Note: For collagen, allow fibrils to be formed at neutral pH in a humid box;

o remove non-bound coating proteins by wash with appropriate rinsing medium (e.g. saline).

- $\quad$ Block coated surfaces with BSA-containing isotonic buffer medium (e.g. modified Tyrode's buffer $\mathrm{pH} 7.45$, consisting of $136 \mathrm{mM} \mathrm{NaCl}, 10 \mathrm{mM}$ glucose, $5 \mathrm{mM}$ Hepes, 2.7 $\left.\mathrm{mM} \mathrm{KCl}, 2 \mathrm{mM} \mathrm{MgCl} 2,2 \mathrm{mM} \mathrm{CaCl}_{2}, 1 \% \mathrm{BSA}\right)$.

- Connect tubing to the flow device if needed. Note: shortly before starting blood flow, check the assembled flow system is leak-tight.

- $\quad$ Rinse the assembled system with isotonic buffer. Add anti-coagulant (e.g. heparin 1 $\mathrm{U} / \mathrm{mL}$ ) to prevent coagulation, if required.

- $\quad$ Carefully check the assembled system for absence of air bubbles. Note: air bubbles may be formed in buffer due to temperature changes.

Non-collagen and complex surfaces

Also non-collagen components present in the vasculature support platelet adhesion and thrombus formation, when coated in a flow chamber, though mostly at shear rates $<800$ $\mathrm{s}^{-1}$ (Table 1) ${ }^{43,44}$. Flowed platelets adhere to coated fibrinogen and fibronectin via integrins $\alpha_{11 b} \beta_{3} / \alpha_{v} \beta_{3}$ and $\alpha_{5} \beta_{1}$, respectively ${ }^{25,26}$. Coated laminin mediates platelet adhesion via integrin $\alpha_{6} \beta_{1}{ }^{31}$. Such surfaces support the adhesion of only single platelets, except when coagulation is introduced and fibrin-containing thrombi are formed ${ }^{27,45}$. Fibrin- 
coated surfaces trap VWF and mediate platelet adhesion in a GPIb-dependent but $\alpha_{\| 1 b} \beta_{3^{-}}$ independent fashion ${ }^{28-30}$.

More complex physiological coatings, representing a damaged arterial wall, have been used for flow perfusion studies. Examples are isolates from atherosclerotic plaques or the endothelial-derived extracellular matrix, where collagen and VWF appear to be the most active components for thrombus formation ${ }^{16,17,33,34}$.

An interesting development is the use of microarrays with various collagen or noncollagen surfaces that are machine-coated on flow-chamber cover slips, so that thrombus formation can be assessed as a function of the surface within one run ${ }^{46}$.

\section{Flow chamber equipment and control of blood flow}

Dedicated, well-designed equipment is needed for reproducible and standardized flow assays. Here, we discuss the use of flow devices constructed as parallel-plate chambers.

\section{Custom-made and commercial parallel-plate flow chambers}

Several types of parallel-plate flow chambers and microcapillaries, both non-commercial and commercial (e.g., Ibidi, Venaflux, Bioflux, and Glycotech) are now in routine use to assay thrombus formation with human, mouse, or rat blood. Specific advantages and disadvantages of the most common chamber devices have recently been listed ${ }^{10}$. In contrast to the early flow chambers, which required relatively large volumes of blood ${ }^{6,7}$, current chamber types are smaller in size and operate with smaller blood volumes, flowed in single pass. It is beyond the scope of this article to describe the differences between individual custom-made and commercial flow chamber devices. Such information is provided elsewhere ${ }^{4,5}$. Here, we focus on common aspects of the reproducible use of parallel-plate type flow chambers.

\section{Chamber preparation and assembly}

Similar types of precautions need to be taken for successful use of the various (commercial) flow chambers. As an example, we will concentrate here on the use of the device manufactured in our institute. It consists of a transparent polycarbonate block in which a rectangular space is engraved with a width of 3.0 or $5.0 \mathrm{~mm}$ and a depth of 50 or $100 \mu \mathrm{m}$ (Figure 1a). At the inlet and outlet sides of the flow chamber space, tubes are drilled at an angle of $20^{\circ}$ (1.5 $\mathrm{mm}$ diameter) to prevent flow perturbations during blood inflow. The block is mounted onto a glass cover slip, that can be pre-coated with collagen or other thrombogenic material, and provides the biologically active side of the chamber. An aluminum holder containing two self-tapping bolts serves to clamp chamber block and cover slip together in a leak-free way (Figure 1b).

If flow chambers with cover slips are used, these need to be assembled in such a way that leakage does not occur. Options for preventing leakage are the use of clamps, a vacuum system, or glue. Many systems work with small tubing (inner diameter $1 \mathrm{~mm}$ ), that is connected to the chamber end. The assembled system needs to be rinsed with bovine serum albumin (BSA) containing buffer to block uncoated parts of the chamber surface and prevent non-specific platelet adhesion and contact activation of the coagulation system (Box 1). Furthermore, it needs to be rigorously checked for the absence of air 
bubbles. When pre-mixing of blood with another fluid is needed, a convenient solution is to use $y$-shaped tubing, whose outlets can be connected to two syringes, so that the mixing occurs immediately before blood entry into the chamber.

Some (commercial) flow chamber devices are already pre-assembled and these, hence, must be coated by incubation of the closed chamber system with the thrombogenic material of interest. Once appropriately assembled and blocked (Box 1), the coated flow chamber system is ready for blood perfusion.

(a)

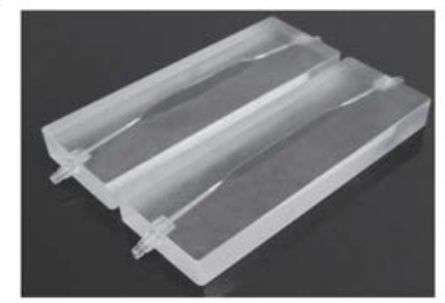

(c)

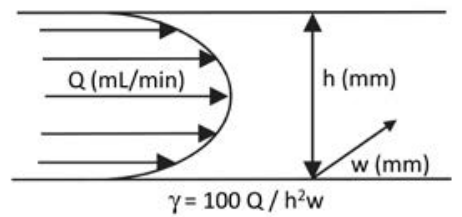

(b)

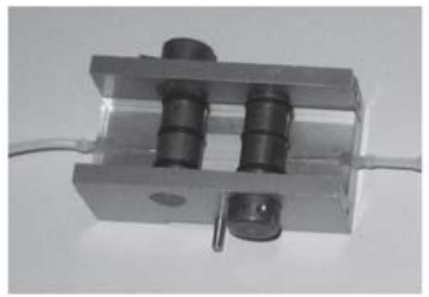

(d)

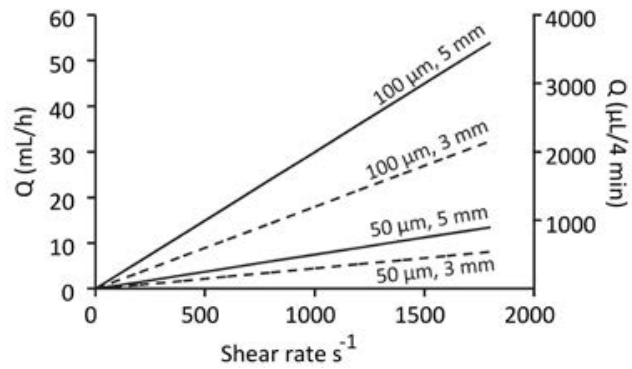

Figure 1. Custom-made flow chamber and blood volume required for measuring thrombus formation. (a) Two parallel-plate flow chambers with channels (height $h=50 \mathrm{~mm}$ and width $w=5$ or 3 $\mathrm{mm}$ ) engraved in polycarbonate blocks. Note the $20^{\circ}$ angled inlet and outlet for connection to tube. (b) Aluminum holder with bolts for leak-tight attachment of a cover slip to the flow chamber block (Maastricht Instruments, Maastricht). (c) Equation, assuming a parabolic flow pattern, for calculating the chamber wall shear rate $\gamma$ from the flow rate $Q$ of blood. (d) Blood volumes required for perfusion at indicated shear rates through chambers with indicated dimensions in height $(50-100 \mathrm{~mm})$ and width (3-5 mm). Blood consumption is shown in both $\mathrm{mL} / \mathrm{h}$ and $\mu \mathrm{L} / 4 \mathrm{~min}$.

\section{Regulation of blood flow and perfusion pumps}

Assuming a parabolic flow pattern, the shear rate $\gamma$ of flowing blood in a parallel-plate chamber is described by the equation, $y=1000 / h^{2} w$ (Figure 1c), provided that the chamber width exceeds the height by far ${ }^{4}$. Herein, $Q$ is the volumetric flow rate $(\mathrm{mL} / \mathrm{min}), \mathrm{h}$ the chamber height $(\mathrm{mm})$, and $w$ the chamber width $(\mathrm{mm})$, while the shear rate $\gamma$ is expressed in inverse seconds $\left(s^{-1}\right)$. The shear stress $(\tau)$ is obtained from the viscosity $(\eta)$ and shear rate $(\gamma)$, as $\tau=\eta \times \gamma$. Obviously, the dimensions of a parallel-plate flow chamber determine the volume of blood that is needed for a particular flow and shear rate inside the chamber 
(Figure 1d). For example, for a chamber of depth $50 \mu \mathrm{m}$ and width $3.0 \mathrm{~mm}$, a volume of $300 \mu \mathrm{L}$ blood is required for a 4-min perfusion at $1000 \mathrm{~s}^{-1}$.

These calculations assume that blood acts as a Newtonian fluid. In reality, blood viscosity changes with the flow rate and even within the flow chamber, as the red blood cells are directed toward the center of the blood stream, forming a layer of plasma and platelets near the chamber wall ${ }^{4}$. For practical purposes, this means that the presence of red cells is required for maximal adhesion of flow platelets to the coated chamber wall (hematocrit $>20 \%$ ). Another characteristic of blood flow in small chambers is that, once multi-platelet thrombi are formed, these partly obstruct the chamber lumen and thus alter the local shear rate and flow pattern. In other words, undisturbed parabolic flow patterns will only exist in the initial phase of thrombus formation.

For the control of the blood flow rate in a chamber, high-precision pulse-free perfusion pumps are available, which can operate with one or two syringes in pushing or pulling mode. An advantage of pushing a syringe filled with blood is that leakage and appearance of air bubbles can better be controlled, but a disadvantage is the need of syringe replacement after blood flow, which increases the chance of manual contact with blood. One advantage of syringe pulling is that blood can be pipetted into a reservoir, from which it is drawn through the flow chamber. Clearly, this requires that the system is completely leaktight. Blood perfusion in most laboratories is performed at constant flow rate, but incidentally step-wise changes in flow rate are introduced, e.g., to determine aggregate stability ${ }^{9}$ or provoke coagulation ${ }^{47}$.

\section{Use of microscopes}

With suitably designed (transparent) flow devices, the process of thrombus formation can be monitored by brightfield as well as fluorescence microscopy. Brightfield microscopic images can be captured with a microscope-attached digital charged coupled device camera, preferably in combination with phase-contrast or differential interference contrast enhancement ${ }^{48}$. For sensitive detection of fluorescence, a high-numerical aperture (oil) objective is required, given the small size of platelets. Both non-confocal (lamp or led) and confocal (one or more lasers) microscopes are suited for fluorescence imaging of a thrombus, but confocal microscopes have the advantage that z-stacks of images can be captured, e.g., to measure the thrombus volume ${ }^{20}$. Many laboratories run flow perfusion experiments at room temperature ${ }^{10}$, as this does not require a temperature-controlled stage.

\section{Control of blood anticoagulation for flow chamber assays}

Stringent control of blood coagulation is needed for reproducible flow assays. The choice is to either fully prevent the coagulation process or trigger it in a controlled way.

\section{Flow assays in the absence of coagulation}

In studies focusing on platelet function, coagulant activity in the flow chamber should be prevented completely. Since platelet adhesion and aggregation are dependent on the concentrations of free $\mathrm{Mg}^{2+}$ and $\mathrm{Ca}^{2+}$, the common choice is to draw blood into an anticoagulant medium that maintains physiological, millimolar concentrations of these divalent 
cations, instead of citrate ${ }^{49}$. To prevent coagulation and fibrin formation in the flow chamber, a combination of anticoagulants is needed. Detailed procedures on how to collect blood are described in Box 2. Human and rat blood can well be collected into PPACK (d-phenylalanyl-I-prolyl-I-arginine chloromethyl ketone) or hirudin, supplemented with low-molecular weight heparin (inhibiting factor $\mathrm{Xa}$ ). Mouse blood is collected into PPACK plus heparin (Sigma grade I-A). As an unstable chloromethyl ketone, PPACK is gradually consumed in the blood, and it needs to be re-added after a certain time.

\section{Box 2. Protocol for flow perfusion assays in the absence of coagulation.}

- $\quad$ Collect blood into suitable anticoagulant medium. Ensure that coagulation is fully prevented. Re-rinse the collection system with anticoagulant medium, and check for proper mixing of blood and this medium. Note: continuous blood flow is a good indication for absence of coagulation.

0 For human blood, draw with large 23 gauge needle to insure undisturbed blood flow. Use PPACK (400 $\mu \mathrm{M}$ in saline $1: 10)$ or hirudin $(200 \mathrm{U} / \mathrm{mL}$ in saline, 1:10) as anticoagulant. When appropriate, add low molecular weight heparin $(5 \mathrm{U} / \mathrm{mL})$ or platelet inhibitor;

o For mouse blood, if possible collect by retro-orbital or vena cava puncture. Use PPACK (400 $\mu \mathrm{M}$ in saline 1:10) plus (low molecular weight) heparin (5 $\mathrm{U} / \mathrm{mL}$ ) as anticoagulants;

o For rat blood, collect by aortic puncture. Use same anticoagulants as for human blood.

- Incubate the collected blood at $37^{\circ} \mathrm{C}$ for $10-15 \mathrm{~min}$ to resensitize platelets. Store then at room temperature. Note: use human or rat blood within $3 \mathrm{~h}$ (in case of PPACK blood, re-add $10 \mu \mathrm{M}$ PPACK after $1 \mathrm{~h}$ ); use mouse blood within $1 \mathrm{~h}$.

- Preferentially check collected blood for normal platelet count. Note: a low platelet count points to platelet activation via autocrine ADP or traces of thrombin.

- Add desired (ant)agonist, fluorescent probe, or vehicle buffer. Note: platelet adhesion under flow is influenced by DMSO or ethanol $(0.3 \%)$, sodium azide $(15 \mu \mathrm{M})$, or $\mathrm{Ca}^{2+}$ chelating media such as phosphate-buffered saline.

- Fill syringe or inlet part of the flow chamber with requested volume of blood. Note: when using a syringe, prevent the formation of air bubbles at connection points with the chamber.

- $\quad$ For perfusion experiments in pushing mode, place syringe with blood on perfusion pump and start blood flow; for experiments in pulling mode, connect tubing to pulling syringe and start the blood flow. Note: check for a regular blood flow and absence of air bubbles.

- Monitor platelet adhesion and thrombus formation by microscopic imaging. Note: at $1000 \mathrm{~s}^{-1}$, platelet should form thrombi on collagen within 4-6 min for human or rat blood, and within 3-4 min using mouse blood.

Several other precautions can be made to suppress residual coagulation (Box 2). A short incubation of drawn blood samples at $37^{\circ} \mathrm{C}$ will inactivate autocrine ADP and traces of thrombin and lead to resensitization of the platelets. The composed flow chamber system should be rinsed with buffer-containing anticoagulant (e.g. heparin), for inhibiting the 
contact activation pathway of coagulation. For some purposes, human citrateanticoagulated blood has been used in flow chamber studies without recalcification. In such experiments, thrombi formed on a collagen surface are more densely packed with highly activated platelets in comparison to perfusion at high levels of divalent cations. The likely explanation is that the relatively low $\mathrm{Ca}^{2+}$ level supports human platelet integrin activation $^{49}$.

(a)

(c)
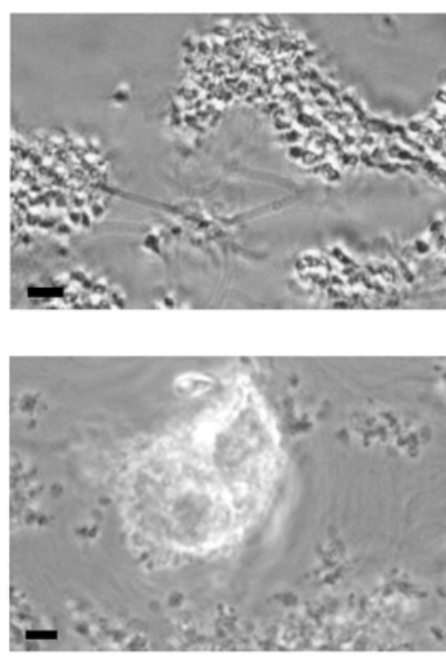

(e)

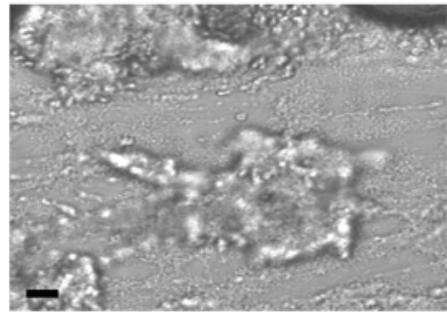

(b)

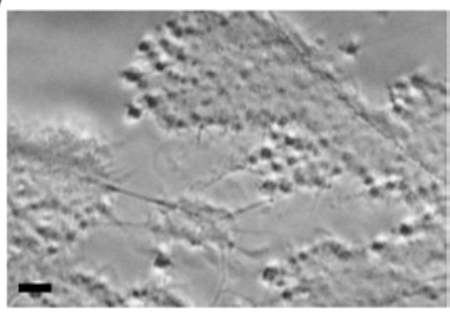

(d)

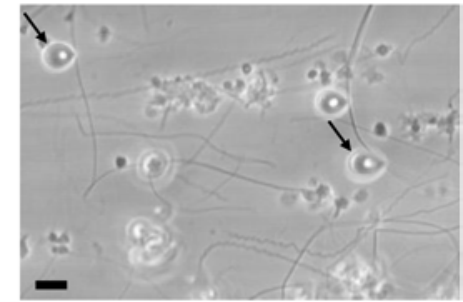

(f)

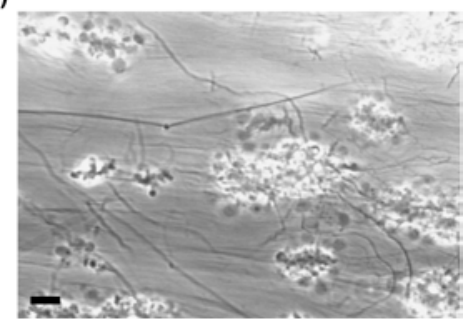

Figure 2. Experimental artifacts resulting in abnormal thrombus formation in parallel-plate flow chambers. Disturbing, necrotic effect of air bubbles. Human thrombi formed on a collagen surface before (a) and after (b) passage of an air bubble. Initial signs of coagulation due to poor action of anticoagulants. Platelet-fibrin clot formed in human blood and trapped on a collagen surface (c); and adhesion of red blood cells (arrows) with few platelets at sites of fibrin formation (d). Signs of poorly controlled coagulation of human blood. Local formation of large platelet-fibrin clots (e); and fibrin fibers between aggregated platelets (f). Bars $=10 \mu \mathrm{m}$.

One of the earliest indications of insufficient anticoagulation is a drop in whole-blood platelet count. In blood perfusion through a flow chamber, this is detected as the incidental passing and adhesion of a 'white' platelet-fibrin clot (Figure 2c). At a later stage, flowing red blood cells adhere to the chamber surface, possibly interacting with locally formed fibrin fibers, while platelet adhesion diminishes (Figure $2 \mathrm{~d}$ ). This stage is quickly 
followed by the appearance of multiple platelet-fibrin clots (Figure 2e) and the formation of fibrin fibers (Figure 2f), especially at sites of flow disturbances within the chamber. Formation of air bubbles should be prevented, since these cause immediate necrosis of adhered platelets (Figure $2 a$ and $b$ ), which then trigger the coagulation process. Important to realize is, that after one or more hours (depending on the species and anticoagulant type), blood samples may contain such high levels of activated coagulation factors, that clot formation in the chamber can no longer be prevented.

Box 3. Protocol for flow perfusion assays in the presence of coagulation.

- Collect blood into trisodium citrate (129 mM, 1:10). Insure that coagulation is fully prevented. Pre-rinse the collection system with anticoagulant medium, and check for proper mixing of blood and this medium. Note: continuous blood flow is a good indication for absence of coagulation:

o for human blood, draw with large 23 gauge needle to insure undisturbed flow.

o for mouse blood, if possible collect by retro-orbital or vena cava puncture.

o for rat blood, collect by aortic puncture.

- Ensure that the right volume of citrate anticoagulant is added. Then, incubate the blood at $37^{\circ} \mathrm{C}$ for $10-15 \mathrm{~min}$ to resensitize platelets.

- If possible, check for a normal platelet count. Preferentially store blood at room temperature. Note: a low platelet count points to platelet activation via autocrine ADP or traces of thrombin.

- $\quad$ Add desired (ant)agonist, fluorescent probe, or vehicle buffer. Note: platelet adhesion under flow is influenced by DMSO or ethanol $(0.3 \%)$, sodium azide $(15 \mu \mathrm{M})$, or $\mathrm{Ca}^{2+}$ chelating media like phosphate-buffered saline.

- $\quad$ Fill a syringe or inlet part of the flow chamber with the requested volume of blood. Fill a second syringe with coagulation buffer, consisting of $75 \mathrm{mM} \mathrm{CaCl}_{2}$ and $37.5 \mathrm{mM}$ $\mathrm{MgCl}_{2}$. If required, add $10 \mathrm{pM}$ tissue factor.

- Connect both syringes to $y$-shaped inlet tubing that is connected directly before the flow chamber. Check for absence of air bubbles.

- Place syringes on perfusion pumps (pushing mode), and start mixing nine volumes of blood with one volume of coagulation buffer.

- $\quad$ Check for regular blood flow and for absence of leakage or air bubbles. Note: check that the mixing occurs well.

- Monitor thrombus and fibrin formation by microscopic imaging. Note: at $1000 \mathrm{~s}^{-1}$ platelets should form thrombi with fibrin within 5-8 $\mathrm{min}$ in case of human, rat, or mouse blood.

- Make sure that blood flow does not stop, as this may facilitate fibrin formation and occlusion of the flow chamber.

Flow assays in the presence of coagulation

Given the interdependency of platelet and coagulation activation and the role of fibrin in thrombus formation ${ }^{50,51}$, there is increasing interest in performing flow chamber assays in the presence of coagulation ${ }^{27,34,52}$. One way of achieving this is by mixing citrate-anticoagulated human, rat, or mouse blood with $\mathrm{CaCl}_{2} / \mathrm{MgCl}_{2}$ medium just before it enters the 
flow chamber (Box 3). If recalcified blood is flowed over a collagen surface, coagulation is stimulated via the intrinsic pathway of collagen-induced factor XII activation, while GPVI signaling results in the formation of procoagulant platelets ${ }^{52}$. By adding tissue factor to the recalcification medium, the extrinsic coagulation pathway can be stimulated as well ${ }^{27,53}$. Another possibility is to immobilize tissue factor on the surface ${ }^{54}$.

\section{Real-time and end-stage measurements of thrombus formation in flow chambers}

Thrombus formation under flow can be followed, not only by brightfield imaging, but also with a whole range of fluorescent probes, the majority of which are suited for human, mouse, and rat blood (Table 2). In this section, we describe staining procedures to measure aspects of thrombus formation in real time during flow and as end stage after the flow experiment.

Real-time measurement of platelet adhesion and $\mathrm{Ca}^{2+}$ response

Platelet adhesion under flow can be observed from recorded time series of brightfield images, but more easily from series of fluorescence images ${ }^{22,38,55-57}$. In the latter case, platelets in the blood need to be labeled in such a way that the background fluorescence of plasma is low. This can be achieved by adding a label to the blood, which binds to platelets with high-affinity, examples being antibodies against surface proteins such as GPIb ${ }^{55}$ or specific membrane probes such as $\mathrm{DiOC}_{6}{ }^{56}$. Alternatively, the platelets can be isolated and prelabeled, e.g. with $\mathrm{Ca}^{2+}$ probe, and after a centrifugation step, re-added to the blood sample ${ }^{38}$.

In human, rat, or mouse platelets loaded with the $\mathrm{Ca}^{2+}$ probe, Fluo-4 (or Fluo-3), flowdependent adhesion can directly be compared with the $\mathrm{Ca}^{2+}$ response ${ }^{13,27,38}$. To monitor the $\mathrm{Ca}^{2+}$ responses in single platelets, a sensitive shutter-controlled fluorescence imaging system is needed, capable to take images of Fluo-4 fluorescence at a relatively high speed $(2 \mathrm{~Hz})^{58}$. Figure 3 shows some typical $\mathrm{Ca}^{2+}$ traces, i.e. a prolonged $\mathrm{Ca}^{2+}$ rise of a platelet stably adhering to collagen (Figure $3 a$ ) and a spiking $\mathrm{Ca}^{2+}$ rise of a cell transiently adhering to VWF (Figure $3 b$ ). Procedures have been developed to analyze the changes in fluorescence in single, adhered platelets ${ }^{58}$. Herein, traces of changes in fluorescence intensity (F) of regions-of-interest, each representing one platelet, are converted into traces of nanomolar levels of $\mathrm{Ca}^{2+}$. Briefly, after background subtraction, per region-of-interest, a baseline fluorescence value $F_{0}$ is determined, which is used for calculation of the pseudoratio $F_{0}=F / F_{0}$. Concentrations of $\left[\mathrm{Ca}^{2+}{ }_{i}\right.$ in nanomolar are obtained from the equation $\left[\mathrm{Ca}^{2+}\right]_{i}=\mathrm{K}_{d} \times \mathrm{F}^{\prime} /\left(\mathrm{F}^{\prime} \mathrm{max}-\mathrm{F}^{\prime}\right)$, where $\mathrm{K}_{\mathrm{d}}$ is the dissociation constant of the fluorescent probe and $\mathrm{F}_{\text {max }}^{\prime}$ the maximal value of a nanospot of $\mathrm{Ca}^{2+}$-bound fluorescent probe. An alternative procedure is to calculate fluorescence ratio values from platelets loaded with two probes exciting at different emission wavelengths, OG-BAPTA-1 and FuraRed ${ }^{59}$. Note that the conventional dual-excitation $\mathrm{Ca}^{2+}$ probe Fura-2 cannot be used here, because of the high background fluorescence of blood plasma at $340 \mathrm{~nm}$ excitation. 


\section{Real-time measurement of platelet shape and thrombus stabilization}

Adhered platelets in a flow chamber are subjected to high shear forces, and can undergo marked changes in shape, e.g., by producing membrane tethers as long as $20 \mu \mathrm{m}^{23}$. Such morphological changes of unlabeled or labeled platelets can be detected by time-lapse microscopy using high-magnification objectives (Table 2). The same equipment can monitor platelet aggregation and thrombus contraction under flow. A common procedure to measure thrombus buildup is continuous fluorescence recording of the accumulation of $\mathrm{DiOC}_{6}$-labeled platelets at a surface. Alternatively, one can record series of z-stacks of confocal images of $\mathrm{DiOC}_{6}$ fluorescence ${ }^{12,63-65}$. In the latter case, three-dimensional (3D) image reconstructions can be made showing the increase in thrombus volume (Figure $3 \mathrm{c}$ and d).

Table 2. Parameters of whole blood thrombus formation as measured with brightfield and fluorescence microscopy. Brightfield illumination preferentially is with contrast-enhancing optics, such as phase-contrast or differential interference contrast. Indicated fluorescent probes can be used with human, mouse, or rat blood, but monoclonal antibodies (mAb) are for use with human blood only, except where indicated otherwise. Probes with excitation wavelength other than $\approx 488 \mathrm{~nm}$ are not indicated.

\begin{tabular}{|c|c|c|}
\hline Parameter & Brightfield and fluorescent probe & Refs. \\
\hline \multicolumn{3}{|l|}{ Real time measurement } \\
\hline $\begin{array}{l}\text { Transient and stable platelet } \\
\text { adhesion }\end{array}$ & Brightfield, calcein, $\mathrm{DiOC}_{6}$ & $22,38,55-57$ \\
\hline Platelet $\mathrm{Ca}^{2+}$ rises & Fluo-3. Fluo-4. OG-BAPTA-1/FuraRed & $13,38,58-61$ \\
\hline $\begin{array}{l}\text { Platelet shape change and tether } \\
\text { formation }\end{array}$ & Brightfield DiOC $_{6}$ & $23,56,62$ \\
\hline Thrombus buildup and contraction & FITC anti-GPIb, mAb, calcein, DiOC $_{6}$ & $12,55,63-65$ \\
\hline Thrombus stability (embolization) & Brightfield, $\mathrm{DiOC}_{6}$ & $55,66-68$ \\
\hline Fibrin fiber and clot formation & Brightfield, OG-fibrinogen & $34,47,69,70$ \\
\hline \multicolumn{3}{|l|}{ End stage measurement } \\
\hline Platelet surface area coverage & Brightfield, $\mathrm{DiOC}_{6}$ & $11,20,56,61$ \\
\hline Platelet aggregate size & Brightfield, $\mathrm{DiOC}_{6}$ & $12,20,52$ \\
\hline $\begin{array}{l}\text { Thrombus volume } \\
\text { (confocal laser scanning) }\end{array}$ & FITC anti-GPIb mAb, $\mathrm{DiOC}_{6}$ & $20,55,63,70$ \\
\hline Platelet integrin $\alpha_{11 \mathrm{~b}} \beta_{3} / \alpha_{2} \beta_{1}$ activation & $\begin{array}{l}\text { FITC PAC1/FITC IAC1 mAb, } \\
\text { FITC JON/A mAb }{ }^{a}, \text { OG-fibrinogen }\end{array}$ & $12,48,71$ \\
\hline Platelet $p$-selectin exposure & FITC anti-CD62 mAb & $48,60,72$ \\
\hline Fibrin fiber and clot formation & OG-fibrinogen & $34,47,52,54,69$ \\
\hline Platelet phosphatidylserine exposure & OG-annexin A5 & $13,14,48,61$ \\
\hline Platelet coagulation factor binding & $\begin{array}{l}\text { OG-prothrombin, OG-factor Xa, OG- } \\
\text { factor Va }\end{array}$ & $47,48,52$ \\
\hline
\end{tabular}

Note: $\mathrm{DiOC}_{6}, 3,3$ '-dihexyloxacarbocyanine iodide; OG, Oregon green 488;

and FITC, fluorescein isothiocyanate.

${ }^{a}$ For use with mouse blood. 
At high physiological levels of $\mathrm{Ca}^{2+}$ and $\mathrm{Mg}^{2+}$, platelet thrombi are dynamic structures that can easily fall apart ${ }^{55}$. Thrombus instability is particularly observed, when the platelet receptors for ADP, Gas6, or fibrinogen are non-functional ${ }^{35,66,67}$. In such case, the $\alpha_{11 b} \beta_{3}$ integrins will inactivate and platelet-platelet interactions are reversed. Thrombus instability and embolization can be assessed by time-lapse recording of brightfield or fluorescence images during flow (Figure $3 e$ and f). Platelet disaggregation can also be imaged after thrombus formation upon post-perfusion with buffers medium ${ }^{55,56}$. Another method to monitor disintegration of thrombi is by applying step-wise increases in shear rate during blood flow ${ }^{9}$. Flow chamber studies can furthermore identify shear-dependent platelet-leukocyte interactions ${ }^{73,74}$.

(a)

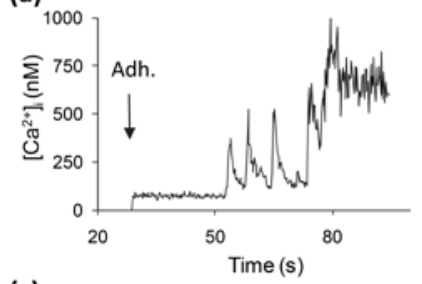

(c)

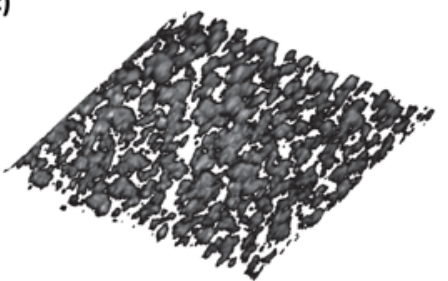

(e)

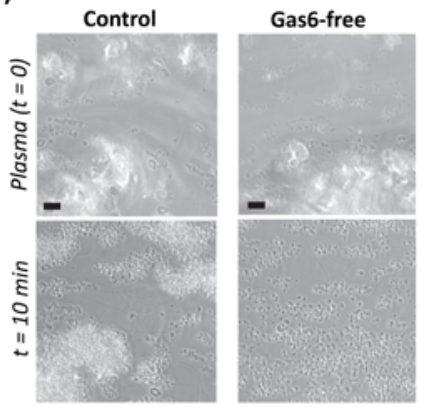

(b)

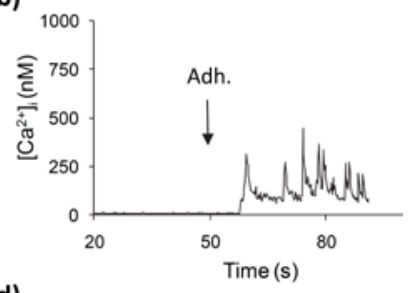

(d)
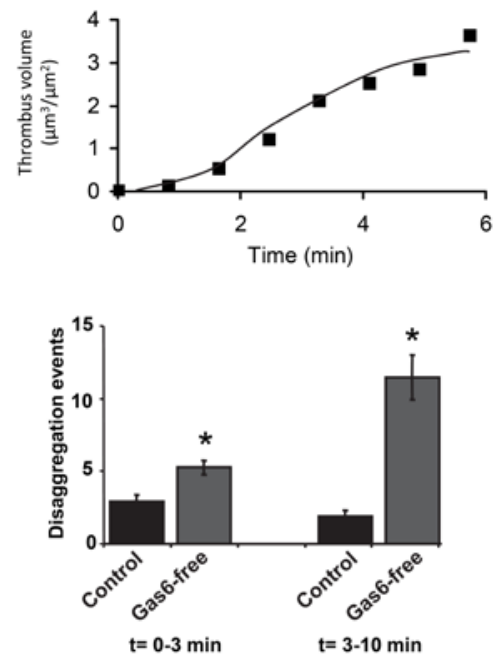

Figure 3. Real-time measurement of thrombus formation. Typical $\mathrm{Ca}^{2+}$ rises of single Fluo-3-loaded platelets during high-shear flow of human blood, which either (a) stably adhere to collagen or (b) transiently adhere to vWF. Measurement of thrombus volume during perfusion of human blood with DiOC $_{6}$-labeled platelets $\left(1000 \mathrm{~s}^{-1}\right.$, collagen surface). 3D reconstruction of image stack after 4 min, recorded by confocal microscopy (c); time-dependent increase in thrombus volume calculated from image stacks (d). Disaggregation of human platelets from thrombi on collagen during postperfusion with control or Gas6-free plasma. Phase-contrast images before and after $10 \mathrm{~min}$ of postperfusion (e); quantification of disaggregation events in the first $3 \mathrm{~min}$ and the next $7 \mathrm{~min}$ (f). Modified from Ref. $67,{ }^{*} \mathrm{p}<0.05$ vs. control. 


\section{Real-time measurement of coagulation parameters}

Under conditions favoring coagulation (see above), the generation of thrombin and fibrin during flow-dependent thrombus formation can be studied by microscopic imaging. Thrombin generation is measured by adding the fluorogenic thrombin substrate, Z-GGR$\mathrm{AMC}$ to the blood, and recording time series of fluorescence images at sites of a thrombus under stasis ${ }^{47}$. High amounts of thrombin are generated only after a lag time, once platelets in a thrombus show high rises in $\mathrm{Ca}^{2+}$ and respond to this by contraction ${ }^{27,47,52}$. The formation of clots and fibrin fibers can be followed in time by adding labeled fibrinogen 34,69

\section{End-stage measurements after thrombus formation}

Clear recognition of the thrombi formed in a flow chamber is helped by a short perfusion with rinsing buffer to remove red blood cells. Care should be taken to prevent coagulation (anticoagulant in rinsing buffer) and not to allow platelet disaggregation (short rinse). In addition, the thrombi can be post-stained by adding suitable labels to the perfusate. Brightfield and fluorescence images can be taken from representative microscopic windows (Figure 4).

For end-stage measurements of thrombus volume and platelet aggregate size, the same labels can be used as for real-time assays, e.g., the membrane probe $\mathrm{DiOC}_{6}$. Fluorescent markers are available to assess low and high activation states of platelets in a thrombus. Many of these are suitable for use with human, mouse, and rat blood (Table 2). Basically, the same probes can be used as in flow cytometry. Activated $\alpha_{11 b} \beta_{3}$ is stained with fluorescent-labeled antibodies such as PAC1 (human) or JON/A (mouse), or with fibrinogen (human, mouse, and rat) ${ }^{12,48,71}$. Antibodies against P-selectin are available to mark platelet $\alpha$-granule secretion ${ }^{48,60,72}$. Procoagulant platelets, expressing phosphatidylserine, are labeled with fluorescent annexin A5 ${ }^{14,48,61}$. Interestingly, the phosphatidylserine expressing platelets promote fibrin formation, which is also detected with fluorescent-labeled fibrinogen ${ }^{34,47,69}$. Coagulant activity is recognized from the binding of fluorescent-labeled coagulation factors to platelets in a thrombus, such as (pro)thrombin, factor Va, and factor $\mathrm{Xa}{ }^{47,48,52}$.

\section{Recording and analysis of microscopic images from flow assays}

Brightfield and fluorescence images from flow studies are to be recorded at well-defined optical and sensitivity settings for reproducible results. Box 4 provides some guidelines for optimal microscopic image recording and analysis. Several software packages are available for image analysis using semi-automatic pattern recognition, most popular being ImageJ, Metamorph, and ImagePro ${ }^{10}$. En-face brightfield contrast images provide only twodimensional information of the thrombi formed. Yet, analyzing such images for surfacearea-coverage is a useful surrogate measure for overall platelet deposition ${ }^{13,53,61}$. The surface-area-coverage usually correlates with thrombus volume, if the platelets on the surface are assembled in (contracted) thrombi with a pyramidal structure. On the other hand, when platelets are present as single structures or platelet aggregates are unstable, a high surface-area-coverage can be obtained at limited thrombus formation. In this case, 
procedures are available to determine the average size of aggregates by morphometric analysis of individual features on the surface ${ }^{20,55,61}$.

Specific analysis tools have been developed to measure thrombus volume from z-stacks of recorded fluorescence images ${ }^{12,20}$. An elegant way is to calculate the sum of the surfacearea-coverage of all images in a stack, and multiply this with the stack distance. Dividing this value by the field area results in a measure of thrombus formation (in units of $\mu \mathrm{m}^{3} / \mu \mathrm{m}^{2}$, Figure $3 \mathrm{~d}$ ), which reflects the mean height of all thrombi on the surface ${ }^{20}$.

(a)
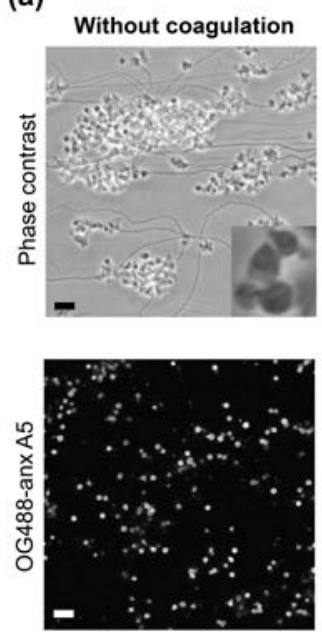

With coagulation
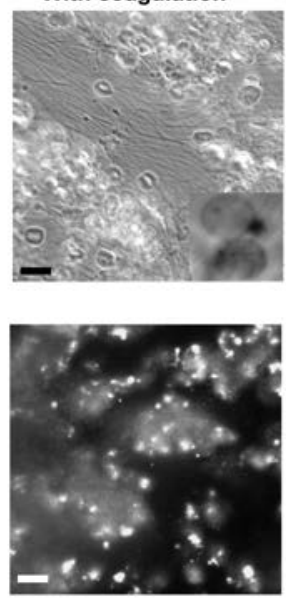

(b)

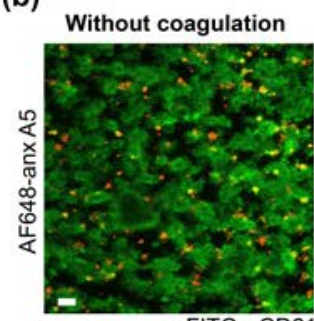

FITC- $\alpha$ CD6 1

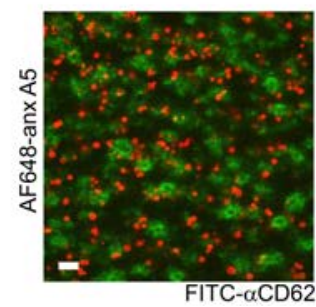

With coagulation
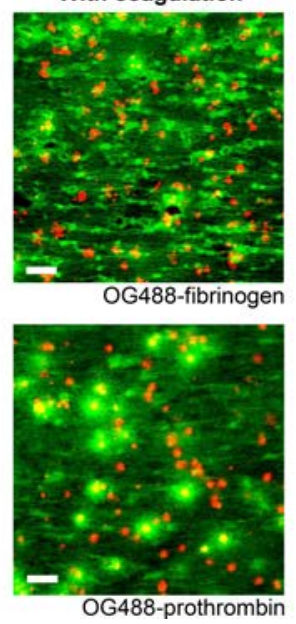

Figure 4. Different platelet responses in thrombus formation without or with coagulation. (a) Human thrombi formed under flow on collagen in the absence of coagulation (PPACK/fragminanticoagulated blood). Non-confocal images show collagen-adhered aggregated platelets and single procoagulant platelet staining with OG488-annexin A5. Dual-color confocal images show that the aggregated platelets aggregates stain for integrin $\beta_{3}$ (CD61) and P-selectin (CD62) in green, while the single platelets bind AF547-annexin A5 in red. (b) Human thrombi formed under flow on collagen in the presence of coagulation (recalcified citrate-anticoagulated blood). Non-confocal images show aggregated platelets and massive coagulation with fibrin fibers. Aggregates are surrounded by patches of OG488-annexin A5-staining platelets. Dual-color confocal images show fibrin fibers stained with OG488-fibrinogen or OG488-prothrombin in green, and single procoagulant platelets in red. Modified from Ref. 47. Bars $=10 \mu \mathrm{m}$.

\section{Flow chambers and control of antiplatelet medication}

Current antiplatelet drugs employed in clinical practice are directed against $\mathrm{P} 2 \mathrm{Y}_{12}$ receptors (clopidogrel, previously ticlopidine), integrin $\alpha_{11 b} \beta_{3}$ (tirofiban, abciximab), or formation of thromboxane $A_{2}$ (aspirin). These drugs prevent secondary thrombotic events, but their efficacy is not always complete (clopidogrel and aspirin) and they may cause an increased risk of bleeding (tirofiban and clopidogrel/aspirin) ${ }^{75-77}$. Clinical trials with agents targeting the platelet thromboxane or thrombin receptors are still ongoing ${ }^{78}$. Given the ongoing debate on how to monitor antiplatelet treatment and prevent undesired bleeding, flow 
chamber-based assays may provide a useful method to answer these questions. Table 3 summarizes the results from published patient studies regarding effects of antiplatelet medication on whole-blood thrombus formation, using collagen as a surface. It is shown that aspirin intake alone has a variable effect on thrombus formation, while the combination of aspirin and clopidogrel or ticlopidine causes a marked reduction ${ }^{79-82}$. Although limited in number, these studies illustrate the potency of the flow chamber technology in this area.

As described elsewhere, also other flow devices such as the PFA-100 and the IMPACT cone and plate(let) analyzer are able to measure platelet aggregate formation under high-shear conditions $^{5,84,85}$. However, these devices give only endpoint values (closure time or final thrombus size, respectively), while flow chamber measurements provide real-time information on a whole panel of output parameters, such as platelet adhesion and activation, thrombus build-up, and fibrin formation/coagulation, at well-predicted venous $\left(150 \mathrm{~s}^{-1}\right)$ or arterial shear rates $\left(>1500 s^{-1}\right)$. The PFA-100 is sensitive for aberrant vWF levels and limitedly for aspirin treatment ${ }^{84}$. Similarly, parallel-plate flow chambers detect vWF dysfunction in von Willebrand disease types 2 and $3^{86-88}$.

Box 4. Protocol for microscopic image recording and analysis.

- During the flow of human, mouse, or rat blood, record brightfield and/or fluorescence images with camera or laser scanner, as required. Note: for recording clear brightfield images, flow chambers preferentially have a depth of 50-100 $\mu \mathrm{m}$.

- At predefined end point, change from perfusion with blood to perfusion with rinsing buffer (e.g. modified Tyrode's buffer). If required, add fluorescent probe to the rinsing buffer. Note: prevent fluid stasis, since this may cause fibrin formation.

- Record brightfield images of the formed thrombi during flow, since rapidly moving erythrocytes will not distort images. Note: capture images before thrombi start to fall apart.

- Record fluorescence images after washing away unbound probe, to reduce background fluorescence. Note: stained thrombi might be fixed for later examination.

- For recording brightfield and fluorescence images, check for optimal settings with respect to:

o optical focality;

o magnification (objective, camera, and zoom);

o phase-contrast or differential interference contrast optics;

0 sensitivity and specificity of the fluorescence detection; (lamp/laser power and gain, diaphragm, filters, and dichroics);

o homogeneity of fluorescence staining;

o low background fluorescence.

- Record in-focus images from representative areas with thrombi. Prevent photobleaching when recording fluorescence images. Note: in case of rapidly bleaching probes such as fluorescein and phycoerythrin, record from unexposed windows.

- Check the recorded images for focality, homogeneity of illumination or staining, and absence of artifacts (clots, red blood cells, or air bubbles).

- Analyze the recorded images blinded for the condition, using appropriate software and semi-automatic macros. 
Table 3. Effects of antiplatelet medication on whole blood thrombus ex vivo, as obtained with custom-made parallel-plate flow chambers. Cited studies were performed with blood from patients or healthy volunteers.

\begin{tabular}{lllll}
\hline Medication & $\begin{array}{l}\text { Coating } \\
\text { Material }\end{array}$ & $\begin{array}{l}\text { Overall effect on } \\
\text { thrombus } \\
\text { formation }\end{array}$ & $\begin{array}{l}\text { Stability of } \\
\text { thrombus }\end{array}$ & Refs. \\
\hline Aspirin & Collagen I/III & $\begin{array}{l}\text { Unchanged/ } \\
\text { reduced }\end{array}$ & $\begin{array}{l}\text { Variable effect on } \\
\text { thrombus stability }\end{array}$ & $79-83$ \\
Aspirin + clopidogrel & Collagen I & Reduced & Instable thrombi & 80,81 \\
Aspirin + ticlopidine & Collagen I & Reduced & Instable thrombi, & $79,81,82$ \\
& & & normal adhesion & \\
\hline
\end{tabular}

\section{Conclusions}

Parallel-plate flow chambers are suitable devices for measurement of the process of thrombus formation, as they allow assaying both platelet function and coagulation within the same experiment at predefined shear rates. By combining the flow chamber technology with brightfield and fluorescence microscopy and image analysis, the knowledge on platelet receptors and signaling processes under conditions of low (venous) and high (arterial) shear rates has greatly increased. With the practical information in this methods article, on how to perform reproducible flow chamber assays, we hope to have set a further step forward to the accepted use of this technology in the research laboratory. For implementation in the clinic, a main challenge is to convert current flow chamber devices with complex microscopic monitoring to relatively simple devices with easy and quick read-out.

\section{Acknowledgements}

This study was supported by Zon-MW (11-400- 0076) and the Center for Translational Molecular Medicine (INCOAG).

\section{Declaration of interest statement:}

The authors declare that no conflicts of interest exist.

\section{References}

1. Gibbins JM. Platelet adhesion signalling and the regulation of thrombus formation. J Cell Sci 2004;117:3415-3425.

2. Ruggeri ZM, Mendolicchio GL. Adhesion mechanisms in platelet function. Circ Res 2007;100:16731685.

3. Munnix IC, Cosemans JM, Auger JM, Heemskerk JW.Platelet response heterogeneity in thrombus formation. Thromb Haemost 2009;102:1149-1156.

4. Zwaginga JJ, Nash G, King MR, Heemskerk JW, Frojmovic M, Hoylaerts MF, Sakariassen KS. Flow-based assays for global assessment of hemostasis. Part 1: Biorheologic considerations. J Thromb Haemost 2006;4:2486-2487.

5. Zwaginga JJ, Sakariassen KS, Nash G, King MR, Heemskerk JW, Frojmovic M, Hoylaerts MF. Flow-based assays for global assessment of hemostasis. Part 2: Current methods and considerations for the future. J Thromb Haemost 2006, 4:2716-2717. 
6. Sakariassen KS, Aarts PA, de Groot PG, Houdijk WP, Sixma JJ. A perfusion chamber developed to investigate platelet interaction in flowing blood with human vessel wall cells, their extracellular matrix, and purified components. J Lab Clin Med 1983;102:522-535.

7. De Groot PG, IJsseldijk MJW, Sixma JJ. Platelet adhesion to the subendothelium under flow. Methods Mol Biol 1999;96:159-170.

8. Sakariassen KS, Hanson SR, Cadroy Y. Methods and models to evaluate shear-dependent and surface reactivity-dependent antithrombotic efficacy. Thromb Res 2001;104:149-174.

9. Neeves KB, Maloney SF, Fong KP, Schmaier AA, Kahn ML, Brass LF, Diamond SL. Microfluidic focal thrombosis model for measuring murine platelet deposition and stability: PAR4 signaling enhances shear-resistance of platelet aggregates. J Thromb Haemost 2008;6:2193-2201.

10. Roest M, Reininger A, Zwaginga JJ, King MR, Heemskerk JWM, the Biorheology Subcommittee of the SSC of the ISTH. Flow chamber-based assays to measure thrombus formation in vitro: Requirements for standardization. J Thromb Haemost 2011, [Epub ahead of print].

11. Nieswandt B, Brakebusch C, Bergmeier W, Schulte V, Bouvard D, Mohtari-Nejad R, Lindhout T, Heemskerk JW, Zirngibl H, Fässler R. Glycoprotein VI but not $\alpha_{2} \beta_{1}$ integrin is essential for platelet interaction with collagen. EMBO J 2001;20:2120-2130.

12. Lecut C, Schoolmeester A, Kuijpers MJ, Broers JL, van Zandvoort MA, Vanhoorelbeke K, Deckmyn H, Jandrot-Perrus $M$, Heemskerk JW. Principal role of glycoprotein VI in $\alpha_{2} \beta_{1}$ and $\alpha_{11 b} \beta_{3}$ activation during collagen-induced thrombus formation. Arterioscler Thromb Vasc Biol 2004;24: 1727-1733.

13. Kuijpers MJ, Schulte V, Bergmeier W, Lindhout T, Brakebusch C, Offermanns S, Fassler R, Heemskerk JW, Nieswandt B. Complementary roles of glycoprotein $\mathrm{VI}$ and $\alpha_{2} \beta_{1}$ integrin in collagen-induced thrombus formation in flowing whole blood ex vivo. FASEB J 2003;17:685-687.

14. Bergmeier W, Oh-Hora M, McCarl CA, Roden RC, Bray PF, Feske S. R93W mutation in Orai1 causes impaired calcium influx in platelets. Blood 2009;113:675-678.

15. Savage B, Ginsberg MH, Ruggeri ZM. Influence of fibrillar collagen structure on the mechanisms of platelet thrombus formation under flow. Blood 1999;94:2704-2715.

16. Wu YP, de Groot PG, Sixma JJ. Shear-stress-induced detachment of blood platelets from various surfaces. Arterioscler Thromb Vasc Biol 1997;17:3202-3207.

17. Cosemans JM, Kuijpers MJ, Lecut C, Loubele ST, Heeneman S, Jandrot-Perrus M, Heemskerk JW. Contribution of platelet glycoprotein $\mathrm{VI}$ to the thrombogenic effect of collagens in fibrous atherosclerotic lesions. Atherosclerosis 2005;181:19-27.

18. Zhao XM, Wu YP, Cai HX, Wei R, Lisman T, Han JJ, Xia ZL, de Groot PG. The influence of the pulsatility of the blood flow on the extent of platelet adhesion. Thromb Res 2008;121:821-825.

19. Munnix IC, Gilio K, Siljander PR, Raynal N, Feijge MA, Hackeng TM, Deckmyn H, Smethurst PA, Farndale RW, Heemskerk JW. Collagen-mimetic peptides mediate flow-dependent thrombus formation by high- or low-affinity binding of integrin $\alpha_{2} \beta_{1}$ and glycoprotein VI. J Thromb Haemost 2008;6:21322142.

20. Pugh N, Simpson AM, Smethurst PA, de Groot PG, Raynal N, Farndale RW. Synergism between platelet collagen receptors defined using receptor-specific collagen-mimetic peptide substrata in flowing blood. Blood 2010;115:5069-5079.

21. Lisman T, Raynal N, Groeneveld D, Maddox B, Peachey AR, Huizinga EG, de Groot PG, Farndale RW. A single high-affinity binding site for von Willebrand factor in collagen III, identified using synthetic triple-helical peptides. Blood 2006;108:3753-3756.

22. Savage B, Saldivar E, Ruggeri ZM. Initiation of platelet adhesion by arrest onto fibrinogen or translocation on von Willebrand factor. Cell 1996;84:289-297.

23. Maxwell MJ, Dopheide SM, Turner SJ, Jackson SP. Shear induces a unique series of morphological changes in translocating platelets: Effects of morphology on translocation dynamics. Arterioscler Thromb Vasc Biol 2006;26:663-669.

24. Elvers M, Stegner D, Hagedorn I, Kleinschnitz C, Braun A, Kuijpers ME, BoesI M, Chen Q, Heemskerk JW, Stoll G, et al. Impaired $\alpha_{\| b} b_{3}$ integrin activation and shear-dependent thrombus formation in mice lacking phospholipase D1. Sci Signal 2010;3:ra1. 
25. Beumer S, IJsseldijk MJ, de Groot PG, Sixma JJ. Platelet adhesion to fibronectin in flow: Dependence on surface concentration and shear rate, role of platelet membrane glycoproteins GP IIb/IIla and VLA5, and inhibition by heparin. Blood 1994;84:3724-3733.

26. Zaidi TN, McIntire LV, Farrell DH, Thiagarajan P. Adhesion of platelets to surface-bound fibrinogen under flow. Blood 1996;88:2967-2972.

27. Kuijpers MJ, Nieuwenhuys CM, Feijge MA, Kloots W, Giesen PL, Jerling JC, oude Egbrink MG, Heemskerk JW. Regulation of tissue factor-induced coagulation and platelet aggregation in flowing whole blood. Thromb Haemost 2005;93:97-105.

28. Jen CJ, Lin JS. Direct observation of platelet adhesion to fibrinogen- and fibrin-coated surfaces. Am J Physiol 1991;261:H1457-H1463.

29. Endenburg SC, Hantgan RR, Lindeboom-Blokzijl L, Lankhof H, Jerome WG, Lewis JC, Sixma JJ, de Groot PG. On the role of von Willebrand factor in promoting platelet adhesion to fibrin in flowing blood. Blood 1995;86:4158-4165.

30. Keuren JF, Baruch D, Legendre P, Denis CV, Lenting PJ, Girma JP, Lindhout T. von Willebrand factor C1C2 domain is involved in platelet adhesion to polymerized fibrin at high shear rate. Blood 2004;103:1741-1746.

31. Hindriks G, IJsseldijk MJ, Sonnenberg A, Sixma JJ, de Groot PG. Platelet adhesion to laminin: Role of $\mathrm{Ca}^{2+}$ and $\mathrm{Mg}^{2+}$ ions, shear rate, and platelet membrane glycoproteins. Blood 1992;79:928-935.

32. Inoue O, Suzuki-Inoue K, Ozaki Y. Redundant mechanism of platelet adhesion to laminin and collagen under flow: Involvement of von Willebrand factor and glycoprotein Ib-IX-V. J Biol Chem 2008;283:16279-16282.

33. Penz SM, Reininger AJ, Toth O, Deckmyn H, Brandl R, Siess W. Glycoprotein Ibalpha inhibition and ADP receptor antagonists, but not aspirin, reduce platelet thrombus formation in flowing blood exposed to atherosclerotic plaques. Thromb Haemost 2007;97:435-443.

34. Reininger AJ, Bernlochner I, Penz SM, Ravanat C, Smethurst P, Farndale RW, Gachet C, Brandl R, Siess W. A 2-step mechanism of arterial thrombus formation induced by human atherosclerotic plaques. J Am Coll Cardiol2011;55:1147-1158.

35. Nergiz-Unal R, Cosemans JM, Feijge MA, van der Meijden PE, Storey RF, van Giezen JJ, oude Egbrink MG, Heemskerk JW, Kuijpers MJ. Stabilizing role of platelet $P 2 Y_{12}$ receptors in shear-dependent thrombus formation on ruptured plaques. Plos One 2010;5:e10130.

36. Saelman EU, Kehrel B, Hese KM, de Groot PG, Sixma JJ, Nieuwenhuis HK. Platelet adhesion to collagen and endothelial cell matrix under flow conditions is not dependent on platelet glycoprotein IV. Blood 1994;83:3240-3244.

37. Nieswandt B, Watson SP. Platelet-collagen interaction: Is GPVI the central receptor? Blood 2003;102:449-461.

38. Auger JM, Kuijpers MJ, Senis YA, Watson SP, Heemskerk JW. Adhesion of human and mouse platelets to collagen under shear: A unifying model. FASEB J 2005;19:825-827.

39. Jackson SP, Mistry N, Yuan YP. Platelets and the injured vessel wall: Rolling into action. Focus on glycoprotein Ib/V/IX and the platelet cytoskeleton. Trends Cardiovasc Med 2000;10:192-197.

40. Kuijpers MJ, Schulte V, Oury C, Lindhout T, Broers J, Hoylaerts MF, Nieswandt B, Heemskerk JW. Facilitating roles of murine platelet glycoprotein $\mathrm{Ib}$ and $\alpha_{11 \mathrm{~b}} \beta_{3}$ in phosphatidylserine exposure during vWFcollagen-induced thrombus formation. J Physiol 2004;558:403-415.

41. Jackson SP. The growing complexity of platelet aggregation. Blood 2007;109:5087-5095.

42. Heemskerk JW, Sakariassen KS, Zwaginga JJ, Brass LF, Jackson SP, Farndale RW, the Biorheology Subcommittee of the SSC, of the ISTH. Collagen surfaces to measure thrombus formation under flow: Possibilities for standardization. J Thromb Haemost 2011;9:856-858.

43. Sixma JJ, de Groot PG. Regulation of platelet adhesion to the vessel wall. Ann N Y Acad Sci 1994;714:190-199.

44. Ruggeri ZM. Platelet adhesion under flow. Microcirculation 2009;16:58-83.

45. Lisman T, Adelmeijer J, Cauwenberghs S, Van Pampus EC, Heemskerk JW, De Groot PG. Recombinant factor VIla enhances platelet adhesion and activation under flow conditions at normal and reduced platelet count. J Thromb Haemost 2005;3:742-751. 
46. Okorie UM, Diamond SL. Matrix protein microarrays for spatially and compositionally controlled microspot thrombosis under laminar flow. Biophys J 2006;91:3474-3481.

47. Berny MA, Munnix IC, Auger JM, Schols SE, Cosemans JM, Panizzi P, Bock PE, Watson SP, McCarty OJ, Heemskerk JW. Spatial distribution of factor Xa, thrombin, and fibrin(ogen) on thrombi at venous shear. PLoS One 2010;5:e10415.

48. Munnix IC, Kuijpers MJ, Auger J, Thomassen CM, Panizzi P. van Zandvoort MA, Rosing J, Bock PE, Watson SP, Heemskerk JW. Segregation of platelet aggregatory and procoagulant microdomains in thrombus formation: Regulation by transient integrin activation. Arterioscler Thromb Vasc Biol 2007;27:2484-2490.

49. Cosemans JM, Iserbyt BF, Deckmyn H, Heemskerk JW. Multiple pathways to switch platelet integrins on and off. J Thromb Haemost 2008;6:1253-1261.

50. Heemskerk JW, Bevers EM, Lindhout T. Platelet activation and blood coagulation. Thromb Haemost 2002;88:186-193.

51. Brass LF. Thrombin and platelet activation. Chest 2003;124: 18S-25S.

52. Van der Meijden PE, Munnix IC, Auger JM, Govers- Riemslag JW, Cosemans JM, Kuijpers MJ, Spronk HM, Watson SP, Renne T, Heemskerk JW. Dual role of collagen in factor XII-dependent thrombus formation. Blood 2009;114:881-890.

53. Munnix IC, Strehl A, Kuijpers MJ, Auger JM, van der Meijden PE, van Zandvoort MA, oude Egbrink MG, Nieswandt B, Heemskerk JW. The glycoprotein VI-phospholipase C 2 signaling pathway controls thrombus formation induced by collagen and tissue factor in vitro and in vivo. Arterioscler Thromb Vasc Biol 2005;25:2673-2678.

54. Diamond SL. Tissue factor activity under flow. Thromb Res. 2010;125:S29-S30.

55. Cosemans JM, Munnix IC, Wetzker R, Heller R, Jackson SP, Heemskerk JW. Continuous signaling via $\mathrm{PI3K}$ isoforms beta and gamma is required for platelet ADP receptor function in dynamic thrombus stabilization. Blood 2006;108:3045-3052.

56. Maxwell MJ, Westein E, Nesbitt WS, Giuliano S, Dopheide SM, Jackson SP. Identification of a 2-stage platelet aggregation process mediating shear-dependent thrombus formation. Blood 2007;109:566576.

57. Meyer dos Santos S, Klinkhardt U, Schneppenheim R, Harder S. Using ImageJ for the quantitative analysis of flow-based adhesion assays in real-time under physiologic flow conditions. Platelets 2010;21:60-66.

58. Heemskerk JW, Willems GM, Rook MB, Sage SO. Ragged spiking of free calcium in ADP-stimulated human platelets: Regulation of puff-like calcium signals in vitro and ex vivo. J Physiol 2001;535:625635 .

59. Nesbitt WS, Giuliano S, Kulkarni S, Dopheide SM, Harper IS, Jackson SP. Intercellular calcium communication regulates platelet aggregation and thrombus growth. J Cell Biol 2003;160:1151-1161.

60. Gilio K, Munnix IC, Mangin P, Cosemans JM, Feijge MA, van der Meijden PE, Olieslagers S, Chrzanowska-Wodnicka MB, Lillian R, Schoenwaelder S, et al. Non-redundant roles of phosphoinositide 3-kinase isoforms alpha and beta in glycoprotein $\mathrm{VI}$-induced platelet signaling and thrombus formation. J Biol Chem 2009;284:33750-33762.

61. Siljander PR, Munnix IC, Smethurst PA, Deckmyn H, Lindhout T, Ouwehand WH, Farndale RW, Heemskerk JW. Platelet receptor interplay regulates collagen-induced thrombus formation in flowing human blood. Blood 2004;103:1333-1341.

62. Nesbitt WS, Westein E, Tovar-Lopez FJ, Tolouei E, Mitchell A, Fu J, Carberry J, Fouras A, Jackson SP. A shear gradient-dependent platelet aggregation mechanism drives thrombus formation. Nat Med 2009;15:665-673.

63. Jones KL, Hughan SC, Dopheide SM, Farndale RW, Jackson SP, Jackson DE. Platelet endothelial cell adhesion molecule-1 is a negative regulator of platelet-collagen interactions. Blood 2001;98:1456-1463.

64. Ono A, Westein E, Hsiao S, Nesbitt WS, Hamilton JR, Schoenwaelder SM, Jackson SP. Identification of a fibrinindependent platelet contractile mechanism regulating primary hemostasis and thrombus growth. Blood 2008;112: 90-99.

65. Auger JM, Watson SP. Dynamic tyrosine kinase-regulated signaling and actin polymerisation mediate aggregate stability under shear. Arterioscler Thromb Vasc Biol 2008;28: 1499-1504. 
66. Goto S, Tamura N, Ishida H, Ruggeri ZM. Dependence of platelet thrombus stability on sustained glycoprotein Ilb/IIla activation through adenosine $5^{\prime}$-diphosphate receptor stimulation and cyclic calcium signaling. J Am Coll Cardiol 2006;47:155-162.

67. Cosemans JM, Van Kruchten R, Olieslagers S, Schurgers LJ, Verheyen FK, Munnix IC, Waltenberger J, Angelillo-Scherrer A, Hoylaerts MF, Carmeliet P, et al. Potentiating role of Gas6 and Tyro3, Axl and Mer (TAM) receptors in human and murine platelet activation and thrombus stabilization. J Thromb Haemost 2010;8:1797-1808.

68. Kuijpers MJ, Pozgajova M, Cosemans JM, Munnix IC, Eckes B, Nieswandt B, Heemskerk JW. Role of murine integrin $\alpha_{2} \beta_{1}$ in thrombus stabilization and embolization: Contribution of thromboxane $A 2$. Thromb Haemost 2007;98:1072-1080.

69. Cosemans JM, Schols SE, Stefanini L, de Witt S, Feijge MA, Hamulyak K, Deckmyn H, Bergmeier W, Heemskerk JW. Key role of glycoprotein Ib/V/IX and von Willebrand factor in platelet activationdependent fibrin formation at low shear flow. Blood 2011;117:651-660.

70. Mizuno T, Sugimoto M, Matsui H, Hamada M, Shida Y, Yoshioka A. Visual evaluation of blood coagulation during mural thrombogenesis under high shear blood flow. Thromb Res 2008;121:855-864.

71. Van de Walle G, Schoolmeester A, Iserbyt BF, Cosemans JM, Heemskerk JW, Hoylaerts MF, Nurden A, Vanhoorelbeke K, Deckmyn H. Activation of $\alpha_{11 b} \beta_{3}$ is sufficient but also an imperative prerequisite to activate $\alpha_{2} \beta_{1}$ on platelets. Blood 2007;109:595-602.

72. Gilio K, Harper MT, Cosemans JM, Konopatskaya O, Munnix IC, Prinzen L, Leitges M, Liu Q, Molkentin $J D$, Heemskerk JW, et al. Functional divergence of platelet protein kinase C (PKC) isoforms in thrombus formation on collagen. J Biol Chem 2010;285:23410-23419.

73. Kulkarni S, Woollard KJ, Thomas S, Oxley D, Jackson SP. Conversion of platelets from a proaggregatory to a proinflammatory adhesive phenotype: Role of PAF in spatially regulating neutrophil adhesion and spreading. Blood 2007;110:1879-1886.

74. Hu H, Zhu L, Huang Z, Ji Q, Chatterjee M, Zhang W, Li N. Platelets enhance lymphocyte adhesion and infiltration into arterial thrombus. Thromb Haemost 2011;104:1184-1192.

75. Cattaneo M. Bleeding manifestations of congenital and druginduced defects of the platelet P2 $\mathrm{Y}_{12}$ receptor for adenosine diphosphate. Thromb Haemost 2011;105(Suppl. 1):S67-S74.

76. Storey RF. Pharmacology and clinical trials of reversiblybinding $P 2 Y_{12}$ inhibitors. Thromb Haemost 2011; 105(Suppl. 1):S75-S81.

77. Gurbel PA, Tantry US. Clopidogrel response variability and the advent of personalised antiplatelet therapy. A bench to bedside journey. Thromb Haemost 2011;106:265-271.

78. Siller-Matula JM, Krumphuber J, Jilma B. Pharmacokinetic, pharmacodynamic and clinical profile of novel antiplatelet drugs targeting vascular diseases. Br J Pharmacol 2010;159: 502-517.

79. Bossavy JP, Thalamas C, Sagnard L, Barret A, Sakariassen K, Boneu B, Cadroy Y. A double-blind randomized comparison of combined aspirin and ticlopidine therapy versus aspirin or ticlopidine alone on experimental arterial thrombogenesis in humans. Blood 1998;92:1518-1525.

80. Cadroy Y, Bossavy JP, Thalamas C, Sagnard L, Sakariassen K, Boneu B. Early potent antithrombotic effect with combined aspirin and a loading dose of clopidogrel on experimental arterial thrombogenesis in humans. Circulation 2000;101:2823-2828.

81. Mendolicchio GL, Zavalloni D, Bacci M, Corrada E, Marconi M, Lodigiani C, Presbitero P, Rota L, Ruggeri ZM. Variable effect of $\mathrm{P}_{2} \mathrm{Y}_{12}$ inhibition on platelet thrombus volume in flowing blood. J Thromb Haemost 2011;9:373-382.

82. Sakakibara M, Goto S, Eto K, Tamura N, Isshiki T, Handa S. Application of ex vivo flow chamber system for assessment of stent thrombosis. Arterioscler Thromb Vasc Biol 2002; 22:1360-1364.

83. Andre P, LaRocca T, Delaney SM, Lin PH, Vincent D, Sinha U, Conley PB, Phillips DR. Anticoagulants (thrombin inhibitors) and aspirin synergize with $\mathrm{P}_{2} \mathrm{Y}_{12}$ receptor antagonism in thrombosis. Circulation 2003;108:2697-2703.

84. Favaloro EJ. Clinical utility of the PFA-100. Semin Thromb Hemost 2008;34:709-733.

85. Michelson AD. Methods for the measurement of platelet function. Am J Cardiol 2009;103:20A-26A.

86. Tsuji S, Sugimoto M, Miyata S, Kuwahara M, Kinoshita S, Yoshioka A. Real-time analysis of mural thrombus formation in various platelet aggregation disorders: Distinct shear-dependent roles of platelet receptors and adhesive proteins under flow. Blood 1999;94:968-975. 
87. Sugimoto $M$, Matsui $H$, Mizuno $T$, Tsuji S, Miyata S, Matsumoto $M$, Matsuda M, Fujimura $Y$, Yoshioka A. Mural thrombus generation in type $2 \mathrm{~A}$ and $2 \mathrm{~B}$ von Willebrand disease under flow conditions. Blood 2003;101:915-920.

88. Zwaginga JJ, Sakariassen KS, King MR, Diacovo TG, Grabowski EF, Nash G, Hoylaerts M, Heemskerk JW. Can blood flow assays help to identify clinically relevant differences in von Willebrand factor functionality in von Willebrand disease types 1-3? J Thromb Haemost 2007;5:2547-2549. 


\section{Chapter 3}

\section{Roles of platelet STIM1 and Orai1 in glycoprotein VI- and thrombin-dependent procoagulant activity and thrombus formation}

Gilio K, van Kruchten R, Braun A, Berna-Erro A, Feijge MA, Stegner D, van der Meijden PE, Kuijpers MJ, Varga-Szabo D, Heemskerk JW, Nieswandt B.

J Biol Chem. 2010;285:23629-23638

Reprinted with permission 


\begin{abstract}
In platelets, STIM1 has been recognized as the key regulatory protein in store-operated $\mathrm{Ca}^{2+}$ entry (SOCE) with Orai1 as principal $\mathrm{Ca}^{2+}$ entry channel. Both proteins contribute to collagen-dependent arterial thrombosis in mice in vivo. It is unclear whether STIM2 is involved. A key platelet response relying on $\mathrm{Ca}^{2+}$ entry is the surface exposure of phosphatidylserine (PS), which accomplishes platelet procoagulant activity. We studied this response in mouse platelets deficient in STIM1, STIM2, or Orai1. Upon high shear flow of blood over collagen, Stim $1^{-/}$and Orai $^{-/-}$platelets had greatly impaired glycoprotein (GP)VI-dependent $\mathrm{Ca}^{2+}$ signals, and they were deficient in PS exposure and thrombus formation. In contrast, Stim $2^{-/}$platelets reacted normally. Upon blood flow in the presence of thrombin generation and coagulation, $\mathrm{Ca}^{2+}$ signals of Stim $1^{-1-}$ and Orai $1^{-1-}$ platelets were partly reduced, whereas the PS exposure and formation of fibrin-rich thrombi were normalized. Washed Stim $1^{-/-}$and Orai $1^{-/-}$platelets were deficient in GPVI-induced PS exposure and prothrombinase activity, but not when thrombin was present as co-agonist. Markedly, SKF96365, a blocker of (receptor-operated) $\mathrm{Ca}^{2+}$ entry, inhibited $\mathrm{Ca}^{2+}$ and procoagulant responses even in Stim $1^{-/-}$and $\mathrm{Orai}^{-/-}$platelets. These data show for the first time that: (i) STIM1 and Orai1 jointly contribute to GPVI-induced SOCE, procoagulant activity, and thrombus formation; (ii) a compensating $\mathrm{Ca}^{2+}$ entry pathway is effective in the additional presence of thrombin; (iii) platelets contain two mechanisms of $\mathrm{Ca}^{2+}$ entry and PS exposure, only one relying on STIM1-Orai1 interaction.
\end{abstract}

\title{
Introduction
}

In platelets, elevation in cytosolic $\left[\mathrm{Ca}^{2+}\right]_{i}$ is imperative to almost all functional responses. Moderate and transient rises in $\left[\mathrm{Ca}^{2+}\right]_{i}$ mediate shape change, integrin $\alpha_{11 b} \beta_{3}$ activation, thromboxane formation, and secretion of granule contents, whereas high and prolonged $\left[\mathrm{Ca}^{2+}\right]_{i}$ rises are required for the procoagulant response ${ }^{1,2}$. The latter is achieved by a Ca ${ }^{2+}$ activated scramblase mechanism disturbing the normal phospholipid asymmetry in the plasma membrane, with, as a result, the exposure of phosphatidylserine (PS) ${ }^{5}$ at the outer membrane surface ${ }^{3,4}$. Exposed PS provides high affinity binding sites for key coagulation factors and, thereby, facilitates the assembly of tenase and prothrombinase complexes, which are responsible for the formation of factor $X$ a and thrombin, respectively ${ }^{3}$. Because thrombin is one of the most potent platelet agonists, the procoagulant platelet response triggers a potent positive feedback loop of platelet and coagulation activation. Recent in vivo studies have indicated that PS exposure and ensuing thrombin generation are key regulatory events in murine arterial thrombus formation ${ }^{5,6}$.

Whereas stored platelets may expose procoagulant PS in a $\mathrm{Ca}^{2+}$-independent way, PS exposure in activated platelets relies on a high and prolonged rise in cytosolic $\left[\mathrm{Ca}^{2+}\right]_{\mathrm{i}}{ }^{7}$. Platelet stimulation with single G protein-coupled agonists, like thrombin and ADP, results in limited PS exposure ${ }^{8,9}$, but stimulation of the tyrosine kinase-linked collagen receptor glycoprotein VI (GPVI), with ligands such as collagen-related peptide (CRP) or convulxin, results in appreciable procoagulant activity ${ }^{10,11}$. Combined stimulation of the collagen and thrombin receptors though results in high PS exposure, likely because these agonists use different signaling pathways for mobilizing cytosolic $\mathrm{Ca}^{2+1}$. Although thrombin transiently activates $G_{q \alpha}$ and phospholipase $C \beta 2 / \beta 3$ isoforms, activation of GPVI causes a more persis- 
tent activation of the phospholipase $\mathrm{C} \gamma 2$ isoform ${ }^{2,12}$. For PS exposure, entry of extracellu$\operatorname{lar} \mathrm{Ca}^{2+}$ is required, complementing the $\mathrm{Ca}^{2+}$-mobilizing effect of phospholipase $\mathrm{C}$ stimulation, to reach sufficiently high $\left[\mathrm{Ca}^{2+}\right]_{i}^{10,13,14}$.

In platelets, like other cells, $\mathrm{Ca}^{2+}$ entry can be triggered by receptor stimulation, as well as by $\mathrm{Ca}^{2+}$ mobilization from stores via the processes of receptor-operated $\mathrm{Ca}^{2+}$ entry and store-operated $\mathrm{Ca}^{2+}$ entry (SOCE), respectively ${ }^{15}$. For long, not only the responsible $\mathrm{Ca}^{2+}$ entry channels, but also the coupling mechanisms of receptor activation and $\mathrm{Ca}^{2+}$ store depletion to channel opening have remained elusive. In earlier work with platelets, roles of the TRPC1 and TRPC6 channel proteins in $\mathrm{Ca}^{2+}$ entry have been proposed ${ }^{16,17}$. Recent studies, however, have shown the importance of the Orai class of plasma membrane $\mathrm{Ca}^{2+}$ channels. The channel Orai1 (also called CRACM1) oligomerizes and opens, following depletion of the $\mathrm{Ca}^{2+}$ stores, by interacting with $\mathrm{Ca}^{2+}$ sensing STIM1, which is a transmembrane protein located in the endoplasmic reticulum ${ }^{18-20}$. The homologous protein STIM2 can have a similar regulatory role in $\mathrm{Ca}^{2+}$ entry ${ }^{21}$. Both Orai1 and STIM1 have been implicated in the physiological activation of $\mathrm{T}$ cells and mast cells ${ }^{22,23}$. Recent studies using genetically modified mice have established that STIM1 and Orai1 account for the large majority of SOCE in platelets. The importance of this SOCE pathway appeared from the finding that platelet deficiency in either Orai1 or STIM1 protects against collagendependent arterial thrombus formation and brain infarction in vivo ${ }^{24,25}$. In confirmation, others have provided evidence that a functional R93W mutation in Orai1 leads to impaired GPVI-induced platelet activation ${ }^{26}$. In the present paper, we investigated whether the STIM isoforms and Orai1 provide the main $\mathrm{Ca}^{2+}$ entry mechanism responsible for PS exposure and procoagulant activity in platelets stimulated by the collagen and thrombin

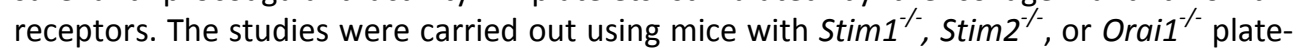
lets.

\section{Experimental Procedures}

\section{Mouse strains}

Animal studies were approved by the local animal care and use committees. Mice homozygously deficient in Stim1 or Orai1 were generated from embryonic stem cell clones and germ line transmission, as described ${ }^{24,25}$. Because these animals suffered from early lethality and growth retardation, bone marrow chimeras were created which had normal viability. Female, 5-6-week-old C57BL/6 mice were irradiated with a single dose of $10 \mathrm{~Gy}$ and injected intravenously with bone marrow cells from donor Stim $1^{-1}$, Orail ${ }^{-1}$, or wild type mice $\left(4 \times 10^{6}\right.$ cells/animal). The recipient mice received acidified water containing 2 $\mathrm{g} /$ liter neomycin sulfate for 6 weeks after transplantation. Blood was taken from the chimeras after $>6$ weeks. Mice homozygously deficient in Stim2 had a mixed genetic background and were compared with wild types of the same background ${ }^{27}$. Blood cell counts of all mice were in the normal range. Purified platelets from (bone marrowtransplanted) mice were subjected to Western blotting to confirm knock-out of STIM proteins. Deficiency in Orai1 transcripts was confirmed by reverse transcription-PCR analysis $^{25}$. 


\section{Materials}

H-Phe-Pro-Arg chloromethyl ketone (PPACK) was obtained from Calbiochem. Annexin A5 labeled with fluorescein isothiocyanate (FITC), Fura-2 and Fluo-4 acetoxymethyl esters, and pluronic F-127 were from Invitrogen. Thrombin substrate, Z-Gly-Gly-Arg aminomethyl coumarin (Z-GGR-AMC), was from Bachem. Fibrillar type I collagen (Horm) was from Nycomed. Recombinant human tissue factor was from Dade Behring. Apyrase (grade $\mathrm{V}$ ), bovine serum albumin (BSA), heparin, SKF96365, and thrombin were from Sigma. The GPVI agonist CRP was synthesized and cross-linked by Tana Laboratories. The agonist convulxin was purified as described ${ }^{11}$. FITC-labeled anti-mouse P-selectin monoclonal antibody was from Emfret Analytics. Bovine coagulation factors and other materials were from sources indicated before ${ }^{28}$.

\section{Blood collection and platelet preparation}

Mouse blood was obtained via orbital puncture under anesthesia. For perfusion studies in the absence of coagulation, blood was collected into a mixture of $40 \mu \mathrm{M}$ PPACK, 5 units $/ \mathrm{ml}$ heparin, and 40 units/ml fragmin. For later perfusions with coagulation, blood was collected into $12.9 \mathrm{mM}$ trisodium citrate. Citrate-anticoagulated blood was also used to prepare platelet-rich plasma (PRP), normalized with autologous platelet-poor plasma to a platelet count of $1 \times 10^{8} / \mathrm{ml}$. Washed platelets were prepared from PRP by supplementation with ACD solution ( $85 \mathrm{mM}$ sodium citrate, $78 \mathrm{mM}$ citric acid, and $11 \mathrm{mM}$ D-glucose) (1:25). After centrifugation, platelets were suspended in Hepes buffer, pH 7.45 (136 mM $\mathrm{NaCl}, 5 \mathrm{mM}$ Hepes, $2.7 \mathrm{mM} \mathrm{KCl}, 2 \mathrm{mM} \mathrm{MgCl}$, $0.42 \mathrm{mM} \mathrm{Na}_{2} \mathrm{HPO}_{4}, 5 \mathrm{mM}$ glucose, and $0.1 \%$ BSA). Cells were counted with a Coulter counter.

\section{Activation of suspended platelets}

Washed mouse platelets were loaded with the ratiometric $\mathrm{Ca}^{2+}$ probe Fura-2, as described ${ }^{24}$. Platelets suspended in the presence or absence of $1 \mathrm{mM} \mathrm{CaCl}_{2}$, were preincubated with $100 \mu \mathrm{M}$ SKF96365 and activated with collagen and/or thrombin receptor agonists, as indicated. Changes in fluorescence were measured with a PerkinElmer Life Sciences 55 fluorometer. Excitation was alternated between 340 and $380 \mathrm{~nm}$, and emission was measured at $509 \mathrm{~nm}$. Calibration parameters of nanomolar $\left[\mathrm{Ca}^{2+}\right]_{i}$ were obtained by lysis with $1 \%$ Triton X-100 and addition of a surplus of EGTA. For flow cytometry, unloaded washed platelets $\left(1 \times 10^{8} / \mathrm{ml}\right)$ were activated in the presence of $\mathrm{CaCl}_{2}$ with the indicated agonists for $10 \mathrm{~min}$; stirring was absent to prevent platelet aggregation ${ }^{29}$. Surface expression of PS was detected in the presence of $\mathrm{CaCl}_{2}(2 \mathrm{mM})$ with FITC-annexin A5 $(0.5 \mu \mathrm{g} / \mathrm{ml})$.

\section{Thrombus formation on collagen}

Glass cover slips were coated with fibrillar type I collagen and blocked with BSA-containing Hepes buffer, $\mathrm{pH}$ 7.45. The cover slips were mounted in a transparent, $50 \mu \mathrm{m}$-deep parallel-plate poly(methyl) methacrylate flow chamber ${ }^{30}$. Mouse blood was perfused through the flow device at a defined shear rate under physiological, millimolar concentrations of divalent cations. For experiments in the absence of coagulation, PPACK/heparin-treated blood was flowed over collagen at $1000 \mathrm{~s}^{-1}$ for $4 \mathrm{~min}$. For experiments in the presence of coagulation, citrate-anticoagulated blood was recalcified directly before entering the flow 
chamber, using a two-pump system ${ }^{29}$. Briefly, 1-ml syringes were filled with citrateanticoagulated blood or isotonic $\mathrm{CaCl}_{2} / \mathrm{MgCl}_{2}$ solution $(110 \mathrm{mM} \mathrm{NaCl}, 13.3 \mathrm{mM} \mathrm{CaCl}$, and $6.7 \mathrm{mM} \mathrm{MgCl}$ ). The syringes were connected to the flow chamber via a $y$-shaped inlet, designed to give optimal fluid mixing. By co-infusing both fluids into the chamber at an equal flow rate (final shear rate, $1000 \mathrm{~s}^{-1}$ ), coagulation was started by collagen- and factor XII-dependent activation ${ }^{31}$. The thrombi on coverslips were postlabeled by perfusion with FITC-annexin A5 $(0.5 \mu \mathrm{g} / \mathrm{ml})$ in Hepes buffer, $\mathrm{pH} 7.45$, containing $2 \mathrm{mM} \mathrm{CaCl}_{2}$ and 1 unit/ml heparin. Brightfield and fluorescence images were recorded from at least 10 randomly chosen microscopic fields ${ }^{32}$. Images were analyzed with ImagePro software (Media Cybernetics). The procoagulant index of thrombi was determined as the ratio of surface coverage of PS-exposing platelets (FITC-annexin A5) to the coverage of total platelets ${ }^{33}$.

\section{Single-platelet $\mathrm{Ca}^{2+}$ fluxes under flow}

Mouse platelets were loaded with Fluo-4 ${ }^{34}$ and added to PPACK/fragmin- or citrateanticoagulated blood from the same genotype ( $10 \%$ labeled platelets). During blood flow over collagen, 16-bit digital fluorescence images were recorded at high speed $(5 \mathrm{~Hz})$ using an EM-CCD camera ${ }^{31}$. Regions of interest representing single adhered platelets were analyzed off-line for changes in fluorescence $(F)^{34}$. Pseudoratio $F / F_{0}$ values were converted into nanomolar concentrations of $\left[\mathrm{Ca}^{2+}\right]_{i}$ using predefined calibration parameters ${ }^{35}$. For quantitative purposes, traces from individual cells were superimposed so that $\left[\mathrm{Ca}^{2+}\right]_{i}$ rises started at the same frame number.

\section{Prothrombinase activity}

Prothrombinase-stimulating activity was determined at linear assay conditions, as previously assessed for human platelets ${ }^{36}$. Washed mouse platelets were diluted in Hepes buffer, $\mathrm{pH} 7.45$, containing $3 \mathrm{mM} \mathrm{CaCl}_{2}$ to a count of $4 \times 10^{5} / \mathrm{ml}$ and incubated with $0.5 \mu \mathrm{M}$ prothrombin, $2 \mathrm{nM}$ factor $\mathrm{Va}$, and $1 \mathrm{nM}$ factor $\mathrm{Xa}\left(37^{\circ} \mathrm{C}\right)$. Samples were taken after exactly $3 \mathrm{~min}$ and transferred to vials containing $0.5 \mathrm{mM}$ thrombin substrate S2238 for chromogenic measurement of the thrombin formed.

\section{Thrombin generation}

Thrombin generation was measured in citrate- anticoagulated PRP ${ }^{28}$. The PRP, pooled from three animals with the same (chimeric) genotype, was diluted with autologous platelet-poor plasma to a count of $1.5 \times 10^{8}$ platelets $/ \mathrm{ml}$. Samples were activated with convulxin $(100 \mathrm{ng} / \mathrm{ml})$, ionomycin $(20 \mu \mathrm{M})$, or vehicle for $15 \mathrm{~min}$. Aliquots (4 volumes) were then transferred to a polystyrene 96-wells plate (Immulon 2HB, Dynex Technologies), already containing 1 volume of buffer A (20 mM Hepes, $140 \mathrm{mM} \mathrm{NaCl}, 0.5 \% \mathrm{BSA}$, and $6 \mathrm{pM}$ tissue factor). Coagulation was started by adding 1 volume of buffer $\mathrm{B}$ ( $2.5 \mathrm{mM}$ Z-GGR-AMC, $20 \mathrm{mM}$ Hepes, $140 \mathrm{mM} \mathrm{NaCl}, 100 \mathrm{mM} \mathrm{CaCl}_{2}$, and 6\% BSA). First-derivative curves were converted into nanomolar thrombin concentrations using a calibrator for human $\alpha$-thrombin ${ }^{28}$. All analyses were in duplicate. 
(a)

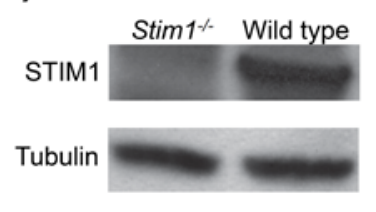

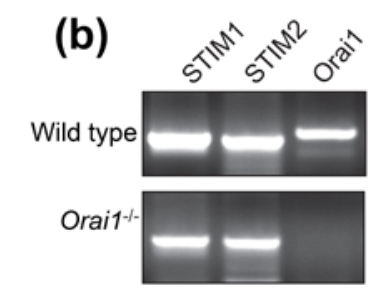

(c)
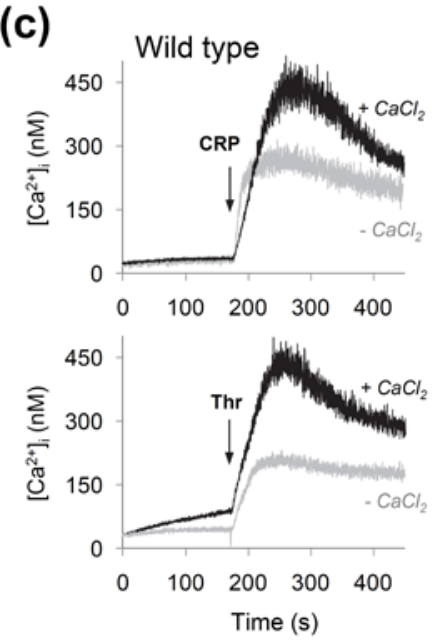

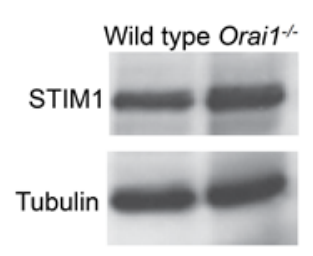

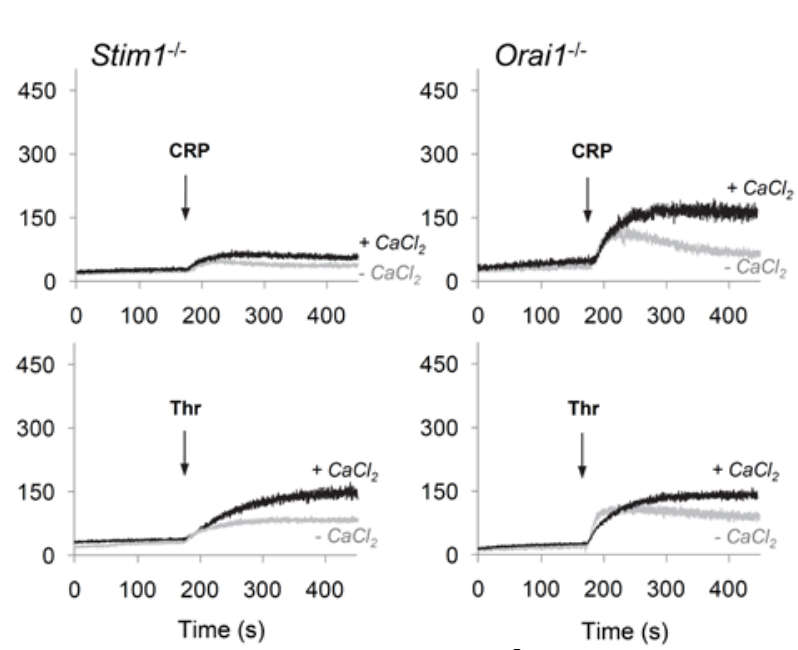

Supplemental Figure 1. Defective GPVI- and thrombin-receptor induced $\mathrm{Ca}^{2+}$ signaling in platelets deficient in STIM1 or Orai1. (a) Expression profiles of STIM1 protein in platelets from wild type (WT) and chimeric Stim $1^{--}$or Orail ${ }^{-1}$ mice. Western blots are given after probing with anti-STIM1 mAb; blots were reprobed with anti-tubulin mAb as control. (b) RT-PCR indicating absence of Orai1 transcript, but presence of Stim1 and Stim2 transcripts in platelets from chimeric Orai1 ${ }^{-1-}$ mice. (c) Impaired $\mathrm{Ca}^{2+}$ responses of Stim $1^{--}$and Orai1 $^{-1-}$ platelets especially in the presence of $\mathrm{CaCl}_{2}$. Fura-2loaded platelets were stimulated with $10 \mu \mathrm{g} / \mathrm{ml} \mathrm{CRP}$ (upper panels) or $0.9 \mathrm{nM}$ thrombin (Thr, lower panels) in the presence or absence of $1 \mathrm{mM} \mathrm{CaCl}_{2}$, as indicated. Shown are representative traces of rises in $\left[\mathrm{Ca}^{2+}\right]_{i}(n=3-5)$.

\section{Statistics}

Differences between groups were tested for significance with the nonparametric MannWhitney $U$ test. Paired data were compared with Student's t test. The statistical package for social sciences (SPSS 15.0) was used.

\section{Results}

Deficiency in platelet STIM1 or Orai1 impedes GPVI-mediated PS exposure and thrombus formation

For the experiments, chimeric mice were generated by transplantation of irradiated wild type animals with Stim $1^{-/}$, Orai1 ${ }^{-/}$, or wild type bone marrow cells. Platelets from these mice, isolated at least 4 weeks after transplantation, were checked for the absence of 
STIM1 protein or Orai1 transcript (supplemental Figure 1, a and b). The platelets from chimeric Stim $1^{-1-}$ and Orai1 ${ }^{-1-}$ mice were greatly impaired in $\mathrm{Ca}^{2+}$ rises evoked by the GPVI agonist CRP (a triple-helical collagen peptide), or by thrombin; most markedly when extracellular $\mathrm{CaCl}_{2}$ was present (supplemental Figure 1c), which is in full agreement with earlier data ${ }^{24,25}$. In addition, Stim $1^{-1-}$ platelets showed reduced $\mathrm{Ca}^{2+}$ rises in the absence of $\mathrm{CaCl}_{2}$ and $\mathrm{Ca}^{2+}$ entry, supporting the concept that STIM1 controls the filling state of $\mathrm{Ca}^{2+}$ stores $^{24}$.

Blood from these chimeric mice was anticoagulated with PPACK/heparin and perfused at high shear flow rate over a collagen surface. By using these thrombin inhibitors, blood coagulation was ablated, whereas high, physiological concentrations of free $\mathrm{Ca}^{2+}$ and $\mathrm{Mg}^{2+}$ were maintained. In this test of collagen-induced thrombus formation, platelets in contact with the collagen fibers become activated via GPVI and respond by $\mathrm{Ca}^{2+}$ elevation, PS exposure, and secretion of autocrine mediators, and as a result platelet aggregate formation ${ }^{5,33,37}$. Strikingly, with blood from chimeric Stim $1^{-1-}$ and Orail ${ }^{-1-}$ mice, no or only small aggregates were formed, whereas PS exposure was almost completely absent, as apparent from the lack of staining with FITC-labeled annexin A5 (Figure 1a). This contrasted to the large aggregates and many PS-exposing platelets observed with blood from corresponding wild type mice. Analysis of microscopic images pointed to a markedly reduced deposition of Stim1 $1^{-/}(-70 \%)$ and Orai1 ${ }^{-1-}(-46 \%)$ platelets compared with wild type. The procoagulant index, i.e. the relative formation of PS-exposing platelets compared with all adhered platelets ${ }^{33}$, was also greatly reduced in either knockout (Figure $1 b$ ).

Mouse platelets were loaded with Fluo-4 and back-added to blood of the same genotype to measure $\mathrm{Ca}^{2+}$ rises in the cells during blood flow over collagen. Wild type platelets showed high $\mathrm{Ca}^{2+}$ responses shortly after adhesion (Figure 2a). However, adhered Stim $1^{-1-}$ platelets gave only minute $\mathrm{Ca}^{2+}$ spikes, in a manner resembling the low responses of Fcer $1 g^{-/-}$platelets, known to lack GPVI signaling activity ${ }^{34}$. Many of the adhered Orai1 ${ }^{-1}$ platelets gave similar, minute $\mathrm{Ca}^{2+}$ spikes (-50\%), but the remaining Orai $1^{-1-}$ cells showed a short series of medium amplitude spikes (Figure 2a). Quantitative analysis demonstrated a nearly complete ablation of the average $\mathrm{Ca}^{2+}$ signal in Stim $1^{-1-}$ platelets and a greatly reduced signal in Orai $^{-/}$platelets (Figure $2 \mathrm{~b}$ ). Together, these results point to important roles of both STIM1 and Orai1 in collagen-dependent $\mathrm{Ca}^{2+}$ signaling, PS exposure, and thrombus formation under non-coagulant conditions.

\section{Deficiency in STIM1 or Orai1 does not abolish PS exposure and thrombus formation under coagulant conditions}

GPVI-induced platelet activation has been shown to control collagen-dependent thrombus formation also under conditions favoring coagulation ${ }^{29}$. To determine the role of STIM1 and Orai1 in this setting, citrate-anticoagulated blood from chimeric animals was coinfused with $\mathrm{CaCl}_{2} / \mathrm{MgCl}_{2}$ to achieve again millimolar free $\mathrm{Ca}^{2+}$ and $\mathrm{Mg}^{2+}$ concentrations. Perfusion of the recalcified blood over collagen leads to onset of coagulation via collagendependent activation of factor XII ${ }^{31}$. With wild type blood, massive and dense thrombi (clots) were formed within 4 min of perfusion, which were covered with PS-exposing platelets and connected by fibrin fibers (Figure 3a). Surprisingly, dense fibrin-containing 
thrombi were also formed with Stim $1^{-1-}$ or Orai1 $^{-1}$ blood. These thrombi were also surrounded by PS-exposing platelets, but to a lesser degree compared with wild type blood.

A
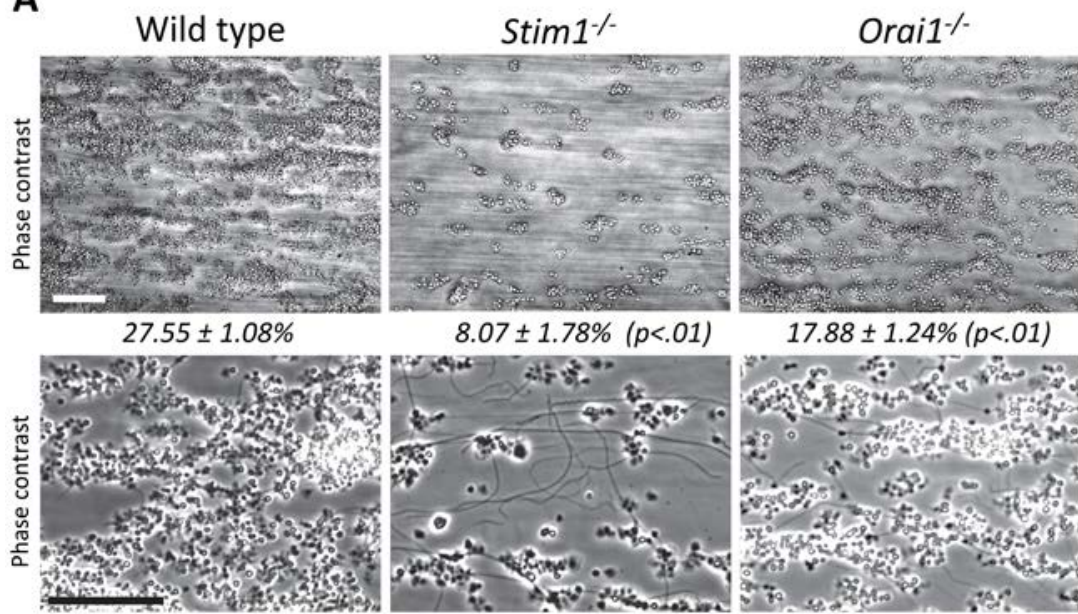

$8.07 \pm 1.78 \%(p<.01)$

$17.88 \pm 1.24 \%(p<.01)$
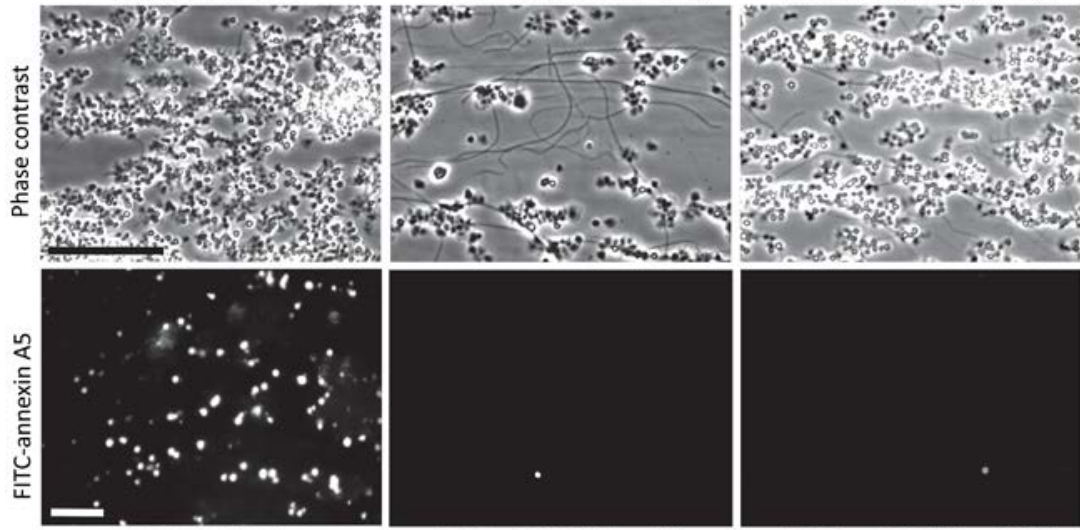

$4.24 \pm 0.22 \%$

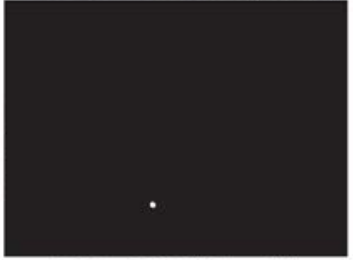

$0.16 \pm 0.05 \%(p<.01)$

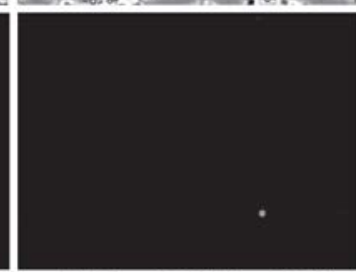

$0.12 \pm 0.03 \%(p<.001)$

B

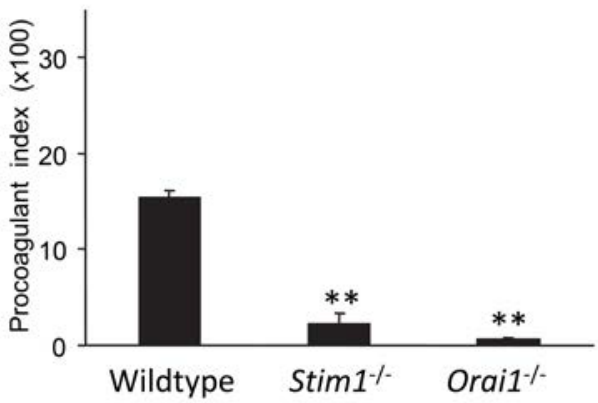

Figure 1. Deficiency in STIM1 or Orai1 impedes GPVI-dependent thrombus formation and PS exposure under flow. PPACK/heparin-anticoagulated blood of C57BL/6 mice transplanted with bone marrow from wild type, Stim $1^{--}$or Orai1 $1^{--}$animals was flowed over collagen at a shear rate of 1000 $\mathrm{s}^{-1}$. (a) Representative contrast images after $4 \mathrm{~min}$, captured at low (top panels) or high (middle panels) magnification. Bottom panels, fluorescence images after staining with FITC-annexin A5. Percentages in italic indicate area covered with platelets (scale bars, $50 \mu \mathrm{m}$ ). (b) Procoagulant index representing relative number of PS-exposing platelets. Data are percentage fractions of adhered platelets exposing PS. Means \pm S.E. (error bars) are shown. $n=6-8 ; * *, p<0.01$ versus wild type. 
However, the procoagulant index was similarly high for images recorded from wild type, $\mathrm{Stim}^{-1-}$, and Orai1 ${ }^{-1-}$ thrombi (Figure $3 \mathrm{~b}$ ). These results thus indicate that neither STIM1 nor Orai1 is essential for collagen-dependent thrombus formation and PS exposure under coagulant conditions.

Fluo-4-loaded platelets were then used to determine rises in $\mathrm{Ca}^{2+}$ under the same conditions of flow and coagulation. Wild type platelets, adhered to collagen, showed prolonged, high $\mathrm{Ca}^{2+}$ responses (Figure 4a), which were higher in level than those measured in anticoagulated blood (Figure $2 \mathrm{~b}$ ). With the thrombin inhibitor hirudin present, the mean $\mathrm{Ca}^{2+}$ rises reduced from about 400 to $250 \mathrm{nM}$, which confirmed the contribution of thrombin to the $\mathrm{Ca}^{2+}$ signal. Interestingly, in recalcified blood, collagen-adhered $\mathrm{Stim}^{-1-}$ and Orai ${ }^{-1-}$ platelets also showed prolonged $\mathrm{Ca}^{2+}$ responses, but these remained lower in magnitude than those of wild type platelets (Figure $4 b$ ). The effect of STIM1 knock-out was again more pronounced than that of Orai1 deficiency. Hence, under these conditions of in situ formation of thrombin, platelet $\mathrm{Ca}^{2+}$ responses seem to be sufficiently high for PS exposure even in the absence of the STIM1-Orai1-SOCE pathway.
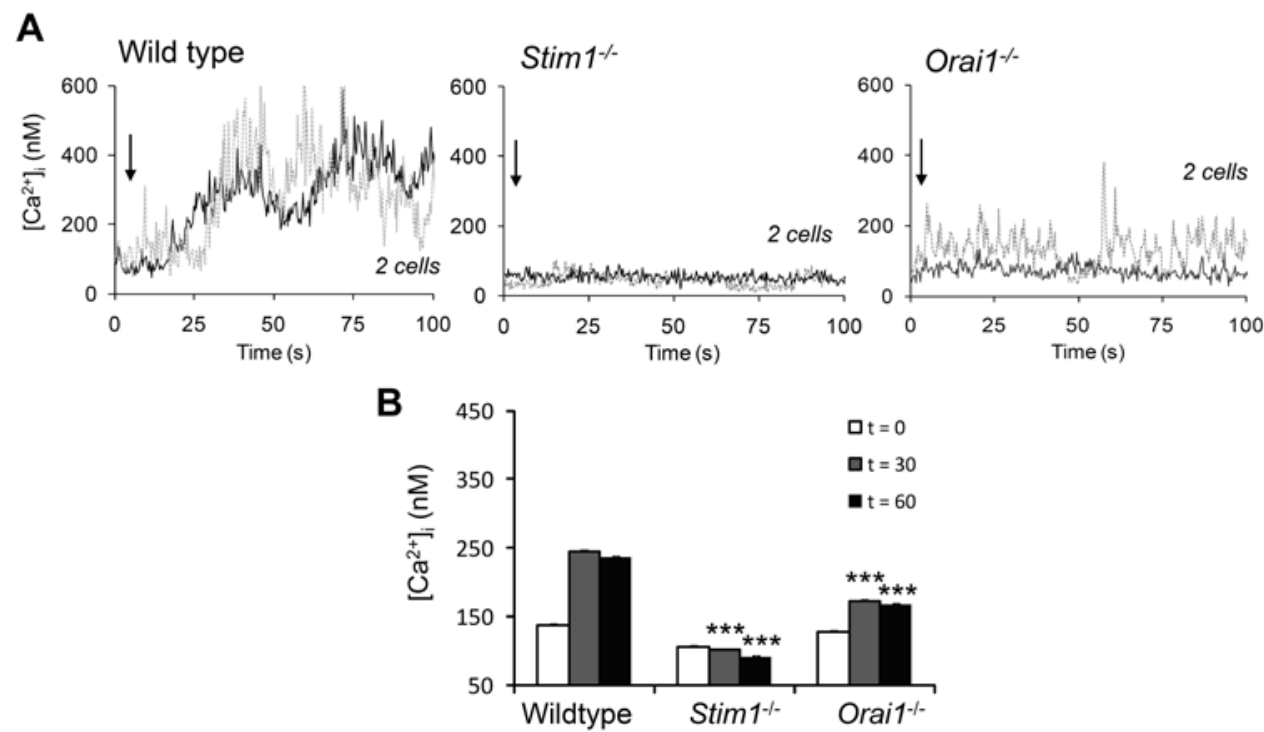

Figure 2. Deficiency in STIM1 or Orai1 impedes GPVI-dependent $\mathrm{Ca}^{2+}$ responses of collagenadhered platelets under flow. PPACK/heparin-anticoagulated blood of wild type or chimeric Stim $1^{-1}$ or Orai ${ }^{\%}$ mice was supplemented with $10 \%$ Fluo-4-loaded platelets of the same genotype. Blood samples were flowed over collagen at $1000 \mathrm{~s}^{-1}$, and fluorescence images from the collagen surface were recorded at $5 \mathrm{~Hz}$. (a) Single-cell rises in $\mathrm{Ca}^{2+}$ of two representative platelets per genotype. Arrows indicate time point of adhesion. (b) Quantitative analysis of $\mathrm{Ca}^{2+}$ responses at 30 and $60 \mathrm{~s}$ after initial $\mathrm{Ca}^{2+}$ rises. Means \pm S.E. are shown. $\mathrm{n}=35-45$ cells; $* * *, \mathrm{p}<0.001$ compared with wild type. 


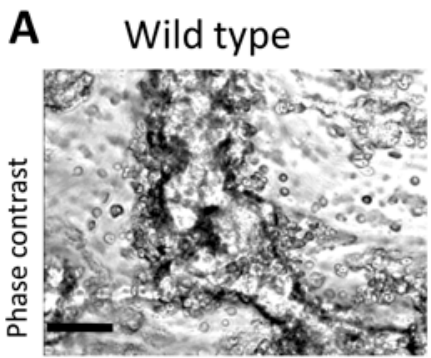

$53.22 \pm 2.34 \%$

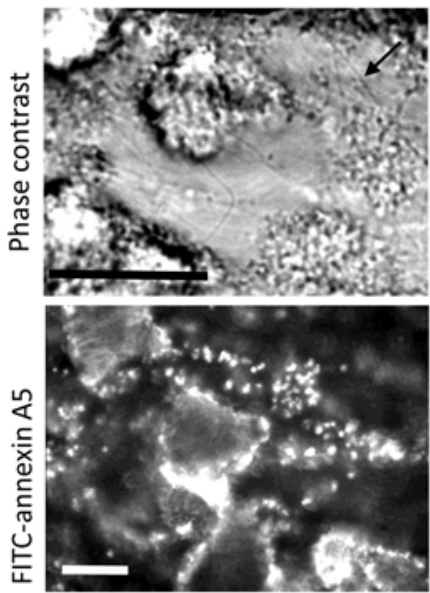

$42.75 \pm 4.10 \%$
Stim $1^{\%}$

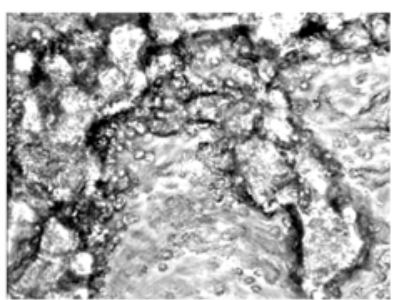

$32.71 \pm 6.80 \%(p=.068)$
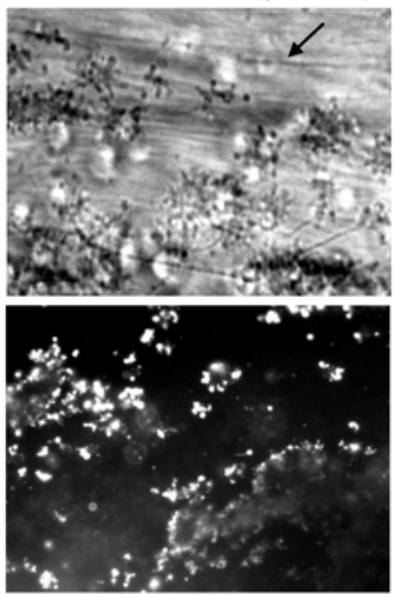

$23.52 \pm 4.42 \%(p<.05)$
Orai1 $\%$

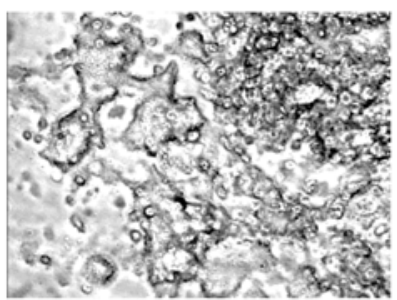

$33.20 \pm 2.68 \%(p<.01)$
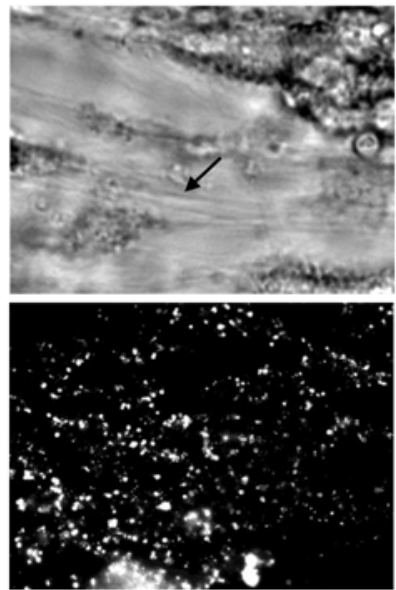

$23.46 \pm 4.57 \%(p<.05)$

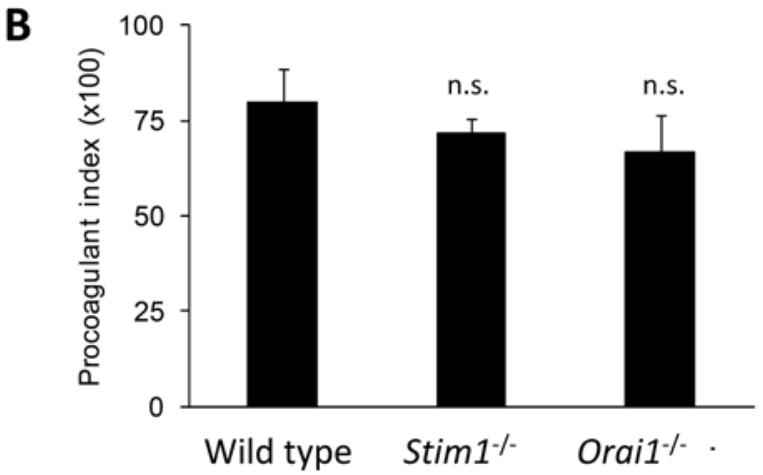

Figure 3. Deficiency in STIM1 or Orai1 permits GPVI-dependent thrombus formation and PS exposure in the presence of coagulation. Citrate-anticoagulated blood of the indicated mice was recalcified with $\mathrm{CaCl}_{2} / \mathrm{MgCl}_{2}$ and flowed over collagen for $4 \mathrm{~min}$. Thrombi with platelets and fibrin (arrows) were poststained with FITC-annexin A5. (a) Representative phase contrast and fluorescence images after $4 \mathrm{~min}$ (scale bars, $50 \mu \mathrm{m}$ ). Percentages in italic indicate area covered with (fluorescent) platelets. (b) Procoagulant index of relative number of PS-exposing platelets. Means \pm S.E. (error bars) are shown. $\mathrm{n}=5-7$; n.s., difference between groups not significant. 


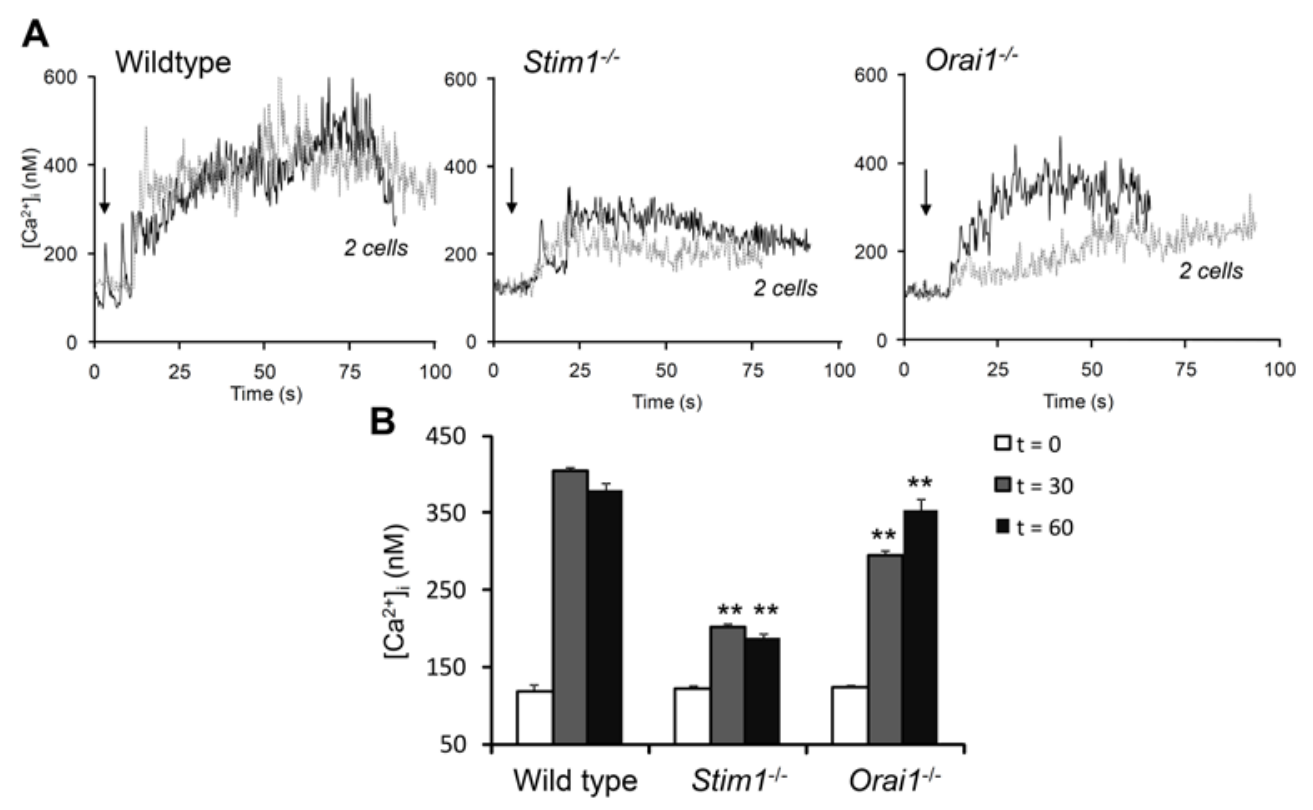

Figure 4. Deficiency in STIM1 or Orai1 partly reduces $\mathrm{Ca}^{2+}$ signaling in the presence of coagulation. Citrate-anticoagulated blood of the indicated mice was supplemented with 10\% Fluo-4-loaded platelets of the same genotype and recalcified. During blood flow over collagen, fluorescence images from the collagen surface were recorded at $5 \mathrm{~Hz}$. (a) Single-cell rises in $\left[\mathrm{Ca}^{2+}\right]_{\mathrm{i}}$ of two representative platelets per genotype. Arrows indicate time point of adhesion. (b) Quantitative analysis of $\mathrm{Ca}^{2+}$ responses at 30 and $60 \mathrm{~s}$ after initial $\left[\mathrm{Ca}^{2+}\right]_{\mathrm{i}}$ rises. Means \pm S.E. (error bars) are shown. $\mathrm{n}=15-29$ cells; ${ }^{* *}, \mathrm{p}<0.01$ compared with wild type.

Deficiency in STIM1 or Orai1 does not affect GPVI-induced PS exposure and prothrombinase activity with thrombin present

To investigate this further, washed platelets were stimulated with collagen (GPVI)- and/or thrombin-receptor agonist, and staining of the cells was observed with the PS probe, FITCannexin A5. Extracellular $\mathrm{CaCl}_{2}$ was present to allow $\mathrm{Ca}^{2+}$ entry. The GPVI agonist convulxin was used for these studies ${ }^{12}$, which is similarly effective as CRP in wild type and Orai1deficient platelets ${ }^{25}$. Flow cytometric analysis showed that convulxin stimulation of wild type platelets resulted in about 20\% PS-exposing platelets (Figure 5a). This fraction increased to $73 \%$ with thrombin as co-agonist, whereas thrombin alone had no more than little effect. Stimulation of platelets from chimeric Stim $1^{-1-}$ and Orai1 ${ }^{-1-}$ mice with convulxin resulted in impaired PS exposure, comparable with stimulation with thrombin alone. However, combined stimulation with convulxin and thrombin resulted in $53-58 \%$ PSpositive platelets, which was similar to that of wild type platelets. Control experiments indicated that all platelets responded nearly completely when stimulated with the $\mathrm{Ca}^{2+}$ ionophore, ionomycin. As an alternative approach, we studied the capacity of platelets to support prothrombinase activity, i.e. the PS-dependent cleavage of prothrombin by factors $\mathrm{Xa}$ and $\mathrm{Va}{ }^{13}$. In wild type platelets, but not $\mathrm{Stim}^{-1-}$ or Orai1 $^{-1-}$ platelets, convulxin 
caused a moderate increase in prothrombinase activity (Figure 5b). The combination of convulxin and thrombin induced a 5-fold increased prothrombinase activity with wild type platelets and a slightly lower increase with knock-out platelets, but this was not significantly different from wild type. Stimulation with ionomycin $/ \mathrm{CaCl}_{2}$ caused high, maximal prothrombinase activity in all groups.

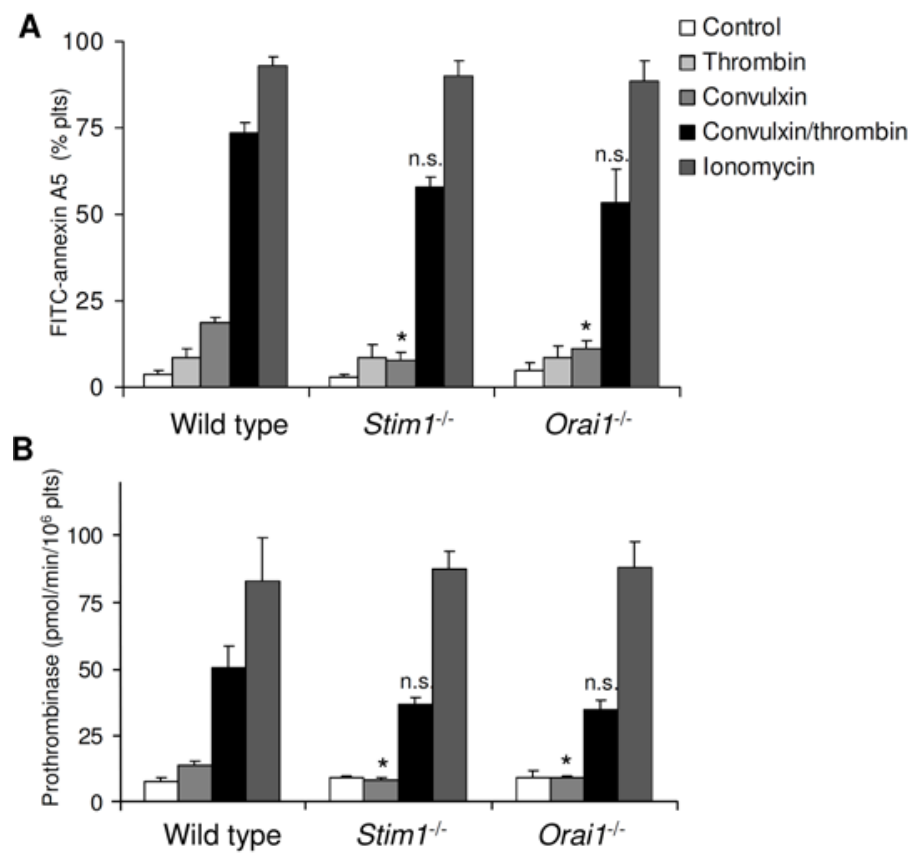

Figure 5. Deficiency in STIM1 or Orai1 permits GPVI-dependent procoagulant activity in the presence of thrombin. Platelets in buffer containing $2 \mathrm{mM} \mathrm{CaCl}_{2}\left(1 \times 10^{8} / \mathrm{ml}\right)$ were stimulated for $10 \mathrm{~min}$ with convulxin $(100 \mathrm{ng} / \mathrm{ml})$, thrombin $(4 \mathrm{nM})$, or ionomycin $(20 \mu \mathrm{M})$, as indicated. (a) Flow cytometric analysis of binding of FITC-annexin A5 to platelets $(n=5)$. (b) Determination of prothrombinase activity of platelet suspensions. Activity is expressed as pmol of thrombin/min per $10^{6}$ platelets. $n=7-8$. Means \pm S.E. (error bars) are shown. ${ }^{*}, p<0.05$; n.s., not significant compared with wild type.

The procoagulant response of platelets was also studied in a natural plasma environment, by activating PRP with tissue factor $/ \mathrm{CaCl}_{2}$ and measuring generation of thrombin ${ }^{5}$. Similar thrombin generation curves were obtained with PRP from wild type, Stim $1^{-1-}$, and Orai $1^{-1-}$ mice (Figure 6a). In all groups, prestimulation with ionomycin caused a 3-4-fold increase in thrombin generation, indicating that the knock-out platelets were normally capable to support thrombin generation (Figure 6b). Prestimulation with convulxin resulted in a significant increase in thrombin peak height in all groups, but in this case STIM1- or Orai1deficient PRP was less effective than wild type PRP compared with prestimulation with ionomycin. The time-to-peak was less shortened in convulxin-stimulated knock-out PRP compared with wild type (Figure $6 \mathrm{c}$ ). Taken together, these results show that, in the pres- 
ence of thrombin (either externally added or formed in situ), GPVI-dependent PS exposure and procoagulant activity are only partly affected by deficiency in platelet STIM1 or Orai1.

\section{Roles of $\mathrm{Ca}^{2+}$ entry channels other than Orai1}

The modest roles of STIM1 and Orai1 in GPVI-dependent platelet procoagulant activity in the presence of thrombin suggest the presence of a compensating $\mathrm{Ca}^{2+}$ entry mechanism, that, for instance, could be triggered in a receptor-operated fashion. In other cell types, it has been shown also that STIM2 regulates $\mathrm{Ca}^{2+}$ entry by controlling cytoplasmic $\mathrm{Ca}^{2+}$ levels ${ }^{38}$. Because mouse platelets highly express this isoform (supplemental Figure 1b), we studied the possibility that STIM2-mediated $\mathrm{Ca}^{2+}$ regulation controls the extent of PS exposure. Mice homozygously deficient in STIM2 are viable and have normal platelet counts ${ }^{27}$. Stimulation of Fura-2-loaded Stim $2^{-1-}$ platelets showed unaltered $\mathrm{Ca}^{2+}$ responses upon stimulation of GPVI (Figure 7, a and b) or thrombin-receptors (not shown). Flow perfusion experiments over collagen, performed with blood from the Stim $2^{-/-}$mice, indicated the formation of large thrombi and the presence of many PS-exposing platelets (Figure 7c). Furthermore, detailed image analysis pointed to an unchanged procoagulant index of Stim $2^{-/-}$thrombi compared with Stim $2^{-/-}$thrombi (Figure 7d).

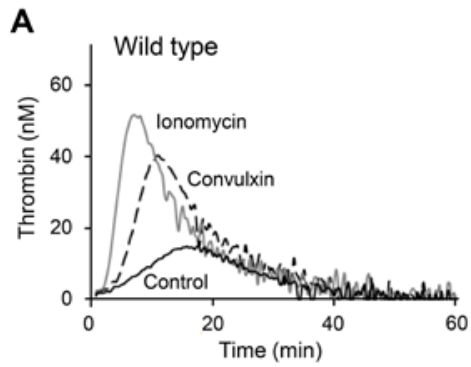

B

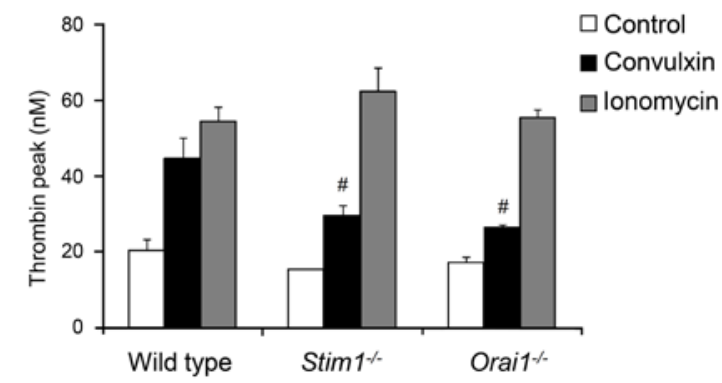

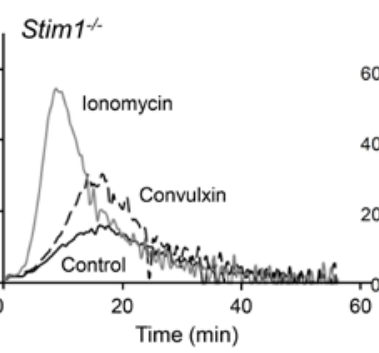

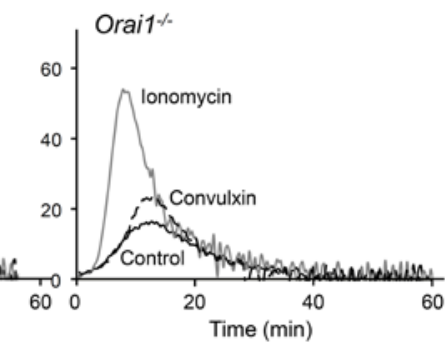

C

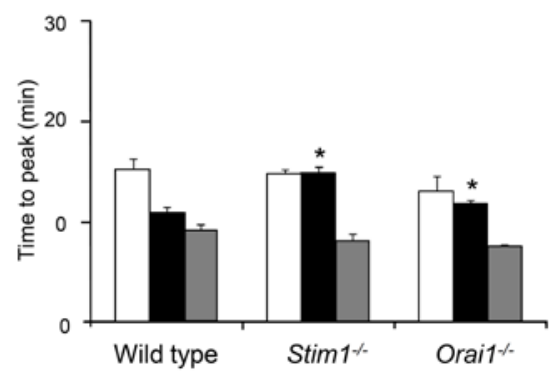

Figure 6. Deficiency in STIM1 or Orai1 reduces GPVI-dependent thrombin generation. Citrateanticoagulated PRP $\left(1 \times 10^{8}\right.$ platelets $\left./ \mathrm{ml}\right)$ of the indicated mice was preincubated with vehicle solvent (control), convulxin $(100 \mathrm{ng} / \mathrm{ml})$, or ionomycin $(20 \mu \mathrm{M})$. Thrombin generation was triggered with tissue factor $/ \mathrm{CaCl}_{2}$. (a), representative thrombin generation curves per genotype. (b), quantification of thrombin peak height. (c), quantification of time to peak. Means \pm S.E. (error bars) are shown. $n=4-6$. \#, $p<0.05$ compared with wild type (ionomycin); ${ }^{*}, p<0.05$ compared with control vs. wild type. 
The putative role of other $\mathrm{Ca}^{2+}$ entry channels was investigated by using the established $\mathrm{Ca}^{2+}$ entryblocker SKF96365 ${ }^{39}$. To compare with earlier established $\mathrm{Ca}^{2+}$ traces (supplemental Figure 1), Fura-2-loaded platelets were activated with GPVI agonist CRP, thrombin, or a combination of both. In wild type platelets, pre-treatment with SKF96365 inhibited the $\mathrm{Ca}^{2+}$ responses to all agonists with $60-70 \%$, only if $\mathrm{CaCl}_{2}$ was present in the incubation medium (Figure 8a). On the other hand, when no $\mathrm{CaCl}_{2}$ was added and $\mathrm{Ca}^{2+}$ entry was prevented, SKF96365 did not have a significant effect (Figure 8b). Pre-treatment with SKF96365 had a similar, 70\% inhibitory effect on the $\mathrm{Ca}^{2+}$ response evoked by convulxin, again only in the presence of $\mathrm{CaCl}_{2}$. Strikingly, in Stim1 ${ }^{-1-}$ and $\mathrm{Orai1}^{-1-}$ platelets, SKF96365 still suppressed both the CRP- and thrombin-induced $\mathrm{Ca}^{2+}$ responses by $40-60 \%$, again if extracellular $\mathrm{CaCl}_{2}$ was present (Figure 8b). For all genotypes, the inhibition by SKF96365 was significant in the presence of $\mathrm{CaCl}_{2}(p<0.001)$, but not without $\mathrm{CaCl}_{2} \quad(p=0.05-0.38)$. The Stim $1^{-/}$and Orai1 ${ }^{-1-}$ platelets responded similarly, but the former had a lower residual
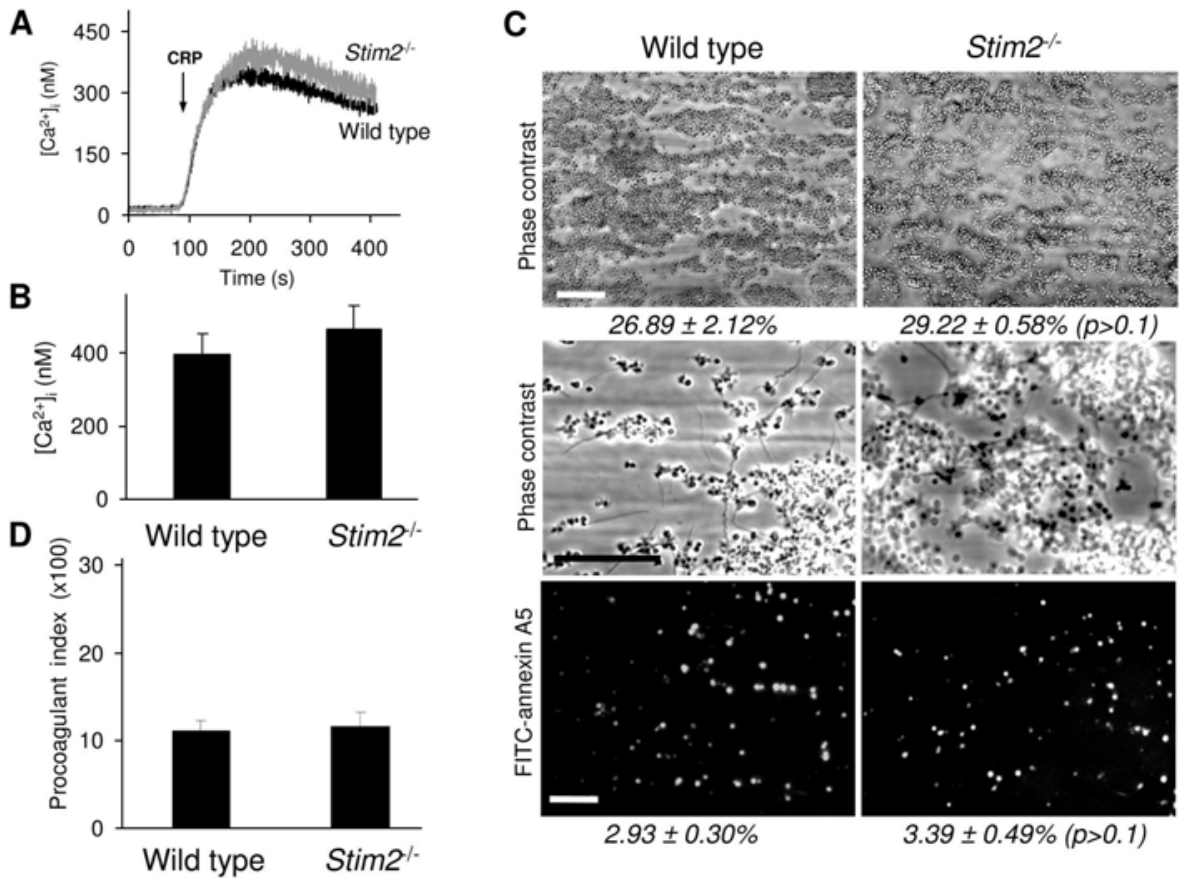

Figure 7. Unchanged GPVI-dependent $\mathrm{Ca}^{2+}$ responses and thrombus formation of STIM2-deficient platelets. (a) Representative $\mathrm{Ca}^{2+}$ rises of Fura-2-loaded platelets from wild type and Stim2 ${ }^{-/}$mice, induced by CRP $(10 \mu \mathrm{g} / \mathrm{ml})$ plus $\mathrm{CaCl}_{2}(1 \mathrm{mM})$. (b) Quantification of maximal $\mathrm{Ca}^{2+}$ rises. (c) and (d) Thrombus formation after flow of PPACK/heparin-anticoagulated blood over collagen at high shear rate (4 $\mathrm{min}$ ). (c) Representative contrast images captured at low (top panels) or high (middle panels) magnification. Bottom panels, fluorescence images after staining with FITC-annexin A5 (scale bars, $50 \mu \mathrm{m})$. (d) Procoagulant index of relative number of PS-exposing platelets. Means \pm S.E. (error bars) are shown. $n=4-6$. The difference between groups was not significant. 
$\mathrm{Ca}^{2+}$ signal in the presence of SKF96365, which is explained by the reduced $\mathrm{Ca}^{2+}$ store content in the these cells. Comparison of time traces of knock-out platelets shows that the SKF96365-inhibitable $\mathrm{Ca}^{2+}$ signal is a relatively slow component, operating after $\approx 10-60 \mathrm{~s}$ (Figure 8a).

Further experiments demonstrated that the SKF96365-inhibitable $\mathrm{Ca}^{2+}$ entry pathway was important for procoagulant activity because it suppressed the GPVI/thrombin-mediated PS exposure in both wild type $(-73 \pm 8 \%)$ and Orai1 $^{-1-}$ platelets $(-34 \pm 6 \%, p<0.05)$. Together, these data point to the involvement of a second $\mathrm{Ca}^{2+}$ entry pathway in platelet PS exposure that is different from the Orai1 channels.

A
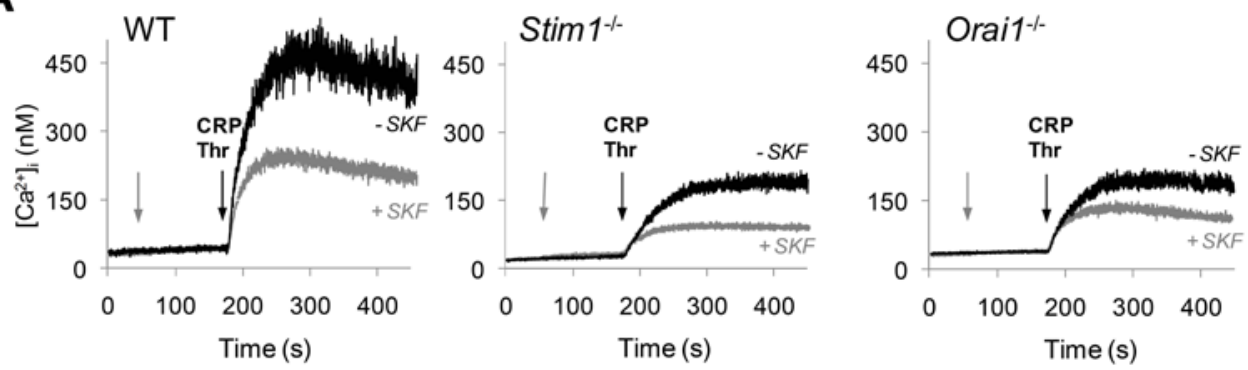

B
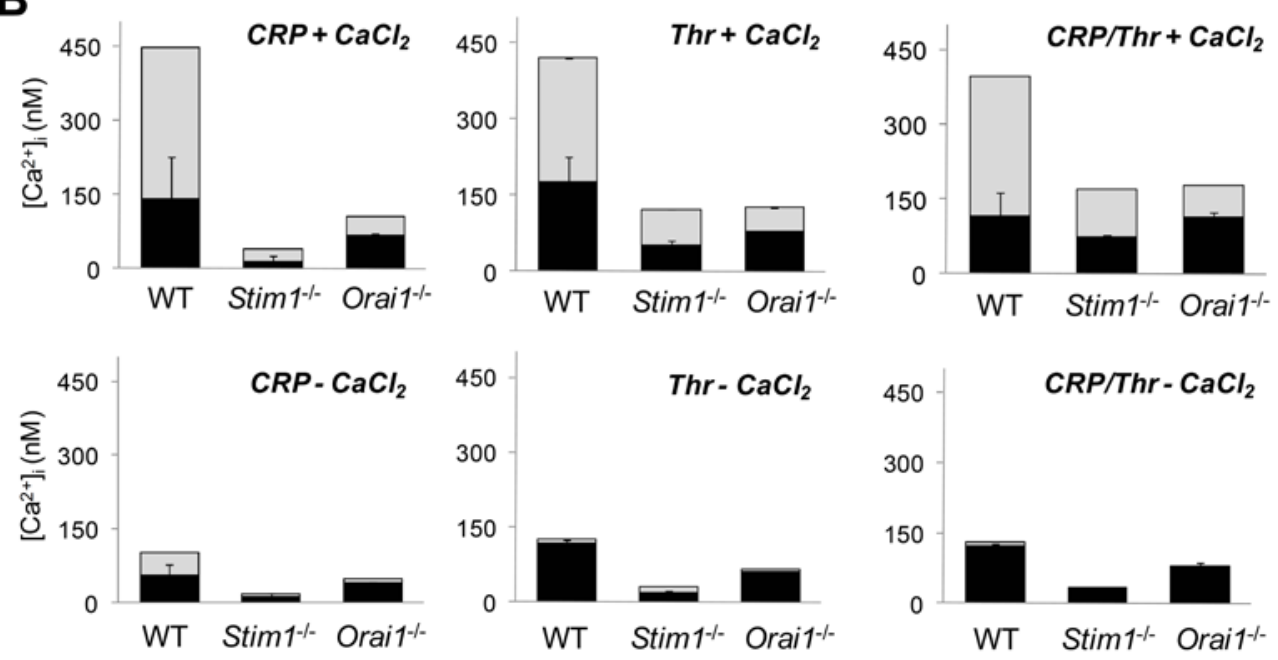

Figure 8. Residual receptor-induced $\mathrm{Ca}^{2+}$ entry in STIM1- and Orai1-deficient platelets. Calcium responses were measured of Fura-2-loaded platelets from wild type (WT), chimeric Stim $1^{-1}$, or Orai1 $^{--}$mice, induced by CRP $(10 \mu \mathrm{g} / \mathrm{ml})$ and/or thrombin $(\mathrm{Thr}, 0.9 \mathrm{nM})$ and $\mathrm{CaCl}_{2}(1 \mathrm{mM})$, as indicated. (a) Representative traces of SKF96365 (SKF, $100 \mu \mathrm{M}$ ) effect on $\mathrm{Ca}^{2+}$ rises. Arrows indicate addition of SKF96365 and agonist(s), respectively. B, quantitative effect of SKF96365 on $\mathrm{Ca}^{2+}$ rises. Total bars give rises without SKF96365; black bars indicate rises with SKF96365; and gray bars represent inhibition by SKF96365 (means \pm S.E., $n=3-4$ ). 


\section{Discussion}

This study examines the contribution of recently discovered $\mathrm{Ca}^{2+}$ entry pathways to the regulation of platelet procoagulant activity and thrombus formation. A first key finding is that deficiency in the $\mathrm{Ca}^{2+}$ sensor STIM1 or the $\mathrm{Ca}^{2+}$-selective channel Orai1 greatly reduces GPVI-dependent PS exposure and thrombus formation under conditions of flow and absence of coagulation. This corresponds to a major reduction in the $\mathrm{Ca}^{2+}$ responses of collagen-adhered Stim $1^{-/-}$and Orair ${ }^{-1-}$ platelets. Thus, it can be concluded that the reduced GPVI-induced $\mathrm{Ca}^{2+}$ signaling leads to impaired PS exposure and platelet aggregation. Interestingly, platelets from Stim $2^{-1-}$ mice are normally active in thrombus formation and PS exposure under the same flow conditions, indicating that the STIM2 homolog is not implicated in these platelet responses.

Detailed single-cell analysis yet points to discernible differences between the genotypes, in that a subpopulation of the collagen-adhered Orai1 $^{-/-}$platelets, but not of the Stim $1^{-/-}$ platelets, displays residual spiking in $\mathrm{Ca}^{2+}$. This residual $\mathrm{Ca}^{2+}$ signal will be a consequence of the appreciable GPVI-induced $\mathrm{Ca}^{2+}$ mobilization from internal stores of Orai1-deficient platelet ${ }^{25}$, in contrast to the markedly reduced $\mathrm{Ca}^{2+}$ store mobilization of STIM1-deficient platelets ${ }^{24}$. This difference between the genotypes was confirmed in CRP- and thrombininduced activation studies with Fura-2-loaded platelets. The present findings agree with the recent evidence that a dysfunctional R93W mutation of the Orail channel leads to partial impairment of GPVI-induced PS exposure ${ }^{26}$. Collectively, our data underline the importance of both SOCE-regulating proteins in shear-dependent platelet activation by collagen, under conditions where the contribution of thrombin is absent or limited.

The second key finding is that, under conditions of flow and coagulation, deficiency in platelet STIM1 or Orai1 does not abolish the capability to expose PS and to form a fibrincontaining thrombus. Under these conditions, collagen-adhered Stim $1^{-1-}$ and Orail ${ }^{-1-}$ platelets still show prolonged rises in $\mathrm{Ca}^{2+}$, although these are lower in magnitude compared with wild type platelets. Although the number of PS-exposing Stim $1^{-1-}$ and Orai1 ${ }^{-1-}$ platelets is still reduced, the procoagulant index is similar for all genotypes. This suggests that the GPVI-induced SOCE pathway mediated by STIM1 and Orai1 becomes redundant in the regulation of thrombus formation in cases where thrombin acts as a co-agonist. This conclusion is supported by the data showing that stimulation of isolated Stim $1^{-1-}$ or Orail ${ }^{-1-}$ platelets with a combination of GPVI and thrombin receptor agonists results in nearly unchanged PS exposure and prothrombinase activity. Furthermore, these platelets are partly inhibited in tissue factor-triggered thrombin generation when stimulated with GPVI ligand. It has been shown that polyphosphates released from platelets significantly contribute to thrombin generation in PRP by activating factor XII ${ }^{40}$. The above findings suggest that the polyphosphate contribution is still effective in the absence of STIM1 or Orai1.

The standard protocol for assessment of SOCE is measurement of entry of extracellular $\mathrm{Ca}^{2+}$ after $\mathrm{Ca}^{2+}$ store depletion, e.g. by the reticular $\mathrm{Ca}^{2+}$-ATPase inhibitor thapsigargin. This $\mathrm{Ca}^{2+}$ entry is almost totally blocked in $\mathrm{Stim}^{-1-}$ and Orai1 ${ }^{-1-}$ platelets, implying that the STIM1-Orai1 interaction forms the principal SOCE mechanism ${ }^{24,25}$. A similar conclusion has been drawn for other secretory cells, e.g. T cells and mast cells ${ }^{41}$. However, it now appears that both $\mathrm{Stim}^{-/-}$and $\mathrm{Orail}^{-/-}$platelets show significant $\mathrm{Ca}^{2+}$ responses and PS 
exposure, when co-stimulated via GPVI and thrombin receptors. This is suggestive for the presence of another, compensatory mechanism of $\mathrm{Ca}^{2+}$ entry, acting in a (thrombin) receptor-operated fashion. This hypothesis is supported by our finding that the imidazole antagonist SKF96365, which is a well studied inhibitor of $\mathrm{Ca}^{2+}$ entry in platelets ${ }^{39}$, is still capable of suppressing the $\mathrm{Ca}^{2+}$ and procoagulant responses of platelets deficient in STIM1 or Orai1. Unfortunately, this compound cannot be used in measurements of thrombus formation because it rapidly inactivates in the presence of blood plasma (data not shown). In Fura-2-loaded Stim1 ${ }^{-1-}$ and Orai1 $^{-1-}$ platelets, SKF96365 still inhibits $40-60 \%$ of the $\mathrm{Ca}^{2+}$ signal independently of the agonist (GPVI ligand and/or thrombin). The slow, non-Orai1 $\mathrm{Ca}^{2+}$ entry most likely does not involve the TRPC1 channel ${ }^{16}$, because $\operatorname{Trpc} 1^{-1-}$ platelets have a fully intact $\mathrm{Ca}^{2+}$ signalling machinery ${ }^{42}$. Other candidate target proteins of SKF96365 are the non-SOCE channels, TRPC6 and Orai3, both of which act in a receptoroperated way and are expressed in platelets ${ }^{17,19}$. Further studies are required to identify this channel.

A pending question is whether the SOCE mechanism per se is implicated in the transmembrane scrambling of phospholipids, which is the underlying event of PS exposure. Such a role of SOCE has been proposed by others ${ }^{43}$. However, the current findings do not support this because Stim $1^{-/-}$and Orai1 $1^{-/-}$platelets (both devoid of SOCE) almost normally expose PS upon combined collagen- and thrombin-receptor stimulation. This is in agreement with the finding that platelets from Scott syndrome patients, which have a defect in PS exposure, show unchanged $\mathrm{Ca}^{2+}$ signals in response to collagen/thrombin ${ }^{44}$. Together, this strongly argues against a role of SOCE or other $\mathrm{Ca}^{2+}$ channels as phospholipid scramblase proteins.

The present findings support the idea that the Orail channel is an attractive target for pharmacological treatment of thrombosis. Previous results have demonstrated that the deficiency of Orai1 in mouse platelets protects from arterial thrombus formation, particularly in thrombosis models that are collagen-dependent ${ }^{24,25}$. Because collagen-independent thrombosis models mostly rely on tissue factor exposure and thrombin generation ${ }^{6}$, it is plausible that specific targeting of Orai1 (or STIM1) restricts platelet procoagulant activity and thrombus formation only under conditions, where the role of tissue factor is limited. Hence, targeting of Orai1 may be more effective to prevent thrombosis in arteries, where (tissue factor-dependent) thrombin accumulation is confined by the high shear flow conditions. In contrast, blockage of Orai1 may not impair bleeding from wounds where tissue factor is abundantly exposed. Indeed, mice deficient in Orai1 have only a mild prolongation of the tail bleeding time ${ }^{25}$. Whether inhibition of the non-Orai1 (non-SOCE) channels targeted by SKF96365 also provides antithrombotic protection still needs to be investigated.

\section{Acknowledgements}

We thank Dr. E. M. Bevers for critical discussions and for correcting the manuscript. This work was supported in part by Nederlandse Organisatie voor Wetenschappelijk Onderzoek Grant 11.400.0076, The Netherlands Heart Foundation Grant 2005-B079, and Deutsche Forschungsgemeinschaft Grants Sonderforschungsbereich 688 and 487. 


\section{References}

1. Heemskerk JW, Bevers EM, Lindhout T. Platelet activation and blood coagulation. Thromb Haemost. 2002;88:186-193.

2. Heemskerk JW, Feijge MA, Henneman L, Rosing J, Hemker HC. The $\mathrm{Ca}^{2+}$-mobilizing potency of alphathrombin and thrombin-receptor-activating peptide on human platelets -- concentration and time effects of thrombin-induced $\mathrm{Ca}^{2+}$ signaling. Eur J Biochem. 1997;249:547-555.

3. Zwaal RF, Schroit AJ. Pathophysiologic implications of membrane phospholipid asymmetry in blood cells. Blood. 1997;89:1121-1132.

4. Heemskerk JW, Kuijpers MJ, Munnix IC, Siljander PR. Platelet collagen receptors and coagulation. A characteristic platelet response as possible target for antithrombotic treatment. Trends Cardiovasc Med. 2005;15:86-92.

5. Munnix IC, Strehl A, Kuijpers MJ, Auger JM, van der Meijden PE, van Zandvoort MA, oude Egbrink MG, Nieswandt B, Heemskerk JW. The glycoprotein VI-phospholipase C 2 signaling pathway controls thrombus formation induced by collagen and tissue factor in vitro and in vivo. Arterioscler Thromb Vasc Biol. 2005;25:2673-2678.

6. Kuijpers MJ, Munnix IC, Cosemans JM, Vlijmen BV, Reutelingsperger CP, Egbrink MO, Heemskerk JW. Key role of platelet procoagulant activity in tissue factor-and collagen-dependent thrombus formation in arterioles and venules in vivo differential sensitivity to thrombin inhibition. Microcirculation. 2008;15:269-282.

7. Schoenwaelder SM, Yuan Y, Josefsson EC, White MJ, Yao Y, Mason KD, O'Reilly LA, Henley KJ, Ono A, Hsiao S, Willcox A, Roberts AW, Huang DC, Salem HH, Kile BT, Jackson SP. Two distinct pathways regulate platelet phosphatidylserine exposure and procoagulant function. Blood. 2009;114:663-6.

8. Leon C, Ravanat C, Freund M, Cazenave JP, Gachet C. Differential involvement of the $P 2 Y_{1}$ and $P 2 Y_{12}$ receptors in platelet procoagulant activity. Arterioscler Thromb Vasc Biol. 2003;23:1941-1947.

9. van der Meijden PE, Feijge MA, Giesen PL, Huijberts M, van Raak LP, Heemskerk JW. Platelet P2Y12 receptors enhance signalling towards procoagulant activity and thrombin generation. A study with healthy subjects and patients at thrombotic risk. Thromb Haemost. 2005;93:1128-1136.

10. Thiagarajan P, Tait JF. Collagen-induced exposure of anionic phospholipid in platelets and plateletderived microparticles. J Biol Chem. 1991;266:24302-24307.

11. Siljander P, Farndale RW, Feijge MA, Comfurius P, Kos S, Bevers EM, Heemskerk JW. Platelet adhesion enhances the glycoprotein VI-dependent procoagulant response: Involvement of p38 MAP kinase and calpain. Arterioscler Thromb Vasc Biol. 2001;21:618-627.

12. Nieswandt B, Watson SP. Platelet-collagen interaction: is GPVI the central receptor? Blood. 2003; 102:449-461.

13. Bevers EM, Comfurius P, van Rijn JL, Hemker HC, Zwaal RF. Generation of prothrombin-converting activity and the exposure of phosphatidylserine at the outer surface of platelets. Eur J Biochem. 1982; 122:429-436.

14. Dachary-Prigent J, Pasquet JM, Freyssinet JM, Nurden AT. Calcium involvement in aminophospholipid exposure and microparticle formation during platelet activation: a study using $\mathrm{Ca}^{2+}$-ATPase inhibitors. Biochemistry. 1995;34:11625-11634.

15. Sage SO. The Wellcome Prize Lecture. Calcium entry mechanisms in human platelets. Exp Physiol. 1997;82:807-823.

16. Rosado JA, Brownlow SL, Sage SO. Endogenously expressed Trp1 is involved in store-mediated $\mathrm{Ca}^{2+}$ entry by conformational coupling in human platelets. J Biol Chem. 2002;277:42157-42163.

17. Hassock SR, Zhu MX, Trost C, Flockerzi V, Authi KS. Expression and role of TRPC proteins in human platelets: evidence that TRPC6 forms the store-independent calcium entry channel. Blood. 2002;100:2801-2811.

18. Soboloff J, Spassova MA, Tang XD, Hewavitharana T, Xu W, Gill DL. Orai1 and STIM reconstitute storeoperated calcium channel function. J Biol Chem. 2006;281:20661-20665.

19. Zhang SL, Kozak JA, Jiang W, Yeromin AV, Chen J, Yu Y, Penna A, Shen W, Chi V, Cahalan MD. Storedependent and -independent modes regulating $\mathrm{Ca}^{2+}$ release-activated $\mathrm{Ca}^{2+}$ channel activity of human Orai1 and Orai3. J Biol Chem. 2008;28325:17662-17671. 
20. Luik RM, Wang B, Prakriya M, Wu MM, Lewis RS. Oligomerization of STIM1 couples ER calcium depletion to CRAC channel activation. Nature. 2008;454:538-542.

21. Parvez S, Beck A, Peinelt C, Soboloff J, Lis A, Monteilh-Zoller M, Gill DL, Fleig A, Penner R. STIM2 protein mediates distinct store-dependent and store-independent modes of CRAC channel activation. FASEB J. 2008;22:752-761.

22. Baba $Y$, Nishida K, Fujii Y, Hirano T, Hikida M, Kurosaki T. Essential function for the calcium sensor STIM1 in mast cell activation and anaphylactic responses. Nat Immunol. 2008;9:81-88.

23. Oh-Hora M, Yamashita M, Hogan PG, Sharma S, Lamperti E, Chung W, Prakriya M, Feske S, Rao A. Dual functions for the endoplasmic reticulum calcium sensors STIM1 and STIM2 in T cell activation and tolerance. Nat Immunol. 2008;9:432-443.

24. Varga-Szabo D, Braun A, Kleinschnitz C, Bender M, Pleines I, Pham M, Renné T, Stoll G, Nieswandt B. The calcium sensor STIM1 is an essential mediator of arterial thrombosis and ischemic brain infarction. J Exp Med. 2008;205:1583-1591.

25. Braun A, Varga-Szabo D, Kleinschnitz C, Pleines I, Bender M, Austinat M, Bösl M, Stoll G, Nieswandt B. Orai1 (CRACM1) is the platelet SOC channel and essential for pathological thrombus formation. Blood. 2009;113:2056-2063.

26. Bergmeier W, Oh-Hora M, McCarl CA, Roden RC, Bray PF, Feske S. R93W mutation in Orai1 causes impaired calcium influx in platelets. Blood. 2009;113:675-678.

27. Berna-Erro A, Braun A, Kraft R, Kleinschnitz C, Schuhmann MK, Stegner D, Wultsch T, Eilers J, Meuth SG, Stoll G, Nieswandt B. STIM2 regulates capacitive $\mathrm{Ca}^{2+}$ entry in neurons and plays a key role in hypoxic neuronal cell death. Sci Signal. 2009;2:ra67.

28. Vanschoonbeek K, Wouters K, van der Meijden PE, van Gorp PJ, Feijge MA, Herfs M, Schurgers LJ, Hofker $\mathrm{MH}$, de Maat MP, Heemskerk JW. Anticoagulant effect of dietary fish oil in hyperlipidemia: a study of hepatic gene expression in Apoe2 knock-in mice. Arterioscler Thromb Vasc Biol. 2008; 28:2023-2029.

29. Munnix IC, Kuijpers MJ, Auger J, Thomassen CM, Panizzi P, van Zandvoort MA, Rosing J, Bock PE, Watson SP, Heemskerk JW. Segregation of platelet aggregatory and procoagulant microdomains in thrombus formation: regulation by transient integrin activation. Arterioscler Thromb Vasc Biol. 2007; 27:2484-2490.

30. Kuijpers MJ, Schulte V, Bergmeier W, Lindhout T, Brakebusch C, Offermanns S, Fässler R, Heemskerk JW, Nieswandt B. Complementary roles of glycoprotein VI and $\alpha_{2} \beta_{1}$ integrin in collagen-induced thrombus formation in flowing whole blood ex vivo. FASEB J. 2003;17:685-687.

31. van der Meijden PE, Munnix IC, Auger JM, Govers-Riemslag JW, Cosemans JM, Kuijpers MJ, Spronk HM, Watson SP, Renné T, Heemskerk JW. Dual role of collagen in factor XII-dependent thrombus formation. Blood. 2009;114:881-890.

32. Nieswandt B, Brakebusch C, Bergmeier W, Schulte V, Bouvard D, Mokhtari-Nejad R, Lindhout T, Heemskerk JW, Zirngibl H, Fässler R. Glycoprotein VI but not $\alpha_{2} \beta_{1}$ integrin is essential for platelet interaction with collagen. EMBO J. 2001;20:2120-2130.

33. Siljander PR, Munnix IC, Smethurst PA, Deckmyn H, Lindhout T, Ouwehand WH, Farndale RW, Heemskerk JW. Platelet receptor interplay regulates collagen-induced thrombus formation in flowing human blood. Blood. 2004;103:1333-1341.

34. Auger JM, Kuijpers MJ, Senis YA, Watson SP, Heemskerk JW. Adhesion of human and mouse platelets to collagen under shear: a unifying model. FASEB J. 2005;19:825-827.

35. Heemskerk JW, Willems GM, Rook MB, Sage SO. Ragged spiking of free calcium in ADP-stimulated human platelets: regulation of puff-like calcium signals in vitro and ex vivo. J Physiol. 2001;535:625635 .

36. Bevers EM, Comfurius P, Reutelingsperger CP, Zwaal, RF (1996). Platelet procoagulant activity and its measurement. In: Platelets: A Practical Approach (Watson, S.P., and Authi, K. S., eds.). IRL Press, Oxford, U.K., 1996:319-340.

37. Lecut C, Schoolmeester A, Kuijpers MJ, Broers JL, van Zandvoort MA, Vanhoorelbeke K, Deckmyn H, Jandrot-Perrus $M$, Heemskerk JW. Principal role of glycoprotein $\mathrm{VI}$ in alpha2beta1 and $\alpha_{11 \mathrm{~b}} \beta_{3}$ activation during collagen-induced thrombus formation. Arterioscler Thromb Vasc Biol. 2004;24:1727-1733. 
38. Brandman O, Liou J, Park WS, Meyer T. STIM2 is a feedback regulator that stabilizes basal cytosolic and endoplasmic reticulum $\mathrm{Ca}^{2+}$ levels. Cell. 2007;131:1327-1339.

39. Merritt JE, Armstrong WP, Benham CD, Hallam TJ, Jacob R, Jaxa-Chamiec A, Leigh BK, McCarthy SA, Moores KE, Rink TJ. SK\&F96365, a novel inhibitor of receptor-mediated calcium entry. Biochem J. 1990;271:515-522.

40. Müller F, Mutch NJ, Schenk WA, Smith SA, Esterl L, Spronk HM, Schmidbauer S, Gahl WA, Morrissey JH, Renné T. Platelet polyphosphates are proinflammatory and procoagulant mediators in vivo. Cell. 2009;139:1143-1156.

41. Hewavitharana T, Deng X, Wang Y, Ritchie MF, Girish GV, Soboloff J, Gill DL. Location and function of STIM1 in the activation of $\mathrm{Ca}^{2+}$ entry signals. J Biol Chem. 2008;283:26252-26262.

42. Varga-Szabo D, Authi KS, Braun A, Bender M, Ambily A, Hassock SR, Gudermann T, Dietrich A, Nieswandt B. Store-operated $\mathrm{Ca}^{2+}$ entry in platelets occurs independently of transient receptor potential (TRP) C1. Pflugers Arch. 2008;457:377-387.

43. Martin S, Laude-Lemaire I, Kerbiriou-Nabias D, Freyssinet JM, Martínez MC.Relation between phosphatidylserine exposure and store-operated $\mathrm{Ca}^{2+}$ entry in stimulated cells. Biochem Biophys Res Commun. 2000;279:639-645.

44. Munnix IC, Harmsma M, Giddings JC, Collins PW, Feijge MA, Comfurius P, Heemskerk JW, Bevers EM. Store-mediated calcium entry in the regulation of phosphatidylserine exposure in blood cells from Scott patients. Thromb Haemost. 2003;89:687-695. 


\section{Chapter 4}

\section{Antithrombotic potential of blockers of store-operated calcium channels in platelets}

van Kruchten R, Braun A, Feijge MA, Kuijpers MJ, Rivera-Galdos

R, Kraft P, Stoll G, Kleinschnitz C, Bevers EM, Nieswandt B, Heemskerk JW.

Arterioscler Thromb Vasc Biol. 2012;32:1717-1723

Reprinted with permission 


\begin{abstract}
Objective: Platelet Orai1 channels mediate store-operated $\mathrm{Ca}^{2+}$ entry (SOCE), which is required for procoagulant activity and arterial thrombus formation. Pharmacological blockage of these channels may provide a novel way of antithrombotic therapy. Therefore, the thromboprotective effect of SOCE blockers directed against platelet Orai1 is determined. Methods and Results: Candidate inhibitors were screened for their effects on SOCE in washed human platelets. Tested antagonists included the known compounds, SKF96365, 2-aminoethyldiphenylborate, and MRS1845 and the novel compounds, Synta66 and GSK-7975A. The potency of SOCE inhibition was in the order of Synta66> 2-aminoethyl diphenylborate> GSK-7975A> SKF96365> MRS1845. The specificity of the first 3 compounds was verified with platelets from Orai1-deficient mice. Inhibitory activity on procoagulant activity and high-shear thrombus formation was assessed in plasma and whole blood. In the presence of plasma, all 3 compounds suppressed platelet responses and restrained thrombus formation under flow. Using a murine stroke model, arterial thrombus formation was provoked in vivo by transient middle cerebral artery occlusion. Postoperative administration of 2-aminoethyldiphenylborate markedly diminished brain infarct size. Conclusion: Plasma-soluble SOCE blockers such as 2-aminoethyldiphenylborate suppress platelet-dependent coagulation and thrombus formation. The platelet Orai1 channel is a novel target for preventing thrombotic events causing brain infarction.
\end{abstract}

\title{
Introduction
}

Elevation in cytosolic $\mathrm{Ca}^{2+}$ is fundamental to most platelet responses to physiological agonists, including pseudopod formation, integrin $\alpha_{11 b} \beta_{3}$ activation, secretion, procoagulant activity, and formation of platelet aggregates ${ }^{1,2}$. Hence, elevated $\mathrm{Ca}^{2+}$ is a central signaling event in regulating the formation of a multi-platelet thrombus after arterial damage. Surprisingly, attempts to pharmacologically attack platelet $\mathrm{Ca}^{2+}$ signaling to suppress thrombus formation and, hence, arterial thrombosis have so far been unsuccessful. This is attributable to a lack of knowledge of the molecular mechanism implicated in platelet $\mathrm{Ca}^{2+}$ signaling and to the absence of suitable $\mathrm{Ca}^{2+}$ signal inhibitors.

Most platelet agonists raise cytosolic $\mathrm{Ca}^{2+}$ via inositol 1,4,5-trisphosphate $\left(\mathrm{InsP}_{3}\right)$-mediated mobilization of $\mathrm{Ca}^{2+}$ from internal stores in the endoplasmic reticulum, which is dramatically enhanced by $\mathrm{Ca}^{2+}$ influx from the extracellular medium ${ }^{1-3}$. Recent work has shown that, in both human and mouse platelets, the $\mathrm{Ca}^{2+}$ channel Orai1 (also indicated as CRACM1) is responsible for the majority of $\mathrm{Ca}^{2+}$ entry into activated platelets through the pathway of store-operated $\mathrm{Ca}^{2+}$ entry (SOCE) ${ }^{4-6}$. The permeability of the Orai1 channel appears to be strictly regulated by the interaction with the $\mathrm{Ca}^{2+}$-sensing endoplasmic protein, stromal-interacting molecule 1 (STIM1) ${ }^{7}$. Platelets also express other channels implicated in $\mathrm{Ca}^{2+}$ influx, particularly isoforms of the transient receptor potential channels, transient receptor potential channel 1 and transient receptor potential channel 6 , of which only the latter plays a modest role in platelet activation via the pathway of receptor-operated $\mathrm{Ca}^{2+}$ entry ${ }^{8,9}$. In other (nonexcitable) cell types, however, these non-Orai $\mathrm{Ca}^{2+}$ channels can have a more important role.

Recent data using mice deficient in Orai1 or STIM1 have shown that both proteins in platelets play key roles in arterial thrombus formation, as determined in various in vivo 
thrombosis models ${ }^{4,5}$. In addition, deficiency in platelet Orai1 or STIM1 appeared to suppress experimental induction of ischemic brain infarction but did not result in a bleeding phenotype. In agreement with this, deficiency in platelet Orai1 or STIM1 reduced the build up of platelet thrombi during high-shear blood flow over a collagen surface ${ }^{5,6,10}$. These studies indicated that the $\mathrm{Ca}^{2+}$ entry process via Orai1 and STIM1 enhanced the formation of platelet aggregates, but was essential for platelet procoagulant activity ${ }^{6,10}$.

Platelet procoagulant activity is induced by strong $\mathrm{Ca}^{2+}$ - mobilizing agonists such as collagen, activating the glycoprotein VI (GPVI) receptor, in combination with thrombin, activating the protease-activated receptors (PAR). This response requires a sustained rise in intracellular $\mathrm{Ca}^{2+}$, surpassing a threshold level of $\approx 400 \mathrm{nmol} / \mathrm{L}^{1,11}$. This causes surface exposure of the negatively charged phospholipid phosphatidylserine (PS), which serves as a binding site for coagulation factors ${ }^{12-14}$. By providing a key link between platelet and coagulation activation, the platelet procoagulant response was found to regulate arterial thrombus formation in vivo in various experimental mouse models ${ }^{15,16}$.

Considering the relevant role of Orai1 in arterial thrombosis, we hypothesized that pharmacological blockage of the Orai1 channels may provide a novel way of antithrombotic therapy by suppressing platelet aggregate formation and particularly platelet procoagulant activity. In this article, we first screened established and novel pharmacological inhibitors of SOCE for their suppressive effects on platelet $\mathrm{Ca}^{2+}$ responses and thrombus formation. Using Orai1-deficient platelets, we verified this channel as the target of the most potent inhibitors. We furthermore determined the efficacy of inhibitors to suppress arterial thrombus formation in an established model of ischemic brain infarction.

\section{Methods}

Mice

Experiments with mice were approved by the local animal care and use committees. Wild type C57BL/6, bone marrow chimeras of C57BL/6 mice with Orail $^{+/+}$or Orail $^{-/-}$platelets have been described before ${ }^{10}$.

\section{$\mathrm{Ca}^{2+}$ entry inhibitors}

SKF96365, MRS1845, and 2-aminoethyldiphenylborinate (2APB) were from Sigma (St. Louis, MO). LOE-908Cl was kindly provided by Boehringer Ingelheim Pharma. The novel inhibitors, Synta66, 3-fluoropyridine-4-carboxylic acid (2',5-dimethoxybiphenyl-4-yl)amide (compound 66 from patent WO 2005/009954 A2), and GSK-7975A, 2,6-difluoro-N-(1-\{[4hydroxy-2-(trifluoromethyl)phenyl]methyl\}-1H-pyrazol-3-yl)benzamide (compound 36 from patent WO 2010/122089 A1), were kindly provided by GlaxoSmithKline (UK). The latter 2 compounds were selected by their ability to suppress $I_{\text {CRAC }}$ in Jurkat or basophilic leukemia cells (see patents). Synta66 and GSK-7975A were $>99 \%$ pure, as determined by proton nuclear magnetic resonance spectroscopy, liquid chromatography-mass spectrometry, and high-performance liquid chromatography.

\section{Thrombus formation and platelet $\mathrm{Ca}^{2+}$ responses under flow}

Glass cover slips were coated with $10 \mu \mathrm{L}$ of $50 \mu \mathrm{g} / \mathrm{mL}$ Horm collagen $\left(1 \mathrm{~cm}^{2}\right)$ for 1 hour in a humid box, and subsequently blocked with 1\% BSA in HEPES buffer, pH 7.45. Collagen- 
coated cover slips were perfused with whole blood that was anticoagulated with PPACK/ fragmin (human) ${ }^{17}$ or PPACK/heparin (mouse) ${ }^{10,18}$. Platelets in thrombi were postlabeled with FITC-annexin A5. To measure single-cell $\mathrm{Ca}^{2+}$ responses under flow, platelets were loaded with fluo-4 acetoxymethyl ester and re-added to autologous blood at an amount of $10 \%$ fluo-4-loaded platelets ${ }^{19}$. Inhibitor or vehicle was added 10 minutes before perfusion.

In vivo thrombosis

Wild type or chimeric Orai1 ${ }^{-1-}$ mice were injected with vehicle solution or 2 APB $(3 \mathrm{mg} / \mathrm{kg})$ as indicated. In blood samples isolated 60 minutes after injection, collagen-induced thrombus formation was measured, as described above. To induce focal cerebral ischemia in mice, the middle cerebral artery (MCA) was transiently occluded for 60 minutes using an intraluminal filament as described elsewhere (transient MCA occlusion model) ${ }^{20}$. Immediately after reperfusion of the MCA territory, vehicle solution or $2 A P B(3 \mathrm{mg} / \mathrm{kg})$ was injected postoperatively. Animals were euthanized on day 1 after transient MCA occlusion, and brain sections were stained with 2\% 2,3,5-triphenyltetrazolium chloride to quantify the ischemic brain volume (corrected for edema) ${ }^{20}$.

A

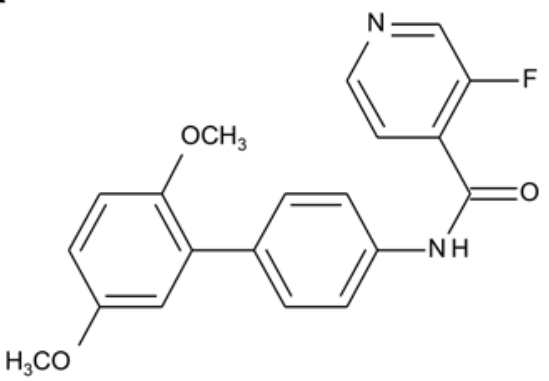

B<smiles>O=C(Nc1ccn(CC2=C(C(F)(F)F)CC(O)C=C2)n1)c1c(F)cccc1F</smiles>

Supplemental Figure 1. Chemical structure of (a) Synta66, 3-fluoropyridine-4-carboxylic acid [2',5'dimethoxybiphenyl-4-yl)amide, and (b) GSK-7975A, 2,6-difluoro-N-(1-\{[4-hydroxy-2-(trifluoromethyl) phenyl]methyl\}-1H-pyrazol-3-yl)benzamide.

\section{Results}

Pharmacological inhibition of platelet $\mathrm{Ca}^{2+}$ and procoagulant responses

Several compounds known to affect agonist-evoked influx of extracellular $\mathrm{Ca}^{2+}$ were screened for their potency to block SOCE and exposure of procoagulant PS in washed human platelets. The platelets were stimulated with a combination of strong agonists, convulxin (activating GPVI) and thrombin (activating protease-activated receptors), which is a condition known to maximally trigger $\mathrm{Ca}^{2+}$ signaling ${ }^{1,21}$. Platelet stimulation in the presence of low EGTA (baseline $\mathrm{Ca}^{2+} \approx 15 \mathrm{nmol} / \mathrm{L}$ ) resulted in full mobilization of $\mathrm{Ca}^{2+}$ from intracellular stores, which was detected as a transient $\mathrm{Ca}^{2+}$ rise peaking at $400 \mathrm{nmol} / \mathrm{L}$ (Figure 1a). Subsequent addition of a surplus of $\mathrm{CaCl}_{2}$ induced massive $\mathrm{Ca}^{2+}$ influx attributable to SOCE, resulting in $\mathrm{Ca}^{2+}$ peak levels up to $1300 \mathrm{nmol} / \mathrm{L}$. Candidate compounds tested included the known SOCE inhibitor, bimethoxyphenyl imidazole, SKF96365 ${ }^{22}$; the less well-studied lipophilic biaromates, Synta66 and GSK-7975A (supplemental Figure 1) ${ }^{23}$; 
and furthermore the diphenylborate $2 \mathrm{APB}$, initially used as $\mathrm{InsP}_{3}$ receptor inhibitor at high concentrations, but now recognized as a more potent antagonist of $\mathrm{Ca}^{2+}$ entry ${ }^{24,25}$. Other tested compounds were LOE-908Cl and the nitrophenyl pyridine, MRS1845, both of which block $\mathrm{Ca}^{2+}$ entry in $\mathrm{HL}-60$ cells ${ }^{26,27}$. Because platelets lack voltage-dependent $\mathrm{Ca}^{2+}$ channels ${ }^{3}$, specific inhibitors of these were not tested.

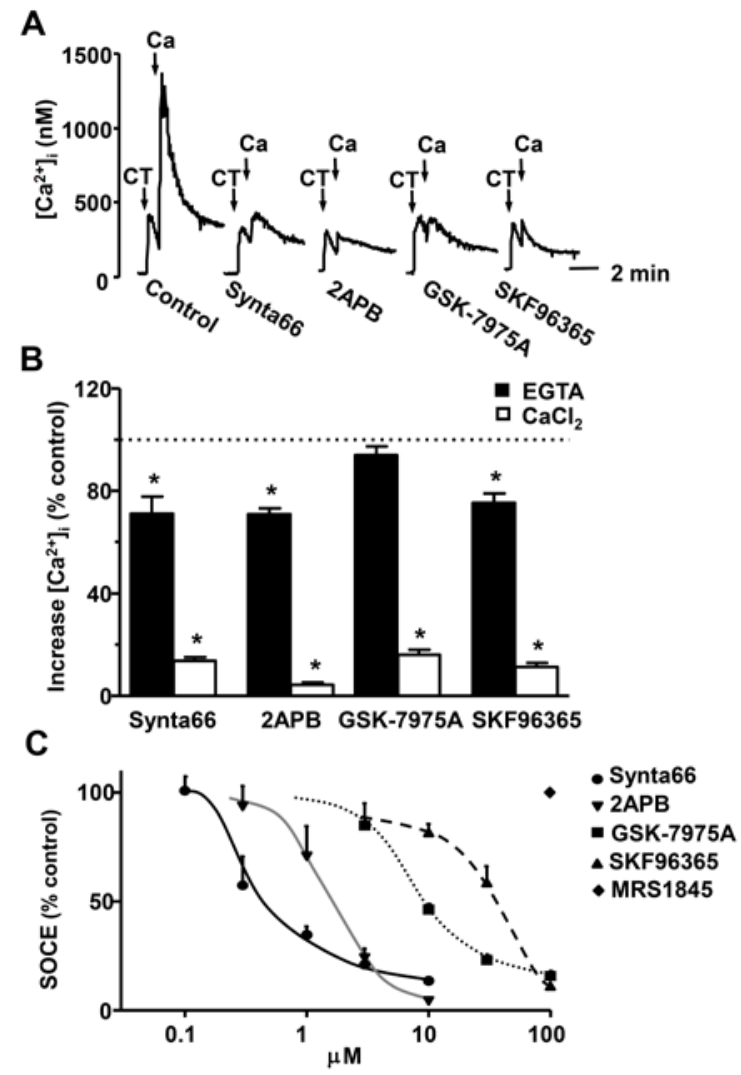

Figure 1. Effects of pharmacological inhibitors on platelet $\mathrm{Ca}^{2+}$ responses. (a) Human, Fura-2loaded platelets $\left(1 \times 10^{8} / \mathrm{mL}\right)$ in HEPES buffer plus $0.1 \mathrm{mmol} / \mathrm{L}$ EGTA were preincubated 10 minutes with vehicle (dimethyl sulfoxide), Synta66 $(10 \mu \mathrm{mol} / \mathrm{L})$, SKF96365 $(100 \mu \mathrm{mol} / \mathrm{L}), 2$ APB $(10 \mu \mathrm{mol} / \mathrm{L})$, or GSK-7975A (30 $\mu \mathrm{mol} / \mathrm{L})$. Platelets were stimulated with convulxin and thrombin (CT, $50 \mathrm{ng} / \mathrm{mL}$ and 4 $\mathrm{nmol} / \mathrm{L}$ ), after which $\mathrm{CaCl}_{2}(\mathrm{Ca}, 2 \mathrm{mmol} / \mathrm{L})$ was added to determine store-operated $\mathrm{Ca}^{2+}$ entry (SOCE). (b) Effects of inhibitors on SOCE; data are compared with vehicle control. (c) Dose-response curves of inhibitor effects. Mean \pm s.e.m $(n=3-5),{ }^{*} p<0.05$ vs control.

At maximally effective concentrations, Synta66 and 2APB (10 $\mu \mathrm{mol} / \mathrm{L})$ as well as SKF96365 and GSK-7975A (100 $\mu \mathrm{mol} / \mathrm{L})$ nearly completely blocked the $\mathrm{Ca}^{2+}$ entry signal evoked by $\mathrm{CaCl}_{2}$ addition, whereas they moderately reduced $\mathrm{Ca}^{2+}$ mobilization from stores with $10 \%$ to $30 \%$ (Figure $1 \mathrm{a}$ and $1 \mathrm{~b}$ ). In contrast, MRS1845 up to $100 \mu \mathrm{mol} / \mathrm{L}$ did not suppress the $\mathrm{Ca}^{2+}$ entry. The compound LOE-908Cl strongly interfered with the Fura-2 fluorescence signal and, hence, was not used for experiments. Dose-response curves for all inhibitors 
showed that the $\mathrm{IC}_{50}$ concentration for SOCE in washed platelets increased in the order of Synta66< 2APB < GSK-7975A< SKF96365< MRS1845 (Figure 1c).

Platelet procoagulant activity resulting from surface exposure of PS is known to be greatly impaired by deficiency or mutations of the SOCE channel, Orai1 ${ }^{6,10}$. Using fluorescentlabeled annexin A5, we investigated the ability of all inhibitors to affect PS exposure in platelets stimulated with convulxin and thrombin. Flow cytometric analysis showed that Synta66 (10 $\mu \mathrm{mol} / \mathrm{L}), 2$ APB $(10 \mu \mathrm{mol} / \mathrm{L})$, GSK-7975A (30 $\mu \mathrm{mol} / \mathrm{L})$, and SKF96365 (100 $\mu \mathrm{mol} / \mathrm{L}$ ) each potently suppressed the fractions of PS-exposing platelets (supplemental Figure 2). Quantitative analysis indicated that among these, at a maximally effective concentration, 2APB was the most potent inhibitor. These results thus show that all tested SOCE inhibitors restrain platelet procoagulant activity.

A

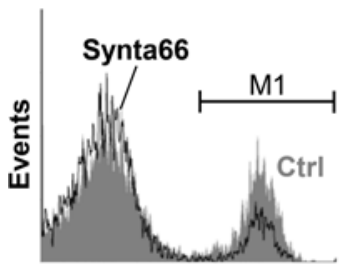

FL1 (FITC-annexin A5)

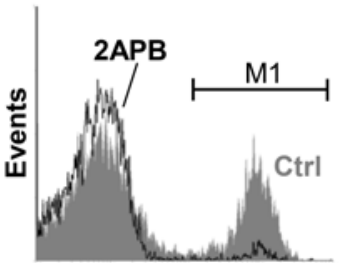

FL1
B

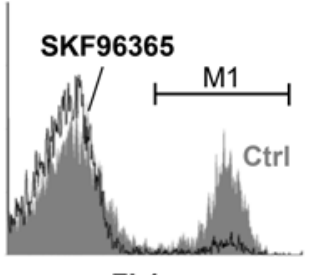

FL1

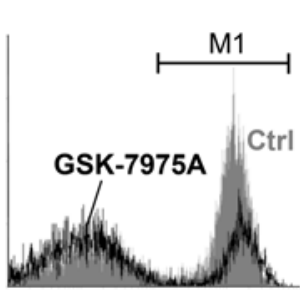

FL1

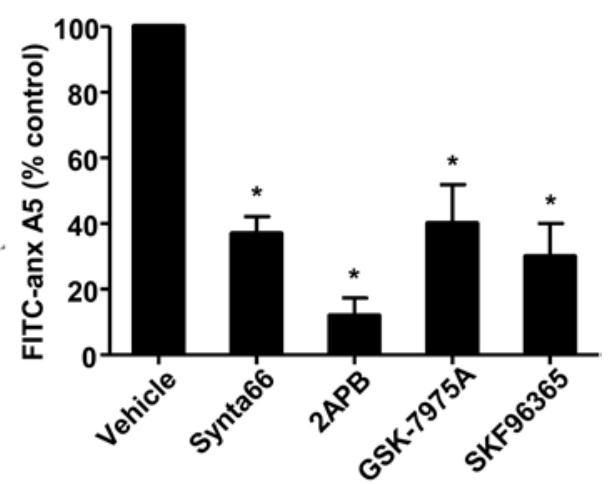

Supplemental Figure 2. SOCE inhibitors suppress platelet procoagulant reactivity. Human platelets in Hepes buffer plus $2 \mathrm{mmol} / \mathrm{L} \mathrm{CaCl}$ were $10 \mathrm{~min}$ preincubated with vehicle (control), Synta66 (10 $\mu \mathrm{mol} / \mathrm{L})$, SKF96365 $(100 \mu \mathrm{mol} / \mathrm{L}), 2$ APB $(10 \mu \mathrm{mol} / \mathrm{L})$ or GSK-7975A $(30 \mu \mathrm{mol} / \mathrm{L})$, and stimulated with convulxin $(50 \mathrm{ng} / \mathrm{mL})$ plus thrombin $(4 \mathrm{nmol} / \mathrm{L})$ during $15 \mathrm{~min}$. Using FITC-annexin A5, PS-exposing platelets (marker, M1) were detected by flow cytometry. (a) Representative histograms. (B) Effects of various compounds on PS exposure. Mean \pm s.e.m. $(n=4-7),{ }^{*} p<0.05$.

SOCE bockers suppress human platelet activation in plasma and whole-blood thrombus formation

In plasma or whole blood systems, lipophilic inhibitors often need to be added at $10 \mathrm{x}$ to $50 x$ higher concentrations than in nonplasma-based buffer systems to affect platelet function ${ }^{28}$. This also appeared to be the case for the SOCE inhibitors. When added to plateletrich plasma, concentrations of $100 \mu \mathrm{mol} / \mathrm{L}$ Synta66, 2APB, or GSK-7975A were required for inhibition of convulxin-induced $\mathrm{Ca}^{2+}$ rises and PS exposure with $41 \%$ to $49 \%$ (data not shown). To verify that these inhibitors influenced platelet procoagulant activity, the effects of Synta66, 2APB, or GSK-7975A (100 $\mu \mathrm{mol} / \mathrm{L})$ in platelet-rich plasma were measured 
on thrombin generation. Upon triggering with $1 \mathrm{pmol} / \mathrm{L}$ tissue factor, peak heights of thrombin generation were reduced with Synta66, 2APB, and GSK-7975A to $29 \pm 2 \%, 58 \pm 2 \%$, and $28 \pm 2 \%$ of control, respectively. SKF96365 (100 $\mu \mathrm{mol} / \mathrm{L})$ was inactive in platelet-rich plasma (not shown). Because Synta66, 2APB, or GSK-7975A retained their inhibitory activity in plasma, the compounds were tested in whole-blood thrombus formation. Therefore, PPACK-anticoagulated human blood was flowed at high shear rate over collagen (i.e., a condition where the thrombus forming process is regulated via Orai1-mediated platelet activation) ${ }^{5}$. In this flow perfusion assay, collagen-adhered platelets are activated in a

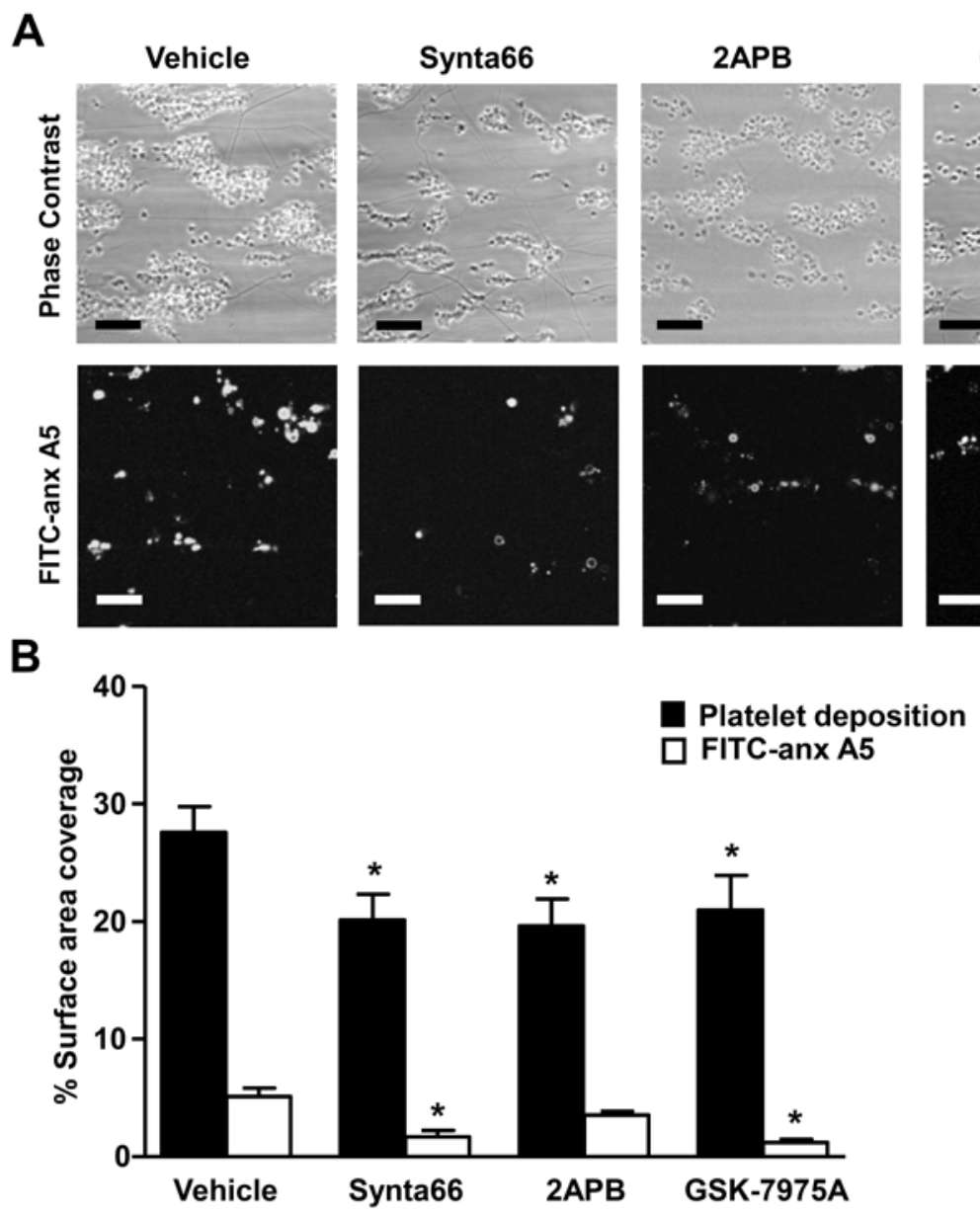

Figure 2. Store-operated $\mathrm{Ca}^{2+}$ entry (SOCE) blockers suppress whole-blood thrombus formation. Human PPACK -anticoagulated blood was perfused 4 minutes over collagen at a shear rate of 1000/s. Samples were preincubated for 10 minutes with vehicle, Synta66, 2APB, or GSK-7975A (each $100 \mu \mathrm{mol} / \mathrm{L}$ ). Platelet deposition (phase-contrast) and procoagulant platelets (FITC-annexin A5 fluorescence) were assessed by quantitative microscopy. (a) Representative images (bars, $20 \mu \mathrm{m}$ ). (b) Surface area coverage (SAC) of total platelets and FITC-annexin A5-labeled platelets. Mean \pm s.e.m. ( $n=6-7), * p<0.05, \# p<0.1$. 
GPVI-dependent way by elevating intracellular $\mathrm{Ca}^{2+}$ and aggregating and exposing PS ${ }^{15,17}$. With all 3 inhibitors, the deposition of platelets on the collagen surface was markedly reduced in comparison with the vehicle control, as was the number of platelets exposing PS (Figure $2 \mathrm{a}$ and $2 \mathrm{~b}$ ). Subsequent experiments with fluo-4-loaded platelets indicated that, at the same flow conditions, all 3 SOCE inhibitors did reduce the $\mathrm{Ca}^{2+}$ rises of collagenadhered platelets by $25 \%$ (Figure 3 ). In control flow experiments, the effect of chelation of extracellular $\mathrm{Ca}^{2+}$ by EGTA was examined. This resulted in the formation of small aggregates on the collagen surface, while PS exposure (measured with FITC-labelled lactadherin) was also reduced by $>90 \%$. With EGTA present, the extra addition of 2APB, Synta66, or GSK-7975A (100 $\mu \mathrm{mol} / \mathrm{L})$ was without further effect on PS exposure and platelet deposition (surface area coverage: vehicle 7.8\%; 2APB 7.8\%; Synta66 8.3\%; GSK-7975A 7.5\%). Together, these data demonstrate that the tested compounds reduce $\mathrm{Ca}^{2+}$ signaling and markedly suppress collagen-dependent thrombus formation of flowing human blood.

A
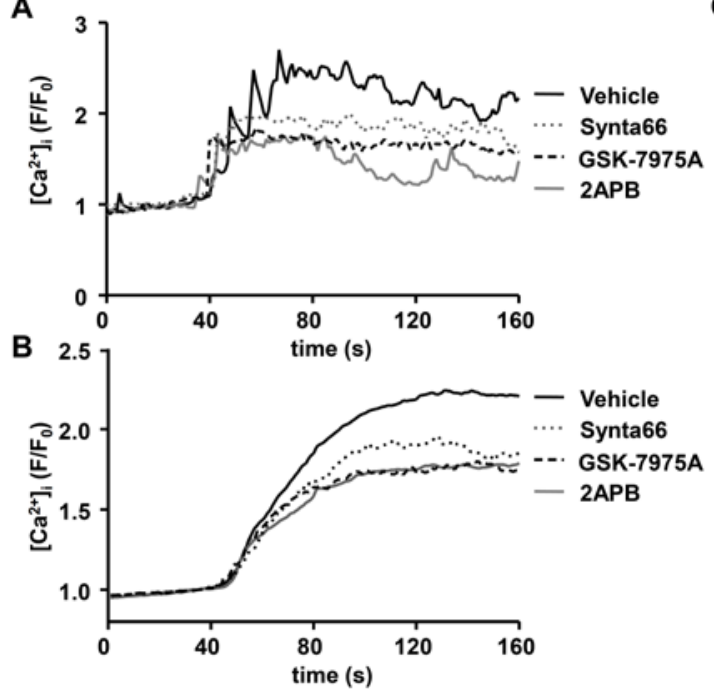

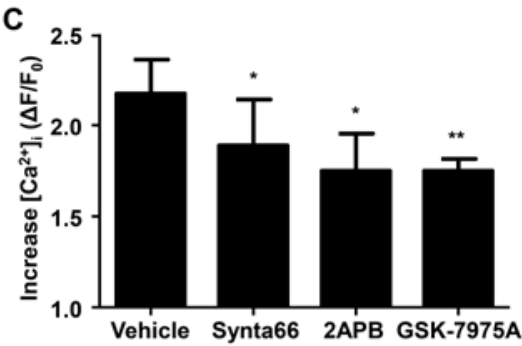

Figure 3. Store-operated $\mathrm{Ca}^{2+}$ entry (SOCE) blockers attenuate $\mathrm{Ca}^{2+}$ signals during thrombus formation. Human PPACK-anticoagulated blood was supplemented with $10 \%$ autologous fluo-4-loaded platelets and preincubated as described in Figure 2. Blood was perfused 4 minutes over collagen at a shear rate of $1000 / \mathrm{s}$, while fluorescence video images were recorded to determine rises in $\mathrm{Ca}^{2+}$. (a) Representative $\mathrm{Ca}^{2+}$ traces from single, adhered platelets, represented as pseudo-ratio $\mathrm{F} / \mathrm{F}_{0}$. (b) Averaged $\mathrm{Ca}^{2+}$ traces from $>40$ platelets per condition. (c) Quantification of mean $\mathrm{Ca}^{2+}$ rises during 90 to $150 \mathrm{~s}$ after initial adhesion. Mean \pm s.e.m., ${ }^{*} p<0.05,{ }^{*} p<0.01$.

\section{SOCE blockers suppress murine platelet responses and thrombus formation}

Considering that Orai1 forms the main SOCE channel in mouse platelets ${ }^{2,5,10}$, we used platelets from wild type and Orai1-deficient mice to verify the selectivity of the inhibitory compounds for this $\mathrm{Ca}^{2+}$ channel. In Fura-2-loaded platelets from wild type mice, the GPVI agonist CRP caused a prominent $\mathrm{Ca}^{2+}$ rise in the presence of $\mathrm{CaCl}_{2}$ attributable to SOCE (supplemental Figure 3). This $\mathrm{Ca}^{2+}$ rise with CRP was inhibited by $>50 \%$ with Synta66 (10 
$\mu \mathrm{mol} / \mathrm{L}), 2$ APB $(100 \mu \mathrm{mol} / \mathrm{L})$, or GSK-7975A (100 $\mu \mathrm{mol} / \mathrm{L})$. In Fura-2-loaded Orai1 ${ }^{-/}$platelets, CRP evoked a much lower $\mathrm{Ca}^{2+}$ response because of the absence of SOCE, which is in confirmation with earlier results ${ }^{5,10}$. The $\mathrm{Ca}^{2+}$ signal in knockout platelets was not affected by Synta66 or 2APB, whereas GSK-7975A was slightly inhibitory (supplemental Figure 3). In wild type platelets, all 3 inhibitors markedly suppressed thrombin-evoked $\mathrm{Ca}^{2+}$ rises, whereas Synta66 and GSK-7975A but not 2APB had a limited reducing effect on the already impaired thrombin-evoked $\mathrm{Ca}^{2+}$ rise in Orai $^{-1-}$ platelets. Together, these data point to $2 A P B$ as a most specific inhibitor of murine Orai1.

A

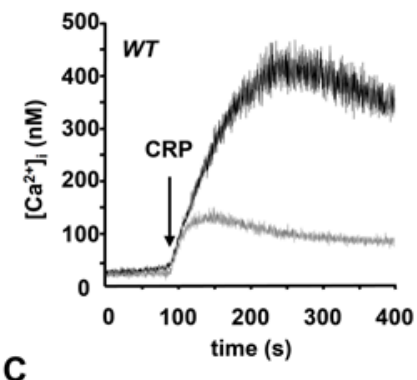

C

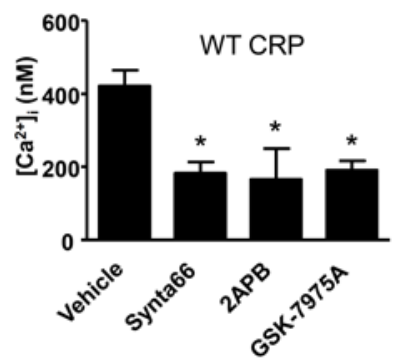

E

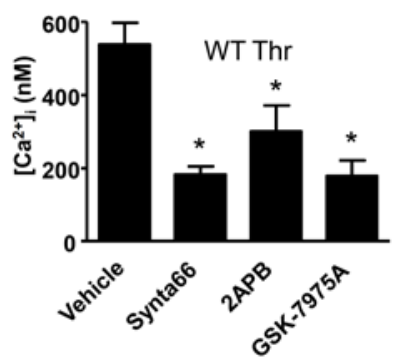

B

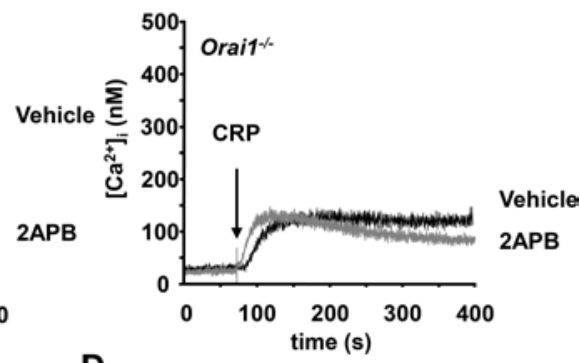

D

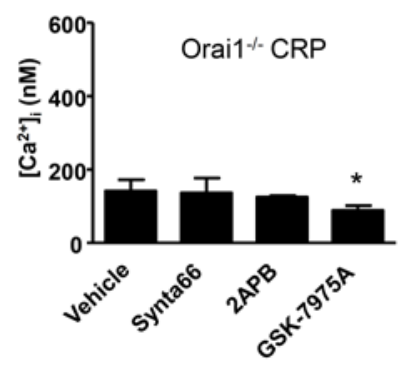

$\mathbf{F}$

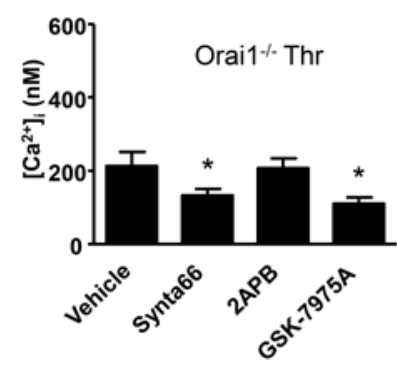

Supplemental Figure 3. SOCE blockers primarily block Orai1 signaling. Rises in $\mathrm{Ca}^{2+}$ were measured in wild type and Orai $1^{-1-}$ mouse platelets, loaded with Fura-2. Stimulation was with collagen-related peptide (CRP, $10 \mu \mathrm{g} / \mathrm{mL}$ ) or thrombin $(0.9 \mathrm{nM})$ in $\mathrm{CaCl}_{2}$-containing Hepes buffer; preincubation was with vehicle (DMSO), Synta66 (10 $\mu \mathrm{mol} / \mathrm{L}), 2$ APB $(100 \mu \mathrm{mol} / \mathrm{L})$ or GSK-7975A (100 $\mu \mathrm{mol} / \mathrm{L}) .(\mathrm{a}, \mathrm{b})$ Representative traces of $\mathrm{Ca}^{2+}$ rises in the presence of $2 \mathrm{APB}$ or vehicle for (a) wildtype and (b) Orai $1^{-}$ mouse platelets. (c-f) Quantitative effect of inhibitors on maximal $\mathrm{Ca}^{2+}$ rises in wildtype (c, e) or Orai1 $^{-/-}$platelets $(d, f)$ after activation by CRP (c, d) or thrombin respectively (e, f). Mean \pm s.e.m. $(n=3-5),{ }^{*} p<0.05$ vs vehicle control. 
A
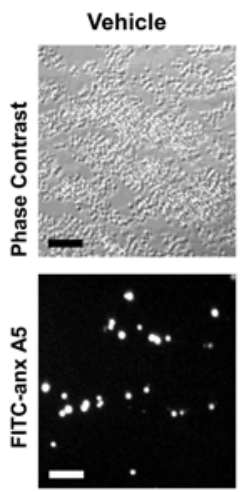

Synta66
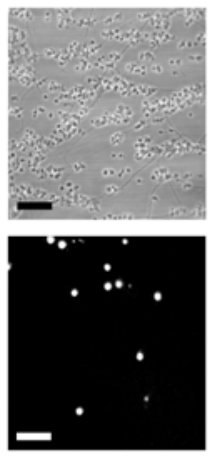

2APB
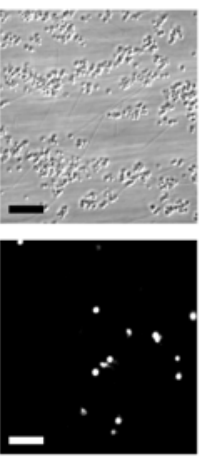

GSK-7975A
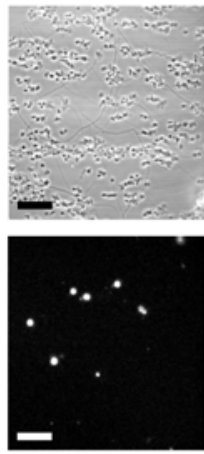

B

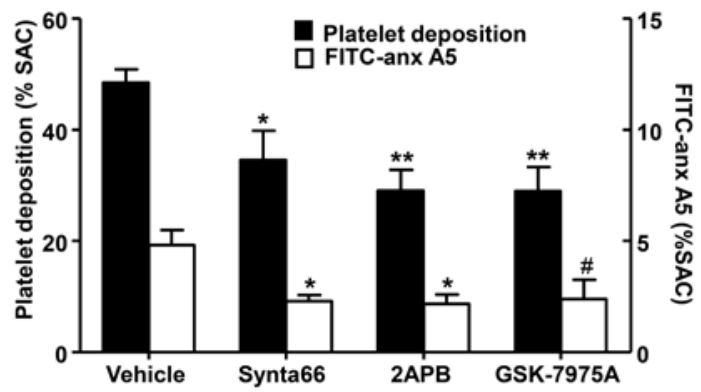

C

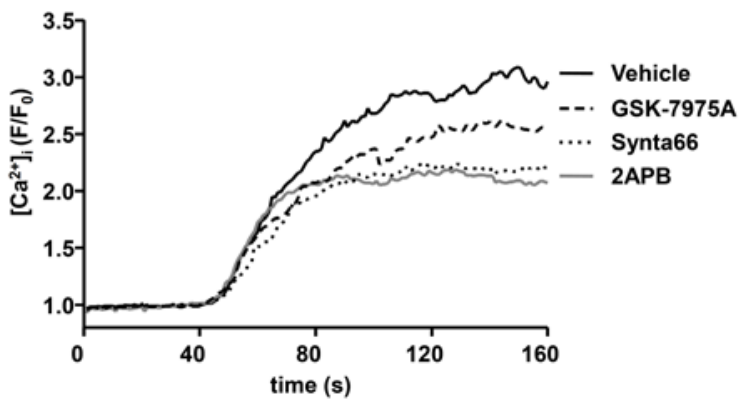

Figure 4. Store-operated $\mathrm{Ca}^{2+}$ entry (SOCE) blockers suppress thrombus formation in wild type mice in vitro. PPACK-anticoagulated wild-type mouse blood was perfused 4 minutes over collagen at a shear rate of $1000 / \mathrm{s}$. Samples were preincubated with vehicle (control), Synta66, 2APB, or GSK7975A (100 $\mu \mathrm{mol} / \mathrm{L})$. (a) Microscopic images of phase-contrast and FITC-annexin A5 fluorescence (bars, $20 \mu \mathrm{m}$ ). (b) Surface area coverage (SAC) of total and annexin A5-binding platelets. Mean \pm s.e.m. $(n=4-6),{ }^{*} p<0.05, \# p<0.1$. (c) Averaged $\mathrm{Ca}^{2+}$ traces of fluo-4-loaded wild-type platelets supplemented to wild-type blood; $>40$ platelets per condition. 
We then examined the efficacy of the compounds to suppress murine thrombus formation in flow experiments over collagen with isolated wild type blood. In comparison with the vehicle condition, all 3 compounds $(100 \mu \mathrm{mol} / \mathrm{L})$ significantly lowered platelet deposition by $\approx 30 \%$ (leaving small aggregates) and PS exposure by $50 \%$ (Figure $4 \mathrm{a}$ and $4 \mathrm{~b}$ ). This was again accompanied by a marked reduction in $\mathrm{Ca}^{2+}$ responses of the collagen-adherent platelets (Figure 4c). The relatively high reduction in PS exposure in comparison with platelet aggregate formation is compatible with the results of flow studies using Orai ${ }^{-1}$ blood ${ }^{5,10}$. Earlier data have indicated that platelet adhesion and aggregation are less dependent on the $\mathrm{Ca}^{2+}$ signal than PS exposure, which requires a prolonged elevation in cytosolic $\mathrm{Ca}^{2+1}$.

Flow experiments were also performed with Orai1 $^{-1-}$ blood to check for potential non-Orai effects of 2APB, Synta66, and GSK-7975A (supplemental Figure 4). However, in the absence of Orai1 none of these compounds $(100 \mu \mathrm{mol} / \mathrm{L})$ caused a further reduction in platelet deposition or PS exposure. Together, this points to Orai1 as principal target of these inhibitors in whole-blood thrombus formation.

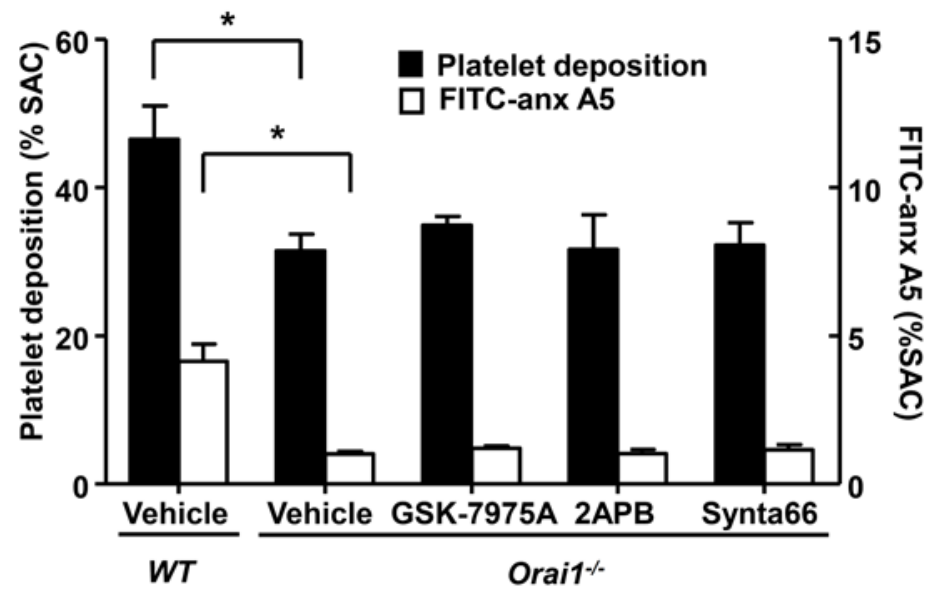

Supplemental Figure 4. PPACK-anticoagulated wildtype and Orai $1^{--}$mouse blood was perfused over collagen at $1000 \mathrm{~s}^{-1}$ for $4 \mathrm{~min}$. Samples were preincubated with vehicle (control), Synta66, 2APB or GSK-7975A (100 $\mu \mathrm{mol} / \mathrm{L})$. Surface area coverage (SAC) of total and Annexin A5-binding platelets. Mean \pm s.e.m. $(n=3),{ }^{*} p<0.05$.

Given the marked effects of 2APB in flow experiments, this compound was used to examine the consequences of SOCE inhibition on arterial thrombus formation in vivo. Wild type mice were injected with a bolus of $2 A P B(3 \mathrm{mg} / \mathrm{kg}$ ) or vehicle solution, and blood was taken after 60 minutes to assess collagen-dependent thrombus formation under flow. The in vivo $2 A P B$ treatment resulted in the formation of smaller platelet aggregates and in a marked decrease in platelet deposition by $\approx 35 \%$ (Figure $5 \mathrm{a}$ and $5 \mathrm{~b}$ ). This resembled the diminished thrombus formation after in vitro addition of 2APB (Figure 4).

Because platelet activation via glycoprotein Ib, GPVI, and Orai1 significantly contributes to the development of brain infarction after thrombus formation in the cerebral arteries ${ }^{5,20}$, 
we tested the efficacy of 2APB on this process using an established experimental stroke model. Herein, ischemic stroke is evoked by transient MCA occlusion, and the brain infarct volume is assessed after 1 day. Administration of 2APB to wild type mice significantly reduced the infarction volume by $\approx 30 \%$ compared with the vehicle control (Figure $5 \mathrm{c}$ ). In Orai1 $^{-1-}$ mice, transient MCA occlusion caused a smaller infarction volume, which is in agreement with previous results ${ }^{5}$. Importantly, administration of $2 \mathrm{APB}$ to Orai1 ${ }^{-1-}$ mice did not result in a further decrease in infarction size (Figure $5 c$ and $5 d$ ). Altogether, these results indicate that the blockage of platelet SOCE via Orai1 has a thromboprotective effect.

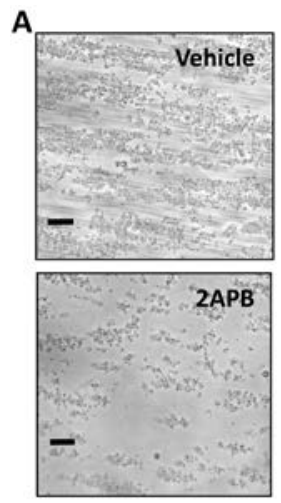

D

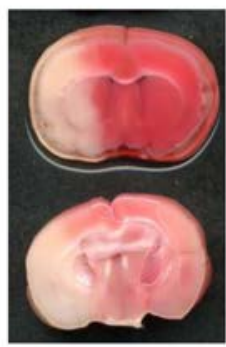

Vehicle

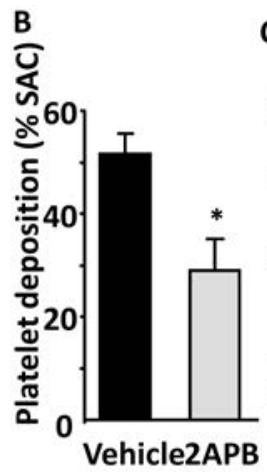

C

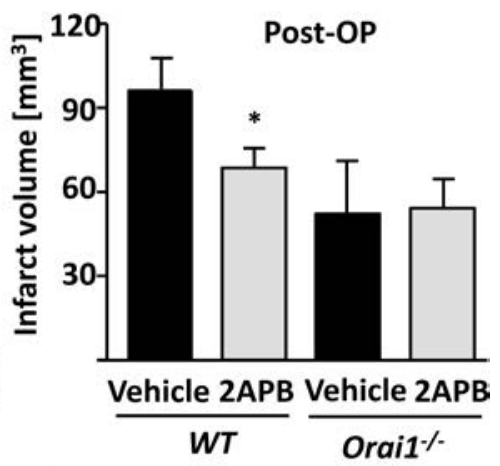

Post-OP

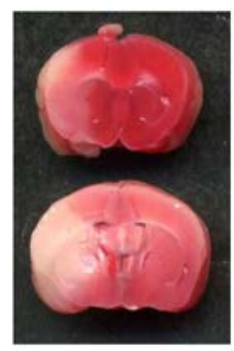

2APB

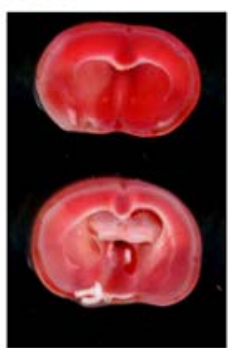

Vehicle

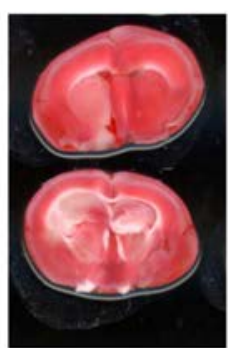

2APB

$W T$

Orai1 $\%$

Figure 5. Suppressive effect of 2-aminoethyldiphenylborinate (2APB) on murine thrombus formation and experimental stroke in vivo. (a) and (b) Wild type mice were injected with vehicle or 2 APB ( $3 \mathrm{mg} / \mathrm{kg}$ ). Thrombus formation on collagen surface was assessed in blood samples collected 60 minutes after injection, as in Figure 4. Shown are representative phase-contrast images (bars, 20 $\mu \mathrm{m})$ and surface area coverage (SAC) of deposited platelets $(n=6)$. (c) and (d) Wild type and Orai1 ${ }^{-1}$ chimeric mice were injected with vehicle or $2 A P B(3 \mathrm{mg} / \mathrm{kg})$ and subjected to transient middle cerebral artery occlusion, resulting in thrombosis and subsequent brain infarction. (c) Infarct volumes in brains of mice injected with vehicle or 2APB after 1 day tMCAO. Mean \pm s.d. ( $n=8-10, * p<0.05$ compared with vehicle control). (d) Representative 2,3,5-triphenyltetrazolium chloride (TTC) stainings of brains from wild-type and Orai1 $^{-1-}$ mice treated with vehicle or 2APB. 


\section{Discussion}

In the present study, we show for the first time that pharmacological blockage of platelet SOCE channels has a thromboprotective potential by suppressing thrombus formation and reducing platelet procoagulant activity. In both human and mouse platelets, the novel compounds, Synta66 and GSK-7975A, and 2APB, at concentrations that inhibited SOCE, effectively antagonized whole-blood thrombus formation and PS exposure. These results are in agreement with the earlier reported impaired thrombus formation and platelet procoagulant activity in mice with Orai1-deficient platelets ${ }^{5,10}$ and in human platelets with a dysfunctional Orai ${ }^{\mathrm{R91W}}$ mutation ${ }^{6}$. In contrast, we found that the compound SKF96365, earlier identified as blocker of $\mathrm{Ca}^{2+}$ influx in platelets, was ineffective in the presence of blood plasma.

We find that in suspensions of washed human platelets, 2APB, Synta66, and GSK-7975A effectively suppressed agonist-induced $\mathrm{Ca}^{2+}$ influx via SOCE (>85\%), at concentrations where $\mathrm{Ca}^{2+}$ mobilization from stores was only moderately affected (10-25\%). The mechanism of this moderate reduction of $\mathrm{Ca}^{2+}$ mobilization is unclear. Similar to 2ABP, both inhibitors may modulate $\mathrm{Ins}_{3}$ receptor function (e.g., by affecting $\mathrm{Ca}^{2+}$-induced $\mathrm{Ca}^{2+}$ release). Alternatively, they may interfere in a proposed interaction of $\mathrm{InsP}_{3}$ receptors with Orai1 channels ${ }^{29}$.

Both 2APB and Synta66 abrogated GPVI-induced $\mathrm{Ca}^{2+}$ signaling in wild type but not in Orai1 $^{-1-}$ mouse platelets, whereas GSK-7975A caused limited additional inhibition in Orai1deficient platelets. Furthermore, 2APB did not affect thrombin-induced $\mathrm{Ca}^{2+}$ signaling in Orail $^{-1-}$ mouse platelets, thus pointing to this compound as a more selective inhibitor of the Orai1 channels. Synta66 has been shown to block $I_{\text {CRAC }}$ currents in mast cells ${ }^{23}$, whereas the structural analog GSK-7975A has not been tested before. The compound 2APB was previously considered to be an antagonist of InsP $\mathrm{P}_{3}$ receptors but later identified as a much more potent $\mathrm{Ca}^{2+}$ influx blocker ${ }^{24,25,30}$, which is confirmed by the current data. Other tested compounds were much less effective in inhibiting SOCE and could not be used in the presence of blood plasma (i.e., MRS1845, and SKF96365, the first described antagonist of $\mathrm{Ca}^{2+}$ influx in isolated platelets and leukocytes) ${ }^{22}$.

In GPVI-stimulated platelets, Synta66, GSK-7975A, and 2APB markedly inhibited the procoagulant response (i.e. PS exposure) at concentrations that also affected $\mathrm{Ca}^{2+}$ responses. This inhibition was observed in washed platelets with thrombin as co-agonist and in collagen-adhered platelets after blood perfusion. Previous studies suggested a role of $\mathrm{Ca}^{2+}$ influx in PS exposure of human platelets ${ }^{31,32}$. and the present data are the first to demonstrate that pharmacological blockage of SOCE suppresses this process in whole blood. However, the moderate reduction in $\mathrm{Ca}^{2+}$ responses in collagen-adhered platelets points to partial inhibition of SOCE in whole blood despite the presence of high concentrations $\left(10^{-4} \mathrm{~mol} / \mathrm{L}\right)$ of blockers, which is compatible with their incomplete inhibition of PS exposure. Given the limited water solubility of all tested compounds, next generation Orai1 antagonists preferably combine reduced hydrophobicity with increased affinity to the $\mathrm{Ca}^{2+}$ channel.

Injection of a single bolus of 2APB into wild type mice effectively reduced whole blood thrombus formation ex vivo in mouse and significantly diminished brain infarct volume after middle cerebral artery occlusion (i.e., an arterial thrombosis model known to rely on 
platelet Orai1 activity) ${ }^{5}$. Given the fact that this model of brain infarction relies on glycoprotein Ib- and GPVI-dependent platelet activation and on factor XII-dependent thrombin generation ${ }^{20,33}$, the protective effect of $2 \mathrm{APB}$ can rely on the inhibition of both thrombus formation and platelet procoagulant activity.

In conclusion, we have shown that SOCE inhibitors, including 2APB, directed against Orai1, have a high potential in reducing platelet-dependent coagulation and thrombus formation. The relatively high doses needed for the presently available SOCE (Orai1) inhibitors, however, urge for a search to higher affinity channel blockers before starting preclinical studies. Given the reported immune deficiency of patients with missense Orai1 mutations ${ }^{34}$, total or long-term blockage of SOCE may not be desirable in the treatment of patients with thrombosis. Hence, possible toxic side effects after administration of Orai1 channel blockers need to be monitored thoroughly. With such compounds available, our data indicate that the platelet Orai1 channel is a novel target for attacking arterial thrombosis to brain infarction.

\section{Acknowledgments}

We thank Drs M. Begg and D. House (GlaxoSmithKline, Stevenage, UK) for their stimulating discussions.

\section{Sources of funding}

We acknowledge support from the Cardiovascular Centre (HVC), Maastricht; the Center for Translational Molecular Medicine (CTMM) INCOAG; and the Deutsche Forschungsgemeinschaft (DFG), SFB 688 (TP A13 to C.K.).

\section{Disclosures}

None.

\section{References}

1. Heemskerk JW, Bevers EM, Lindhout T. Platelet activation and blood coagulation. Thromb Haemost. 2002;88:186-193.

2. Varga-Szabo D, Braun A, Nieswandt B. Calcium signaling in platelets. J Thromb Haemost. 2009;7:10571066.

3. Sage SO. The Wellcome Prize Lecture. Calcium entry mechanisms in human platelets. Exp Physiol. 1997;82:807-823.

4. Varga-Szabo D, Braun A, Kleinschnitz C, Bender M, Pleines I, Pham M, Renne T, Stoll G, Nieswandt B. The calcium sensor STIM1 is an essential mediator of arterial thrombosis and ischemic brain infarction. J Exp Med. 2008;205:1583-1591.

5. Braun A, Varga-Szabo D, Kleinschnitz C, Pleines I, Bender M, Austinat M, BosI M, Stoll G, Nieswandt B. Orai1 (CRACM1) is the platelet SOC channel and essential for pathological thrombus formation. Blood. 2009;113:2056-2063.

6. Bergmeier W, Oh-Hora M, McCarl CA, Roden RC, Bray PF, Feske S. R93W mutation in Orai1 causes impaired calcium influx in platelets. Blood. 2009;113:675-678.

7. Zhang SL, Yu Y, Roos J, Kozak JA, Deerinck TJ, Ellisman MH, Stauderman KA, Cahalan MD. STIM1 is a $\mathrm{Ca}^{2+}$ sensor that activates CRAC channels and migrates from the $\mathrm{Ca}^{2+}$ store to the plasma membrane. Nature. 2005;437:902-905. 
8. Hassock SR, Zhu MX, Trost C, Flockerzi V, Authi KS. Expression and role of TRPC proteins in human platelets: evidence that TRPC6 forms the store-independent calcium entry channel. Blood. 2002;100:2801-2811.

9. Ramanathan G, Gupta S, Thielmann I, Pleines I, Varga-Szabo D, May F, Mannhalter C, Dietrich A, Nieswandt B, Braun A. Defective diacylglycerol-induced $\mathrm{Ca}^{2+}$ entry but normal agonist-induced activation responses in TRPC6-deficient mouse platelets. J Thromb Haemost. 2012;10:419-429.

10. Gilio K, van Kruchten R, Braun A, Berna-Erro A, Feijge MA, Stegner D, van der Meijden PE, Kuijpers MJ, Varga-Szabo D, Heemskerk JW, Nieswandt B. Roles of platelet STIM1 and Orai1 in glycoprotein VI- and thrombin-dependent procoagulant activity and thrombus formation. J Biol Chem. 2010;285:2362923638.

11. Keuren JF, Wielders SJ, Ulrichts H, Hackeng T, Heemskerk JW, Deckmyn H, Bevers EM, Lindhout T. Synergistic effect of thrombin on collagen-induced platelet procoagulant activity is mediated through protease-activated receptor-1. Arterioscler Thromb Vasc Biol. 2005;25:1499-1505.

12. Bevers EM, Comfurius P, van Rijn JL, Hemker HC, Zwaal RF. Generation of prothrombin-converting activity and the exposure of phosphatidylserine at the outer surface of platelets. Eur J Biochem. 1982;122:429-436.

13. Heemskerk JW, Kuijpers MJ, Munnix IC, Siljander PR. Platelet collagen receptors and coagulation. A characteristic platelet response as possible target for antithrombotic treatment. Trends Cardiovasc Med. 2005;15:86-92.

14. Berny MA, Munnix IC, Auger JM, Schols SE, Cosemans JM, Panizzi P, Bock PE, Watson SP, McCarty OJ, Heemskerk JW. Spatial distribution of factor Xa, thrombin, and fibrin(ogen) on thrombi at venous shear. PLoS ONE. 2010;5:e10415.

15. Munnix IC, Strehl A, Kuijpers MJ, Auger JM, van der Meijden PE, van Zandvoort MA, oude Egbrink MG, Nieswandt B, Heemskerk JW. The glycoprotein VI-phospholipase C 2 signaling pathway controls thrombus formation induced by collagen and tissue factor in vitro and in vivo. Arterioscler Thromb Vasc Biol. 2005;25:2673-2678.

16. Kuijpers MJ, Gilio K, Reitsma S, Nergiz-Unal R, Prinzen L, Heeneman S, Lutgens E, van Zandvoort MA, Nieswandt B, Egbrink MG, Heemskerk JW. Complementary roles of platelets and coagulation in thrombus formation on plaques acutely ruptured by targeted ultrasound treatment: a novel intravital model. J Thromb Haemost. 2009;7:152-161.

17. Siljander PR, Munnix IC, Smethurst PA, Deckmyn H, Lindhout T, Ouwehand WH, Farndale RW, Heemskerk JW. Platelet receptor interplay regulates collagen-induced thrombus formation in flowing human blood. Blood. 2004;103:1333-1341.

18. Nieswandt B, Brakebusch C, Bergmeier W, Schulte V, Bouvard D, Mokhtari-Nejad R, Lindhout T, Heemskerk JW, Zirngibl H, Fassler R. Glycoprotein VI but not $\alpha_{2} \beta_{1}$ integrin is essential for platelet interaction with collagen. EMBO J. 2001;20:2120-2130.

19. Auger JM, Kuijpers MJ, Senis YA, Watson SP, Heemskerk JW. Adhesion of human and mouse platelets to collagen under shear: a unifying model. FASEB J. 2005;19:825-827.

20. Kleinschnitz C, Pozgajova M, Pham M, Bendszus M, Nieswandt B, Stoll G. Targeting platelets in acute experimental stroke: impact of glycoprotein Ib, VI, and Ilb/IIla blockade on infarct size, functional outcome, and intracranial bleeding. Circulation. 2007;115: 2323-2330.

21. Munnix IC, Kuijpers MJ, Auger J, Thomassen CM, Panizzi P, van Zandvoort MA, Rosing J, Bock PE, Watson SP, Heemskerk JW. Segregation of platelet aggregatory and procoagulant microdomains in thrombus formation: regulation by transient integrin activation. Arterioscler Thromb Vasc Biol. 2007;27:2484-2490.

22. Merritt JE, Armstrong WP, Benham CD, Hallam TJ, Jacob R, Jaxa-Chamiec A, Leigh BK, McCarthy SA, Moores KE, Rink TJ. SK\&F96365, a novel inhibitor of receptor-mediated calcium entry. Biochem J. 1990;271:515-522.

23. Ng SW, di Capite J, Singaravelu K, Parekh AB. Sustained activation of the tyrosine kinase Syk by antigen in mast cells requires local $\mathrm{Ca}^{2+}$ influx through $\mathrm{Ca}^{2+}$ release-activated $\mathrm{Ca}^{2+}$ channels. J Biol Chem. 2008;283:31348-31355. 
24. Bootman MD, Collins TJ, Mackenzie L, Roderick HL, Berridge MJ, Peppiatt CM. 2-aminoethoxydiphenyl borate (2-APB) is a reliable blocker of store-operated $\mathrm{Ca}^{2+}$ entry but an inconsistent inhibitor of InsP $\mathrm{P}^{-}$ induced $\mathrm{Ca}^{2+}$ release. FASEB J. 2002;16:1145-1150.

25. Dobrydneva Y, Abelt CJ, Dovel B, Thadigiri CM, Williams RL, Blackmore PF. 2-aminoethoxydiphenyl borate as a prototype drug for a group of structurally related calcium channel blockers in human platelets. Mol Pharmacol. 2006;69:247-256.

26. Harper JL, Camerini-Otero CS, Li AH, Kim SA, Jacobson KA, Daly JW. Dihydropyridines as inhibitors of capacitative calcium entry in leukemic HL-60 cells. Biochem Pharmacol. 2003;65:329-338.

27. Krautwurst D, Hescheler J, Arndts D, Losel W, Hammer R, Schultz G. Novel potent inhibitor of receptor-activated nonselective cation currents in HL-60 cells. Mol Pharmacol. 1993;43:655-659.

28. Strehl A, Munnix IC, Kuijpers MJ, van der Meijden PE, Cosemans JM, Feijge MA, Nieswandt B, Heemskerk JW. Dual role of platelet protein kinase $C$ in thrombus formation: stimulation of pro-aggregatory and suppression of procoagulant activity in platelets. J Biol Chem. 2007;282:7046-7055.

29. Lur G, Sherwood MW, Ebisui E, Haynes L, Feske S, Sutton R, Burgoyne RD, Mikoshiba K, Petersen OH, Tepikin AV. Ins $\mathrm{P}_{3}$ receptors and Orai channels in pancreatic acinar cells: co-localization and its consequences. Biochem J. 2011;436:231-239.

30. Diver JM, Sage SO, Rosado JA. The inositol trisphosphate receptor antagonist 2aminoethoxydiphenylborate (2-APB) blocks $\mathrm{Ca}^{2+}$ entry channels in human platelets: cautions for its use in studying $\mathrm{Ca}^{2+}$ influx. Cell Calcium. 2001;30:323-329.

31. Williamson P, Bevers EM, Smeets EF, Comfurius P, Schlegel RA, Zwaal RF. Continuous analysis of the mechanism of activated transbilayer lipid movement in platelets. Biochemistry. 1995;34:1044810455.

32. Siljander P, Farndale RW, Feijge MA, Comfurius P, Kos S, Bevers EM, Heemskerk JW. Platelet adhesion enhances the glycoprotein VI-dependent procoagulant response: Involvement of p38 MAP kinase and calpain. Arterioscler Thromb Vasc Biol. 2001;21:618-627.

33. Kleinschnitz C, Stoll G, Bendszus M, Schuh K, Pauer HU, Burfeind P, Renne C, Gailani D, Nieswandt B, Renne T. Targeting coagulation factor XII provides protection from pathological thrombosis in cerebral ischemia without interfering with hemostasis. J Exp Med. 2006;203:513-518.

34. Feske S, Gwack Y, Prakriya M, Srikanth S, Puppel SH, Tanasa B, Hogan PG, Lewis RS, Daly M, Rao A. A mutation in Orai1 causes immune deficiency by abrogating CRAC channel function. Nature. 2006;441:179-185.

\section{Supplemental methods}

Mice

Bone-marrow chimeras of mice with Orail $^{+/+}$or Orai1 $^{-/-}$platelets at C57BL/6 background were generated as described ${ }^{1,2}$. Deficiency in Orai1 was confirmed by reverse transcription PCR analysis. Wildtype mice were at C57BL/ 6 genetic background.

\section{Materials}

H-Phe-Pro-Arg chloromethyl ketone (PPACK) was obtained from Calbiochem; fragmin from Pfizer; annexin A5 labeled with fluorescein isothiocyanate (FITC) from PharmaTarget; fibrillar type I collagen (Horm) from Nycomed. Fura-2, and Fluo-4 acetoxymethyl esters, Alexa Fluor-647 annexin A5, and pluronic F-127 were all from Invitrogen. Apyrase (grade V), bovine serum albumin (BSA), heparin, 2,3,5-triphenyltetrazolium chloride (TTC) and thrombin were from Sigma. Convulxin was purified as described ${ }^{3}$.

\section{Blood collection and platelet preparation}

Human blood was obtained from healthy volunteers after full informed consent. For perfusion studies, the blood was collected into $40 \mu \mathrm{mol} / \mathrm{L} \mathrm{PPACK}$ and $40 \mathrm{U} / \mathrm{mL}$ fragmin (f.c.). For the preparation of washed platelets, blood was collected into acid citrate dextrose 
(ACD) anticoagulant ${ }^{4}$. Platelets were resuspended in Hepes buffer pH 7.45 (136 mmol/L $\mathrm{NaCl}, 10 \mathrm{mmol} / \mathrm{L}$ Hepes, $2.7 \mathrm{mmol} / \mathrm{L} \mathrm{KCl}, 2 \mathrm{mmol} / \mathrm{L} \mathrm{MgCl}_{2}, 0.1 \%$ glucose and $\left.0.1 \% \mathrm{BSA}\right)^{5}$. For the preparation of platelet-poor plasma, blood was collected in $1 / 10$ volume 129 $\mathrm{mmol} / \mathrm{L}$ trisodium citrate. Cells were counted with a Coulter counter. Mouse blood was collected via retro-orbital puncture. For perfusion experiments, blood was collected into $40 \mu \mathrm{M}$ PPACK and $5 \mathrm{U} / \mathrm{mL}$ low molecular weight heparin (f.c). Washed mouse platelets were prepared as described ${ }^{1}$.

\section{$\mathrm{Ca}^{2+}$ measurements of platelets in suspension}

Human 6 and mouse ${ }^{1}$ platelets were loaded with Fura-2 acetoxymethyl ester and washed, as described. Calcium responses in the loaded platelets $\left(1 \times 10^{8} / \mathrm{mL}\right)$ were measured by ratio fluorometry under stirring at $37^{\circ} \mathrm{C}$. Calibration of Fura-2 fluorescence ratios to nanomolar levels of $\mathrm{Ca}^{2+}$ was performed by lysis with Triton X-100 and subsequent application of a surplus of EGTA in Tris buffer $\mathrm{pH}$ 8, as reported for human and mouse platelets ${ }^{1,6}$. Cells were pretreated with vehicle (DMSO) or inhibitor during $10 \mathrm{~min}$.

\section{Flow cytometry}

Surface exposed PS as a measure of procoagulant activity of platelets in suspension was determined by flow cytometry, as described ${ }^{7}$. Briefly, cells $\left(1 \times 10^{8} / \mathrm{mL}\right)$ were preincubated with vehicle or inhibitor for $10 \mathrm{~min}$, activated with the indicated agonist in the presence of $2 \mathrm{mmol} / \mathrm{L} \mathrm{CaCl}_{2}$, and stained with appropriate label, e.g. with FITC-annexin A5 to determine PS exposure. For measurements in plasma environment, washed platelets were added to plasma that was recalcified in the presence of $40 \mu \mathrm{mol} / \mathrm{L}$ PPACK and 40 $\mathrm{U} / \mathrm{mL}$ fragmin, as described ${ }^{8}$.

\section{Thrombin generation}

PRP and platelet-free plasma collected on citrate were used to measure thrombin generation under standard conditions with the calibrated automated thrombogram method ${ }^{5}$. Thrombin generation was initiated by $1 \mathrm{pmol} / \mathrm{L}$ tissue factor, and first-derivative curves of fluorescence generation from cleaved Z-GGR-AMC were made using Thrombogram software. Thrombin peak heights were corrected for contribution of microparticles.

\section{Thrombus formation and platelet $\mathrm{Ca}^{2+}$ responses under flow}

Collagen type I coated cover slips, placed in a transparent parallel-plate flow chamber, were perfused with whole blood anticoagulated with PPACK/fragmin (human) ${ }^{9}$ or PPACK/heparin (mouse) ${ }^{2,10}$, thus containing physiologically high levels of free $\mathrm{Ca}^{2+}$ and $\mathrm{Mg}^{2+}$. Pretreatment with vehicle or inhibitors was for $10 \mathrm{~min}$. After 4 min perfusion at arterial shear rate of $1000 \mathrm{~s}^{-1}$, platelet thrombi formed on the collagen surface were postlabeled with FITC-annexin A5 $(0.25 \mu \mathrm{g} / \mathrm{mL})$ in Hepes buffer $\mathrm{pH} 7.45$ containing $2 \mathrm{mmol} / \mathrm{L}$ $\mathrm{CaCl}_{2}$. Phase contrast and fluorescent images were recorded by a Visitech digital imaging system, equipped with two intensified, charge-coupled device cameras ${ }^{2}$. Images were analyzed off-line by Metamorph software. To measure single-cell $\mathrm{Ca}^{2+}$ responses under flow, human or mouse platelets were loaded with Fluo-4 acetoxymethyl ester, and readded to the autologous blood at an amount of $10 \%$ Fluo-4-loaded platelets ${ }^{4}$. During 
blood perfusion over collagen, Fluo-4 fluorescence images were recorded at high frequency $(1 \mathrm{~Hz})$ from the optical plane of the collagen coating. Changes in fluorescence were analyzed off-line by selecting regions of interest, representing single adhered platelets. Traces of fluorescence intensity $(F)$ per platelet were converted into pseudo-ratio $F / F_{0}$ values ${ }^{4}$.

\section{Statistics}

Significance of differences was determined with the paired t-test or the independent samples t test, as appropriate, using the statistical package for social sciences (SPSS 11.0).

\section{Supplemental references}

1. Braun A, Varga-Szabo D, Kleinschnitz C, Pleines I, Bender M, Austinat M, BosI M, Stoll G, Nieswandt B. Orai1 (CRACM1) is the platelet SOC channel and essential for pathological thrombus formation. Blood. 2009;113:2056-2063.

2. Gilio K, van Kruchten R, Braun A, Berna-Erro A, Feijge MA, Stegner D, van der Meijden PE, Kuijpers MJ, Varga-Szabo D, Heemskerk JW, Nieswandt B. Roles of platelet STIM1 and Orai1 in glycoprotein VI- and thrombin-dependent procoagulant activity and thrombus formation. J Biol Chem. 2010;285:2362923638.

3. Siljander P, Farndale RW, Feijge MA, Comfurius P, Kos S, Bevers EM, Heemskerk JW. Platelet adhesion enhances the glycoprotein VI-dependent procoagulant response: Involvement of p38 MAP kinase and calpain. Arterioscler Thromb Vasc Biol. 2001;21:618-627.

4. Auger JM, Kuijpers MJ, Senis YA, Watson SP, Heemskerk JW. Adhesion of human and mouse platelets to collagen under shear: a unifying model. Faseb J. 2005;19:825-827.

5. van der Meijden PE, Feijge MA, Giesen PL, Huijberts M, van Raak LP, Heemskerk JW. Platelet P2Y 12 receptors enhance signalling towards procoagulant activity and thrombin generation. A study with healthy subjects and patients at thrombotic risk. Thromb Haemost. 2005;93:1128-1136.

6. Feijge MA, van Pampus EC, Lacabaratz-Porret C, Hamulyak K, Levy-Toledano S, Enouf J, Heemskerk JW. Inter-individual variability in $\mathrm{Ca}^{2+}$ signalling in platelets from healthy volunteers: effects of aspirin and relationship with expression of endomembrane $\mathrm{Ca}^{2+}$-ATPases. Br J Haematol. 1998;102:850-859.

7. Munnix IC, Strehl A, Kuijpers MJ, Auger JM, van der Meijden PE, van Zandvoort MA, oude Egbrink MG, Nieswandt B, Heemskerk JW. The glycoprotein VI-phospholipase C 22 signaling pathway controls thrombus formation induced by collagen and tissue factor in vitro and in vivo. Arterioscler Thromb Vasc Biol. 2005;25:2673-2678.

8. van der Meijden PE, Munnix IC, Auger JM, Govers-Riemslag JW, Cosemans JM, Kuijpers MJ, Spronk HM, Watson SP, Renne T, Heemskerk JW. Dual role of collagen in factor XII-dependent thrombus formation. Blood. 2009;114:881-890.

9. Siljander PR, Munnix IC, Smethurst PA, Deckmyn H, Lindhout T, Ouwehand WH, Farndale RW, Heemskerk JW. Platelet receptor interplay regulates collagen-induced thrombus formation in flowing human blood. Blood. 2004;103:1333-1341.

10. Nieswandt B, Brakebusch C, Bergmeier W, Schulte V, Bouvard D, Mokhtari-Nejad R, Lindhout T, Heemskerk JW, Zirngibl H, Fassler R. Glycoprotein VI but not $\alpha_{2} \beta_{1}$ integrin is essential for platelet interaction with collagen. Embo J. 2001;20:2120-2130. 
Chapter 5

\section{Both TMEM16F-dependent and TMEM16F- independent pathways contribute to phosphatidylserine exposure in platelet apoptosis and platelet activation.}

van Kruchten R, Mattheij NJ, Saunders C, Feijge MAH, Wolfs JL, Collins PW, Heemskerk JW, Bevers EM.

Blood. 2013;121(10):1850-1857

reprinted with permission 


\begin{abstract}
Scott syndrome, a bleeding disorder caused by defective phospholipid scrambling, has been associated with mutations in the TMEM16F gene. The role of TMEM16F in apoptosisor agonist-induced phosphatidylserine (PS) exposure was studied in platelets from a Scott syndrome patient and control subjects. Whereas stimulation of control platelets with the BH3-mimetic ABT737 resulted in 2 distinct fractions with moderate and high PS exposure, the high PS-exposing fraction was markedly delayed in Scott platelets. High, but not moderate, PS exposure in platelets was suppressed by chelation of intracellular $\mathrm{Ca}^{2+}$, whereas caspase inhibition completely abolished ABT737-induced PS exposure in both Scott and control platelets. On the other hand, high PS exposure induced by the $\mathrm{Ca}^{2+}$-mobilizing agonists convulxin/thrombin fully relied onmitochondrial depolarization and was virtually absent in Scott platelets. Finally, PS exposure induced by collagen/thrombin was partly affected in Scott platelets, and the residual PS positive fraction was insensitive to inhibition of caspases or mitochondrial depolarization. In conclusion, TMEM16F is not required for, but enhances, caspase-dependent PS exposure; convulxin/thrombin-induced PS exposure is entirely dependent on TMEM16F, whereas collagen/thrombin-induced PS exposure results from 2 distinct pathways, one of which involves mitochondrial depolarization and is mediated by TMEM16F.
\end{abstract}

\title{
Introduction
}

Transbilayer lipid asymmetry in platelets and other cells is maintained by an aminophospholipid translocase, an active transporter pumping aminophospholipids phosphatidylserine (PS) and phosphatidylethanolamine from the outer to the inner leaflet of the plasma membrane. Under particular conditions, phospholipid asymmetry is disrupted by a "scrambling" process, in which the phospholipids become increasingly randomized over both plasma membrane leaflets ${ }^{1}$. As a consequence, PS, which in resting cells is exclusively located in the inner leaflet, becomes exposed at the membrane outer leaflet and can be probed with the PS-binding proteins annexin A5 or lactadherin. For apoptotic cells, externalized PS provides a signal for removal by the mononuclear phagocytic system ${ }^{2}$. In blood cells, PS-exposing membranes strongly promote the process of thrombin generation and fibrin clot formation ${ }^{3,4}$. In platelets, phospholipid scrambling and PS externalization are induced by activation with strong agonists like convulxin/thrombin and collagen/thrombin, stimulating glycoprotein $\mathrm{VI}$, and the platelet thrombin receptors ${ }^{5,6}$. Known requirements for agonist-induced phospholipid scrambling are a sustained high intracellular $\mathrm{Ca}^{2+}$ concentration ${ }^{1,3}$ and loss of the mitochondrial membrane potential ${ }^{7,8}$. Hence, platelets lacking cyclophilin D, a positive modulator of the mitochondrial permeability transition pore (MPTP), are protected against PS externalization upon convulxin/thrombin stimulation ${ }^{9}$.

Scott syndrome is a rare bleeding disorder in which the $\mathrm{Ca}^{2+}$-dependent phospholipid scrambling of platelets and other blood cells is impaired ${ }^{10}$. Although agonist-induced $\mathrm{Ca}^{2+}$ responses were found to be unchanged, Scott syndrome platelets show diminished PS exposure upon stimulation with convulxin/thrombin, collagen/thrombin, or $\mathrm{Ca}^{2+}$ ionophore ionomycin compared with healthy subjects ${ }^{11}$. Recently, TMEM16F was recog- 
nized as a protein critically involved in $\mathrm{Ca}^{2+}$-induced phospholipid scrambling. A homozygous mutation in TMEM16F (IVS12-1G $\rightarrow$ T, causing premature termination of translation) was found in the genome of the propositus Scott patient ${ }^{12}$. Another Scott syndrome patient appeared to be compound heterozygous in TMEM16F ${ }^{13}$, suggesting that a defective TMEM16F is the cause of the Scott syndrome phenotype.

Besides the agonist-induced pathway, platelets possess a distinct pathway to PS exposure, which was shown to be elicited with ABT737 or ABT263 (Navitoclax), both of which are $\mathrm{BH}-3$ mimetics that activate caspase-dependent apoptosis in a Bax/Bak-dependent manner ${ }^{14,15}$. This apoptotic pathway may play a role in the clearance of aging platelets ${ }^{16}$. As $\mathrm{Bcl}-\mathrm{x}_{\mathrm{L}}$ is gradually degraded in such platelets, its restraint of the proapoptotic function of Bax and Bak will gradually diminish in time and hence prime platelets for apoptosis ${ }^{17,18}$. This explains why BH3 mimetics like ABT737 and ABT263 induce thrombocytopenia and affect the platelet hemostatic function ${ }^{19,20}$. Whether TMEM16F is involved in PS exposure upon apoptosis has not been investigated.

In this study, we aimed to elucidate the roles of TMEM16F in agonist- and apoptosisinduced PS exposure using platelets from a Scott patient. We provide evidence for TMEM16F-independent phospholipid scrambling in the apoptotic pathway that leads to moderate PS exposure in a caspase-dependent way. The data furthermore point to a TMEM16F-independent process of caspase/mitochondrial-independent PS exposure in response to collagen/thrombin.

\section{Methods}

Materials

ABT737 and Ac-DEVD-AFC were obtained from Santa Cruz Biotechnology (Santa Cruz, CA), ABT-263 from Selleckchem (Houston, TX), and annexin A5-labeled with fluorescein isothiocyanate (FITC) from PharmaTarget (Maastricht, The Netherlands). Acetylsalicylic acid (aspirin) was from Genfarma (Maarssen, The Netherlands). Fibrillar type I collagen (Horm) was from Nycomed (Munich, Germany). Fluo-4 acetoxymethyl ester, Alexa Fluor647 (AF647)-labeled annexin A5, dimethyl BAPTA acetoxymethyl ester, ionomycin, and pluronic F-127 were from Invitrogen (Carlsbad, CA). Apyrase (grade V), dimethylsulfoxide, bovine serum albumin, human fibrinogen, MRS2179, and thrombin were from SigmaAldrich (St. Louis, MO). FITC-lactadherin was from Haematologic Technologies (Essex Junction, VT). Tetramethyl rhodamine methyl ester (TMRE) was from Anaspec (San Jose, CA). Q-VD-Oph and cyclosporin A were from Calbiochem (San Diego, CA). A fluorometric assay for caspase 3 activity (BF1100) came from R\&D Systems (Minneapolis, MN). Convulxin was purified as described before ${ }^{21}$. Cangrelor was kindly provided by AstraZeneca (Mölndahl, Sweden).

\section{Blood collection and platelet preparation}

Human blood was obtained from healthy volunteers and a patient from the UK with Scott syndrome after they provided informed consent in accordance with the Declaration of Helsinki under protocols reviewed by the local ethics committees. The UK Scott patient was described earlier as compound heterozygous in TMEM16F with one mutation, IVS6 + $1 \mathrm{G} \rightarrow \mathrm{A}$, resulting in exon 6 skipping and another mutation (c.1219insT) leading to a prema- 
ture stop of translation, causing defective TMEM16F expression ${ }^{13}$. Blood was collected into acid citrate dextrose to prepare washed platelets in N-2-hydroxyethylpiperazine- $\mathrm{N}^{\prime}$-2ethanesulfonic acid (HEPES) buffer, pH 7.45 (136 mM NaCl, $10 \mathrm{mM} \mathrm{HEPES,} 2.7 \mathrm{mM} \mathrm{KCl}, 2$ $\mathrm{mM} \mathrm{MgCl}_{2}, 0.1 \%$ glucose, and $0.1 \%$ bovine serum albumin) as described ${ }^{22}$. Platelet counts were determined using a Coulter counter (Beckman).

\section{Measurement of PS exposure}

Washed platelets $\left(1 \times 10^{8} / \mathrm{mL}\right)$ were preincubated with inhibitor or vehicle control (dimethylsulfoxide) and activated with indicated agents under nonstirring conditions at $37^{\circ} \mathrm{C}$. For aging experiments, platelets were stored at room temperature in sterile HEPES buffer, $\mathrm{pH} 7.45$, supplemented with $0.2 \%$ penicillin/streptomycin. For experiments performed in the absence of extracellular $\mathrm{Ca}^{2+}$, HEPES buffer was supplied with $1 \mathrm{mM}$ EGTA. Where indicated, intracellular $\mathrm{Ca}^{2+}$ was chelated by platelet treatment with $20 \mu \mathrm{M}$ dimethyl BAPTA acetoxymethyl ester. Phospholipid scrambling was measured as PS exposure by labeling in the presence of $2 \mathrm{mM} \mathrm{CaCl}_{2}$ with fluorescent annexin $\mathrm{A} 5(0.25 \mu \mathrm{g} / \mathrm{mL})$ or fluorescent lactadherin $(16 \mathrm{nM})$. Labeling was done by transferring $2 \mu \mathrm{L}$ platelet suspension into $60 \mu \mathrm{L}$ measurement buffer with $2 \mathrm{mM} \mathrm{CaCl}_{2}$. After $2 \mathrm{~min}$ of labeling, samples were analyzed with an Accuri C6 flow cytometer and Flow C6 software. Threshold forward scatter and side scatter gates were set to exclude microparticles. The range $\mathrm{M} 3$ was defined as the annexin A5 fluorescence comprising $95 \%$ of maximally activated platelets using ionomycin. The range M1 was set to include $95 \%$ of all unstimulated platelets, and M2 was the range between $\mathrm{M} 1$ and $\mathrm{M} 3$.

\section{Calcium measurements}

For measurements of $\left[\mathrm{Ca}^{2+}\right]_{i}$ by flow cytometry, washed platelets $\left(3 \times 10^{8} / \mathrm{mL}\right)$ were loaded for $45 \mathrm{~min}$ with $8 \mu \mathrm{M}$ Fluo-4 AM in the presence of $0.4 \mu \mathrm{g} / \mathrm{mL}$ pluronic F-127. Following a wash step, the platelets were resuspended in HEPES buffer, $\mathrm{pH} 7.45$, containing $2 \mathrm{mM}$ $\mathrm{CaCl}_{2}$ and activated by convulxin/thrombin $(70 \mathrm{ng} / \mathrm{mL}, 4 \mathrm{nM})$ at $2 \times 10^{6}$ platelets $/ \mathrm{mL}$.

\section{Detection of mitochondrial depolarization}

Platelets were loaded with TMRE (50 nM) for 30 min prior to stimulation for assessment of mitochondrial membrane depolarization by flow cytometry. In combination with confocal microscopy, platelets were allowed to adhere to fibrinogen-coated coverslips before stimulation with indicated agonist. Slides were precoated with $500 \mu \mathrm{g} / \mathrm{mL}$ fibrinogen for $10 \mathrm{~min}$. After stimulation with the indicated agonists, confocal images were taken with a Live-7 Zeiss line-scanning microscope system.

\section{Caspase activity assay}

Washed platelets $\left(1 \times 10^{8} / \mathrm{mL}\right)$ were preincubated and activated as indicated. At fixed time points, $100 \mu \mathrm{L}$ samples were centrifuged ( $2 \mathrm{~min}$ at $2300 \mathrm{~g}$ ), and platelet pellets were resolved into $100 \mu \mathrm{L}$ lysis buffer (caspase-3 fluorometric assay, R\&D Systems). Samples in lysis buffer were mixed 1:1 with $50 \mu \mathrm{L}$ caspase substrate mix containing $9.8 \mu \mathrm{M}$ dithiothreitol and $49 \mu \mathrm{M}$ Ac-DEVD-AFC. Fluorescence was measured in time using a Spectramax M2. Caspase-3 activity was assessed as fluorescence units per minute. 
A
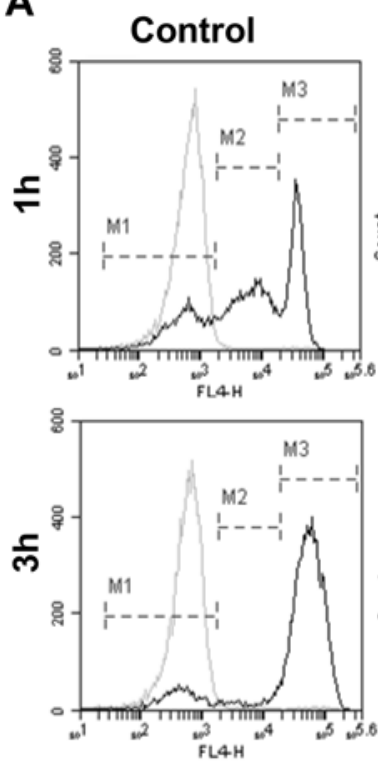
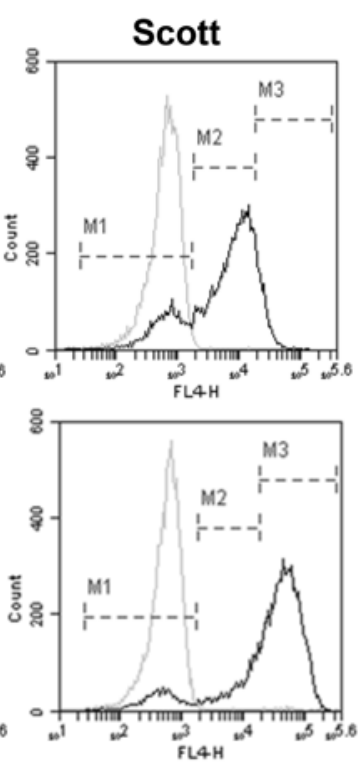

B

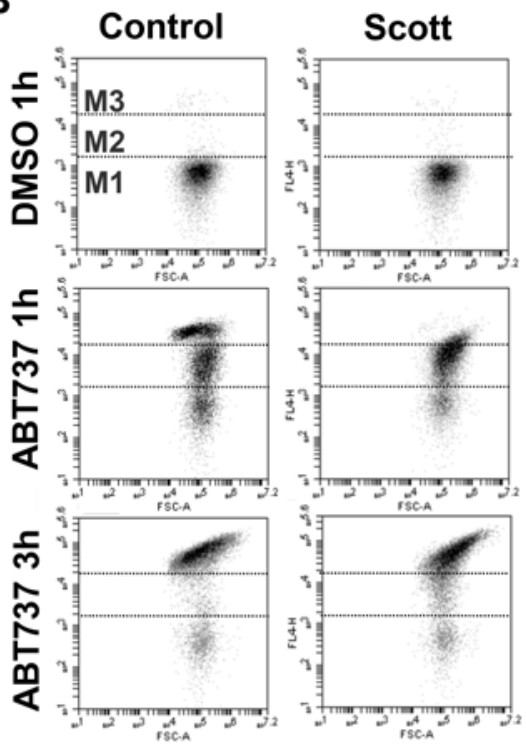

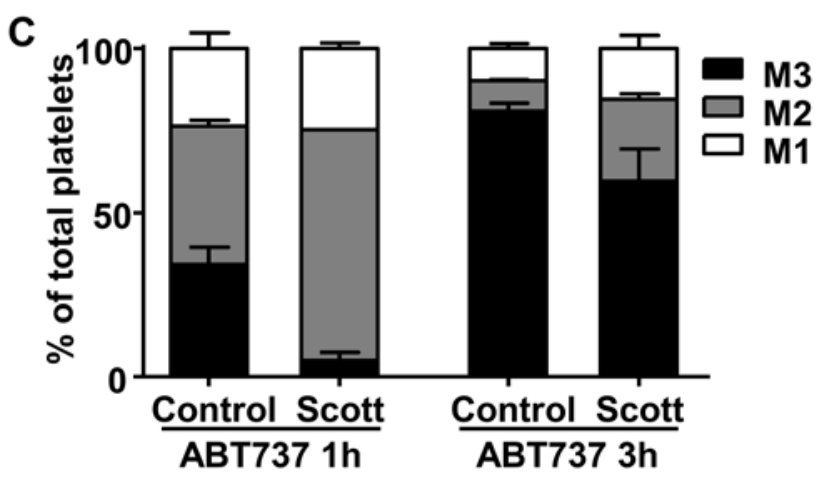

Figure 1. Proapoptotic agent ABT737 causes PS exposure in platelets from a patient with Scott syndrome. Washed platelets from healthy control subjects or a patient with Scott syndrome were treated with ABT737 (10 $\mu \mathrm{M})$ in the presence of $1 \mathrm{mM} \mathrm{CaCl}_{2}$. (a) Representative histograms (black lines) for AF647-annexin A5 binding after 1- or 3-h stimulation with ABT737. Markers M1, M2, and $\mathrm{M} 3$ indicate fractions of platelets with no, moderate, or high annexin A5 binding, respectively. Gray curves show unstimulated platelets treated with vehicle. (b) Corresponding dot plots (forward scatter vs. AF647 fluorescence) of platelets treated with ABT737 or vehicle. (c) Distribution of M1, M2, and $\mathrm{M} 3$ platelet populations upon $\mathrm{ABT737}$ treatment $(10 \mu \mathrm{M})$.

\section{Statistical analysis}

Data are presented as means \pm SEM. As appropriate, the significance of differences was determined by analysis of variance analysis with Bonferroni post-testing, paired $t$ test, or the independent samples $t$ test, using GraphPad Prism software. 


\section{Results}

BH3-mimetics induce delayed PS exposure in Scott syndrome platelets

To investigate the role of TMEM16F in apoptosis-induced PS exposure, platelets from a patient with Scott syndrome and from healthy control subjects were treated with the $\mathrm{BH} 3$ mimetic ABT737. As shown in Figure $1 \mathrm{a}$, a $1 \mathrm{~h}$ treatment with $10 \mu \mathrm{M}$ ABT737 caused $\approx 70 \%$ of the platelets to expose PS for both control and Scott platelets. However, whereas for control platelets the histogram of the annexin A5-positive fraction gave a bimodal distribution with moderate (marker region $\mathrm{M} 2$ ) and high (marker region M3) PS exposure, the Scott platelets exhibited a fraction with mainly moderate PS exposure. Similar results were found at lower concentrations of $\mathrm{ABT737}$, ranging from 3.3 to $0.33 \mu \mathrm{M}$ (supplemental Figure 1a).
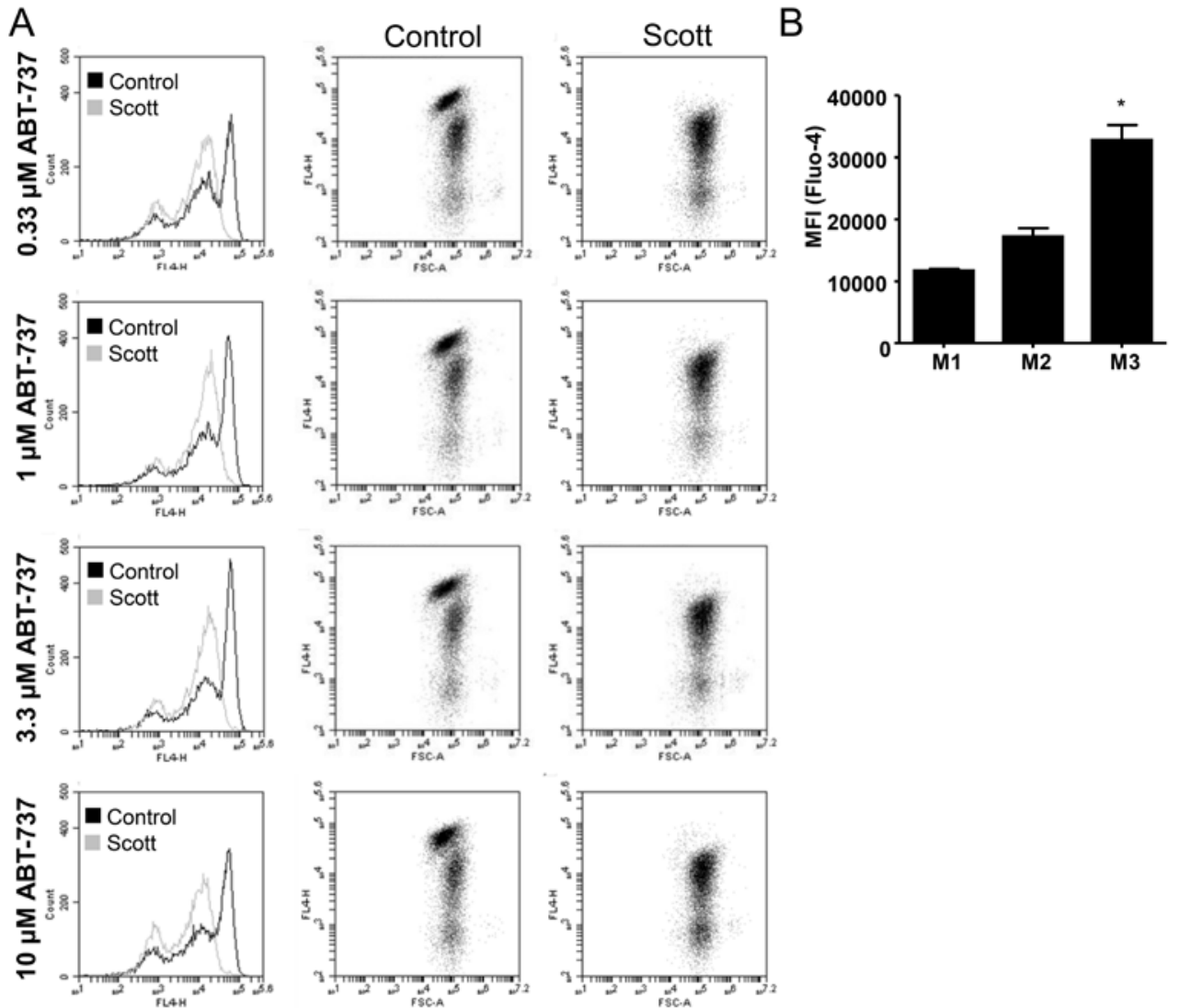

Supplemental Figure 1. Absence of high PS-exposing fraction in Scott syndrome platelets treated with ABT737 (a) Washed platelets from healthy control subjects or a patient with Scott syndrome were stimulated by ABT737 $(0.33-10 \mu \mathrm{M})$ in the presence of $1 \mathrm{mM} \mathrm{CaCl}$. Representative flow cytometry histograms and dot plots of AF647-annexin A5 binding after 1 hour stimulation with ABT737 of control (black) and Scott platelets (grey curves). (b) Fluo-4-loaded platelets were stimulated with ABT737 $(1 \mu \mathrm{M})$ for 1 hour in the presence of $1 \mathrm{mM} \mathrm{CaCl} 2$. Fluo-4 fluorescence was determined of the $M 1, M 2$ and $M 3$ fractions. Mean \pm S.E.M. $(n=4), * p<0.05$. 
Note that the extent of annexin A5 binding in the M3 fraction of the ABT737-treated control platelets was comparable with that of platelets stimulated with ionomycin or convulxin/thrombin (see below). A similar bimodal labeling pattern was found with the PSselective probe, FITC-lactadherin (data not shown). Prolonged incubation with ABT737 up to $3 \mathrm{~h}$ increased the fraction with the highest (M3) annexin $\mathrm{A} 5$ binding at the expense of the fraction with moderate (M2) annexin A5 binding for both Scott and control platelets (Figure 1a-c). Similar results were obtained with the related compound ABT263 (data not shown).

The ABT737-induced PS exposure in platelets was previously shown to be dependent on caspase proteases ${ }^{14}$. This was confirmed by the measurement of caspase activity in platelets. Comparable caspase activity was detected in Scott syndrome platelets and platelets from controls (supplemental Figure 2a), ruling out the possibility that a difference in caspase activity attributed to the observed effects. Furthermore, the pan-caspase inhibitor QVD-Oph completely abolished ABT737-induced PS exposure in both Scott syndrome and control platelets (supplemental Figure $2 b$ ). These data suggest that the proapoptotic agent ABT737 activates two mechanisms leading to PS exposure, one of which causes a gradual increase in PS exposure that is independent of TMEM16F and one resulting in high PS exposure that requires the presence of a functional TMEM16F.

Because TMEM16F is considered to be essential for $\mathrm{Ca}^{2+}$-dependent phospholipid scrambling, we questioned to what extent the scrambling process observed after ABT737 treatment is regulated by intracellular $\mathrm{Ca}^{2+}$ levels. Indeed, chelation of intracellular $\mathrm{Ca}^{2+}$ levels in platelets loaded with dm-BAPTA resulted in strong suppression of the high annexin A5-binding population, with little effect on the moderate PS-exposing fraction (Figure 2a-f).
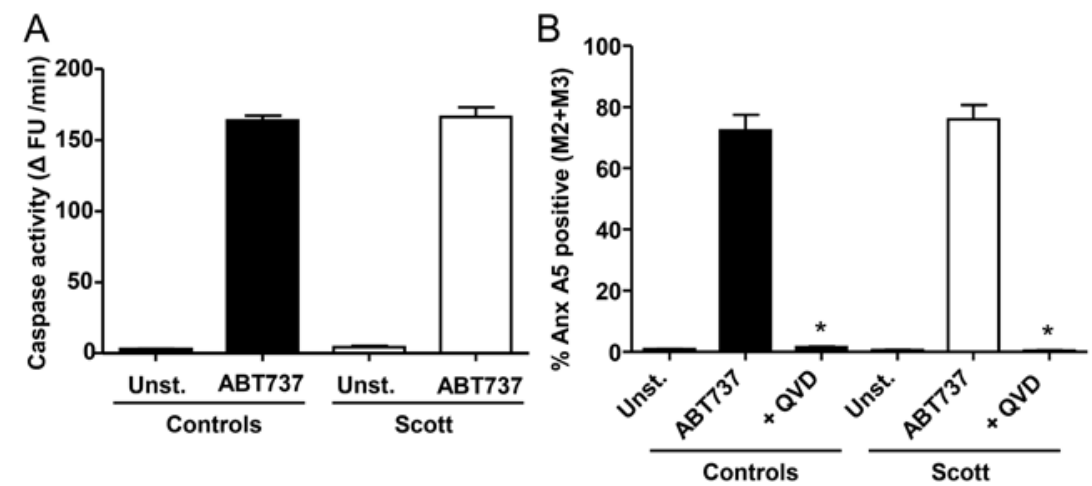

Supplemental Figure 2. ABT737-induced PS exposure in Scott syndrome platelets is caspasedependent. Washed platelets from healthy control subjects or a patient with Scott syndrome were stimulated by ABT737 $(10 \mu \mathrm{M})$ in the presence of $1 \mathrm{mM} \mathrm{CaCl}_{2}$. (a) Caspase activity after 1 hour of ABT737 treatment (arbitrary fluorescence units/min). (b) Effects of caspase inhibition (20 $\mu M$ Q-VDOph, 10 minutes) on percentage of annexin A5-positive platelets (M2 plus M3 fractions). Mean \pm S.E.M. $(n=3), * p<0.05$. 
A

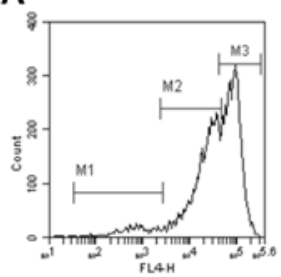

E

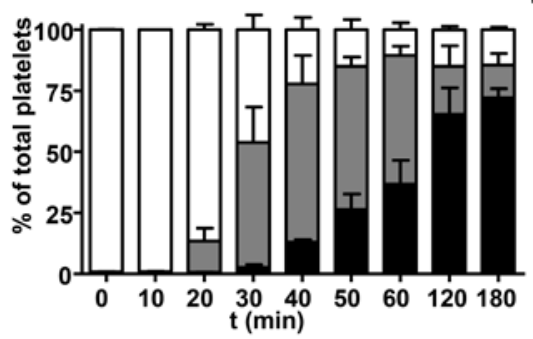

G

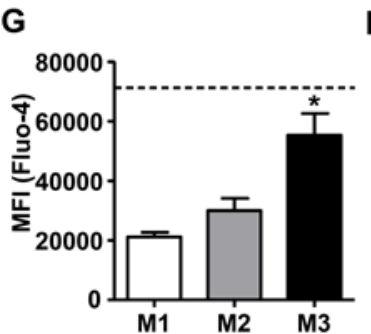

B

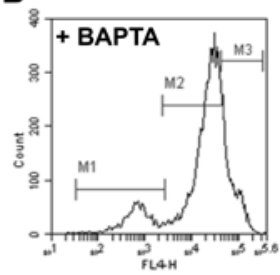

$\mathrm{H}$
C.

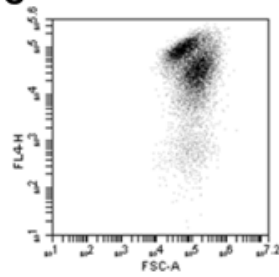

D

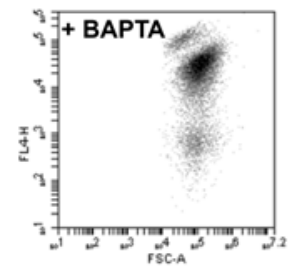

$\mathbf{F}$
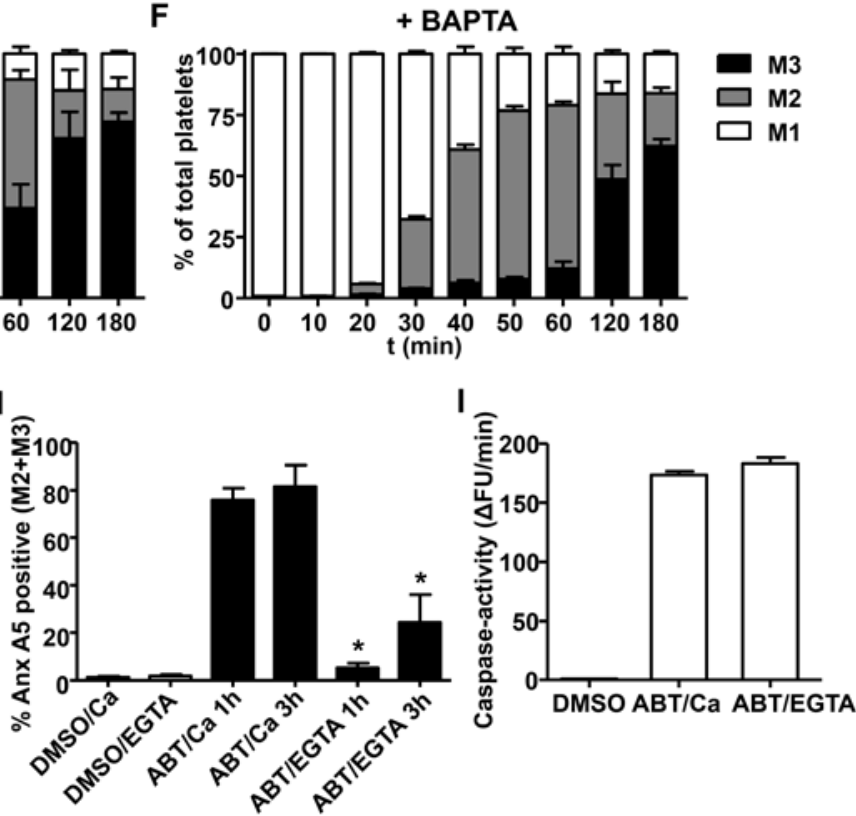

Figure 2. High PS exposure induced by $A B T 737$ depends on elevated intracellular $\mathrm{Ca}^{2+}$. (a-f) Washed platelets were stimulated by $10 \mu \mathrm{M} \mathrm{ABT737}$ in the absence of $\mathrm{CaCl}_{2}$ or after loading with dimethyl-BAPTA (+ BAPTA) in the presence of $2 \mathrm{mM} \mathrm{CaCl}_{2}$. Representative flow cytometry histograms (a-b) and dot plots (c-d) of AF647-annexin (Anx) A5 binding after $1 \mathrm{~h}$ treatment with ABT737. Markers M1, M2, and M3 indicate fractions of platelets with no, moderate, or high Anx A5 binding, respectively. (e-f) Distribution of platelet populations over $M 1, M 2$, and $M 3$ during treatment in time. (g) Platelets were loaded with the intracellular $\mathrm{Ca}^{2+}$ probe Fluo-4 and stimulated with ABT737 $(10 \mu \mathrm{M}, 1 \mathrm{~h})$ in the presence of $1 \mathrm{mM} \mathrm{CaCl} 2$. Fluo-4 fluorescence was determined for the $\mathrm{M} 1, \mathrm{M} 2$, and $\mathrm{M} 3$ fractions. Dotted line represents maximal Fluo-4 fluorescence obtained with $10 \mu \mathrm{M}$ ionomycin as positive control. (h) Annexin A5 binding of platelets stimulated by ABT737 in the presence of $1 \mathrm{mM} \mathrm{CaCl} 2$ or $1 \mathrm{mM}$ EGTA after 1 to $3 \mathrm{~h}$. (i) Caspase activity (arbitrary fluorescence units $/ \mathrm{min}$ ) of ABT737-stimulated platelets in the presence of $1 \mathrm{mM} \mathrm{CaCl} 2$ or $1 \mathrm{mM} \mathrm{EGTA}$. Mean \pm $\operatorname{SEM}(n=3-6) ;{ }^{*} p<0.05$. 
Furthermore, Fluo-4 measurements revealed that the high annexin A5-binding fraction had increased $\mathrm{Ca}^{2+}$ levels compared to the moderate PS-exposing fractions (Figure $2 \mathrm{~g}$ ). However, chelation of extracellular $\mathrm{Ca}^{2+}$ by $1 \mathrm{mM}$ EGTA resulted in a significant suppression of ABT737-induced PS exposure in both the moderate and high annexin A5-binding populations (Figure $2 \mathrm{~h}$ ). The defective PS exposure in the presence of EGTA was not due to a reduction in caspase activity (Figure $2 \mathrm{i})$. Further experiments with aspirin $(100 \mu \mathrm{M}), \mathrm{P}^{2} \mathrm{Y}_{1}$ blocker MRS-2179 $(50 \mu \mathrm{M})$, and $\mathrm{P}_{2 \mathrm{Y}_{12}}$ blocker cangrelor $(10 \mu \mathrm{M})$ indicated that the fractions of moderate and high annexin A5-binding platelets changed with $<2 \%$ by blocking of the secondary mediator release.

Normal PS exposure in Scott syndrome platelets during prolonged storage

A gradual increase in surface-exposed PS can be observed in platelets that are stored for a prolonged time (C.S., unpublished data, 2012). To determine whether Scott syndrome platelets possess a similar mechanism to expose PS under aging conditions, Scott and control platelets were stored up to 4 days at room temperature. As shown in Figure 3 , the patient's platelets were equally able to expose PS upon storage as controls, indicating that in vitro aging-related PS exposure occurs independently of TMEM16F activity.

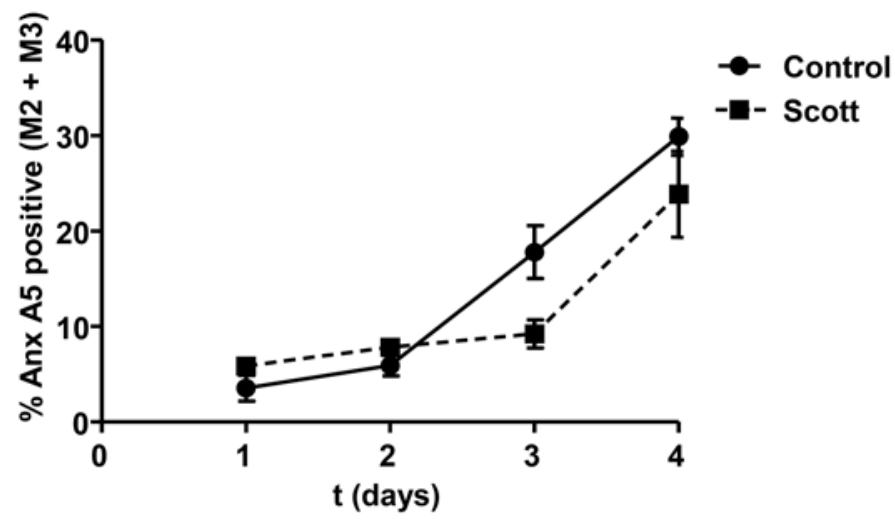

Figure 3. Prolonged storage causes PS exposure in Scott syndrome platelets. Percentage of annexin (Anx) A5-positive platelets (M2 and M3 fractions) from healthy controls and Scott patient during 1 day to 4 days storage at room temperature in sterile buffer medium. Mean $\pm \operatorname{SEM}(n=3)$.

Convulxin-/thrombin-stimulated Scott platelets do not expose PS despite normal cyclophilin $D$-mediated mitochondrial depolarization and intracellular $\mathrm{Ca}^{2+}$ response

Mitochondrial depolarization through cyclophilin D-dependent formation of the MPTP has been shown to be crucial for convulxin-/thrombin-induced PS exposure in platelets ${ }^{9}$. Involvement of cyclophilin D-mediated mitochondrial depolarization was assessed by measuring TMRE fluorescence and by investigating the effect of the MPTP inhibitor cyclosporin A. Stimulation of Scott syndrome platelets by convulxin/thrombin did not cause significant PS exposure (Figure 4a), whereas in healthy controls, $40 \%$ of the platelets became annexin A5 positive. This response was almost completely suppressed by cyclosporin A. The lack of PS exposure in convulxin-/thrombin-stimulated Scott platelets was not due 
to the absence of mitochondrial depolarization, as demonstrated by flow cytometry (Figure 4b). The loss of TMRE from mitochondria in Scott platelets stimulated with convulxin/thrombin was confirmed by confocal microscopy (Figure $4 \mathrm{e}-\mathrm{f})$. No differences in intracellular $\mathrm{Ca}^{2+}$ levels were found between Scott syndrome platelets and healthy controls after convulxin/thrombin stimulation (Figure $5 a-c$ ), which is in line with previous results showing normal store-operated $\mathrm{Ca}^{2+}$ entry with such agonists ${ }^{11}$.

Analysis of the flow cytometry histograms revealed a marked difference between ABT737 and convulxin/thrombin stimulation. Whereas ABT737 treatment resulted in 2 populations of platelets with moderate and high PS exposure, after convulxin/thrombin stimulation, even at early time points, only high PS-exposing platelets residing in marker region M3 were found (Figure 4c-d). Because this response was virtually absent in Scott platelets, we concluded that convulxin-/thrombin-induced PS exposure depends on a functional TMEM16F.

A

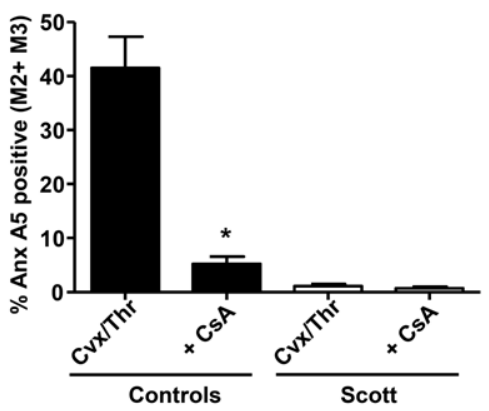

B

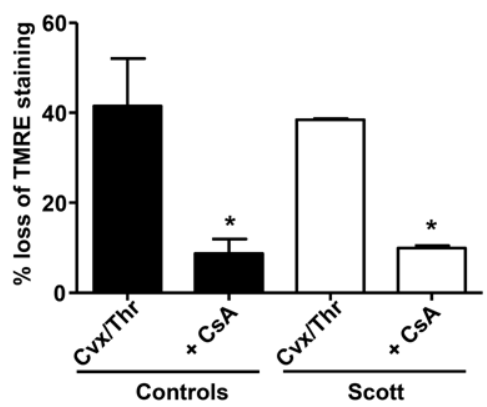

C

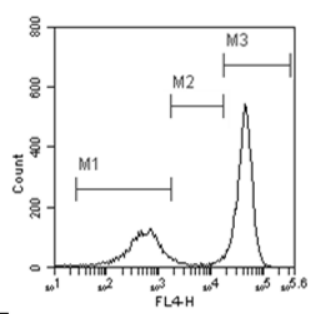

E
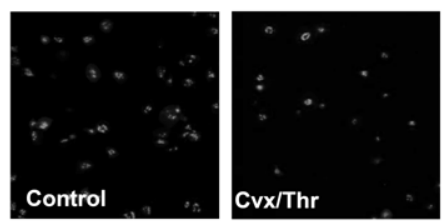

$\mathbf{F}$

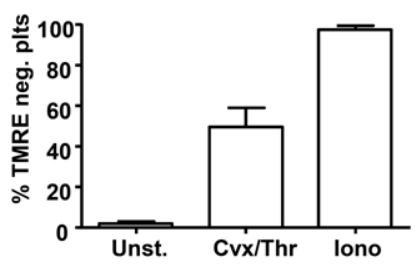

Figure 4. Cvx/Thr-induced PS exposure is absent in Scott syndrome platelets despite normal cyclophilin D-dependent mitochondrial depolarization. (a-d) Platelets from healthy controls or a Scott patient were loaded with TMRE and preincubated with vehicle (dimethylsulfoxide) or cyclosporin $\mathrm{A}$ (CsA) $(4 \mu \mathrm{M})$ for 10 min prior to stimulation by $\mathrm{Cvx} / \mathrm{Thr}(70 \mathrm{ng} / \mathrm{mL}, 4 \mathrm{nM}$, for $15 \mathrm{~min})$ in the presence of $2 \mathrm{mM} \mathrm{CaCl}_{2}$. Graphs show annexin (Anx) A5 binding (a) and loss of TMRE (b) of washed control and Scott syndrome platelets. (c-d) Representative histogram and bar graph showing the distribution of $\mathrm{Cvx} / \mathrm{Thr}$-stimulated control platelets ( $15 \mathrm{~min}$ ) over the fractions $\mathrm{M} 1, \mathrm{M} 2$, and $\mathrm{M} 3$. (e-f) TMRE-loaded Scott platelets adhered to fibrinogen $(10 \mathrm{~min}$ ) were stimulated with $\mathrm{Cvx} / \mathrm{Thr}$ (70 $\mathrm{ng} / \mathrm{mL}, 4 \mathrm{nM})$ or ionomycin $(10 \mu \mathrm{M})$ in the presence of $2 \mathrm{mM} \mathrm{CaCl}_{2}$. (e) Representative images after 15 min stimulation, (f) The percentage of TMRE-negative platelets. Mean \pm SEM $(n=3-6) ;{ }^{*} P<0.05$. 

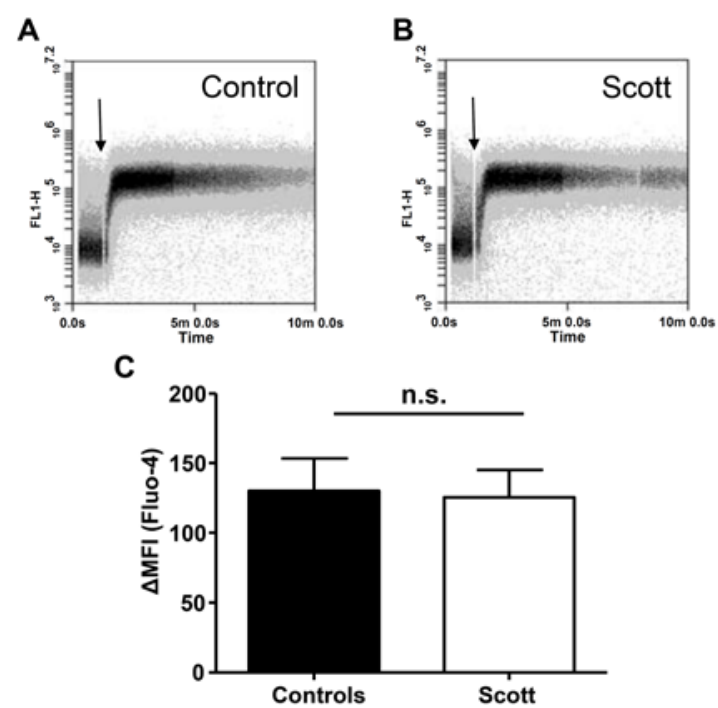

Figure 5. Scott syndrome platelets display normal convulxin (Cvx)/thrombin (Thr)-induced $\mathrm{Ca}^{2+}$ responses. (a-b) Time drive of fluorescence increase of washed control (a) and Scott syndrome (b) platelets loaded with Fluo- 4 and activated by $C v x / T h r(70 \mathrm{ng} / \mathrm{mL}, 4 \mathrm{nM})$ in the presence of $2 \mathrm{mM}$ $\mathrm{CaCl}_{2}$. (c) Average change in mean fluorescence intensity (MFI), representing cytosolic $\mathrm{Ca}^{2+}$, after 10 min stimulation. n.s., not significant.

Collagen/thrombin stimulation induces an additional pathway to platelet PS exposure, which is independent of caspases, cyclophilin D, or TMEM16F

In previous studies, it was found that collagen-/thrombin-induced PS exposure is only partially impaired in platelets from patients with Scott syndrome ${ }^{10,11}$. We questioned whether the residual PS exposure observed after collagen/thrombin stimulation in Scott platelets results from activation of the apoptotic pathway. Figure 6a shows that caspase inhibition by Q-VD-Oph did not affect the fraction of PS-exposing platelets induced by collagen/thrombin in either Scott platelets or healthy control platelets, indicating no appreciable contribution of the apoptotic pathway in collagen/thrombin-induced PS exposure.

We then asked whether the residual PS-exposing activity is cyclophilin D-mediated. The collagen/thrombin-induced PS exposure in Scott syndrome appeared insensitive to inhibition with cyclosporin $A$, whereas this compound effectively reduced mitochondrial depolarization (Figure 6a-b). Treatment of control platelets resulted in a reduction of collagen/thrombin-induced PS exposure from $53 \%$ to $19 \%$ and a correspondingly reduced mitochondrial depolarization. These data suggest that collagen/thrombin activates 2 different pathways leading to PS exposure, one that requires MPTP formation and is dependent on TMEM16F and one that does not involve MPTP and functions independently of TMEM16F. Control studies showed that both collagen/thrombin- and convulxin/thrombin-induced PS exposure are entirely dependent on intracellular $\mathrm{Ca}^{2+}$, as platelet treatment with dm-BAPTA virtually abolished PS exposure (<4\% PS-positive platelets). 

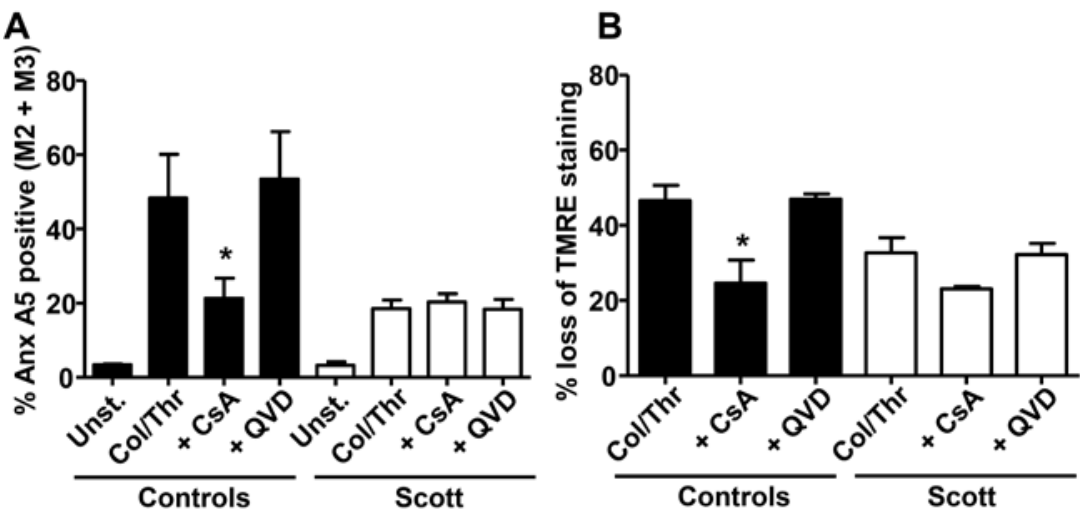

Figure 6. Residual collagen/thrombin-induced PS exposure in Scott syndrome platelets is insensitive to Q-VD-Oph or cyclosporin A (CSA). Annexin (Anx) A5 binding (a) and TMRE loss (b) of washed control and Scott syndrome platelets stimulated by collagen (Col)/thrombin (Thr) $(10 \mu \mathrm{g} / \mathrm{mL}, 4 \mathrm{nM})$ for $15 \mathrm{~min}$ in the presence of $2 \mathrm{mM} \mathrm{CaCl}_{2}$ preincubated with vehicle (dimethylsulfoxide), Q-VD-Oph $(20 \mu \mathrm{M})$, or CsA $(4 \mu \mathrm{M})$ for $10 \mathrm{~min}$. Mean \pm SEM $(n=3-6) ;{ }^{*} p<0.05$.

\section{Discussion}

In this study, we show that Scott syndrome platelets have retained the capacity to expose PS upon ABT737-induced apoptosis. Remarkably, though, Scott syndrome platelets show only moderate levels of annexin A5 binding after $1 \mathrm{~h}$ of ABT737 treatment, whereas healthy controls have an additional platelet fraction with high annexin A5 binding despite the fact that the total fraction of annexin-positive platelets is virtually the same for the patient and healthy controls. This argues for a partial role of TMEM16F in apoptotic PS exposure. Because TMEM16F is reported to be crucial for $\mathrm{Ca}^{2+}$-induced phospholipid scrambling ${ }^{12}$ and the fraction of high annexin A5-binding platelets correlates with platelets high in intracellular $\mathrm{Ca}^{2+}$, we propose that next to a TMEM16F-independent mechanism, a TMEM16F-dependent mechanism is activated during platelet apoptosis, which accelerates the appearance of PS-exposing platelets. The high annexin A5-binding population was effectively suppressed by chelation of intracellular $\mathrm{Ca}^{2+}$, which is in concordance with TMEM16F being a Ca ${ }^{2+}$-dependent scramblase ${ }^{12}$. Interestingly, the onset of the TMEM16F-dependent scrambling process (Figure 2e, platelets in the region M3) appears to be delayed compared with the initiation of the TMEM16F-independent scrambling (region $\mathrm{M} 2$ ). Because the apoptotic process compromises $\mathrm{Ca}^{2+}$ homeostasis 23,24 , it is not unlikely that a certain time span of increased cytosolic $\mathrm{Ca}^{2+}$ concentration is required to activate the TMEM16F-dependent scrambling mechanism. We do not know whether the actual rates of phospholipid scrambling differ between $M 3$ and $M 2$ platelets. It is tempting to speculate that the scrambling process in the M3 platelets is similar to that of ionomycin-induced scrambling, although it should be noted that apoptosis-induced PS exposure is caspase dependent, whereas ionomycin-induced PS exposure is not. Previously, induction of apoptosis in Scott syndrome lymphoid cells resulted in phospholipid scrambling similar to that in control lymphoid cells ${ }^{25}$. In that study, the rate of lipid scrambling did not increase when apoptotic control B-lymphocytes were treated with $\mathrm{Ca}^{2+}$ 
ionophore, suggesting different pathways leading to lipid scrambling rather than the existence of more than one scramblase protein.

Although the role of high cytosolic $\mathrm{Ca}^{2+}$ in agonist-induced PS exposure is well recognized ${ }^{1}$, it is unclear how $\mathrm{Ca}^{2+}$ affects phospholipid scrambling in apoptotic cells. In this paper, we show an inhibitory effect of chelating extracellular $\mathrm{Ca}^{2+}$ on ABT737-induced PS exposure. The lack of response upon removal of extracellular $\mathrm{Ca}^{2+}$ cannot be explained by decreased activity of the apoptotic machinery itself, as caspase activity is not affected by removal of extracellular $\mathrm{Ca}^{2+}$. Previously, Schoenwaelder et al ${ }^{14}$ have shown that ABT737-induced filamin and gelsolin cleavage was not affected by chelation of extracellular $\mathrm{Ca}^{2+}$. Our data indicate that, while the high PS-exposing platelet fraction $\mathrm{M} 3$ is absent upon chelation of intracellular $\mathrm{Ca}^{2+}$, the moderate PS-exposing fraction $\mathrm{M} 2$ also has a $\mathrm{Ca}^{2+}$-sensitive component. At present, we cannot distinguish whether this $\mathrm{Ca}^{2+}$ dependency is located at the level of signaling events downstream of caspase activity or at the level of the scramblase activity.

The most pronounced defect in Scott syndrome platelets was found upon activation with convulxin/thrombin; whereas these agonists induced $\approx 40 \%$ PS-positive platelets in healthy control platelets, PS exposure was virtually absent in the patient's platelets. However, $\mathrm{Ca}^{2+}$ responses and mitochondrial depolarization were not affected in the patient's platelets, indicating that the defect is downstream of $\mathrm{Ca}^{2+}$ signaling and MPTP formation. This finding is supported by a report showing that mitochondrial depolarization is normal in a canine model of impaired phospholipid scrambling ${ }^{26}$. Inhibition of MPTP formation by cyclosporin A almost completely abrogated agonist-induced PS exposure in healthy control platelets (Figure 4a), in line with observations by Jobe et al ${ }^{9}$. Together, these data suggest that MPTP formation is required but not sufficient for agonist-induced platelet PS exposure via TMEM16F.

PS exposure induced by collagen/thrombin was only partially impaired in Scott syndrome platelets, confirming previous observations ${ }^{11,27}$. The residual PS exposure typically was insensitive to inhibition by cyclosporin A (MPTP formation) or inhibition of caspases. In platelets from healthy controls, cyclosporin A was unable to completely suppress collagen/thrombin-induced PS exposure. Earlier, Dasgupta and colleagues ${ }^{28}$ reported a partial impairment in collagen/thrombin-induced PS exposure of cyclophilin D-deficient murine platelets. Taken together, these data suggest that 2 distinct pathways to PS exposure become activated by combined collagen/thrombin stimulation: a pathway sensitive to cyclosporin A inhibition and dependent on TMEM16F, and another pathway, which is cyclosporin A insensitive and operational in the absence of TMEM16F. This may explain the complete deficiency of PS exposure in Scott syndrome platelets activated by convulxin/thrombin, as the latter is more dependent on MPTP formation ${ }^{9}$. The difference in PS exposure between stimulation with collagen/thrombin and convulxin/thrombin is interesting, because both collagen and convulxin are well-recognized GPVI agonists ${ }^{21}$. We emphasize, however, that this difference has been repeatedly observed on different occasions. The distinct effects observed with collagen, compared with convulxin, may indicate the involvement of platelet collagen receptors other than GPVI (e.g. integrin $\alpha_{2} \beta_{1}$, GPIb via von Willebrand factor) in collagen/thrombin-induced PS exposure ${ }^{29}$. 
Acknowledging the inherent limitations of in vitro experimentation, this study demonstrates that TMEM16F-dependent and -independent phospholipid scrambling can be induced in platelets upon apoptosis, aging, and activation. However, it is still unclear whether TMEM16F by itself can act as a phospholipid scramblase or whether this protein has a regulatory function. If TMEM16F proves to be a scramblase itself, this will imply the existence of at least one additional and perhaps more proteins with scramblase activity in platelets. The identification of novel proteins with scramblase activity or the identification of novel regulators of scramblase activity will create new opportunities for interfering with phospholipid scrambling, with consequences for platelet procoagulant activity, life span, and storage.

\section{Acknowledgments}

This work was supported by the Cardiovascular Centre, Maastricht, the Center for Translational Molecular Medicine INCOAG, and the Landsteiner Foundation for Blood Transfusion Research (1006).

\section{Declaration of interest statement:}

The authors declare that no conflicts of interest exist.

\section{References}

1. Bevers EM, Williamson PL. Phospholipid scramblase: an update. FEBS Lett. 2010;584(13):2724-2730.

2. Fadok VA, Voelker DR, Campbell PA, Cohen JJ, Bratton DL, Henson PM. Exposure of phosphatidylserine on the surface of apoptotic lymphocytes triggers specific recognition and removal by macrophages. J Immunol. 1992;148:2207-2216.

3. Heemskerk JW, Bevers EM, Lindhout T. Platelet activation and blood coagulation. Thromb Haemost. 2002;88:186-193.

4. Lentz BR. Exposure of platelet membrane phosphatidylserine regulates blood coagulation. Prog Lipid Res. 2003;42:423-438.

5. Heemskerk JW, Kuijpers MJ, Munnix IC, Siljander PR. Platelet collagen receptors and coagulation. A characteristic platelet response as possible target for antithrombotic treatment. Trends Cardiovasc Med. 2005;15:86-92.

6. Rosing J, van Rijn JL, Bevers EM, van Dieijen G, Comfurius P, Zwaal RF. The role of activated human platelets in prothrombin and factor $X$ activation. Blood. 1985;65:319-332.

7. Arachiche A, Kerbiriou-Nabias D, Garcin I, Letellier T, Dachary-Prigent J. Rapid procoagulant phosphatidylserine exposure relies on high cytosolic calcium rather than on mitochondrial depolarization. Arterioscler Thromb Vasc Biol. 2009;29:1883-1889.

8. Dale GL, Friese P. Bax activators potentiate coated-platelet formation. J Thromb Haemost. 2006;4:2664-2669.

9. Jobe SM, Wilson KM, Leo L, et al. Critical role for the mitochondrial permeability transition pore and cyclophilin D in platelet activation and thrombosis. Blood. 2008;111:1257-1265.

10. Zwaal RF, Comfurius P, Bevers EM. Scott syndrome, a bleeding disorder caused by defective scrambling of membrane phospholipids. Biochim Biophys Acta. 2004;1636:119-128.

11. Munnix IC, Harmsma M, Giddings JC, et al. Store-mediated calcium entry in the regulation of phosphatidylserine exposure in blood cells from Scott patients. Thromb Haemost. 2003;89:687-695.

12. Suzuki J, Umeda M, Sims PJ, Nagata S. Calcium-dependent phospholipid scrambling by TMEM16F. Nature. 2010;468:834-838.

13. Castoldi E, Collins PW, Williamson PL, Bevers EM. Compound heterozygosity for 2 novel TMEM16F mutations in a patient with Scott syndrome. Blood. 2011;117:4399-4400. 
14. Schoenwaelder SM, Yuan Y, Josefsson EC, et al. Two distinct pathways regulate platelet phosphatidylserine exposure and procoagulant function. Blood. 2009;114:663-666.

15. Zhang $\mathrm{H}$, Nimmer PM, Tahir SK, et al. Bcl-2 family proteins are essential for platelet survival. Cell Death Differ. 2007;14:943-951.

16. Kile BT. The role of the intrinsic apoptosis pathway in platelet life and death. J Thromb Haemost. 2009;7 Suppl 1214-217.

17. Kodama T, Takehara T, Hikita $\mathrm{H}$, et al. BH3-only activator proteins Bid and Bim are dispensable for Bak/Bax-dependent thrombocyte apoptosis induced by Bcl- $x_{L}$ deficiency: molecular requisites for the mitochondrial pathway to apoptosis in platelets. J Biol Chem. 2011;286:13905-13913.

18. Mason KD, Carpinelli MR, Fletcher Jl, et al. Programmed anuclear cell death delimits platelet life span. Cell. 2007;128:1173-1186.

19. Schoenwaelder SM, Jarman KE, Gardiner $\mathrm{EE}$, et al. Bcl- $\mathrm{x}_{\mathrm{L}}$-inhibitory BH3 mimetics can induce a transient thrombocytopathy that undermines the hemostatic function of platelets. Blood. 2011;118:16631674.

20. Vogler $\mathrm{M}$, Hamali $\mathrm{HA}$, Sun $\mathrm{XM}$, et al. $\mathrm{Bcl} / 2 / \mathrm{Bcl}-\mathrm{x}_{\mathrm{L}}$ inhibition induces apoptosis, disrupts cellular calcium homeostasis, and prevents platelet activation. Blood. 2011;117:7145-7154.

21. Siljander P, Farndale RW, Feijge MA, et al. Platelet adhesion enhances the glycoprotein VI-dependent procoagulant response: Involvement of p38 MAP kinase and calpain. Arterioscler Thromb Vasc Biol. 2001;21:618-627.

22. van der Meijden PE, Feijge MA, Giesen PL, Huijberts M, van Raak LP, Heemskerk JW. Platelet P2Y 12 receptors enhance signalling towards procoagulant activity and thrombin generation. A study with healthy subjects and patients at thrombotic risk. Thromb Haemost. 2005;93:1128-1136.

23. Jackson SP, Schoenwaelder SM. Procoagulant platelets: are they necrotic? Blood. 2010;116:20112018.

24. Zong WX, Thompson CB. Necrotic death as a cell fate. Genes Dev. 2006;20:1-15.

25. Williamson $P$, Christie $A$, Kohlin $T$, et al. Phospholipid scramblase activation pathways in lymphocytes. Biochemistry. 2001;40:8065-8072.

26. Brooks MB, Catalfamo JL, Friese P, Dale GL. Scott syndrome dogs have impaired coated-platelet formation and calcein release but normal mitochondrial depolarization. J Thromb Haemost. 2007;5:1972-1974.

27. Rosing J, Bevers EM, Comfurius $P$, et al. Impaired factor $X$ and prothrombin activation associated with decreased phospholipid exposure in platelets from a patient with a bleeding disorder. Blood. 1985;65:1557-1561.

28. Dasgupta SK, Argaiz ER, Mercado JE, et al. Platelet senescence and phosphatidylserine exposure. Transfusion. 2010;50:2167-2175.

29. Nieswandt B, Watson SP. Platelet-collagen interaction: is GPVI the central receptor? Blood. 2003;102:449-461. 

Chapter 6

Role of murine TMEM16F in agonist- and apoptosisinduced phospholipid scrambling in platelets and erythrocytes

van Kruchten R, Mattheij NJ, Braun A, Baaten C, van der Meijden PEJ, Ehlen HWA, Vortkamp A, Schreiber R, Ousingsawat J, Bevers EM, Cosemans JMEM, Kunzelmann K, Nieswandt B, Heemskerk JWM.

Submitted 


\begin{abstract}
Calcium-induced phospholipid scrambling facilitates the platelet procoagulant response by mediating phosphatidylserine (PS) exposure in the outer leaflet of the plasma membrane. The membrane protein TMEM16F, deficient in Scott syndrome patients, has been shown to be critically involved in this process. To study its role in platelet and erythrocyte function, we used TMEM16F deficient mice, obtained in different ways. When generated via the AW-0382 stem cells clone, Tmem $16 f^{\prime-}$ embryos died before birth, with some showing major bleedings; when generated via the PAC-379 clone, several Tmem16f $f^{/-}$mice could be obtained to study blood cells. Upon stimulation with ionomycin or convulxin/thrombin, PS exposure was severely impaired in $\mathrm{Tmem}_{16} \mathrm{f}^{/-}$but not in $\mathrm{Tmem}^{16 \mathrm{f}^{+/}}$platelets. Integrin activation and P-selectin expression were unaltered in all genotypes. Upon stimulation with the pro-apoptotic agent ABT-737, PS exposure was similar in all platelets, but Tmem $16 f^{1-}$ platelets failed to show a population with high annexin A5 binding. Markedly, Tmem $16 f^{/-}$erythrocytes were strongly and Tmem $16 f^{+-}$erythrocytes were moderately impaired in ionomycin-induced PS exposure. Together, this indicates a role for TMEM16F in mouse development and $\mathrm{Ca}^{2+}$-induced scrambling of phospholipids in both platelets and erythrocytes.
\end{abstract}

\title{
Introduction
}

In resting platelets and erythrocytes, as in most eukaryotic cells, the membrane phosphoipids are asymmetrically distributed over the two leaflets of the plasma membrane. The amino-phospholipids, phosphatidylserine (PS) and phosphatidylethanolamine (PE) are mainly found in the inner leaflet, while the choline-containing phospholipids, phosphatidylcholine and sphingomyelin, are accumulated in the outer half of the plasma membrane. This asymmetric distribution, maintained by an active amino-phospholipid translocase, is abolished by activation or damage of these blood cells. Responsible for the loss in membrane asymmetry is a so-called phospholipid scramblase, which facilitates rapid transbilayer movement of phospholipids between the two membrane leaflets ${ }^{1}$. The scrambling mechanism can be activated by high cytosolic $\mathrm{Ca}^{2+}$ levels or by the process of apoptosis. Recently, a critical role was reported for the transmembrane protein, TMEM16F (also known as anoctamin 6), in the $\mathrm{Ca}^{2+}$-dependent scrambling of platelet phospholipids ${ }^{2}$. A mutant form of TMEM16F with reduced $\mathrm{Ca}^{2+}$ sensitivity supported phospholipid scrambling even at low levels of intracellular $\mathrm{Ca}^{2+}$. Furthermore, deleterious mutations in the TMEM16F gene were found in two unrelated patients with Scott syndrome, whose platelets and erythrocytes are deficient in $\mathrm{Ca}^{2+}$-dependent phospholipid scrambling ${ }^{2,3}$. The Scott syndrome is a rare bleeding disorder, characterized by a decreased ability of platelets to enhance the coagulation process.

Recently, we have reported that platelets from Scott patients are markedly deficient in phospholipid scrambling and PS exposure after stimulation with the $\mathrm{Ca}^{2+}$-ionophore ionomycin or after activating the collagen and thrombin receptors with the combination of convulxin and thrombin ${ }^{4}$. Interestingly, the Scott syndrome platelets showed only a small impairment in phospholipid scrambling upon treatment with the pro-apoptotic agent, ABT-737, which inhibits the anti-apoptotic action of Bcl-proteins in platelets. This indicates that different mechanisms are involved in phospholipid scrambling upon $\mathrm{Ca}^{2+}$-dependent 
platelet activation and $\left(\mathrm{Ca}^{2+}\right.$-independent) apoptosis ${ }^{4,5}$. Given the rare incidence of patients with Scott syndrome, it is important to extend these observations also to platelets and other blood cells from TMEM16F-deficient mice.

Besides its role in phospholipid scrambling, TMEM16F is proposed to be involved in mediating chloride and cation currents ${ }^{6-9}$. In this preliminary report, we have begun to study the function of TMEM16F in mouse platelets. Experiments were performed with animals from two genetic strains, generated to cause TMEM16F deficiency. We present the observation of differential lethality in the two strains, and assessed the capacity of Tmem16f $f^{-}$ and $\mathrm{Tmem}_{16 \mathrm{f}^{+/-}}$platelets and erythrocytes to express PS after stimulation with $\mathrm{Ca}^{2+}$ elevating and apoptotic agonists.

\section{Material and methods}

\section{Materials}

ABT-737 was obtained from Santa Cruz Biotechnology, annexin A5 labeled with fluorescein isothiocyanate (FITC) was obtained from PharmaTarget. Alexa Fluor-647 (AF647)labeled annexin A5 and ionomycin were purchased from Invitrogen. The glycoprotein $\mathrm{VI}$ (GPVI) agonist convulxin was purified as described ${ }^{10}$. FITC-labeled anti-mouse P-selectin (CD62P) monoclonal antibody (mAb) as well as phycoerythrin (PE)-conjugated JON/A mAb directed against the active conformation of mouse integrin $\alpha_{111} \beta_{3}$, were from Emfret Analytics. Human $\alpha$-thrombin was from Sigma-Aldrich.

\section{Mice}

Animal experiments with mice were approved by the local animal care and use committees. One strain of $\mathrm{Tmem}_{16 f^{+-}}$and Tmem $16 \mathrm{f}^{/-}$mice (C57BL/6 background) was generated using the PAC-379 embryonic stem cell line, as described ${ }^{11}$. Genotyping for heterozygous or homozygous deficiency in TMEM16F expression was performed by PCR, as before ${ }^{11}$.

In addition, an AW-0382 stem cell clone was used to generate mice with deficiency in TMEM16F. This clone contains a splice-acceptor sequence upstream of a $\beta$-geo (fusion of $\beta$-galactosidase and neomycin phosphotransferase II) reporter gene cassette, which is targeted against intron 3 of TMEM16F. Male C57BL/ 6 mouse chimeras derived from this embryonic stem cell line were bred to C57BL/ 6 females to generate heterozygous Tmem $16 f^{+-}$mice. These mice were then cross-bred with the aim to obtain homozygously deficient animals.

Mice containing megakaryocytes and platelets homozygously deficient in TMEM16A (anoctamin 1) were generated by crossing $T m e m 16 a^{\mathrm{fl} / \mathrm{fl}}$ mice with transgenic mice expressing a Cre-recombinase after the PF4 promoter (C57BL/6 background). Nucleotide primers used for genotyping TMEM16A wildtype (229 bp, 2165 bp in flox): GCAGAAAAGT GCCAGAGACC (forward), TTTCCAATGG CCTAGACCTG (reverse); for TMEM16A (462 bp) in flox: ATAGCAGCTT TGCTCCTTCG (forward), CTCGTCCTGC AGTTCATTCA.

\section{Embryonic development}

After breeding $\mathrm{Tmem} 16 \mathrm{f}^{+-}$mice, pregnant female mice were sacrificed at gestational days 10,12 and 16 . Viable embryos and dead bodies were counted, and embryos were checked for macroscopic abnormalities. 
Blood collection and isolation of platelets and erythrocytes

Blood was obtained from mice $>12$ weeks old via orbital puncture under anesthesia. The blood was collected into 1/6 volume of acid-citrate-dextrose anticoagulant (ACD: $85 \mathrm{mM}$ sodium citrate, $78 \mathrm{mM}$ citric acid, and $11 \mathrm{mM}$ D-glucose). Platelets and erythrocytes were separated by centrifugation, washed, and then suspended in Hepes buffer pH 7.45 (136 $\mathrm{mM} \mathrm{NaCl}, 5 \mathrm{mM}$ Hepes, $2.7 \mathrm{mM} \mathrm{KCl}, 2 \mathrm{mM} \mathrm{MgCl}, 0.42 \mathrm{mM} \mathrm{Na}_{2} \mathrm{HPO}_{4}, 5 \mathrm{mM}$ glucose, and $0.1 \%$ bovine serum albumin). Cell concentrations were determined with a Coulter counter.

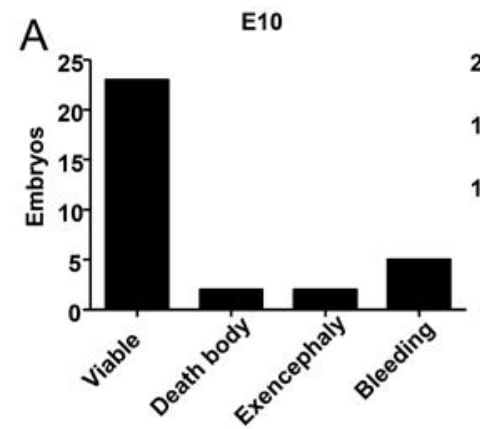

$\mathrm{B}$

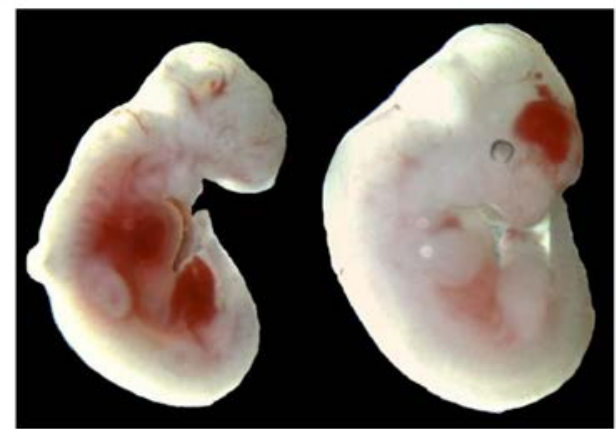

E12

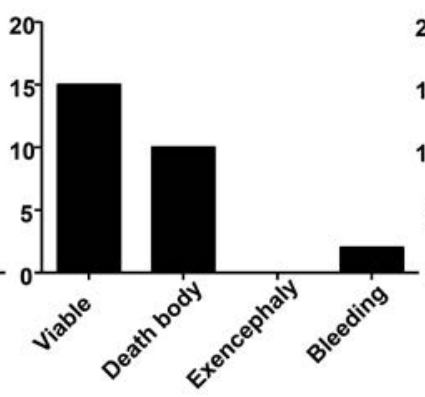

C
E16

Figure 1. Embryonic lethality in offspring from Tmem $16 f^{+/-}$mice (AW-0382 clone). (a) Analysis of viability of embryos after in-breeding of heterozygous Tmem16f $f^{+/-}$mice (AW-0382 clone) at gestational days 10, 12 or 16. (b) Embryos at gestational day 12, presenting with major abdominal and intracranial bleeding, respectively. (c) Embryo at gestational day 16 presenting with exencephaly.

\section{Platelet and erythrocyte analysis}

Washed mouse platelets in suspension $\left(1 \times 10^{8} / \mathrm{ml}\right)$ were stimulated with indicated agonists in the presence of $2 \mathrm{mM} \mathrm{CaCl}_{2}$. Using flow cytometry (BD Accuri C6 flow cytometer), samples were analyzed for PS exposure in combination with either P-selectin expression or integrin $\alpha_{11 b} \beta_{3}$ activation after 10 minutes. Therefore, the cells were co-labeled with AF647-annexin A5 (1:200) and FITC-anti-P-selectin mAb (1:50) or PE-JON/A mAb (1:50), respectively. For studying apoptosis, platelets were stimulated with $\mathrm{BH} 3$ mimetic ABT-737, and analyzed for PS exposure after 1 hour incubation $\left(37^{\circ} \mathrm{C}\right)$.

Washed mouse erythrocytes at a concentration of $1 \times 10^{8} / \mathrm{ml}$ were treated with $10 \mu \mathrm{M}$ ionomycin or DMSO vehicle in presence of $1 \mathrm{mM} \mathrm{CaCl}_{2}$ at $37^{\circ} \mathrm{C}$. At indicated time points, 
samples were labeled with AF647-annexin A5, and analyzed with a BD Facs Calibur or BD Accuri C6 flow cytometer. Data analysis was performed using the programs WinMDI or CFlow Plus.

\section{Results}

Different survival of mice from strains with TMEM16F deficiency

Two independent approaches were used to generate mice deficient in TMEM16F (anoctamin 6). Using the PAC-379 clone, mice were obtained heterozygously deficient in TMEM16F. These were bred to obtain homozygously deficient mice, as checked by PCR (data not shown). With this strain, about $30 \%$ of the expected number of Tmem $16 f^{/-}$embryos were born, which is in agreement with earlier observations with this mouse strain ${ }^{11}$. In embryos dissected out of the uterus (gestational days E14.5-18.5), no lethality or obvious bleeding was observed (H. Ehlen, unpublished data). Embryos (>300, E14.5-18.5) were recovered at the expected Mendelian ratio. The majority of deficient embryos died around birth, e.g. due to asphyxia, but some Tmem $16 f^{\prime-}$ mice survived longer than 2 months, and these could be used for precise assessment of the platelet and erythrocyte phenotypes.

In addition, Tmem $16 f^{+/-}$mice were generated using the AW-0382 stem cell clone containing a $\beta$-geo reporter gene trap in this gene. These mice produced viable offspring, which in part contained the insertion (checked by PCR). However, a lower than expected number of animals was born. Unfortunately, homozygous presence of two reporter gene inserts could not be established, as the exact position of the insertion could not be determined using a series of PCR primers (data not shown). Furthermore, various commercially available antibodies against TMEM16F (anoctamin 6) showed multiple bands on Western blots, so that immunological detection of TMEM16F antigen expression was also difficult to establish.

As lethality of the full knockouts was expected, embryonic development was evaluated by breeding heterozygous females at 10, 12 and 16 days after gestation. Morphological examination indicated that, at all time points, the majority of embryos had developed normally (Figure 1a). This confirms a normal viability of $T m e m 16 f^{+/+}$and $T m e m 16 f^{+/-}$mice. However, at E10-16, a certain number of death bodies and embryos with signs of abdominal or intracranial bleeding could be detected (Figure 1b). Furthermore, exencephaly was detected in a small portion of the embryos (Figure 1c). At later time points, most nonviable embryos were retrieved as residual death bodies, although still some bleeding embryos or embryos showing exencephaly were present. This suggested that, in this mouse strain, full ablation of the wildtype TMEM16F gene resulted in prenatal lethality.

Effect of heterozygous and homozygous TMEM16F deficiency on agonist-induced platelet PS exposure

Platelet PS exposure was studied in response to $\mathrm{Ca}^{2+}$-mobilizing ionomycin or con-

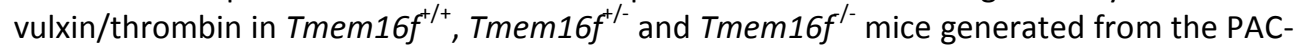
379 clone. Ionomycin induced PS exposure in virtually all platelets from wildtype and heterozygous TMEM16F-deficient mice, but it induced this response in less than $5 \%$ of the Tmem $16 f^{/-}$platelets (Figure 2a). Convulxin/thrombin-induced PS exposure was comparable in wildtype and heterozygous $\operatorname{Tmem}_{16 f^{+-}}$platelets, but was strongly impaired in 
Tmem $16 f^{\prime-}$ platelets, showing a residual activity in about $10 \%$ of the platelets at all tested doses of convulxin (Figure 2a). Previously, platelets derived from a Scott syndrome patient did show no appreciable PS exposure in response to convulxin/thrombin ${ }^{4}$. Ionomycin- and convulxin/thrombin-induced integrin $\alpha_{11 b} \beta_{3}$ activation (Figure $2 b$ ) and P-selectin expression (Figure 2c) were similar in wildtype, heterozygous and homozygous TMEM16F-deficient platelets. The lack of effect on P-selectin expression points to normal $\alpha$-granule secretion in the deficient platelets. We emphasize that these findings need to be substantiated since only a limited number of animals were used for these experiments.

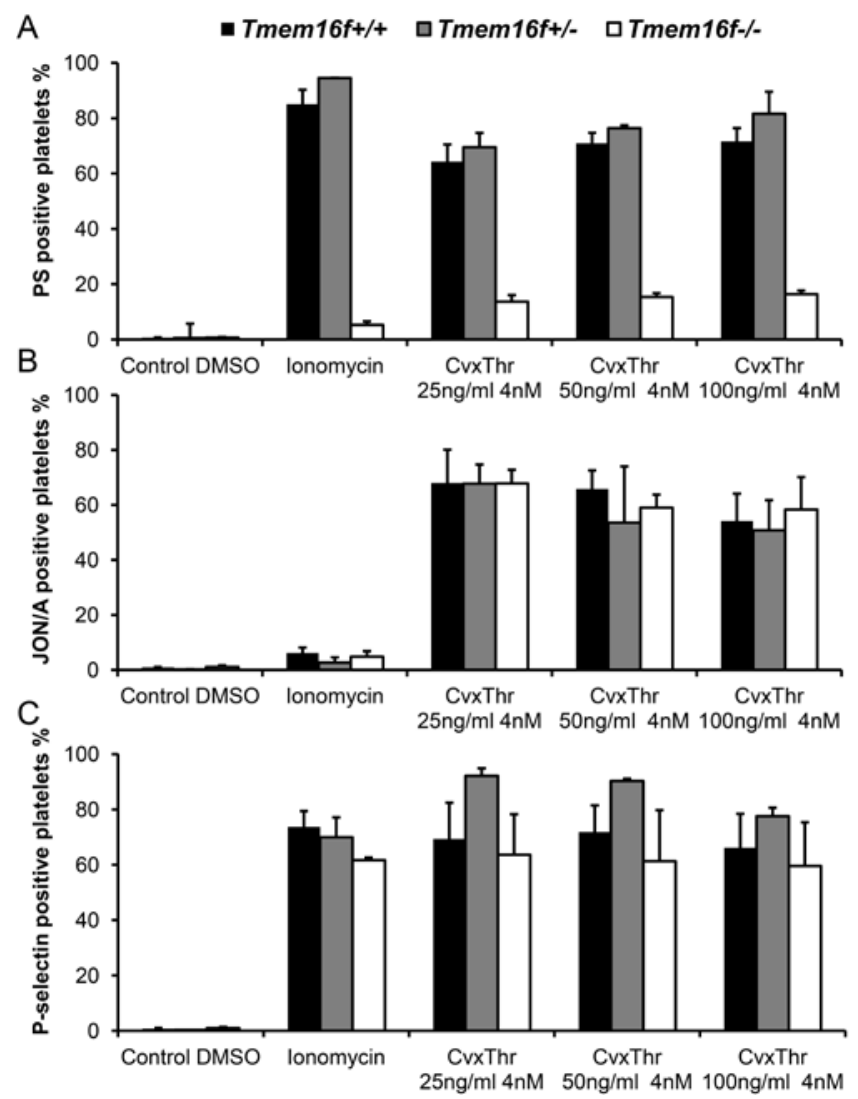

Figure 2. Reduced agonist-induced PS exposure in homozygous but not heterozygous TMEM16Fdeficient platelets (PAC-379 clone). Mice heterozygously and homozygously deficient in TMEM16F were generated using the PAC-379 embryonic stem cell line. Washed platelets were prepared from

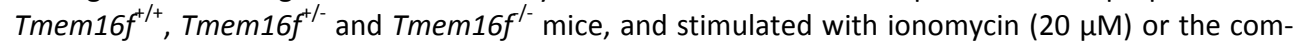
bination of convulxin ( $\mathrm{Cvx}, 25,50$ or $100 \mathrm{ng} / \mathrm{ml}$ ) and thrombin $(\mathrm{Thr}, 4 \mathrm{nM})$ in the presence of $2 \mathrm{mM}$ $\mathrm{CaCl}_{2}$ for 15 minutes. Resting platelets treated with DMSO vehicle served as control. Samples were used to determine PS exposure (AF647-annexin A5 binding), integrin $\alpha_{\| 1} \beta_{3}$ activation (PE-JON/A $\mathrm{mAb}$ binding), and P-selectin exposure (FITC-aCD62P mAb binding). Shown are percentages of platelets exposing PS (a), staining positively with JON/A (b), and expressing P-selectin (c). Means $\pm S D(n=$ 2-3). 
Comparable results were obtained using platelets from $\mathrm{Tmem}_{16 f^{+/+}}$and $\mathrm{Tmem} 16 \mathrm{f}^{+/-}$mice, generated with the AW-0382 clone. These Tmem $16 f^{+/+}$and Tmem $16 f^{+/-}$platelets did not differ from each other in ionomycin- or convulxin/thrombin-induced PS exposure, $\alpha_{11 b} \beta_{3}$ activation or P-selectin expression (Figure 3a-c).

In line with a previous report on Scott syndrome platelets ${ }^{12}$, ionomycin strongly suppressed JON/A-binding, reflecting early integrin closure at high $\mathrm{Ca}^{2+}$ concentrations, while convulxin/thrombin activated integrins in a large fraction of platelets (Figure $2 b, 3 b$ ). Together, these data suggest that integrin $\alpha_{11 b} \beta_{3}$ activation and closure are not affected by TMEM16F deficiency.
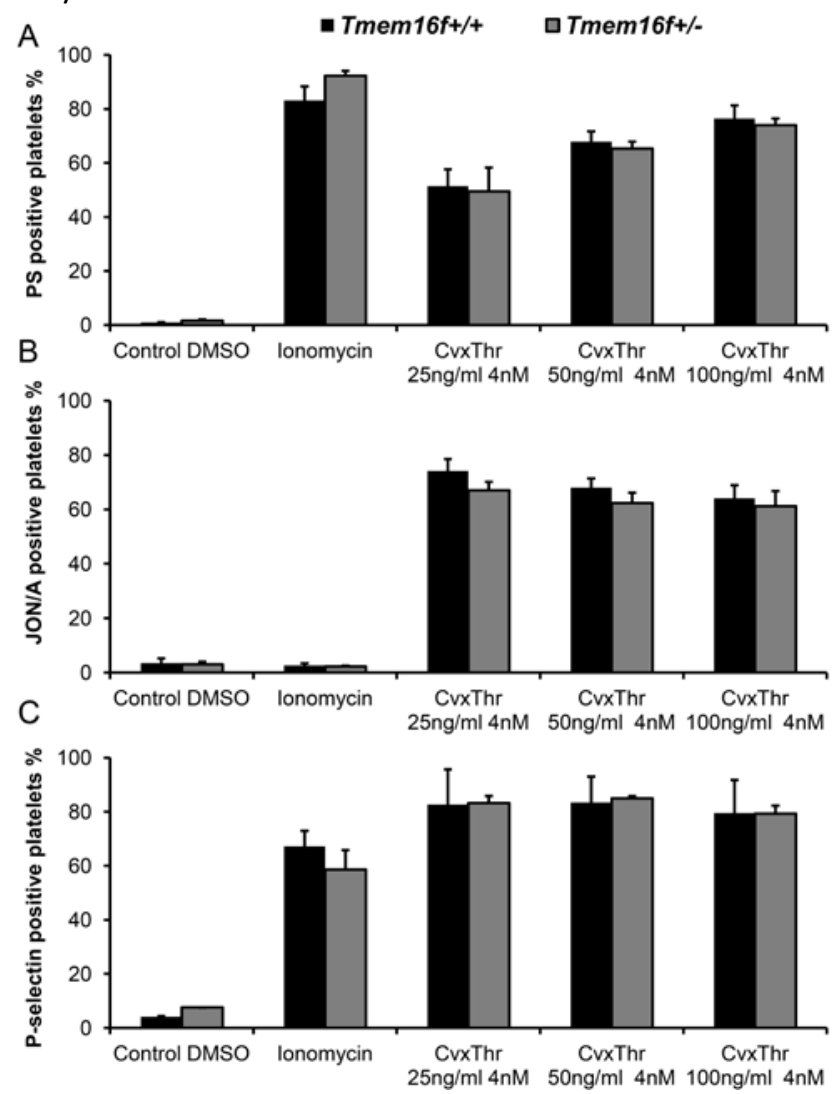

Figure 3. Unchanged agonist-induced PS exposure in heterozygous TMEM16F-deficient platelets (AW-0382 clone). Mice heterozygously deficient in TMEM16F were generated using the AW-3082 embryonic stem cell line. Washed platelets were prepared from Tmem $16 f^{t /+}$ or Tmem $16 f^{+/}$mice, and stimulated with ionomycin $(20 \mu \mathrm{M})$ or the combination of convulxin $(\mathrm{Cvx}, 25,50$ or $100 \mathrm{ng} / \mathrm{ml})$ and thrombin ( $\mathrm{Thr}, 4 \mathrm{nM}$ ) in the presence of $2 \mathrm{mM} \mathrm{CaCl}$ for 15 minutes. Resting platelets treated with DMSO vehicle served as control. Samples were used to determine PS exposure (AF647-annexin A5 binding), integrin $\alpha_{11 b} \beta_{3}$ activation (PE-JON/A mAb binding), and P-selectin exposure (FITC-aCD62P mAb binding). Shown are percentages of platelets exposing PS (a), staining positively with JON/A (b), and expressing P-selectin (c). Means \pm SEM ( $n=3-6)$. 
No effect of homozygous TMEM16A deficiency on agonist-induced platelet PS exposure Platelets deficient in TMEM16A, another member of the family of anoctamins, were also evaluated for agonist-induced PS exposure and other responses. Deficiency of platelet TMEM16A, however, did not affect platelet PS exposure, $\alpha_{111} \beta_{3}$ activation or P-selectin expression after activation with ionomycin or convulxin/thrombin (Figure 4a-c).

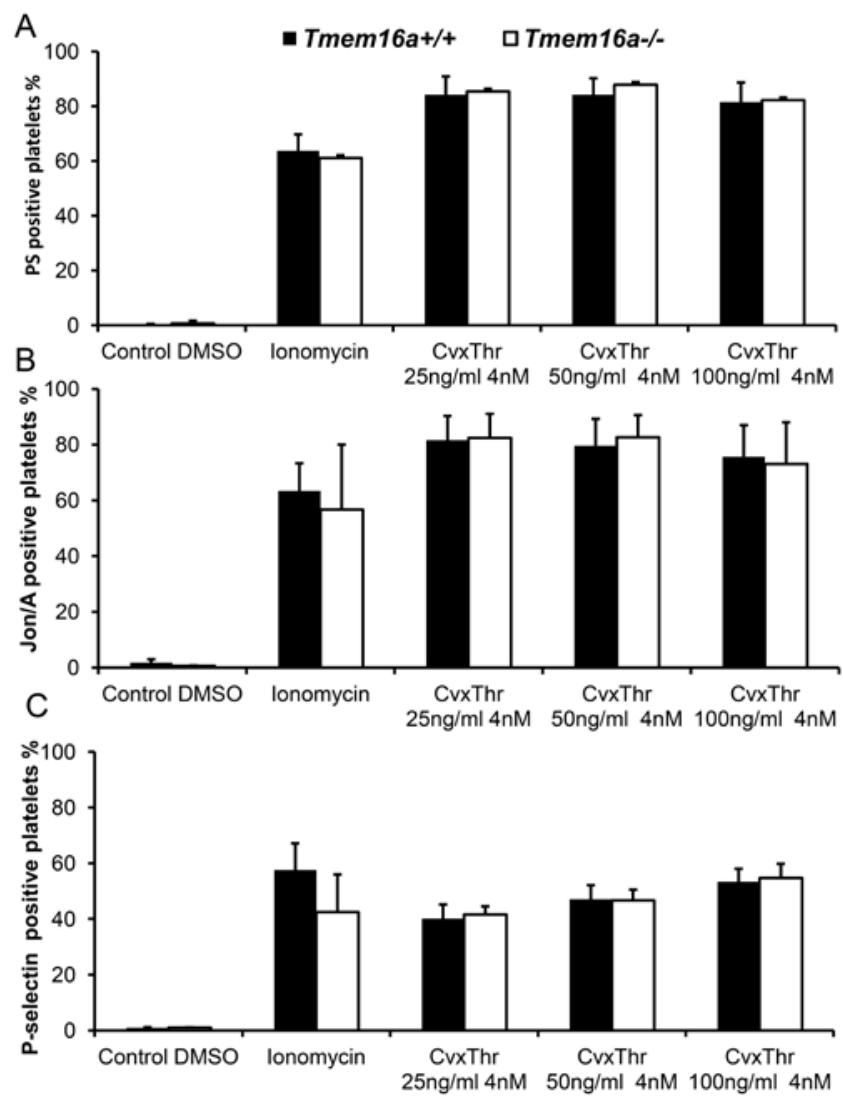

Figure 4. Unchanged agonist-induced PS exposure in TMEM16A-deficient platelets. Mice deficient in platelet TMEM16A were generated by crossing $T m e m 16 a^{\mathrm{fl} / \mathrm{fl}}$ mice with mice expressing Cre

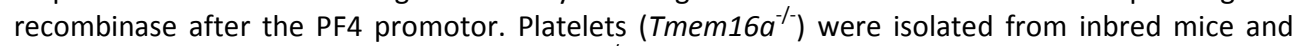

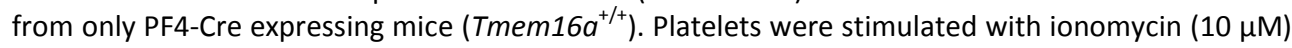
or the combination of convulxin $(25,50$ or $100 \mathrm{ng} / \mathrm{ml})$ and thrombin $(4 \mathrm{nM})$ in presence of $2 \mathrm{mM}$ $\mathrm{CaCl}_{2}$ for 15 minutes. Resting platelets treated with DMSO vehicle served as control. Samples were used to determine PS exposure (AF647-annexin A5 binding), integrin $\alpha_{\| 1} \beta_{3}$ activation (PE-JON/A $\mathrm{mAb}$ binding), and P-selectin exposure (FITC-aCD62P mAb binding). Shown are percentages of platelets exposing PS (a), staining positively with JON/A (b), and expressing P-selectin (c). Means \pm SEM (n $=3-4)$. 

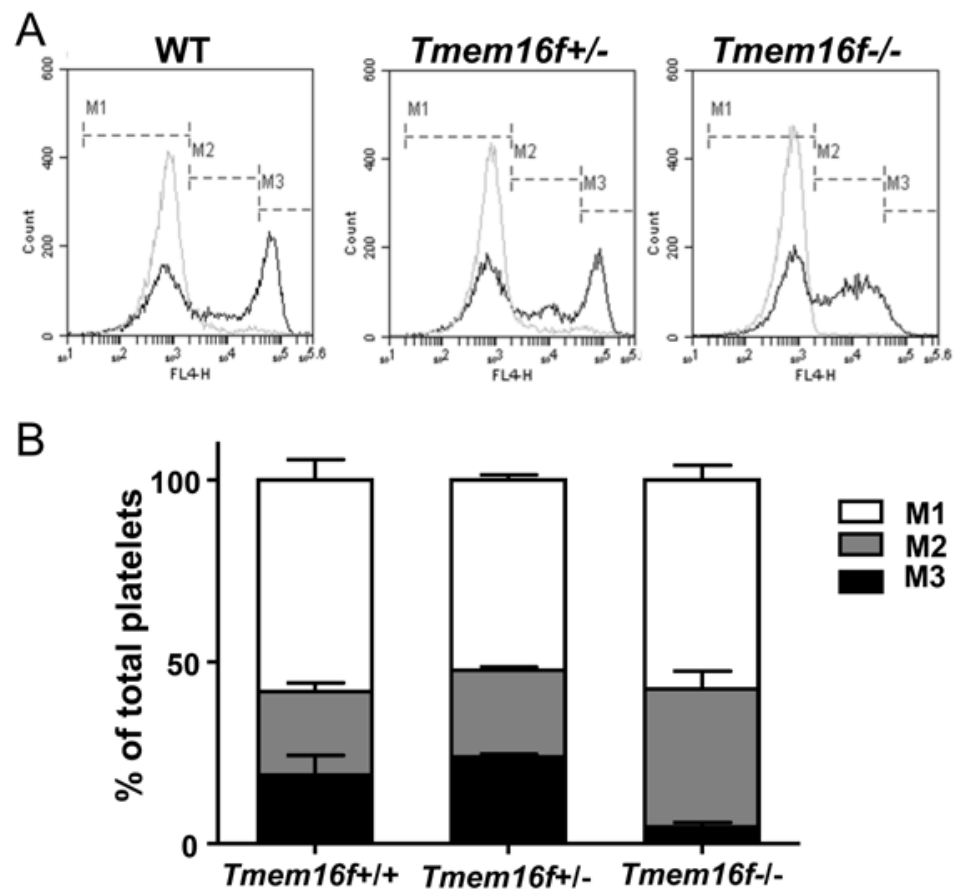

Figure 5. Effect of platelet TMEM16F deficiency on apoptosis-induced PS exposure. Mice heterozygously and homozygously deficient in TMEM16F were generated using the PAC-379 embryonic

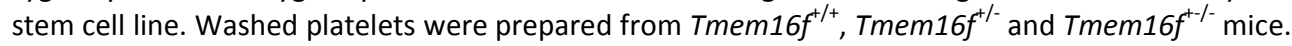
Platelets were stimulated with the BH3 mimetic ABT-737 $(10 \mu \mathrm{M})$ in the presence of $1 \mathrm{mM} \mathrm{CaCl}$ for 1 hour. Cells were then analyzed for FITC-annexin A5 binding by flow cytometry. (a) Representative histograms (black lines) for AF647-annexin A5 binding after 1 hour stimulation. Markers M1, M2 and M3 indicate fractions of platelets with no, moderate or high annexin A5 binding, respectively. Grey curves show unstimulated platelets treated with vehicle (DMSO). (b) Distribution of M1, M2 and M3 platelet populations after 1 hour treatment with ABT-737. Means $\pm S D(n=3)$.

Effect of heterozygous and homozygous TMEM16F deficiency on apoptosis-induced platelet PS exposure

In human platelets, apoptosis induced by the BH3-mimicking agent ABT-737 results in the formation of two populations of PS-exposing platelets; based on the extent of fluorescent annexin A5 binding, platelets with moderate and high PS exposure can be distinguished. In Scott syndrome platelets, the population with highest PS exposure was absent, suggesting secondary activation of a TMEM16F-dependent phospholipid scrambling upon platelet apoptosis ${ }^{4}$. Here, we studied this phenomenon in ABT-737-stimulated platelets from ${\text { Tmem } 16 f^{+/}, \text {Tmem } 16 f^{+/-} \text {and Tmem16f }}^{/-}$mice (PAC-379 clone). As shown in Figure 5b, in wild type and heterozygous platelets stimulated with ABT-737, a population of high annexin A5-binding platelets is observed (M3). In contrast, homozygous TMEM16F-deficient mice failed to show a population of high annexin A5-binding platelets upon ABT-737 treatment. It should be emphasized that the total number of PS-exposing platelets (M2 + 
M3) was similar in all three types of platelets, and hence, not affected by the TMEM16F deficiency (Figure 5b). Jointly, this indicates a prominent role for murine platelet TMEM16F in generating this high annexin A5-binding population.

Effect of heterozygous and homozygous TMEM16F deficiency on ionophore-induced PS exposure in erythrocytes

In human erythrocytes, $\mathrm{Ca}^{2+}$ ionophore-induced PS exposure is known to be a relatively slow process, taking minutes rather than seconds such as in platelets ${ }^{13}$. To investigate the role of TMEM16F herein, we treated erythrocytes from wildtype, Tmem16 $f^{+-}$and Tmem $16 f^{/-}$mice (PAC-379 clone) with ionomycin and measured PS exposure after 1 hour. The ionomycin-induced PS exposure was strongly, but incompletely impaired in Tmem16f /- erythrocytes (Figure 6). Remarkably, in heterozygous Tmem $16 f^{+/-}$mice, the present, preliminary data indicate that the proportion of PS-exposing erythrocytes was intermediate between the levels observed for wildtype and Tmem $16 f^{/-}$erythrocytes. Hence, the expression of TMEM16F seems to be a limiting factor in $\mathrm{Ca}^{2+}$-induced phospholipid scrambling in mouse erythrocytes.

- Tmem16f+/+口Tmem16f+/-ロTmem16f-/-

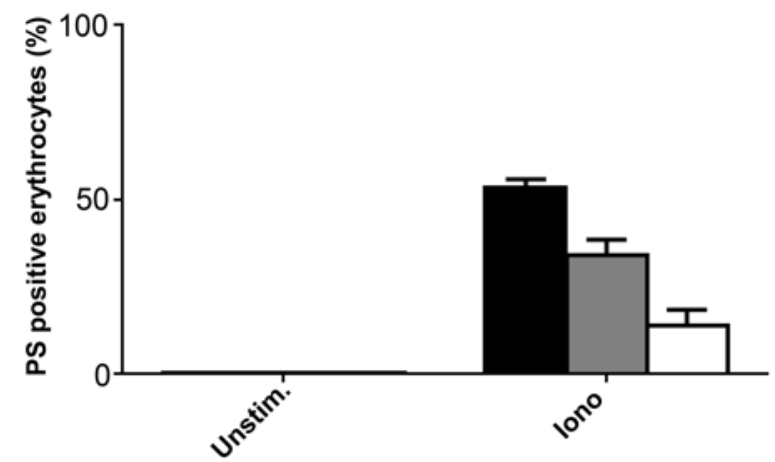

Figure 6. Effect of erythrocyte TMEM16F deficiency on ionophore-induced PS exposure. Mice heterozygously and homozygously deficient in TMEM16F were generated using the PAC-379 embry-

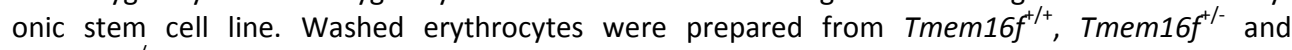
Tmem $16 f^{-}$mice, and stimulated with $10 \mu \mathrm{M}$ ionomycin (iono) in the presence of $1 \mathrm{mM} \mathrm{CaCl}$ for 1 hour at $37{ }^{\circ} \mathrm{C}$. Resting erythrocytes treated with DMSO vehicle served as unstimulated control. Erythrocytes were labeled with AF647-annexin A5 to determine PS exposure by flow cytometry. Indicated are percentages of mouse erythrocytes exposing PS after 1 hour treatment. Means \pm SD ( $n$ $=2-3$ ).

\section{Discussion}

In this initial report, we describe effects of murine TMEM16A and TMEM16F deficiency in platelets on agonist- and apoptosis-induced PS exposure and other platelet responses. We studied the platelets from two different mouse strains with deficiencies in TMEM16F. Generated through the AW-0382 stem cell clone, heterozygous $\mathrm{Tmem}_{16 f^{+/-}}$mice failed to generate Tmem $16 f^{/-}$offspring. Part of the embryos did not survive, and some showed signs of major bleeding or exencephaly. Although the mechanism leading to prenatal death in these - likely TMEM16F-deficient - embryos is unknown, this may point to a de- 
velopmental role of the affected TMEM16F gene. Generated by the PAC-379 clone, Tmem $16 f^{\prime-}$ mice could be retrieved from heterozygotes at the expected Mendelian distribution, but in this case many Tmem $16 f^{/-}$mice died soon after birth, as described earlier ${ }^{11}$. Comparing these two strains, it is tempting to speculate that either multiple defects were present in the AW-0382 cells or that differences in gene expression in the PAC-379 clone rescue the extreme embryonic knockout phenotype observed with the AW-0382 clone.

Platelets of Tmem $16 f^{/-}$mice (PAC-379 clone) showed a major deficiency in $\mathrm{Ca}^{2+}$-mediated PS exposure, i.e. with ionomycin or convulxin/thrombin. This is in line with the observation of Suzuki et al., who showed that TMEM16F in transfected cells is critically involved in $\mathrm{Ca}^{2+}$-dependent phospholipid scrambling ${ }^{2}$. However, the mouse platelets exhibited limited TMEM16F-independent phospholipid scrambling induced with either ionomycin or convulxin/thrombin, whereas in platelets from Scott patients, defective in TMEM16F, it was observed that ionomycin- or convulxin/thrombin-induced PS exposure was completely absent ${ }^{4}$. The reason for this difference between mouse and patient platelets is unclear.

We also determined the role of TMEM16F in PS exposure, induced by the $\mathrm{BH} 3$ mimetic ABT-737, which activates Bax/Bak proteins and caspases in a manner distinct from agonist-induced platelet activation ${ }^{5,14,15}$. Upon ABT-737 treatment of wild type platelets, two distinct annexin A5-binding populations were obtained, showing moderate (M2) and high (M3) annexin A5 binding. However, in Tmem $16 f^{/-}$platelets, the $M 3$ population was strongly reduced. A similar pattern of $M 2$ and $M 3$ populations was previously observed in human platelets stimulated with ABT-737. In agreement with the present results, the high annexin A5-binding population was absent in ABT-737-stimulated Scott syndrome platelets ${ }^{4}$. Considering the $\mathrm{Ca}^{2+}$ dependency reported for TMEM16F-mediated phospholipid scrambling ${ }^{2,4}$ this is suggestive for a role of TMEM16F in (secondarily) accelerating PS exposure upon platelet apoptosis.

A persistent elevated intracellular $\mathrm{Ca}^{2+}$ concentration upon treatment with $\mathrm{Ca}^{2+}$-ionomycin also induces PS exposure in erythrocytes, although the rate of phospholipid scrambling is markedly lower than in ionomycin-stimulated platelets ${ }^{1}$. In this report, we show a reduction in the PS exposure in Tmem $16 \mathrm{f}^{+/-}$erythrocytes, and a greater reduction in Tmem $16 \mathrm{f}^{/-}$ erythrocytes, with a small residual activity remaining. This is in agreement with the observation that $\mathrm{Ca}^{2+}$-induced lipid scrambling in erythrocytes from Scott syndrome patients is completely absent. These observations suggest that the extent of expression of TMEM16F is a limiting factor in $\mathrm{Ca}^{2+}$-mediated PS exposure in mouse erythrocytes. For platelets, no difference was found in ionomycin-induced PS exposure between Tmem $16 \mathrm{f}^{+/-}$and wild type cells. This may be due to the rapid process of lipid scrambling in platelets, which does not allow monitoring differences in rate of scrambling with the present method using annexin A5 binding. Using a different technique, decreased rates of scrambling were found in ionomycin treated platelets from a son and daughter of a French Scott patient, suggesting heterozygosity ${ }^{16}$. Of note, compound heterozygosity in TMEM16F was also found in this Scott patient (F. Toti, personal communication).

Besides its role in phospholipid scrambling, TMEM16F is involved in generating $\mathrm{Ca}^{2+}$ dependent chloride ${ }^{7,8,17}$ and cation ${ }^{9}$ currents. Although we do not have addressed this in the present paper, it is worth noting that a role of chloride channel activity in mediating 
phospholipid scrambling is unlikely, since pharmacologic blockade of TMEM16F-mediated chloride currents or chloride replacement did not affect ionomycin-induced PS exposure in immortalized B-cells ${ }^{18}$. Recent evidence with cell lines indicates that also other members of the TMEM16 family (TMEM16C, TMEM16D, TMEM16G and TMEM16J) can mediate ionomycin-induced phospholipid scrambling ${ }^{19}$. Introduction of TMEM16A did not enhance phospholipid scrambling in this cell model, which is in line with the present results showing no effect of TMEM16A deficiency on PS exposure. Whether TMEM16F and family members contain phospholipid scrambling activity themselves, or whether they are regulators of others proteins initiating phospholipid scrambling, still remains to be resolved.

\section{References}

1. Bevers EM, Comfurius $P$, Dekkers DW, Zwaal RF. Lipid translocation across the plasma membrane of mammalian cells. Biochim Biophys Acta. 1999;1439:317-330.

2. Suzuki J, Umeda M, Sims PJ, Nagata S. Calcium-dependent phospholipid scrambling by TMEM16F. Nature. 2010;468:834-838.

3. Castoldi E, Collins PW, Williamson PL, Bevers EM. Compound heterozygosity for 2 novel TMEM16F mutations in a patient with Scott syndrome. Blood. 2011;117:4399-4400.

4. Van Kruchten R, Mattheij NJ, Saunders C, Feijge MA, Swieringa F, Wolfs JL, Collins PW, Heemskerk JW, Bevers EM. Both TMEM16F-dependent and TMEM16F-independent pathways contribute to phosphatidylserine exposure in platelet apoptosis and platelet activation. Blood. 2013;121:1850-1857

5. Schoenwaelder SM, Yuan Y, Josefsson EC, White MJ, Yao Y, Mason KD, O'Reilly LA, Henley KJ, Ono A, Hsiao S, Willcox A, Roberts AW, Huang DC, Salem HH, Kile BT, Jackson SP. Two distinct pathways regulate platelet phosphatidylserine exposure and procoagulant function. Blood. 2009;114:663-666

6. Grubb S, Poulsen KA, Juul CA, Kyed T, Klausen TK, Larsen EH, Hoffmann EK. TMEM16F (anoctamin 6), an anion channel of delayed $\mathrm{Ca}^{2+}$ activation. J Gen Physiol. 2013;141:585-600.

7. Martins JR, Faria D, Kongsuphol P, Reisch B, Schreiber R, Kunzelmann K. Anoctamin 6 is an essential component of the outwardly rectifying chloride channel. Proc Natl Acad Sci USA. 2011;108:1816818172.

8. Tian Y, Schreiber R, Kunzelmann K. Anoctamins are a family of $\mathrm{Ca}^{2+}$-activated $\mathrm{Cl}^{-}$channels. J Cell Sci. 2012;125:4991-4998.

9. Yang $H$, Kim A, David T, Palmer D, Jin T, Tien J, Huang F, Cheng T, Coughlin SR, Jan YN, Jan LY. TMEM16F forms a $\mathrm{Ca}^{2+}$-activated cation channel required for lipid scrambling in platelets during blood coagulation. Cell. 2012;151:111-122.

10. Siljander P, Farndale RW, Feijge MA, Comfurius P, Kos S, Bevers EM, Heemskerk JW. Platelet adhesion enhances the glycoprotein VI-dependent procoagulant response: Involvement of p38 map kinase and calpain. Arterioscler Thromb Vasc Biol. 2001;21:618-627.

11. Ehlen HW, Chinenkova M, Moser M, Munter HM, Krause Y, Gross S, Brachvogel B, Wuelling M, Kornak $\mathrm{U}$, Vortkamp A. Inactivation of anoctamin-6/TMEM16F, a regulator of phosphatidylserine scrambling in osteoblasts, leads to decreased mineral deposition in skeletal tissues. J Bone Miner Res. 2013;28:246-259.

12. Mattheij NJ, Gilio K, Kruchten RV, Jobe SM, Wieschhaus AJ, Chishti AH, Collins P, Heemskerk JW, Cosemans JM. Dual mechanism of integrin $\alpha_{11 b} \beta_{3}$ closure in procoagulant platelets. J Biol Chem. 2013,288:13325-13336.

13. Bevers EM, Williamson PL. Phospholipid scramblase: an update. FEBS Lett. 2010; 84:2724-30

14. Mason KD, Carpinelli MR, Fletcher JI, Collinge JE, Hilton AA, Ellis S, Kelly PN, Ekert PG, Metcalf D, Roberts AW, Huang DC, Kile BT. Programmed anuclear cell death delimits platelet life span. Cell. 2007;128:1173-1186.

15. Zhang H, Nimmer PM, Tahir SK, Chen J, Fryer RM, Hahn KR, Iciek LA, Morgan SJ, Nasarre MC, Nelson R, Preusser LC, Reinhart GA, Smith ML, Rosenberg SH, Elmore SW, Tse C. Bcl-2 family proteins are essential for platelet survival. Cell Death Differ. 2007;14:943-951. 
16. Zwaal RF, Comfurius P, Bevers EM. Scott syndrome, a bleeding disorder caused by defective scrambling of membrane phospholipids. Biochim Biophys Acta. 2004;1636:119-28.

17. Szteyn K, Schmid E, Nurbaeva MK, Yang W, Munzer P, Kunzelmann K, Lang F, Shumilina E. Expression and functional significance of the $\mathrm{Ca}^{2+}$-activated $\mathrm{Cl}^{-}$channel Ano6 in dendritic cells. Cell Physiol Biochem. 2012;30:1319-1332.

18. Kmit A, van Kruchten R, Ousingsawat J, Mattheij NJ, Senden-Gijsbers B, Heemskerk JW, Schreiber R, Bevers EM, Kunzelmann K. Calcium-activated and apoptotic phospholipid scrambling induced by Ano6 can occur independently of Ano6 ion currents. Cell Death Dis. 2013;4:e611.

19. Suzuki J, Fujii T, Imao T, Ishihara K, Kuba H, Nagata S. Calcium-dependent phospholipid scramblase activity of TMEM16 family members. J Biol Chem. 2013; 288:13305-13316. 

Chapter 7

\section{Calcium-activated and apoptotic phospholipid scrambling induced by Ano6 can occur independently of Ano6 ion currents}

Kmit A, van Kruchten R, Ousingsawat J, Mattheij NJ, SendenGijsbers BL, Heemskerk JW, Schreiber R, Bevers EM, Kunzelmann K.

Cell Death Disease. 2013;25(4):e611 reprinted with permission 


\begin{abstract}
Immune cells and platelets maintain plasma membrane phospholipid asymmetry. Upon activation, this asymmetry is disrupted by phospholipid scrambling, which is a major step during activation of immune cells, hemostasis and apoptosis. Anoctamin 6 (Ano6; TMEM16F) causes chloride $\left(\mathrm{Cl}^{-}\right)$and cation currents and is required for $\mathrm{Ca}^{2+}$-dependent phospholipid scrambling. It is defective in blood cells from patients with Scott syndrome, a rare bleeding disorder. We examined if $\mathrm{Cl}^{-}$currents and phospholipid scrambling are related, whether both processes are $\mathrm{Ca}^{2+}$-dependent, and whether $\mathrm{Ca}^{2+}$-independent scrambling during intrinsic and extrinsic apoptosis is controlled by Ano6. $\mathrm{Ca}^{2+}$ increase by ionomycin activated Ano6 $\mathrm{Cl}^{-}$currents and phospholipid scrambling in normal lymphocytes, but not in B-lymphocytes from two different patients with Scott syndrome. Fas ligand (FasL) did not increase intracellular $\mathrm{Ca}^{2+}$, but activated $\mathrm{Cl}^{-}$currents in normal but not in Scott lymphocytes. Whole-cell currents were inhibited by $\mathrm{Cl}^{-}$channel blockers and by siRNA knockdown of Ano6. In contrast, intrinsic mitochondrial apoptosis by ABT-737 did not induce $\mathrm{Cl}^{-}$currents inlymphocytes. Phospholipid scrambling was not inhibited by blockers of Ano6 or removal of $\mathrm{Cl}^{-}$ions. Remarkably, $\mathrm{Ca}^{2+}$-independent scrambling due to extrinsic (FasL) or intrinsic (ABT-737) apoptosis was unchanged in Scott cells. We conclude that: (i) Ano6 $\mathrm{Cl}^{-}$currents are activated by increase in cytosolic $\mathrm{Ca}^{2+}$, or $\mathrm{Ca}^{2+}$ independent by stimulation of Fas receptors; (ii) $\mathrm{Ca}^{2+}$-dependent phospholipid scrambling induced by Ano6 does not require $\mathrm{Cl}^{-}$currents; (iii) $\mathrm{Ca}^{2+}$-independent phospholipid scrambling does not require Ano6; (iv) Ano6 is necessary for $\mathrm{Ca}^{2+}$-dependent phospholipid scrambling, but not by increasing intracellular $\mathrm{Ca}^{2+}$.
\end{abstract}

\title{
Introduction
}

Endogenous or overexpressed anoctamins produce chloride $\left(\mathrm{Cl}^{-}\right)$or cation currents ${ }^{1-8}$. This putative family of $\mathrm{Cl}^{-}$channels demonstrate variable $\mathrm{Ca}^{2+}$ sensitivity and are activated during cell swelling or by apoptotic stimuli ${ }^{9-12}$. Anoctamins are unique as they do not show any obvious homology to other ion channels. Ano1 contains eight predicted transmembrane helices, intracellular amino- and carboxy-terminal ends, and a pore formed by the fifth and sixth transmembrane helices containing a $p$-loop dipping back into the membrane ${ }^{1}$. However, a different topology has been proposed recently ${ }^{13}$. Anoctamins show a high degree of sequence similarity, particularly for the putative pore region ${ }^{7}$. We were able to demonstrate that anoctamin 6 (Ano6) produces an outwardly rectifying $\mathrm{Cl}^{-}$channel (ORCC) in Jurkat lymphocytes and epithelial cells, which is activated during stimulation of the proapoptotic Fas receptor or by the pro-apoptotic compound staurosporine ${ }^{9}$.

Another recently identified function of Ano6 (gene TMEM16F) is the regulation of membrane phospholipid scrambling ${ }^{14}$. The so-called scramblase process disturbs the asymmetric distribution of membrane phospholipids of nonstimulated cells, in which the negatively charged phosphatidylserine (PS) distributes from the inner to the outer membrane leaflet ${ }^{15}$. Phospholipid scrambling and hence phosphatidylserine exposure can be induced by activation with $\mathrm{Ca}^{2+}$-mobilizing agonists, and by induction of the apoptotic process. We and others have shown that PS exposed at the surface of platelets has an essential role in the process of blood coagulation ${ }^{15,16}$. Recent findings indicate that two different patients with the so-called Scott syndrome, a quite rare congenital bleeding 
disorder, have missense mutations in the TMEM16F gene ${ }^{14,17}$. Defective function of this gene can explain why Scott platelets and other hematopoietic cells are unable to perform $\mathrm{Ca}^{2+}$-dependent phosphatidylserine exposure and, hence, are impaired in supporting blood coagulation ${ }^{16}$. Here, we analyzed Ano6-dependent $\mathrm{Cl}^{-}$currents in immortalized $\mathrm{B}$ lymphocytes from the two Scott patients with characterized TMEM16F mutations, and compared these with their ability to expose PS under conditions of $\mathrm{Ca}^{2+}$ activation and apoptosis.

\section{Results}

\section{Expression of anoctamins in lymphocytes}

The anoctamin family comprises 10 members (Ano1-10). These channels are expressed abundantly in various cell types. We performed a semi-quantitative RT-PCR analysis of the expression of anoctamins in immortalized B lymphocytes from a healthy volunteer (wt) and from two different patients with Scott disease (Scott $\left.{ }_{U S A}, S_{\text {Scott }}{ }_{U K}\right)^{18,19}$. Anoctamin expression was semi-quantified using the house keeper protein GAPDH as an internal standard (Supplementary Figures 1a, b). We detected expression of Ano9 and low levels of Ano1 in all three lymphocyte cell lines. Ano6 mRNA was detected only in control lymphocytes and cells from the Scott $\mathrm{UK}_{\mathrm{UK}}$ patient, but not in Scott $_{\text {USA }}$ lymphocytes. Accordingly, no

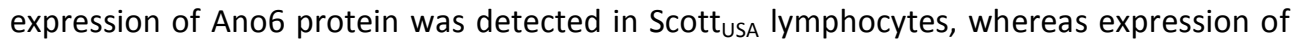
Ano6 protein appears reduced in cells from the Scott ${ }_{U K}$ patient (Supplementary Figures 1c, d).
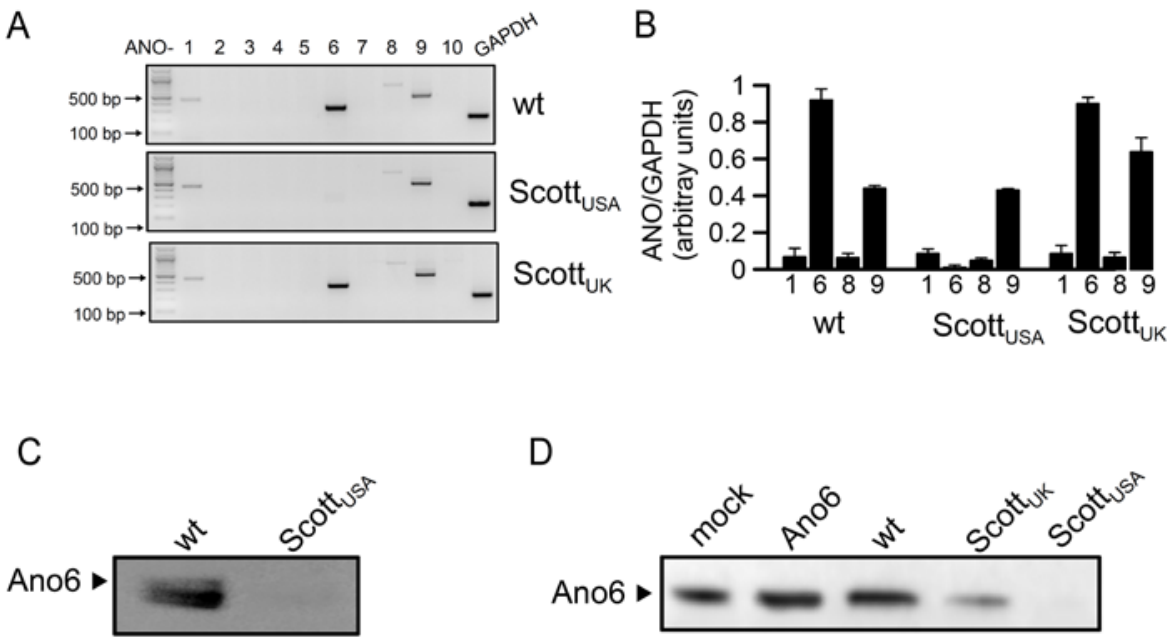

Supplementary Figure 1. a) RT-PCR analysis of the expression of anoctamins in lymphocytes from a healthy volunteer and from two different patients with Scott disease $\left(S_{S^{\prime}} \operatorname{dtt}_{U S A}, S_{\text {Scott }}{ }_{U K}\right)$. b) Quantification of anoctamin expression from 3 semiquantitative RT-PCR reactions using the housekeeper

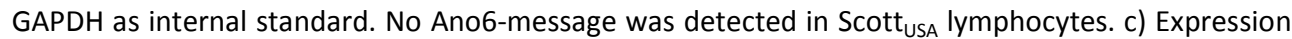
of Ano6 in wt lymphocytes but not in Scott usA lymphocytes (Western blot). d) Western blot analysis of Ano6 -expression in HEK93 cells expressing Ano6 endogenously (mock) or HEK293 cells transfect-

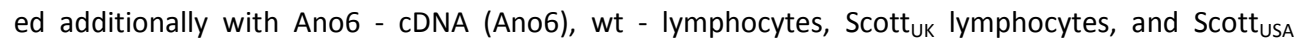
lymphocytes. 

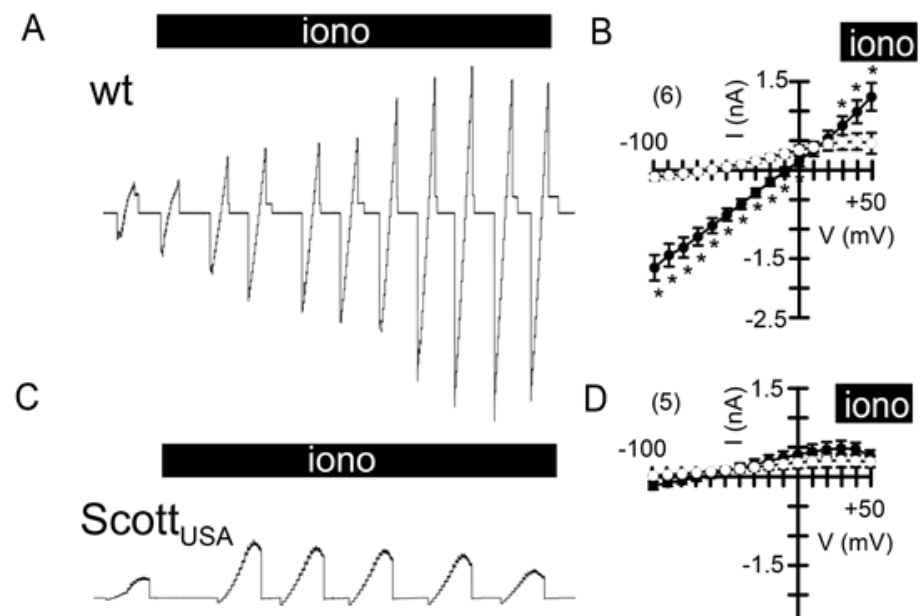
-100 -

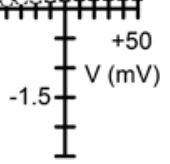

E

F $-2.5$
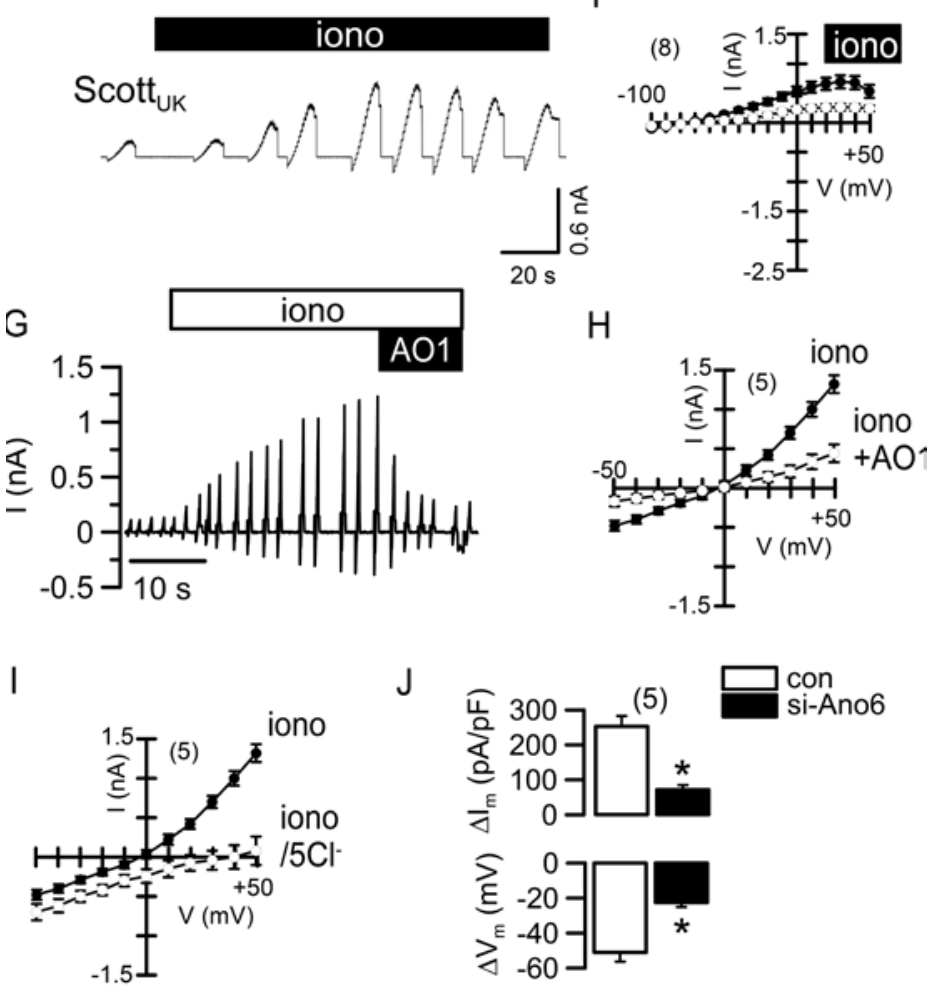
Figure 1. $\mathrm{Ca}^{2+}$-dependent activation of whole-cell currents in normal but not Scott lymphocytes. Original recordings of whole-cell currents measured in normal lymphocytes (a) and lymphocytes from two patients with Scott disease (c and e). Cells were kept under current clamp and were voltage clamped in intervals from -100 to $+50 \mathrm{mV}$ in steps of $10 \mathrm{mV}$. lonomycin $(1 \mu \mathrm{M})$ activated a whole-cell current only in normal lymphocytes (a). Current/voltage relationships were obtained in normal (b) and Scott lymphocytes ( $d$ and f). Note the activation of a large whole-cell current by ionomycin (filled circles) in normal but not in Scott lymphocytes. ( $g$ and $h$ ) Activation of a whole-cell $\mathrm{Cl}^{-}$current by ionomycin $(1 \mu \mathrm{M})$ in normal B lymphocytes, using $145 \mathrm{mM} \mathrm{NMDG}^{+} \mathrm{Cl}^{-}$in pipette and bath. Note the outward rectification of the whole-cell current and the pronounced inhibition by 20 $\mu \mathrm{M}$ AO1. (i) Inhibition of ionomycin-activated outward currents by replacement of extracellular $\mathrm{Cl}^{-}$ with gluconate $\left(5 \mathrm{Cl}^{-}\right)$. (j) Inhibition of ionomycin-induced whole-cell currents (current densities) and depolarization in normal B lymphocytes after knockdown of Ano6 expression with siRNA. Mean \pm S.E.M. (number of cells). * denotes significant activation by ionomycin or effect of siRNA for Ano6 (si-Ano6); $p<0.05$; paired t-test.

Calcium induced $\mathrm{Cl}$ conductance in normal lymphocytes but not in lymphocytes from Scott patients.

When analyzed with the patch clamp technique, we found that normal lymphocytes had a resting membrane voltage $(\mathrm{Vm})$ of $-59 \pm 3.6 \mathrm{mV}$, whereas $\mathrm{Vm}$ of Scott USA and Scott $\mathrm{SK}_{\mathrm{UK}}$ lymphocytes were significantly hyperpolarized $(-79 \pm 2.8$ and $-75 \pm 3.7 \mathrm{mV}$ ) (Figures $1 \mathrm{~b}, \mathrm{~d}$ and $\mathrm{f}$ ). Membrane voltages were obtained as reversal potentials from I/V curves and were also measured directly under current clamp, which supplied the exact same numbers. Stimulation with the $\mathrm{Ca}^{2+}$ ionophore ionomycin $(1 \mu \mathrm{M})$ activated a large whole-cell current in control lymphocytes, but not in lymphocytes from Scott $\mathrm{USA}_{\mathrm{SA}}$ or $\mathrm{Scott}_{\mathrm{UK}}$ patients (Figures 1, $2 \mathrm{a}$ and $2 \mathrm{~b}$ ). Membrane voltage of normal lymphocytes was largely depolarized by ionomy-

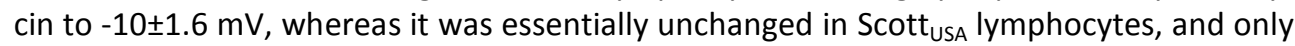

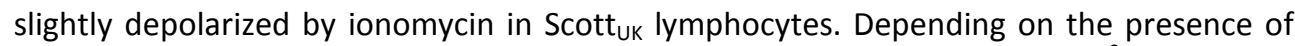
cations, Ano6 whole-cell currents are either linearly or outwardly rectifying ${ }^{9}$. In lymphocytes, currents were linear in the presence of cations (Figure 1b), but were outwardly rectifying in the absence of $\mathrm{Na}^{+}$and $\mathrm{K}^{+}$(Figure $1 \mathrm{~g}$ and $\mathrm{h}$ ). Under these conditions, the $\mathrm{Cl}^{-}$ channel inhibitor $\mathrm{CaCC}_{\text {inh }}-\mathrm{AO} 1(\mathrm{AO} 1 ; 20 \mu \mathrm{M}){ }^{20}$ or removal of bath $\mathrm{Cl}^{-}\left(5 \mathrm{Cl}^{-}\right)$largely reduced outward currents and shifted the reversal potential by almost $40 \mathrm{mV}$ (Figure $1 \mathrm{~g}-\mathrm{i}$ ). Moreover, the whole-cell current activated in normal lymphocytes by ionomycin was significantly reduced after siRNA knockout of Ano6, which also significantly suppressed Ano6 mRNA (by $40 \pm 2.3 \% ; n=3$ ), as measured by quantitative real-time RT-PCR (Figure $1 \mathrm{j}$ ). Taken together, activation of Ano6 not only generates a $\mathrm{Ca}^{2+}$-activated $\mathrm{Cl}^{-}$conductance, but also induces a nonselective cation conductance similar to Ano6 currents activated in HEK293 cells, thereby strongly depolarizing membrane voltage ${ }^{8,9}$. The pronounced depolarization of membrane voltage beyond the equilibrium potential for $\mathrm{Cl}^{-}$probably corresponds to recent findings, demonstrating induction of a nonselective cation channel by $\mathrm{Ano}^{8}$. Lack of $\mathrm{Ca}^{2+}$-activated currents in Scott $_{\mathrm{UK}}$ or Scott $_{\text {USA }}$ lymphocytes was not because of diminished ionomycin-induced $\mathrm{Ca}^{2+}$ rise, as all three cell lines showed pronounced $\mathrm{Ca}^{2+}$ increase upon treatment with ionomycin as measured in single-cell analysis or in suspended cells (Figures 2c-e). This is in excellent agreement with previous findings ${ }^{18}$. 
a

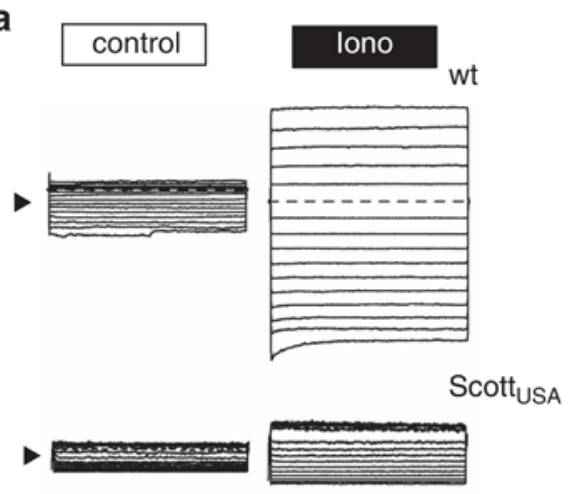

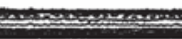

C

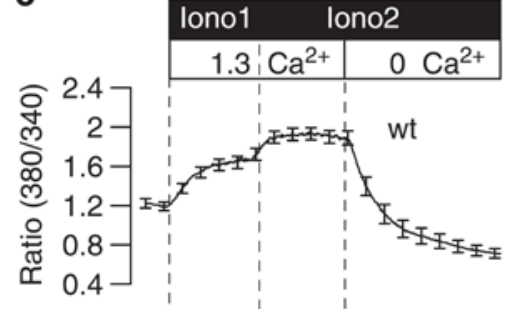

Scott $_{\text {USA }}$

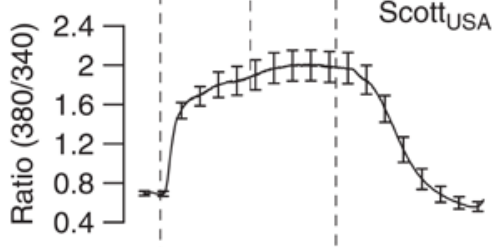

ScottuK $_{\text {UK }}$

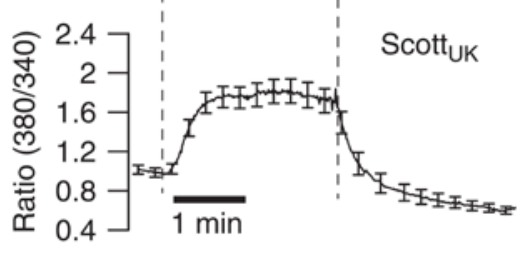

b

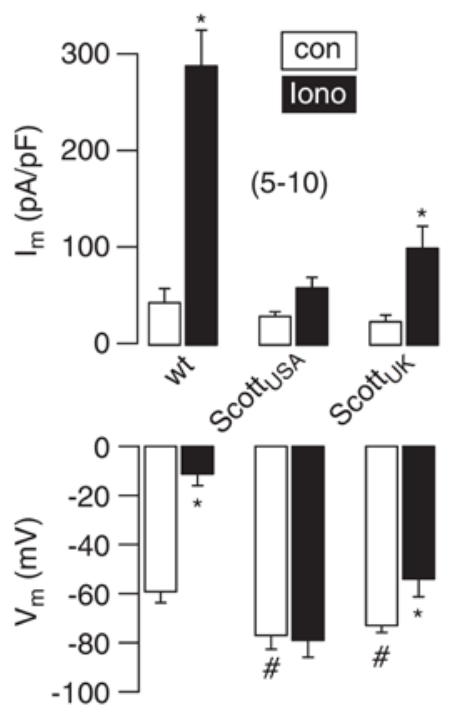

$\frac{\stackrel{\varangle}{\Xi}}{0.2 \mathrm{~s}}$

Scott $_{\text {UK }}$

d

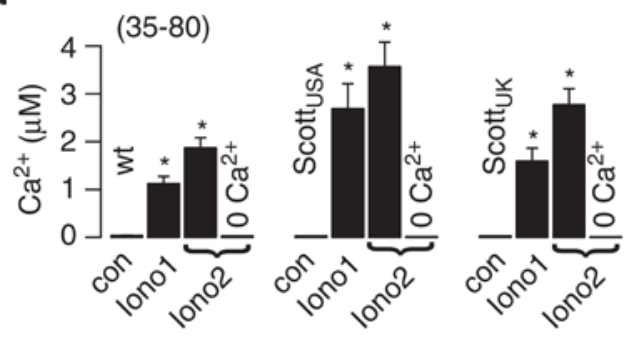

e

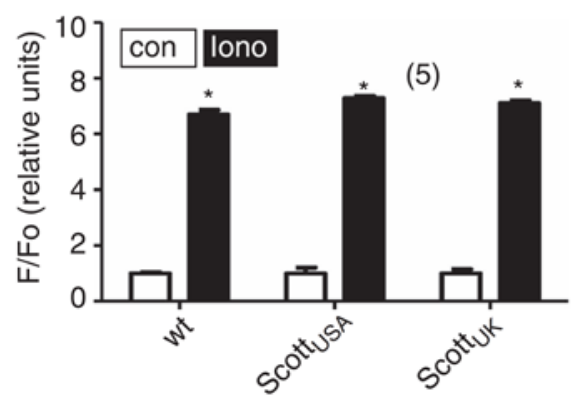


Figure 2. Lack of Ano6 in Scott lymphocytes abrogates $\mathrm{Cl}^{-}$currents but does not affect $\mathrm{Ca}^{2+}$ increase. (a) Whole-cell overlay currents obtained in wt lymphocytes and lymphocytes from two patients with Scott disease, under control conditions and after stimulation with ionomycin $(1 \mu \mathrm{M})$. Cells were voltage clamped from -100 to $+50 \mathrm{mV}$ in steps of $10 \mathrm{mV}$. Arrowhead indicates currents at clamp voltage of $0 \mathrm{mV}$. (b) Summary of whole-cell current densities and membrane voltages under control conditions and after stimulation with ionomycin (filled bars). (c) Continuous recordings of $380 / 340$ ratios (Fura-2) and effects of 1 or $2 \mu \mathrm{M}$ ionomycin (lono1, lono2), and $\mathrm{Ca}^{2+}$ removal in wt and Scott lymphocytes. (d) Summary of $\left[\mathrm{Ca}^{2+}\right]_{i}$ upon application of 1 or $2 \mu \mathrm{M}$ ionomycin. (e) Effects of $10 \mu \mathrm{M}$ ionomycin on $\left[\mathrm{Ca}^{2+}\right]_{i}$ measured in cells in suspensions (Fluo-4). Mean \pm S.E.M. (number of cells). ' ${ }^{* \prime}$ denotes significant increase when compared with control; $p<0.05$; paired t-test.

The whole-cell current induced by ionomycin was largely due to $\mathrm{Cl}^{-}$movement, as indicated by replacement of extracellular $\mathrm{Cl}^{-}$with impermeable gluconate, which strongly inhibited ionomycin-activated whole-cell currents (Figures $1 \mathrm{i}$ and $3 \mathrm{a}$ ). A number of typical blockers for $\mathrm{Ca}^{2+}$-activated $\mathrm{Cl}^{-}$channels were tested, such as tannic acid (TA; $\left.20 \mu \mathrm{M}\right)$ and 5nitro-2-(3-phenylpropylamino)benzoic acid (NPPB; $100 \mu \mathrm{M}), \mathrm{AO} 1(10 \mu \mathrm{M})$, and 4,4'diisothiocyano-2,2'-stilbenedisulfonic acid $(100 \mu \mathrm{M})$ which all potently blocked ionomycinactivated whole-cell conductance ${ }^{20-22}$. A concentration of $10 \mu \mathrm{M}$ AO1 used in the present study had a relatively moderate effect when compared with $20 \mu \mathrm{M}$ AO1 used in Jurkat cells to inhibit Ano ${ }^{9}$. However, $20 \mu \mathrm{M}$ AO1 inhibited Ano6 in human B-lymphocytes with similar potency as in Jurkat T-lymphocytes (Figures $1 \mathrm{~g}$ and $\mathrm{h})^{9}$. Cell-dependent variations of the potency of these inhibitors is well known ${ }^{21}$. Neither $\mathrm{Cl}^{-}$removal nor any of the $\mathrm{Cl}^{-}$ channel blockers showed effects on whole-cell currents in Scott USA $_{\text {lymphocytes, whereas }}$ the small residual whole-cell currents in Scott $_{U K}$ lymphocytes were attenuated by the inhibitors and by $\mathrm{Cl}^{-}$removal (Figures $3 \mathrm{~b}$ and $\mathrm{c}$ ). These data imply that the Ano6 mutant expressed in Scott $_{\mathrm{UK}}$ lymphocytes provides a residual $\mathrm{Cl}^{-}$channel activity. It is caused by a transition at the first nucleotide of intron 6, leading to an in-frame deletion of 38 amino acids in the N-terminal cytoplasmic tail. When expressed in HEK293 cells, this Ano6 mutant generated a small but significant whole-cell $\mathrm{Cl}^{-}$current $(\Delta \mathrm{l}=0.82 \pm 0.13 n A ; n=5)$ upon activation by ionomycin $(1 \mu \mathrm{M})$. For comparison, ionomycin-activated whole-cell current in wt-Ano6-overexpressing HEK cells was $2.93 \pm 0.31 \mathrm{nA}(\mathrm{n}=8)$, whereas no current $(\Delta \mathrm{l}=0.05 \pm 0.006 \mathrm{nA}(\mathrm{n}=5)$ was activated in mock-transfected HEK293 cells.

In normal, but not in Scott lymphocytes, Ano6 whole-cell $\mathrm{Cl}^{-}$currents could also be activated by using a patch pipette filling solution containing $100 \mu \mathrm{M} \mathrm{Ca}^{2+}$. Shortly after forming a whole-cell configuration, a current was activated and the membrane voltage was depolarized. These $\mathrm{Ca}^{2+}$-activated whole-cell currents were potently inhibited by replacement of extracellular $\mathrm{Cl}^{-}$with gluconate $\left(5 \mathrm{Cl}^{-}\right.$) (Figure 3d). No changes were observed in Scott $_{\text {USA }}$ lymphocytes, whereas a small residual $\mathrm{Cl}^{-}$current was found in $\mathrm{Scott}_{\mathrm{UK}}$ lymphocytes (Figure 3e). Taken together, the data indicate that whole-cell $\mathrm{Cl}^{-}$currents stimulated in lymphocytes by high levels of intracellular $\mathrm{Ca}^{2+}$ are because of the activation of Ano6. These currents are completely absent in cells, completely, lacking expression of Ano6 ( Scott $\left._{\text {USA }}\right)$, and are dramatically reduced in lymphocytes expressing mutant Ano6 $\left(\mathrm{Scott}_{\mathrm{UK}}\right)$. 

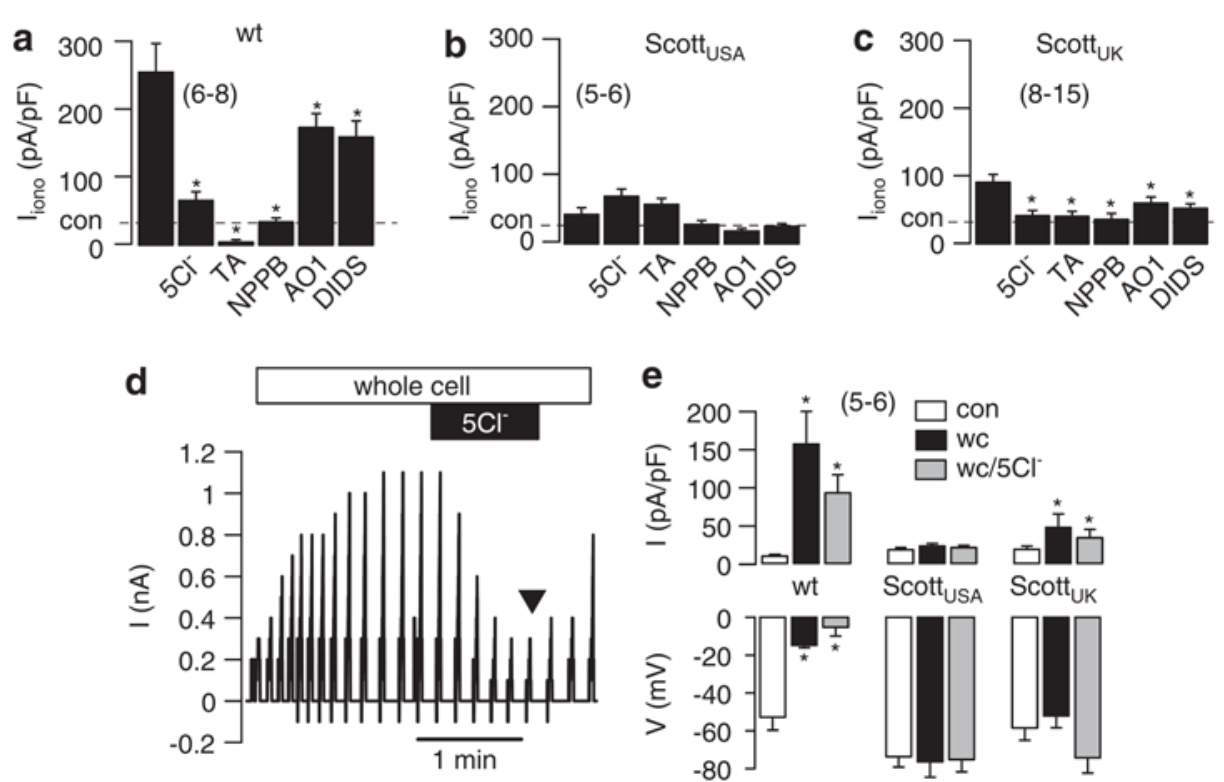

Figure 3. $\mathrm{Ca}^{2+}$ activates Ano6 $\mathrm{Cl}^{-}$conductance in normal but not Scott lymphocytes. (a-c) lonomycin-activated whole-cell currents in normal and Scott lymphocytes. Inhibition of currents by replacement of extracellular $\mathrm{Cl}^{-}$with impermeable gluconate (except of $5 \mathrm{mM} ; 5 \mathrm{Cl}^{-}$), or by application of tannic acid (TA; $20 \mu \mathrm{M})$, NPPB $(100 \mu \mathrm{M}), \mathrm{CaCC}_{\text {inh }}-\mathrm{AO}$ (AO1; $\left.10 \mu \mathrm{M}\right)$, or 4,4'-diisothiocyano$2,2^{\prime}$-stilbenedisulfonic acid $(100 \mu \mathrm{M})$. Dashed lines indicate currents before stimulation with

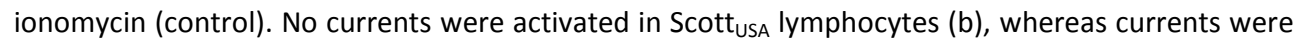
largely reduced in Scott $_{U K}$ lymphocytes (c). (d) Activation of Ano6 currents by high (100 $\left.\mu \mathrm{M}\right)$ pipette $\left[\mathrm{Ca}^{2+}\right]$ in a control lymphocyte and inhibition by removal of extracellular $\mathrm{Cl}^{-}\left(5 \mathrm{Cl}^{-}\right)$. The black arrowhead in $d$ indicates the time point that was chosen to read currents for generation of the summary bars shown in a, b, c and e. (e) Summary of current densities, indicating activation of Ano6 by pipette $\mathrm{Ca}^{2+}$ (black bars) and inhibition by low $\mathrm{Cl}^{-}$. Mean \pm S.E.M. (number of cells). '*' denotes significant difference compared with control; $p<0.05$; paired t-test.

\section{$\mathrm{Ca}^{2+}$-independent activation of whole-cell $\mathrm{Cl}$ currents.}

We recently demonstrated activation of Ano6 currents in Jurkat T lymphocytes, by stimulation of Fas (death) receptors ${ }^{9}$. We therefore examined whether activation of Fas receptors also stimulates whole-cell currents in $B$ lymphocytes. When normal lymphocytes were incubated with Fas ligand (FasL; 2 h, $0.5 \mu \mathrm{g} / \mathrm{ml}$ ), whole-cell currents increased and membrane voltages were depolarized, similar to current activation by ionomycin (Figures $4 \mathrm{a}$ and $\mathrm{b}$ ). These currents were inhibited by removal of extracellular $\mathrm{Cl}^{-}$and by application of the $\mathrm{Cl}^{-}$channel blockers TA $(20 \mu \mathrm{M})$ and NPPB $(100 \mu \mathrm{M})$ (Figures $\left.4 \mathrm{a}-\mathrm{c}\right)$. No whole-cell

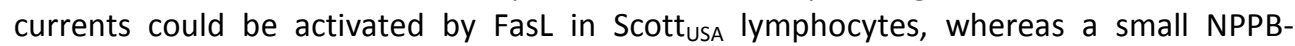
inhibitable current was observed in Scott $_{U K}$ lymphocytes (Figures $4 \mathrm{~d}$ and e). Notably, treatment of normal lymphocytes with siRNA for Ano6 largely reduced FasL-activated whole-cell currents $(\Delta l=76 \pm 9.5 \mathrm{pA} / \mathrm{pF} ; \mathrm{n}=4)$, when compared with control lymphocytes $(\Delta \mathrm{l}=265 \pm 38 \mathrm{pA} / \mathrm{pF} ; \mathrm{n}=8)$. Because FasL did not induce any increase in intracellular $\mathrm{Ca}^{2+}$ (Supplementary Figure 2c), we conclude that Ano6 $\mathrm{Cl}^{-}$currents can be activated by in- 
crease in intracellular $\mathrm{Ca}^{2+}$, or in a $\mathrm{Ca}^{2+}$-independent fashion by activation of the Fas receptor, similar to Jurkat T lymphocytes ${ }^{9}$. In Jurkat $\mathrm{T}$ lymphocytes, $\mathrm{Ca}^{2+}$ increase by stimulation of $\mathrm{P}_{2} \mathrm{Y}_{2}$ receptors did not activate Ano ${ }^{9}$. We therefore examined the effects of larger $\mathrm{Ca}^{2+}$ increase induced by $1 \mu \mathrm{M}$ ionomycin. We found that also in Jurkat cells pronounced $\mathrm{Ca}^{2+}$ increase activates Ano6, which shows a linear I/V relationship, probably by coactivation of a nonselective cation current (Supplementary Figures 2e, f).

a

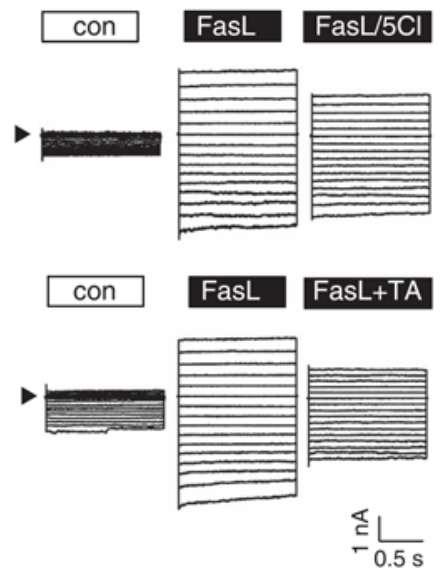

b

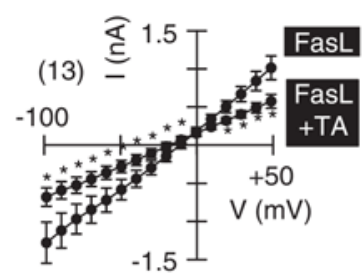

C
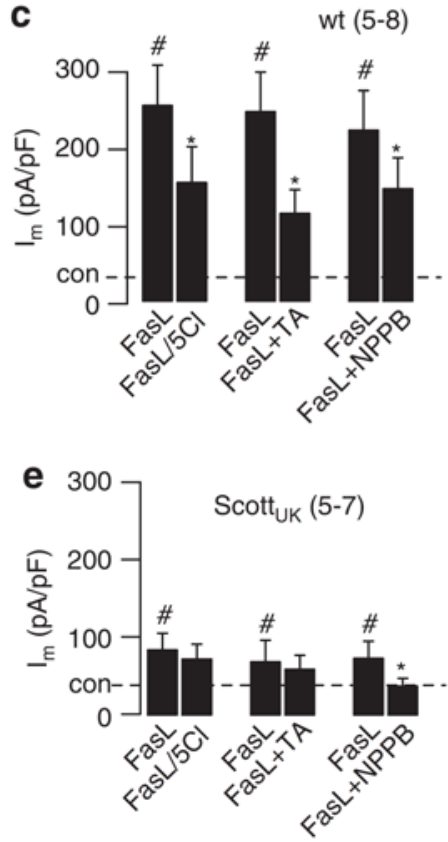

Figure 4. Activation Ano6 $\mathrm{Cl}^{-}$currents by activation of Fas receptors. (a) Whole-cell current overlays obtained in normal lymphocytes before and after incubation with FasL $(0.5 \mu \mathrm{g} / \mathrm{ml} ; 2 \mathrm{~h})$, and inhibition by $\mathrm{Cl}^{-}$replacement $\left(5 \mathrm{Cl}^{-}\right)$and tannic acid $(\mathrm{TA} ; 20 \mu \mathrm{M})$. Cells were voltage clamped from -100 to $+50 \mathrm{mV}$ in steps of $10 \mathrm{mV}$. Arrowhead indicates currents at clamp voltage of $0 \mathrm{mV}$. (b) Current/ voltage relationship of the FasL-activated whole-cell current and effect of TA. (c-e) Calculated whole-cell conductances in normal, Scott $_{\mathrm{USA}}$, and Scott $\mathrm{UK}_{\mathrm{K}}$ lymphocytes and effects of $5 \mathrm{Cl}^{-}$, TA and NPPB. Dashed line indicates conductance before incubation with FasL (control). Mean \pm S.E.M. (number of cells). ' ${ }^{\prime \prime}$ denotes significant inhibition; $p<0.05$; paired t-test. '\#'denotes significant activation by FasL; $p<0.05$; unpaired t-test. 
Stimulation of purinergic $\mathrm{P} 2 \mathrm{X}_{7}$ receptors can activate PS and induce apoptosis in some cell systems ${ }^{23}$. We therefore examined whether similar Ano6 currents are also elicited by activation of $\mathrm{P} 2 \mathrm{X}_{7}$ receptors in lymphocytes. Using semiquantitiative RT-PCR, we detected expression of $\mathrm{P} 2 \mathrm{X}_{7}$ receptors in wt and Scott lymphocytes, albeit at very low levels only (Supplementary Figure 3). Stimulation of wt lymphocytes with $3 \mathrm{mM}$ ATP activated small but significant whole-cell currents, but did neither lead to a measureable increase in $\left[\mathrm{Ca}^{2+}\right]_{\mathrm{i}}$ nor PS exposure (Supplementary Figures $2 a, b$ ), which is explained by the low level of P2 $X_{7}$ receptors expression (Supplementary Figure 3 ). Notably, no current increase was observed in lymphocytes from patients with Scott disease.

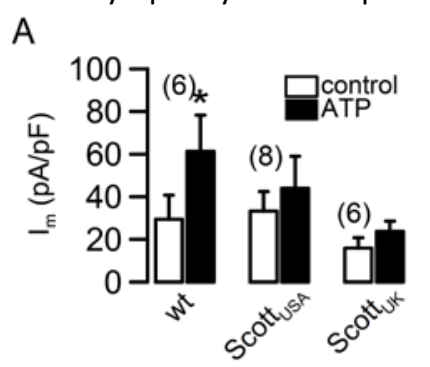

D

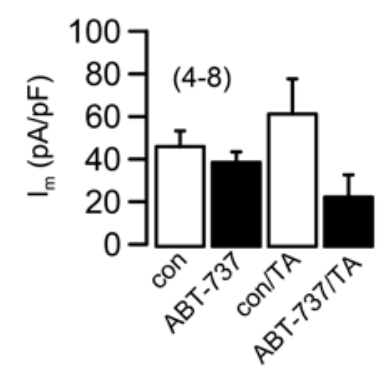

B

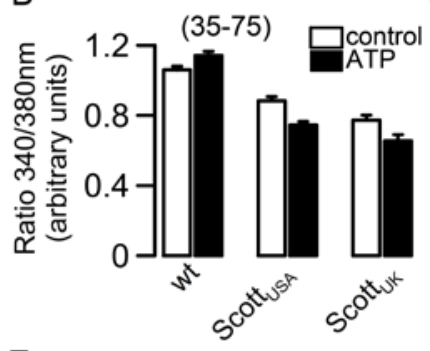

E

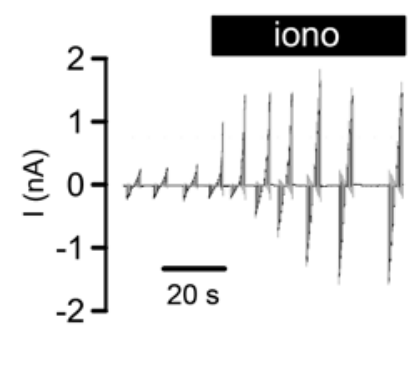

C

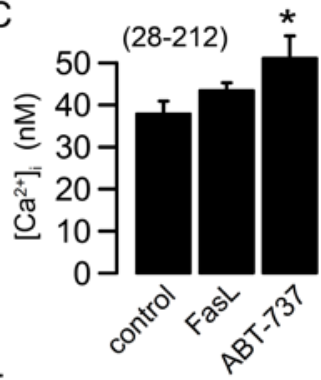

$\mathrm{F}$

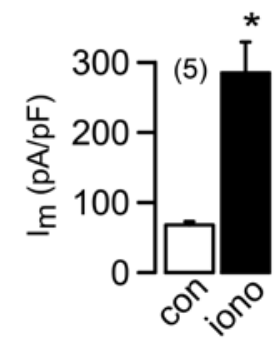

Supplementary Figure 2. a) Summary of whole cell patch clamp experiments in lymphocytes from a healthy volunteer and from two different patients with Scott disease (Scott ${ }_{\text {USA }}$ and Scott $\left._{U K}\right)$. Effect of $5 \mathrm{mM}$ ATP on whole-cell currents. b) Effect of ATP $(5 \mathrm{mM})$ on intracellular $\left[\mathrm{Ca}^{2+}\right]$ as measured by Fura-2. c) Absolute intracellular $\left[\mathrm{Ca}^{2+}\right]$ in wt lymphocytes under control conditions and after incubation with FasL $(0.5 \mu \mathrm{g} / \mathrm{ml} / 2 \mathrm{hrs})$ or ABT-737 $(10-100 \mu \mathrm{M} / 2 \mathrm{~h})$. d) Summary of whole cell conductances in lymphocytes from a healthy volunteer. Effects of incubation with ABT-737 and tannic acid. e) Original recording of the activation of whole cell currents by $1 \mu \mathrm{M}$ ionomycin in Jurkat T-lymphocytes. Note that currents were initially outwardly rectifying and then linearized with ongoing stimulation. f) Summary of the activated whole cel currents. Mean \pm SEM (number of experiments. ${ }^{*}$ significant difference when compared with control (paired t-test).

\section{Calcium-induced PS is independent of $\mathrm{Cl}$ conductance.}

As Ano6 has been reported to be crucial for $\mathrm{Ca}^{2+}$ - activated phospholipid scrambling ${ }^{14}$, we investigated whether Ano6 $\mathrm{Cl}^{-}$currents are required for phospholipid scrambling . To assess phospholipid scrambling, phosphatidylserine expression was measured after stimulation of lymphocytes with ionomycin or by exposure to FasL. Ionomycin treatment resulted in a high percentage of PS exposure in control cells, whereas PS exposure was 
basically abolished in Scott $_{U S A}$ and Scott $_{U K}$ lymphocytes (Figure $5 \mathrm{a}$ ). These results corresponded to the function of Ano6 as a $\mathrm{Cl}^{-}$channel, which was also essentially absent in Scott lymphocytes. However, in contrast to the inhibition of the $\mathrm{Cl}^{-}$channel by NPPB, TA or $\mathrm{Cl}^{-}$replacement with gluconate, none of these maneuvers affected ionomycin-induced PS exposure in control lymphocytes (Figure $5 b$ ).

Stimulation of the extrinsic apoptosis pathway by FasL resulted in appreciable PS exposure in control cells, as well as both Scott lymphocyte cell lines, whereas $\mathrm{Cl}^{-}$currents were only observed in wt lymphocytes (Figures 4, 5c). Although Ano6 $\mathrm{Cl}^{-}$currents were inhibited by NPPB, TA, or by $\mathrm{Cl}^{-}$replacement, these maneuvers did not affect FasL-induced PS exposure (Figure 5d). PS exposure in Scott $_{U K}$ and Scott $_{\text {USA }}$ lymphocytes was slightly lower compared with control cells, which corresponds to a slightly reduced activation of caspase- 3 in these cells (Figure 5e). This was confirmed by pre-treatment with the pan-caspase inhibitor, QVD-Oph (QVD), which completely inhibited FasL-induced PS exposure in control and Scott lymphocytes (Figure 5c). Jointly, these data indicate that FasL-induced phospholipid scrambling is not dependent on functional Ano6.
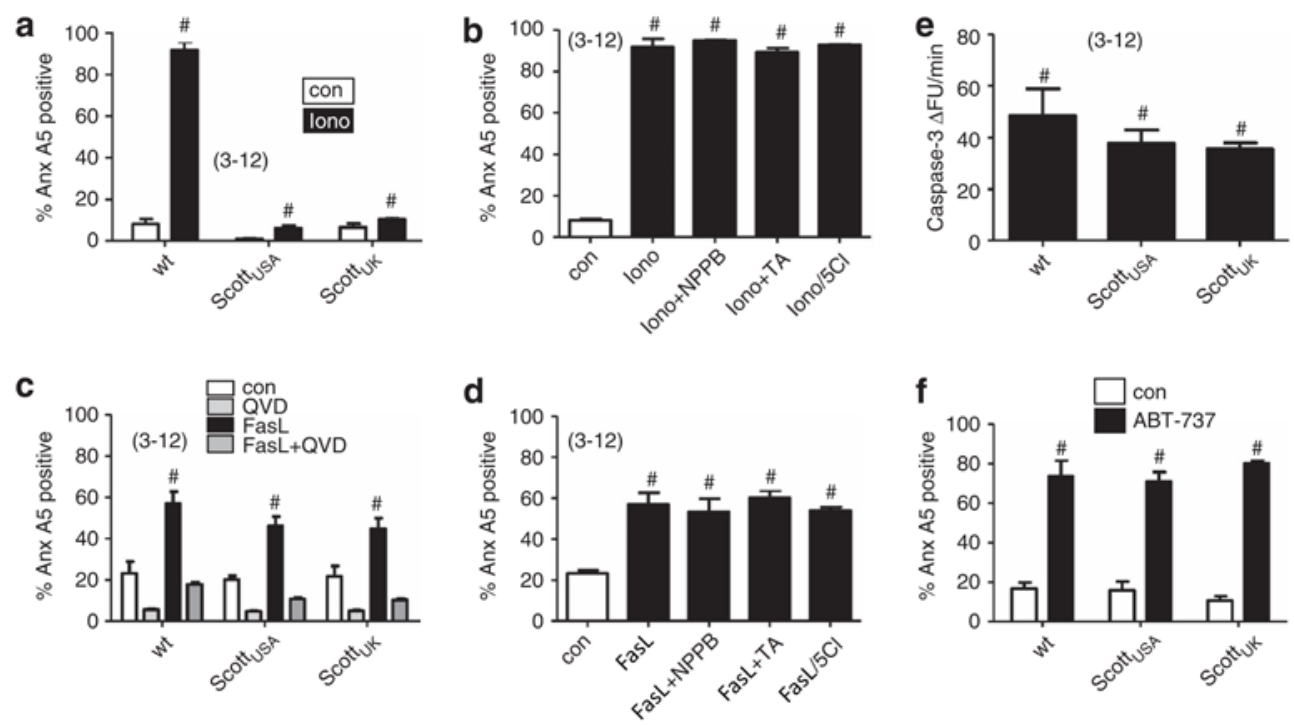

Figure 5. Phospholipid scrambling by ionomycin but not by FasL is impaired in Scott lymphocytes. (a) Percentage of phosphatidylserine (PS)-exposing lymphocytes after 10 min stimulation with 10 $\mu \mathrm{M}$ ionomycin in presence of $1 \mathrm{mM} \mathrm{CaCl}$ for normal and Scott lymphocytes as measured after labeling with annexin A5 for 5 min. (b) Effect of NPPB $(100 \mu \mathrm{M})$, TA $(50 \mu \mathrm{M})$ and replacement of $\mathrm{Cl}^{-}$ by gluconate on ionomycin-induced PS exposure in healthy control lymphocytes. (c) Percentage PSexposing lymphocytes after $4 \mathrm{~h}$ incubation with $0.5 \mu \mathrm{g} / \mathrm{ml} \mathrm{FasL} \mathrm{in} \mathrm{presence} \mathrm{of} 1 \mathrm{mM} \mathrm{CaCl}{ }_{2}$ for control and Scott lymphocytes in presence or absence of $20 \mu \mathrm{M}$ Q-VD-Oph. (d) No effects of NPPB $(100 \mu \mathrm{M})$, TA $(50 \mu \mathrm{M})$ and $\mathrm{Cl}^{-}$replacement on FasL-induced PS exposure in healthy control lymphocytes were observed. (e) Caspase-3 activity of control and Scott lymphocytes after $4 \mathrm{~h}$ stimulation with FasL as measured by a caspase activity assay. (f) Percentage of PS-exposing lymphocytes after incubation with $50 \mu \mathrm{M}$ ABT-737. Mean \pm S.D. ( $n=3-12)$. ' $\#$ ' denotes significant activation of PS exposure or caspase; $p<0.05$; unpaired t-test. 
Role of Ano6 for intrinsic apoptosis

Activation of intrinsic (mitochondrial) apoptosis is potently induced by the compound ABT737, which inhibits B-cell lymphoma 2 and thus directly promotes Bax/Bak pore formation and consecutive release of cytochrome $c{ }^{24}$ Although ABT-737 induced a small $\left[\mathrm{Ca}^{2+}\right]_{\mathrm{i}}$ rise in lymphocytes (Supplementary Figure $2 \mathrm{c}$ ), no whole-cell $\mathrm{Cl}^{-}$currents were activated (Supplementary Figure 2d). Nevertheless, ABT-737 induced high levels of PS exposure, which were identical in Scott $_{U K}$ and Scott $_{U S A}$ cells (Supplementary Figure 2e). Together, these data indicate that Ano $6 \mathrm{Cl}^{-}$currents are activated in normal lymphocytes by elevation of $\left[\mathrm{Ca}^{2+}\right]_{i}$ or by stimulation of extrinsic apoptosis via Fas receptors, but not during mitochondrial apoptosis. PS scrambling activated directly by $\left[\mathrm{Ca}^{2+}\right]_{i}$, extrinsic or intrinsic apoptosis does not require Ano6 $\mathrm{Cl}^{-}$currents.

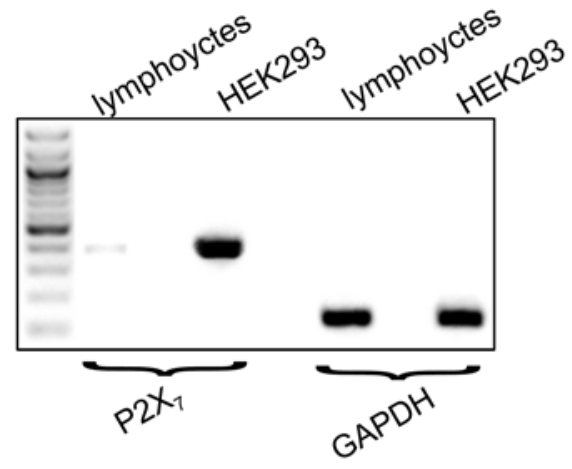

Supplementary Figure 3. Expression of $P 2 X_{7}$ receptors: $R T-P C R$ analysis of expression of $P 2 X_{7}$ receptors in B-lymphocytes and in transfected HEK293 cells, indicating very low levels of P2X $\mathrm{X}_{7}$-expression in lymphocytes. GAPDH was amplified for control.

\section{Discussion}

$\mathrm{Cl}$ currents and scramblase activity by Ano6 are not directly linked.

It was recently shown that Ano6 is an essential component of ORCC in Jurkat T lymphocytes, that is activated by Fas receptor stimulation ${ }^{9}$. ORCC single channels were also observed in membrane patches excised from Jurkat cells ${ }^{9,25}$. Once excised into a bath solution containing high ( $1 \mathrm{mM}$ ) extracellular $\mathrm{Ca}^{2+}$, the channel remained active and was only weakly $\mathrm{Ca}^{2+}$ dependent. It was suggested earlier that very high (cytosolic) $\mathrm{Ca}^{2+}$ or artificial clamp voltage may activate ORCC irreversibly ${ }^{26}$. The present data suggest that strong increase in intracellular $\mathrm{Ca}^{2+}$ by ionomycin in Jurkat cells also activates a whole-cell $\mathrm{Cl}^{-}$current, along with a nonselective cation current (Supplementary Figures 2e, f). Although $\mathrm{Ca}^{2+}$ increase through receptor stimulation was insufficient to activate Ano6 in HEK293 cells and Jurkat lymphocytes ${ }^{4,9}$, larger increases in $\left[\mathrm{Ca}^{2+}\right]_{i}$ such as those induced by ionomycin are able to activate Ano6 (Supplementary Figures 2e, f). Taken together, Ano6 can be activated by strong increase in intracellular $\mathrm{Ca}^{2+}$, as well as in a $\mathrm{Ca}^{2+}-$ independent fashion by FasL in both Jurkat T-lymphocytes as well B-lymphocytes. How FasL activates Ano6 is currently unclear. A recent paper describes release of ATP and activation of $\mathrm{P} 2 \mathrm{X}_{7}$ receptors by stimulation of the Fas receptor, which would resemble one possibility how Fas is connected to activation of Ano6 ${ }^{27}$. However, we have preliminary 
data indicating that preincubation (30 $\mathrm{min}$ ) of lymphocytes with $20 \mu \mathrm{M}$ of the broad caspase inhibitor QVD completely abolished activation of Ano6 by FasL $(\Delta \mathrm{l}=380 \pm 42 \mathrm{pA} / \mathrm{pF}$ versus $\Delta \mathrm{l}=49 \pm 9 \mathrm{pA} / \mathrm{pF} ; \mathrm{n}=7)$. Thus, it may be the Fas-induced caspase itself that activates Ano6. A recent paper reports Ano6 as a $\mathrm{Ca}^{2+}$-activated nonselective cation channel ${ }^{8}$. The paper does not report $\mathrm{Ca}^{2+}$-activated $\mathrm{Cl}^{-}$currents related to Ano6. However, apart from our laboratory ${ }^{4}$, other teams also reported Ano6 as a $\mathrm{Cl}^{-}$channel ${ }^{12,28}$. Similar to previous reports ${ }^{29-31}$, we also demonstrate in the present study that Ano6 is inducing a dominating $\mathrm{Cl}^{-}$current when activated by high cytosolic $\mathrm{Ca}^{2+}$ concentrations, and that this $\mathrm{Cl}^{-}$current is paralleled by activation of a nonselective cation current. It remains to be demonstrated whether Ano6 is a rather nonselective ion channel, or Ano6 interacts with other ion channel proteins (which might be differentially expressed in different cell types) to generate both $\mathrm{Cl}^{-}$and cation currents.

We reported recently that expression of Ano6 in HEK293 cells and activation by ionomycin not only activates a $\mathrm{Cl}^{-}$, but also a nonselective current ${ }^{4}$. This $\mathrm{Ca}^{2+}$-activated nonselective cation might be related to the $\mathrm{Ca}^{2+}$-activated cation current observed recently in other Ano6-expressing cells ${ }^{8}$. Coactivation of this cation conductance leads to strong depolarization during stimulation with ionomycin to a linear $\mathrm{I} / \mathrm{V}$ curve, and to attenuated depolarization because of removal of extracellular $\mathrm{Cl}^{-}$(Figures $1 \mathrm{~b}, 3 \mathrm{e}$ ). In contrast, when a $145 \mathrm{mM} \mathrm{NMDG}{ }^{+} \mathrm{Cl}^{-}$solution was used in the patch pipette and in the bath, the reversal potential of the $\mathrm{Ca}^{2+}$-activated $\mathrm{Cl}^{-}$current was zero, and I/V curves were outwardly rectifying. The reversal potential was shifted by the removal of bath $\mathrm{Cl}^{-}$, following the Nernst equilibrium potential for $\mathrm{Cl}^{-}$(Figures $1 \mathrm{~g}-\mathrm{i}$ ). Thus Ano6 produces a $\mathrm{Ca}^{2+}$-activated $\mathrm{Cl}^{-}$current along with a smaller nonselective cation conductance.

More recently, defective Ano6 has been found to be the cause for the rare bleeding disorder Scott syndrome, which is characterized by defective $\mathrm{Ca}^{2+}$-activated PS ${ }^{14,17}$. The present report, as well as results obtained in other cell types, point to abundant expression of this membrane protein ${ }^{9,14,32,33}$. In the present paper, we have studied how $\mathrm{Cl}^{-}$channel function in healthy control and Scott syndrome lymphocytes relates to the phospholipid scrambling process. The results indicate that Ano6 is implicated in both $\mathrm{Ca}^{2+}$-activated $\mathrm{Cl}^{-}$channel activity and phospholipid scrambling, but only the former function was sensitive to pharmacological inhibition. Thus, the ionomycin-induced $\mathrm{Cl}^{-}$conductance was potently suppressed by TA or NPPB, as well as by $\mathrm{Cl}^{-}$exclusion. In contrast, these interventions did not affect ionomycin-induced PS exposure. In other words, the Scott syndrome phenotype could not be reproduced by inhibition of the Ano6-mediated $\mathrm{Cl}^{-}$currents. This made us conclude that the $\mathrm{Ca}^{2+}$-activated phospholipid scrambling and $\mathrm{Cl}^{-}$channel activity by Ano6 are not functionally linked.

\section{Abrogated $\mathrm{Cl}$ conductance and scramblase activity by mutations of Ano6.}

An interesting observation was that ionomycin still evoked a small but significant $\mathrm{Cl}^{-}$

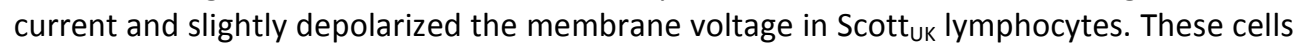
are compound heterozygous for two Ano6 mutations: (i) a transition at the first nucleotide of intron 6, leading to an in-frame deletion of 38 amino acids in the N-terminal cytoplasmic tail and (ii) a single-nucleotide insertion in exon 11, predicting a frameshift and premature termination of translation at codon $411^{17}$. In contrast, Scott USA 
lymphocytes are homozygous for one Ano6 mutation (IVS12-1G3T), causing exon 13 skipping, frameshift, and premature termination of translation ${ }^{14}$, but did not show any residual $\mathrm{Cl}^{-}$current. The Scott $\mathrm{USA}_{\mathrm{SA}}$ mutant cells do not express any Ano6 protein and completely lack of $\mathrm{Cl}^{-}$channel function, whereas the $\mathrm{Scott}_{U \mathrm{UK}}$ cells retained residual $\mathrm{Cl}^{-}$ channel activity. Overexpression of this Scott $_{\mathrm{UK}}$-specific mutant in HEK293 cells suggests a residual $\mathrm{Cl}^{-}$channel function. In contrast, $\mathrm{Ca}^{2+}$-induced PS activity was abrogated in both the Scott $_{U K}$ and Scott $_{\text {USA }}$ lymphocytes. Together, this suggests that the in-frame deletion mutation of Scott $\mathrm{SK}_{\mathrm{K}}$ results in a protein showing limited $\mathrm{Cl}^{-}$conductance and abolished scramblase activity, although other Ano6-independent mechanisms cannot be excluded.

Role of Ano6 for extrinsic and intrinsic apoptosis.

Stimulation of the extrinsic apoptosis pathway by FasL activated both $\mathrm{Cl}^{-}$channels and PS exposure in the control lymphocytes. No $\mathrm{Cl}^{-}$currents were activated by FasL in both Scott lymphocyte cell lines, however, Scott cells still showed Fas receptor-induced PS exposure, which could be prevented by caspase inhibition and hence was apoptosis-induced. Similarly, direct stimulation of Bax/Bak-dependent apoptosis with ABT-737 induced normal PS exposure in the Scott lymphocytes without activating $\mathrm{Cl}^{-}$currents. These data clearly point to a unique function of Ano6 as $\mathrm{Cl}^{-} /$nonselective cation channel, but a redundant role of Ano6 in the regulation of apoptotic PS exposure. We conclude that (i) Ano6 primarily induces a $\mathrm{Cl}^{-}$conductance along with a smaller nonselective cation conductance that is activated either $\mathrm{Ca}^{2+}$ dependently (ionomycin) or $\mathrm{Ca}^{2+}$ independently (Fas receptor), but not during mitochondrial (intrinsic) apoptosis. (ii) $\mathrm{Ca}^{2+}$-dependent phospholipid scrambling induced by $A$ no 6 occurs independent of $\mathrm{Ano} \mathrm{Cl}^{-}$conductance and (iii) $\mathrm{Ca}^{2+}$-independent phospholipid scrambling does not require Ano6. Taking into account the recent proposal that Ano6 in lymphocytes induces a $\mathrm{Ca}^{2+}$ conductance ${ }^{8}$, these findings suggest that the 'Scott' protein $\mathrm{Ano6}^{8}$ acts as a $\mathrm{Ca}^{2+}$-dependent channel for both cations and anions, or regulates these conductances, along with activation of $\mathrm{Ca}^{2+}$-dependent phospholipid scrambling in lymphocytes.

\section{Material and Methods}

\section{Cell culture}

EBV-transformed B lymphoblast cell lines from control subjects and Scott $_{\text {UK }}$ and Scott USA $_{\text {A }}$ patients have been described before ${ }^{18,19}$. The lymphocytes were grown in RPMI 1640 medium (GIBCO, 52140; Darmstadt, Germany) supplemented with $10 \%$ fetal calf serum (GIBCO) and penicillin/streptomycin (GIBCO). For patch clamping, cells were fixed on polylysine-coated coverslips.

\section{Patch clamping}

Coverslips were mounted in a heated chamber on the stage of an inverted microscope (IM35, Zeiss, Munich, Germany) and kept at $37^{\circ} \mathrm{C}$. Cells were perfused continuously with Ringer solution (in $\mathrm{mM}$ : $\mathrm{NaCl} 145, \mathrm{KH}_{2} \mathrm{PO}_{4} 0.4, \mathrm{~K}_{2} \mathrm{HPO}_{4}$ 1.6, D-glucose 5, $\mathrm{MgCl}_{2}$ 1, Cagluconate 1.3, $\mathrm{pH}$ 7.4). For fast whole-cell patch clamping, micropipettes were filled with intracellular like solution (in mM: $\mathrm{KCl} 30$, $\mathrm{K}$-gluconate 95, $\mathrm{NaH}_{2} \mathrm{PO}_{4} 1.2, \mathrm{Na}_{2} \mathrm{HPO}_{4}$ 4.8, EGTA 1, Ca-gluconate 0.758, $\mathrm{MgCl}_{2}$ 1.034, D-glucose 5, ATP 3, pH 7.2) and had an input resis- 
tance of 2-4 M $\Omega$. Changes in membrane voltage were recorded in the current clamp mode. Experiments were conducted as described earlier ${ }^{34}$.

Measurement of intracellular $\mathrm{Ca}^{2+}$ concentration

Cytosolic $\mathrm{Ca}^{2+}$ was measured in a suspension of single cells. (i) Suspended cells were loaded with $0.5 \mu \mathrm{M}$ Fluo-4 AM in the presence of $4 \mu \mathrm{g} / \mathrm{ml}$ pluronic (Molecular Probes, Darmstadt, Germany). After a washing step, cells were resuspended $\left(3 \times 10^{5} / \mathrm{ml}\right)$ in Hepes buffer, pH 7.45 (in $\mathrm{mM}$ : $\mathrm{NaCl} 136$, Hepes $10, \mathrm{KCl} 2.7, \mathrm{MgCl}_{2} 2$, glucose, and $0.1 \% \mathrm{BSA}$ $0.1 \%)$. Agonist-induced changes in Fluo-4 fluorescence $(F)$ were determined by flow cytometry (BD Accuri, Breda, Netherlands). Rises in $\mathrm{Ca}^{2+}$ are expressed as pseudo-ratio $\mathrm{F} / \mathrm{F}_{0}$, with $\mathrm{F}_{0}$, representing the fluorescence before stimulation ${ }^{35}$. (ii) Single-cell $\mathrm{Ca}^{2+}$ measurements were performed with continuously perfused immobilized lymphocytes at $37^{\circ} \mathrm{C}$, using an inverted Axiovert S100 (Zeiss) microscope and a high-speed polychromator system (VisiChrome, Visitron Systems, Puchheim, Germany). Cells were loaded with $2 \mu \mathrm{M}$ Fura-2 and AM (Molecular Probes) with $0.2 \%$ pluronic for $1 \mathrm{~h}$ at $37^{\circ} \mathrm{C}$. Experiments were conducted as described previously ${ }^{36}$.

\section{Phospholipid scrambling (phosphatidylserine exposure)}

Lymphocytes were washed in Hepes buffer, $\mathrm{pH} 7.45$ and diluted to a concentration of $3 \mathrm{x}$ $10 \% \mathrm{ml}$. The cells were stimulated as indicated with ionomycin (Calbiochem, Darmstadt, Germany), FasL (Millipore, Darmstadt, Germany) or ABT-737 (Abbott Laboratories, Wiesbaden, Germany or Active Biochem (Maplewood, NJ, USA)) in the presence of 1-2.5 mM $\mathrm{CaCl}_{2}$. Pan-caspase inhibitor QVD (Millipore) was given $10 \mathrm{~min}$ prior stimulation. Surface exposure of phosphatidylserine was assessed after 5 min labeling with FITC- or Alexa647annexin A5 (Invitrogen, Darmstadt, Germany) by flow cytometry (BD Accuri). A gating was set to exclude apoptotic and dead cells. Propidium iodide labeling revealed that the latter cells appeared as a different population in forward/side scatter plots. Five thousand viable cells were analyzed per experiment.

\section{Semi-quantitative RT-PCR}

Total RNA was isolated from B lymphocytes, and reverse transcribed using a random primer and M-MLV reverse transcriptase (Promega, Mannheim, Germany). The RT-PCR reaction contained sense and antisense primers for anoctamins or GAPDH (0.5 $\mu \mathrm{M}$; Supplementary Table 1), $1 \mu \mathrm{l} \mathrm{cDNA}$ and GoTaq polymerase (Promega). After $2 \mathrm{~min}$ at $95^{\circ} \mathrm{C}$, CDNA was amplified in 30 cycles for $30 \mathrm{~s}$ at $95^{\circ} \mathrm{C}, 30 \mathrm{~s}$ at $56^{\circ} \mathrm{C}$ and $1 \mathrm{~min}$ at $72^{\circ} \mathrm{C}$, and visualized by loading on ethidium bromide-containing agarose gels.

\section{Western blotting}

Protein was isolated from lymphocytes in lysis buffer containing $50 \mathrm{mM}$ Tris- $\mathrm{HCl}, 150 \mathrm{mM}$ $\mathrm{NaCl}, 100 \mu \mathrm{M}$ DTT, $0.2 \%$ Triton X-100, $5 \mathrm{U} / \mathrm{ml}$ of benzonase, and $1 \%$ protease inhibitor cocktail (Sigma-Aldrich, Taufkirchen, Germany). Protein was separated by $10 \%$ SDS-PAGE and transferred to a polyvinylidene difluoride membrane (GE Healthcare, Munich, Germany) using semidry transfer (Bio-Rad, Munich, Germany). Membranes were incubated with anti-Ano6 mAb (1 : 5000; Santa Cruz Biotechnology, Heidelberg, Germany) and pro- 
teins were visualized using a horseradish peroxidase-conjugated secondary antibody (dilution 1 : 10.000) and ECL detection kit (GE Healthcare).

\section{Caspase-3 activity assay}

Lymphocytes were activated in the presence or absence of QVD, as indicated. Cells were centrifuged at $2300 \mathrm{~g}$, and pellets were resolved in lysis buffer. Samples in lysis buffer were mixed $1: 1$ with $50 \mu$ l caspase-3 substrate mix, consisting of $9.8 \mu \mathrm{M}$ DTT and $49 \mu \mathrm{M}$ AcDEVD-AFC (Invitrogen). Fluorescence was measured in time using a Spectramax M2 reader. Caspase- 3 activity was determined as changes in fluorescence units per min, relative to unstimulated samples.

Supplementary Table 1. Primers used for RT-PCR analysis of anoctamins in human lymphocytes.

\begin{tabular}{|c|c|c|}
\hline $\begin{array}{l}\text { Gene } \\
\text { accession number }\end{array}$ & $\begin{array}{l}\text { Primer } \\
\text { sense (s), antisense (as) }\end{array}$ & Size (bp) \\
\hline $\begin{array}{l}\text { human ANO1 } \\
\text { NM 018043.4 }\end{array}$ & $\begin{array}{l}\text { s: 5'- CGACTACGTGTACATTTTCCG } \\
\text { as: 5'- GATTCCGATGTCTTTGGCTC }\end{array}$ & 445 \\
\hline $\begin{array}{l}\text { human ANO2 } \\
\text { NM } 020373.1\end{array}$ & $\begin{array}{l}\text { s: } 5 \text { '-GGACACCTTCTTTGATAATGC } \\
\text { as: } 5 \text {-GCATTCTGCTGGTCACACAT }\end{array}$ & 414 \\
\hline $\begin{array}{l}\text { human ANO3 } \\
\text { NM_031418.2 }\end{array}$ & $\begin{array}{l}\text { s: 5'-CTTCCCTCTTCCAGTCAAC } \\
\text { as: 5'-AAACATGATATCGGGGCTTG }\end{array}$ & 461 \\
\hline $\begin{array}{l}\text { human ANO4 } \\
\text { NM } 178826.2\end{array}$ & $\begin{array}{l}\text { s: } 5^{\prime} \text {-GAACCCATGGAGCAGAAAAC } \\
\text { as: } 5^{\prime} \text {-GCTTCAAACTGGGGTCGTAT }\end{array}$ & 496 \\
\hline $\begin{array}{l}\text { human ANO5 } \\
\text { NM_213599.1 }\end{array}$ & $\begin{array}{l}\text { s: 5'-GAATGGGACCTGGTGGAC } \\
\text { as: 5'-GAGTTTGTCCGAGCTTTTCG }\end{array}$ & 713 \\
\hline $\begin{array}{l}\text { human ANO6 } \\
\text { NM_001025356.1 }\end{array}$ & $\begin{array}{l}\text { s: } 5^{\prime} \text {-GGAGTTTTGGAAGCGACGC } \\
\text { as: } 5 \text {-GTATTTCTGGATTGGGTCTG }\end{array}$ & 325 \\
\hline $\begin{array}{l}\text { Mouse ANO6 } \\
\text { NM_175344.3 }\end{array}$ & $\begin{array}{l}\text { s: } 5^{\prime} \text {-GTATGAGGCCCAGTGCAATC } \\
\text { as: } 5 \text {-CTCTTCGCTTCTGTATTTGCC }\end{array}$ & 520 \\
\hline $\begin{array}{l}\text { human ANO7 } \\
\text { NM_001001891.3 }\end{array}$ & $\begin{array}{l}\text { s: } 5 \text { '-CCTCGACTGCCCTTTCTG } \\
\text { as: } 5 \text {-GGCACGGTACAGGATGATAGA }\end{array}$ & 379 \\
\hline $\begin{array}{l}\text { human ANO8 } \\
\text { NM_020959.1 }\end{array}$ & $\begin{array}{l}\text { s: } 5 \text {-GGAGGACCAGCCAATCATC } \\
\text { as: } 5 \text {-TCCATGTCATTGAGCCAG }\end{array}$ & 705 \\
\hline $\begin{array}{l}\text { human ANO9 } \\
\text { NM_001012302.2 }\end{array}$ & $\begin{array}{l}\text { s: 5'-GCAGCCAGTTGATGAAATC } \\
\text { as: 5'-GCTGCGTAGGTAGGAGTGC }\end{array}$ & 472 \\
\hline $\begin{array}{l}\text { human ANO10 } \\
\text { NM_018075.3 }\end{array}$ & $\begin{array}{l}\text { GTGAAGAGGAAGGTGCAGG } \\
\text { TCATCGTTTCAAAAGCCAACT }\end{array}$ & 301 \\
\hline GAPDH & $\begin{array}{l}\text { s: } 5^{\prime}-\text { GTATTGGGCGCCTGGTCAC } \\
\text { as: } 5^{\prime}-\text { CTCCTGGAAGATGGTGATGG }\end{array}$ & 200 \\
\hline
\end{tabular}

\section{Conflict of Interest}

The authors declare no conflict of interest.

\section{Acknowledgements.}

This work was supported by DFG SFB699A7, Mukoviszidose e.V. and the Cardiovascular Center Maastricht. ABT-737 was a generous gift by Abbott Laboratories (100 Abbott Park Road, Abbott Park, IL, USA).

\section{References}

1. Yang YD, Cho H, Koo JY, Tak MH, Cho Y, Shim WS, Park SP, Lee J, Lee B, Kim BM, Raouf R, Shin YK, Oh U. TMEM16A confers receptor-activated calcium-dependent chloride conductance. Nature 2008; 455 : 1210-1215.

2. Schroeder BC, Cheng T, Jan YN, Jan LY. Expression cloning of TMEM16A as a calcium-activated chloride channel subunit. Cell 2008; 134: 1019-1029. 
Calcium-activated and apoptotic phospholipid scrambling induced by Ano6 can occur independently of Ano6 ion currents

3. Caputo A, Caci E, Ferrera L, Pedemonte N, Barsanti C, Sondo E, Pfeffer U, Ravazzolo R, Zegarra-Moran O, Galietta LJ.TMEM16A, a membrane protein associated with calcium-dependent chloride channel activity. Science 2008; 322: 590-594.

4. Tian Y, Schreiber R, Kunzelmann K. Anoctamins are a family of $\mathrm{Ca}^{2+}$ activated $\mathrm{Cl}^{-}$channels. J Cell Sci 2012; 125: 4991-4998.

5. Ferrera L, Caputo A, Galietta LJ. TMEM16A protein: a new identity for $\mathrm{Ca}^{2+}$-dependent $\mathrm{Cl}$ channels. Physiology. 2010; 25: 357-363.

6. Billig GM, Pál B, Fidzinski P, Jentsch TJ. $\mathrm{Ca}^{2+}$-activated $\mathrm{Cl}^{-}$currents are dispensable for olfaction. Nature Neurosci 2011; 14: 763-769.

7. Kunzelmann K, Kongsuphol P, Aldehni F, Tian Y, Ousingsawat J, Warth R, Schreiber R. Bestrophin and TMEM16- $\mathrm{Ca}^{2+}$ activated $\mathrm{Cl}^{-}$channels with different functions. Cell Calcium 2009; 46: 233-241.

8. Yang H, Kim A, David T, Palmer D, Jin T, Tien J, Huang F, Cheng T, Coughlin SR, Jan YN, Jan LY. TMEM16F forms a $\mathrm{Ca}^{2+}$-activated cation channel required for lipid scrambling in platelets during blood coagulation. Cell 2012; 151: 111-122.

9. Martins JR, Faria D, Kongsuphol P, Reisch B, Schreiber R, Kunzelmann K. Anoctamin 6 is an essential component of the outwardly rectifying chloride channel. Proc Natl Acad Sci USA 2011; 108: 1816818172.

10. Almaca J, Tian Y, Aldehni F, Ousingsawat J, Kongsuphol P, Rock JR, Harfe BD, Schreiber R, Kunzelmann K. TMEM16 proteins produce volume regulated chloride currents that are reduced in mice lacking TMEM16A. J Biol Chem 2009; 284: 28571-28578.

11. Hanzu FA, Gasa R, Bulur N, Lybaert P, Gomis R, Malaisse WJ, Beauwens R, Sener A. Expression of TMEM16A and SLC4A4 in human pancreatic islets. Cell Physiol Biochem 2012; 29: 61-64.

12. Owsianik G, Prenen J, Hermans C, Eggermont J, Nilius B. Functional characterization of TMEM16 anion channels. FASEB J (Abstract) 2010; 608: 12.

13. Yu K, Duran C, Qu Z, Cui YY, Hartzell HC. Explaining calcium-dependent gating of anoctamin-1 chloride channels requires a revised topology. Circ Res 2012; 110: 990-999.

14. Suzuki J, Umeda M, Sims PJ, Nagata S. Calcium-dependent phospholipid scrambling by TMEM16F. Nature 2010; 468: 834-838.

15. Bevers EM, Williamson PL. Phospholipid scramblase: an update. FEBS Lett. 2010; 584: 2724-2730.

16. Heemskerk JW, Bevers EM, Lindhout T. Platelet activation and blood coagulation. Thromb Haemost 2002; 88: 186-193.

17. Castoldi E, Collins PW, Williamson PL, Bevers EM. Compound heterozygosity for 2 novel TMEM16F mutations in a patient with Scott syndrome. Blood 2011; 117: 4399-4400.

18. Munnix IC, Harmsma M, Giddings JC, Collins PW, Feijge MA, Comfurius P, Heemskerk JW, Bevers EM. Store-mediated calcium entry in the regulation of phosphatidylserine exposure in blood cells from Scott patients. Thromb Haemost 2003; 89: 687-695.

19. Williamson P, Christie A, Kohlin T, Schlegel RA, Comfurius P, Harmsma M, Zwaal RF, Bevers EM. Phospholipid scramblase activation pathways in lymphocytes. Biochemistry 2001; 40: 8065-8072.

20. de la Fuente R, Namkung W,Mills A, Verkman AS. Small molecule screen identifies inhibitors of a human intestinal calcium activated chloride channel. Mol Pharmacol 2007; 73: 758-768.

21. Hartzell HC, Putzier I, Arreola J. Calcium-activated chloride channels. Annu Rev Physiol 2005; 67: 719758.

22. Namkung W, Thiagarajah JR, Phuan PW, Verkman AS. Inhibition of $\mathrm{Ca}^{2+}$-activated Cl-channels by gallotannins as a possible molecular basis for health benefits of red wine and green tea. FASEB J 2010; 24 : 4178-4186.

23. Taylor SR, Gonzalez-Begne M, Dewhurst S, Chimini G, Higgins CF, Melvin JE, Elliott JI. Sequential shrinkage and swelling underlie P2X7-stimulated lymphocyte phosphatidylserine exposure and death. J Immunol 2008; 180: 300-308.

24. Schoenwaelder SM, Yuan Y, Josefsson EC, White MJ, Yao Y, Mason KD, O'Reilly LA, Henley KJ, Ono A, Hsiao S, Willcox A, Roberts AW, Huang DC, Salem HH, Kile BT, Jackson SP. Two distinct pathways regulate platelet phosphatidylserine exposure and procoagulant function. Blood 2009; 114: 663-666. 
25. Szabo I, Lepple-Wienhues A, Kaba KN, Zoratti M, Gulbins E, Lang F. Tyrosine kinase-dependent activation of a chloride channel in CD95-induced apoptosis in T lymphocytes. Proc Natl Acad Sci USA 1998; 95: 6169-6174.

26. Kunzelmann K, Pavenstädt H, Greger R. Properties and regulation of chloride channels in cystic fibrosis and normal airway epithelial cells. Pflugers Arch 1989; 415: 172-182.

27. Aguirre A, Shoji KF, Saez JC, Henriquez M, Quest AF. FasL-triggered death of Jurkat cells requires caspase 8-induced, ATP-dependent cross-talk between Fas and the purinergic receptor P2X(7). J Cell Physiol 2013; 228: 485-493.

28. Szteyn K, Schmid E, Nurbaeva MK, Yang W, Münzer P, Kunzelmann K, Lang F, Shumilina E. Expression and functional significance of the Ca-activated $\mathrm{Cl}^{-}$channel ANO6 in dendritic cells. Cell Physiol Biochem 2012; 30: 1319-1332.

29. Blazer-Yost BL, Blacklock BJ, Flaig S, Bacallao RL, Gattone VH. Lysophosphatidic acid is a modulator of cyst growth in autosomal dominant polycystic kidney disease. Cell Physiol Biochem 2011; 28: 12551264.

30. Kunzelmann K, Schreiber R, Kmit A, Jantarajit W, Martins JR, Faria D, Kongsuphol P, Ousingsawat J, Tian Y. Expression and function of epithelial anoctamins. Exp Physiol 2012; 97: 184-192.

31. Kunzelmann K, Tian Y, Martins JR, Faria D, Kongsuphol P, Ousingsawat J, Thevenod F, Roussa E, Rock J, Schreiber R. Anoctamins. Pflugers Arch. 2011; 462: 195-208.

32. Schreiber R, Uliyakina I, Kongsuphol P, Warth R, Mirza M, Martins JR, Kunzelmann K. Expression and function of epithelial anoctamins. J Biol Chem 2010; 285: 7838-7845.

33. Segawa K, Suzuki J, Nagata S. Constitutive exposure of phosphatidylserine on viable cells. Proc Natl Acad Sci USA 2011; 108: 19246-19251.

34. Ousingsawat J, Martins JR, Schreiber R, Rock JR, Harfe BD, Kunzelmann K. Loss of TMEM16A causes a defect in epithelial $\mathrm{Ca}^{2+}$ dependent chloride transport. J Biol Chem 2009; 284: 28698-28703.

35. Heemskerk JW, Willems GM, Rook MB, Sage SO. Ragged spiking of free calcium in ADP-stimulated human platelets: regulation of puff-like calcium signals in vitro and ex vivo. J Physiol 2001; 535: 625635.

36. Barro Soria R, Aldehni F, Almaça J, Witzgall R, Schreiber R, Kunzelmann K. ER localized bestrophin1 acts as a counter-ion channel to activate $\mathrm{Ca}^{2+}$ dependent ion channels TMEM16A and SK4. Pflugers Arch 2009; 459: 485-497. 
Chapter 8

General discussion 


\section{Determining thrombus formation in vitro with parallel-plate flow chambers}

Chapter 2 of this thesis discusses the use of parallel-plate flow chambers to study in vitro thrombus formation. Such flow chambers, equipped with a cover slip that can be coated with a variety of platelet-adhesive substrates, enable platelet function to be studied at defined shear rates, mimicking arterial or venous flow conditions as required ${ }^{1}$. By providing information on the roles of various platelet receptor and signalling molecules involved in thrombus formation, flow chamber technology has significantly contributed to a better understanding of the platelet aggregation process in flow conditions. In Chapter 2, recently developed flow chamber devices with smaller size are discussed, which allow studying thrombus formation in vitro with a few hundreds of micro-litres of mouse or human blood.

Although the flow-chamber assay is expected to be of predictive value for evaluating the risk of arterial thrombosis, caution should be taken in the translation of in vitro to in vivo thrombus formation. For instance, pathological thrombus formation after atherosclerotic plaque rupture will be triggered by multiple platelet-adhesive proteins that become exposed to the blood stream, such in contrast to the common in vitro assay where a single thrombogenic substrate is used. In some studies this limitation is overcome by the coating of atherosclerotic plaque material obtained from human autopsy material or from Apoe $e^{-1-}$ mice ${ }^{2-4}$. Since the availability of native plaque material is limited (and the process of extraction is labour-intensive), this is not preferred for larger size patient studies or for general diagnostic purposes. So far, fibrillar type I collagen appears to be the most suitable substrate, as it captures von Willebrand factor and other prohemostatic plasma proteins, and it is highly adhesive and activating for platelets ${ }^{2,5}$. Furthermore, this collagen type stimulates the coagulation process via factor $\mathrm{XII}^{6}$. In several experimental studies with genetically modified mice, it has been shown that in vitro whole blood thrombus formation on collagen correlates well with in vivo arterial thrombosis, when assessed in collagen-dependent models of vascular injury ${ }^{7}$.

Studies with human blood indicated that in vitro thrombus formation on collagen was either unchanged or reduced in subjects taking aspirin, while this process was unequivocally reduced in subjects using aspirin in combination with a $\mathrm{P}_{2} \mathrm{Y}_{12}$ receptor inhibitor like clopidogrel or ticlopidine ${ }^{8-10}$. In another study, a microchip flow-chamber system coated with collagen was used to determine protective effects of several platelet antagonists like aspirin, abciximab, the prostacyclin analogue beraprost, and the glycoprotein (GP)Iba antagonist OS-1 ${ }^{11}$. These examples illustrate the potential clinical benefit of this test to evaluate the efficacy of antithrombotic therapy. Large clinical studies however will be needed to reveal, to which extent determination of in vitro thrombus formation can predict the occurrence of thrombotic or bleeding events in patients with specific antithrombotic therapies.

Given the multitude of adhesive receptors on platelets, an ideal future flow chamber device makes it possible to test thrombus formation on multiple substrate spots in one run and at different shear rates. For instance, a coated fibrinogen spot may identify defects in integrin $\alpha_{11 b} \beta_{3}$ expression or activation, e.g. as seen in patients with Glanzmann's thrombasthenia ${ }^{12}$. Thanks to the large choice in thrombogenic substrates, shear rates and parameter read-outs of thrombus formation, parallel-plate flow chamber technology 
seems ideal for studying the diverse molecular mechanisms underlying this process under rheological conditions mimicking those in the circulation.

\section{Roles of platelet STIM1 and Orai1 in thrombus formation}

Chapter 3 describes experiments aimed to provide more insight into the role of the endoplasmic reticulum $\mathrm{Ca}^{2+}$ sensor, STIM1, and the plasma membrane $\mathrm{Ca}^{2+}$ channel, Orai1, in platelet function. Previously, both proteins were shown to be responsible for the process of store-operated $\mathrm{Ca}^{2+}$ entry (SOCE) ${ }^{13,14}$. However, the functional role of the STIM1/Orai1 pathway in thrombus formation under coagulating and non-coagulating conditions was not established. Given the lethality of full knockout Stim $1^{-/-}$and Orai1 ${ }^{-/}$mice ${ }^{13,14}$, experiments were performed with bone-marrow transplanted mice in which only the hematologic cells lacked expression of STIM1 or Orai1. We found that, in the absence of coagulation, in vitro thrombus formation on collagen was strongly decreased in STIM1- or Orai1-deficient blood, an observation in line with reports by Varga-Szabo and Braun that deficiency in either protein protected for arterial thrombosis in vivo ${ }^{13,14}$. The decreased in vitro thrombus formation was accompanied by suppressed $\mathrm{Ca}^{2+}$ responses and diminished phosphatidylserine (PS) exposure, thus supporting the evidence that STIM1 and Orai1 are main mediators of $\mathrm{Ca}^{2+}$ entry ${ }^{13-15}$ and $\mathrm{Ca}^{2+}$-dependent phospholipid scramblase activity ${ }^{16 \text {, }}$ ${ }^{17}$. Interestingly, the group of Bergmeier, using STIM1-deficient platelets, did not find a diminished platelet aggregation under flow ${ }^{18}$. It should however be noted, that STIM1deficient as well as Orai1-deficient platelets show a diminished aggregation response to low doses of GPVI agonists, such as collagen or collagen-related peptide ${ }^{13,14,18}$. While aggregation normalizes at higher concentrations ${ }^{13,14,18}$, it is tempting to speculate that in the flow experiments by Bergmeier and colleagues, platelets were more strongly activated, compared to our experiments. This might explain why deficiency in STIM1- or Orai1 did not impact outcome in their flow system.

A remarkable observation in chapter 3 is that GPVI-induced PS exposure was no longer affected in the concomitant presence of thrombin, implicating that STIM1 and Orai1 are redundant for this process under coagulant conditions. This can be explained by the more sustained $\mathrm{Ca}^{2+}$ responses with this agonist combination ${ }^{19-21}$. Although stimulation by GPVI alone or by the combined action of thrombin and GPVI agonist gave reduced $\mathrm{Ca}^{2+}$ responses in STIM1- or Orai1-deficient platelets, it seems after dual agonist stimulation a sufficiently high and sustained $\mathrm{Ca}^{2+}$ response is achieved to induce phospholipid scrambling (Figure 1). In both types of knockout platelets, the general $\mathrm{Ca}^{2+}$ entry blocker SKF$96365{ }^{22}$ was able to further reduce the $\mathrm{Ca}^{2+}$ responses, pointing to the existence of a STIM1/Orai1-independent pathway of $\mathrm{Ca}^{2+}$ entry. We have not identified the nature of this pathway, but it may involve receptor-operated $\mathrm{Ca}^{2+}$ entry via $\mathrm{P} 2 \mathrm{X}_{1}$ channels ${ }^{23}$, or noncapacitive $\mathrm{Ca}^{2+}$ entry through TRPC6 ${ }^{24,25}$. The latter protein, TRPC6, is a cation channel activated by diacylglycerol, and is known to become more active at higher thrombin concentrations ${ }^{24}$. Generation of double knock-out mice for TRPC6 and Orai1 may prove whether TRPC6 is responsible for the residual $\mathrm{Ca}^{2+}$ entry in the absence of Orai1. It should be noted that $\operatorname{Trpc}^{-\sigma_{-}}$mice do not show an antithrombotic phenotype and respond normally to a wide range of agonists ${ }^{25}$, which supports the idea that store-operated $\mathrm{Ca}^{2+}$ entry via STIM1 and Orai1 is the most important $\mathrm{Ca}^{2+}$ entry route in platelets. 

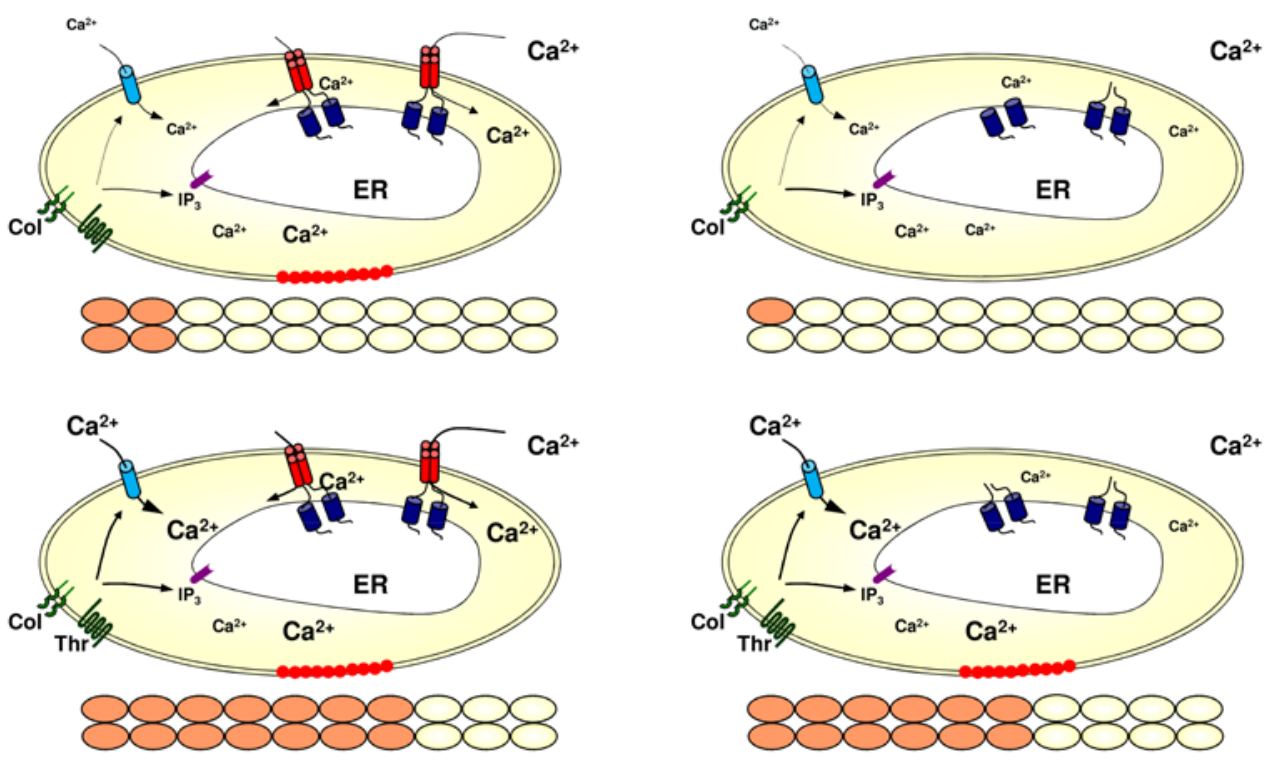

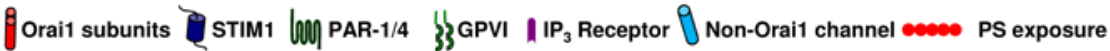

Figure 1. Orai1-dependent and -independent $\mathrm{Ca}^{2+}$ entry regulate platelet PS exposure. Platelet stimulation with collagen receptor agonist alone (upper left) gives a moderate $\mathrm{Ca}^{2+}$ responses, which is further increased by the simultaneous presence of thrombin (lower left). In either case Orai1/STIM1-dependent $\mathrm{Ca}^{2+}$ entry provides the major entry pathway, but with thrombin present, more inositol trisphosphate $\left(\mathrm{IP}_{3}\right)$ is produced and also non-Orai1 $\mathrm{Ca}^{2+}$ channels become activated. This leads to high stimulation of PS exposure. In the absence of Orai1, collagen receptor-induced $\mathrm{Ca}^{2+}$ entry has mostly disappeared (upper right), but thrombin is still capable to produce $\mathrm{IP}_{3}$ and stimulate Orai1-independent $\mathrm{Ca}^{2+}$ entry (lower right). The result is still high stimulation of PS exposure. Fractions of PS-exposing platelet in each condition are visualised by the numbers of redcoloured platelets below the schemes.

\section{Antithrombotic potential of $\mathrm{Ca}^{2+}$ entry blockers}

Knowing that Orai1 has a key role in murine arterial thrombus formation in vivo, we studied in chapter 4 the efficacy of several pharmacological blockers of Orai1 to suppress this process. An overview of the results is given in Figure 2. In washed platelets, the established $\mathrm{Ca}^{2+}$ influx inhibitors, SKF-96365 and 2-aminoethyl diphenylborate (2APB), and the novel $\mathrm{Ca}^{2+}$ entry blockers, Synta66 and GSK-7975A, all dose-dependently inhibited agonistinduced $\mathrm{Ca}^{2+}$ fluxes in platelets. This is in line with earlier reports identifying SKF-96365 and $2 \mathrm{APB}$ as potent inhibitors of $\mathrm{Ca}^{2+}$ entry in platelets ${ }^{22,26}$. The other compounds, Synta66 and GSK-7975A, are characterized as $\mathrm{Ca}^{2+}$ entry inhibitors in mast cells ${ }^{27,28}$. As in platelets, the STIM1/Orai1 pathway is the major SOCE pathway in mast cells ${ }^{29,30}$. Inhibition of platelet $\mathrm{Ca}^{2+}$ entry was accompanied with a decrease in platelet PS exposure, while only SKF-96365 was not able to impact thrombin generation in PRP. Interestingly, we found that SKF-96365, GSK-7975A and Synta66, but not 2-APB, suppressed $\mathrm{Ca}^{2+}$ responses in 
Orai $1^{-/}$platelets upon thrombin stimulation, suggestive for some inhibition of non-Orai1 channel by these compounds.

The effects of these $\mathrm{Ca}^{2+}$ entry blockers - at maximal achievable concentrations - were then tested on whole-blood thrombus formation in vitro. In a similar way as Orail or STIM1 deficiency, the compounds 2-APB, Synta66 and GSK-7975A suppressed: (i) platelet $\mathrm{Ca}^{2+}$ fluxes under flow, (ii) the formation of aggregates and (iii) the exposure of PS, both in human and mouse blood. Furthermore, in vivo, injection of 2APB into mice suppressed inside wire-induced ischemic brain infarction, which is in line with a key role of platelet Orai1 in this experimental infarction model ${ }^{14}$.

\begin{tabular}{|c|c|c|c|c|c|c|c|c|}
\hline \multirow[b]{2}{*}{ System } & & \multicolumn{3}{|c|}{ Mouse } & \multicolumn{4}{|c|}{ Human } \\
\hline & & STIM1\% & Orai $1^{\%}$ & 2APB & 2APB & Synta66 & GSK & SKF \\
\hline \multirow{2}{*}{$\begin{array}{l}\text { Washed } \\
\text { platelets } \\
\text { (GPVI/thr) }\end{array}$} & $\mathrm{Ca}^{2+}$ response & $\cdots$ & $\cdots$ & n.d & $\cdots$ & $\cdots$ & $\cdots$ & $\cdots$ \\
\hline & PS exposure & 0 & 0 & n.d. & $\cdots$ & $\cdots$ & $\cdots$ & $\cdots$ \\
\hline PRP & Thrombin generation & - & $\cdot$ & n.d. & $\cdots$ & $\cdot$ & $\cdot$ & 0 \\
\hline \multirow{3}{*}{$\begin{array}{l}\text { Whole-blood } \\
\text { thrombus } \\
\text { formation }\end{array}$} & Thrombus formation & $\cdots$ & $\cdot$ & $\cdot$ & $\cdot$ & $\cdot$ & $\cdot$ & 0 \\
\hline & $\mathrm{Ca}^{2+}$ response & $\cdots$ & $\cdots$ & $\cdot$ & $\cdot$ & $\cdot$ & $\cdot$ & 0 \\
\hline & PS exposure & $\cdots$ & $\cdots$ & $\cdots$ & $\cdots$ & $\cdots$ & $\cdots$ & 0 \\
\hline In vivo & Ischemic brain inf. & $\cdots$ & --- & - & n.a. & n.a. & n.a. & n.a. \\
\hline
\end{tabular}

Figure 2. Effect of genetic deletion of STIM1 or Orai1 (mouse), or of pharmacologic blockade (human and mouse) by the indicated $\mathrm{Ca}^{2+}$ entry inhibitors on platelet functions and in vitro or in vivo models of thrombus formation. Symbols: 0; no effect; - ; reduction; - -, strong reduction; n.d., not determined; n.a. not assessable. GPVI, glycoprotein VI; thr, thrombin.

Together, chapters 3 and 4 provide proof-of-principle evidence that pharmacological blockage of Orai1-mediated $\mathrm{Ca}^{2+}$ entry may provide a strategy for the prevention of arterial thrombus formation. Deficiency in platelet STIM1 or Orai1 was found to be protective for arterial thrombus formation, whereas tail bleeding was only mildly affected ${ }^{13,14}$. Hence, targeting platelet Orai1 may provide an advantage over current anti-platelet therapies that are accompanied with an increased risk of bleeding. However, when applied in human, it should be realized that SOCE inhibitors may also act as immunosuppressants by blocking of the T cell Orai1 channels and suppressing T-cell functions ${ }^{31,32}$. More preclinical research is needed to address the efficacy and safety of Orai1 inhibitors in cardiovascular disease. This will also require the synthesis of compounds with a better solubility and pharmacokinetic profile.

\section{Role of TMEM16F in apoptosis-induced phospholipid scrambling}

In platelets, phospholipid scrambling can be induced by $\mathrm{Ca}^{2+}$-mobilising agonists as well as by apoptosis. In chapter 5 and 6, we studied the contribution of the membrane protein, anoctamin 6 (TMEM16F), in agonist- and apoptosis-induced PS exposure. Experiments were performed with murine platelets deficient in TMEM16F, and with platelets from a Scott syndrome patient, in whom the TMEM16F gene is mutated. Platelet apoptosis was induced by the $\mathrm{BH} 3$ mimetic $\mathrm{ABT}-737$. This compound activates the pro-apoptotic proteins Bax and Bak and stimulates caspase activity ${ }^{33}$. Treatment of control human or mouse 
platelets with ABT-737 resulted in the formation of two distinct PS-exposing populations, showing moderate or high annexin A5 binding. In Scott syndrome platelets, and also in murine $T$ mem $16 f^{\prime-}$ platelets, the high annexin A5-binding population was initially absent. The total percentage of PS-positive platelets (moderate and high annexin A5 binding) was similar in Tmem $16 f^{+/+}$and Tmem16f $f^{/-}$mice. Prolonged incubation with ABT-737 ultimately resulted in high percentages of high annexin A5-binding platelets in wild type as well as Tmem $16 f^{\prime-}$ mice. The same was true for human control platelets and Scott patient platelets. Thus, it seems TMEM16F is not necessary for apoptotic PS exposure, but yet contributes to this process by accelerating PS exposure, at least in a subset of platelets.

Since TMEM16F is essential for $\mathrm{Ca}^{2+}$-induced phospholipid scrambling ${ }^{34}$, the question arises which mechanism is responsible for elevating the intracellular $\mathrm{Ca}^{2+}$ concentration in apoptotic platelets. Vogler et al. showed that ABT-737 has a stimulatory effect on reticular $\mathrm{Ca}^{2+}$ release ${ }^{35}$. Yet, ABT-737 is unlikely to stimulate TMEM16F-dependent phospholipid scrambling on its own, since caspase inhibition completely blocked all PS exposure. An alternative explanation for elevated $\mathrm{Ca}^{2+}$ levels in a subset of apoptotic platelets is the loss of ATP during apoptosis, resulting in inhibition of the $\mathrm{Ca}^{2+}$ pumps $^{36}$. Alternatively, apoptotic platelets may exhibit an increased permeability of the plasma membrane for $\mathrm{Ca}^{2+}$. In summary, although PS exposure during platelet apoptosis is not dependent on TMEM16F, this protein may accelerate phospholipid scrambling in $\mathrm{Ca}^{2+}$-dependent way (Figure 3, IIIa and IIIb). A limitation of this work is that it relies on the use of ABT-737, which not necessarily needs to mimic platelet apoptosis in vivo ${ }^{37}$. Another remark is that long-term in vitro storage may not be a good model for $\mathrm{Bcl}-\mathrm{x}_{\mathrm{L}}$-mediated apoptosis, as PS exposure during in vitro storage is driven by glucose deprivation and ATP depletion ${ }^{38}$.

\section{Role of TMEM16F in agonist-induced phospholipid scrambling}

Phospholipid scrambling induced by $\mathrm{Ca}^{2+}$-elevating agonists is characteristically impaired in Scott syndrome platelets. Such platelets show no appreciable PS exposure upon activation with convulxin/thrombin, while their $\mathrm{Ca}^{2+}$ responses including SOCE and mitochondrial depolarisation are normal ${ }^{39,40}$. Jobe et al. have proposed a crucial role for the mitochondrial permeability transition pore (MPTP) in mediating platelet PS exposure based on the fact that convulxin/thrombin-induced PS exposure was impaired in mice lacking cyclophilin D, a regulator of MPTP formation ${ }^{41}$. In line with this, in human platelets, inhibition of mitochondrial depolarisation by cyclosporin A suppressed PS exposure in response to convulxin/thrombin (chapter 5 ) or collagen-related peptide/thrombin ${ }^{33}$.

We confirmed the role of TMEM16F in agonist-induced phospholipid scrambling using Tmem16f ${ }^{\prime-}$ mice. Platelets from TMEM16F-deficient mice exhibited a reduced, though not completely annulled, convulxin/thrombin- and ionomycin-induced PS exposure. A similar observation has been made by Yang et al. ${ }^{42}$ using a different mouse strain. The latter mice were protected against arterial thrombosis employing the $\mathrm{FeCl}_{3}$-induced injury mode ${ }^{42}$. In concordance with the mild bleeding disorder in Scott syndrome patients ${ }^{43,44}$, these mice had a prolonged tail bleeding time ${ }^{42}$.

As we found residual PS exposure in Tmem16f $f^{--}$mouse platelets after stimulation with convulxin/thrombin, also in platelets from Scott patients some agonist combinations (e.g. collagen/thrombin) cause residual PS exposure. This remaining activity was not prevented 
by caspase inhibition, in line with a previous report that PS exposure upon platelet activation is distinct from apoptotic PS exposure ${ }^{33}$. Jointly, these data thus may point to two pathways of PS exposure upon agonist stimulation, one involving TMEM16F (and cyclophilin D-mediated MPTP formation) and one acting independently of TMEM16F (Figure 3, $\mathrm{Ila}$ and IIb). The latter pathway, however, still relies on $\mathrm{Ca}^{2+}$ elevation. The exact mechanism remains to be elucidated, but might involve one of the other TMEM16-family members.

I

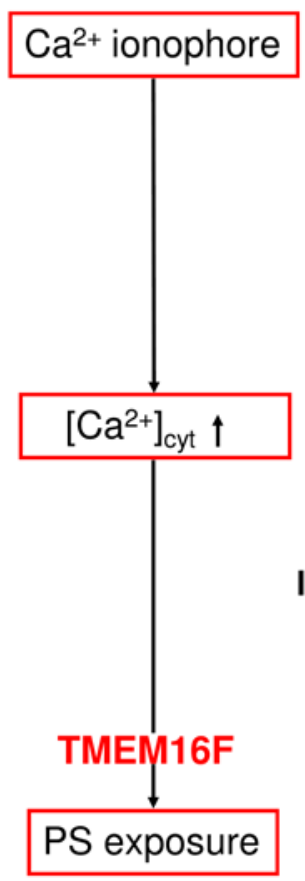

II

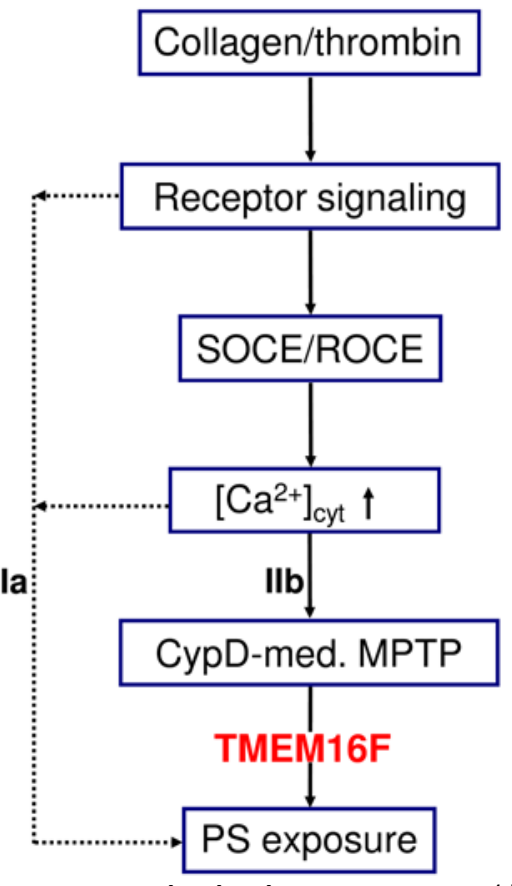

III

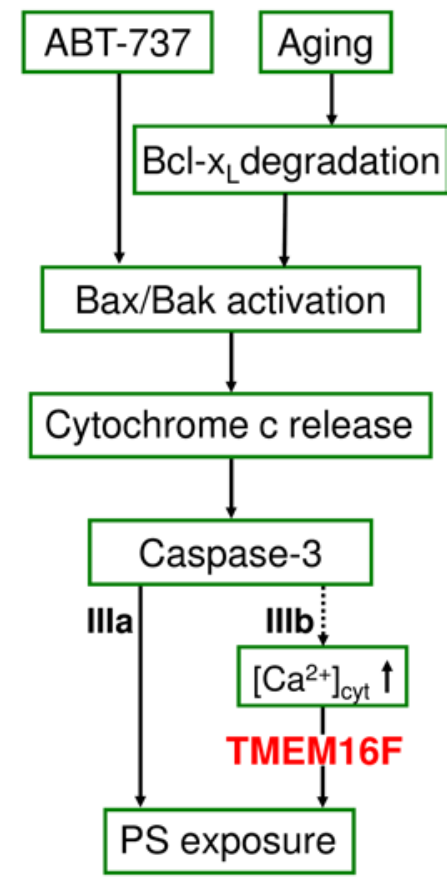

Figure 3. Multiple pathways towards platelet PS exposure. (I) lonomycin-induced PS exposure is mediated through elevation of $\mathrm{Ca}^{2+}$ and subsequent activation of TMEM16F. (II) Collagen/thrombininduced signalling raises intracellular $\mathrm{Ca}^{2+}$ through store-operated- and receptor-operated $\mathrm{Ca}^{2+}$ entry (SOCE/ROCE) pathways. High sustained $\mathrm{Ca}^{2+}$ levels stimulate cyclophilin D-dependent MPTP formation followed by TMEM16F-dependent phospholipid scrambling (IIb), while also another pathway to PS exposure can be activated, independently of TMEM16F and cyclophilin D (Ila). Stimulation with the $\mathrm{BH} 3-$ mimetic $\mathrm{ABT}-737$, or aging-induced $\mathrm{BCl}-\mathrm{x}_{\mathrm{L}}$ degradation induces $\mathrm{PS}$ exposure via a process dependent on activation of Bax/Bak, cytochrome $c$ release and caspase activity. Apoptotic PS exposure occurs independently of TMEM16F (IIla). However, TMEM16F can accelerate apoptosis-induced PS exposure under conditions of elevated $\mathrm{Ca}^{2+}(\mathrm{IIIb})$.

\section{Role of MPTP in platelet PS exposure}

Although the precise formation of MPTP in platelets with elevated $\mathrm{Ca}^{2+}$ is unknown, a close relationship between mitochondrial depolarisation and PS exposure has been reported by various groups ${ }^{45,46}$. One suggestion is that formation of the MPTP is a consequence of $\mathrm{Ca}^{2+}$ overload of the inner mitochondrial matrix ${ }^{45,47}$. Basso et al. demon- 
strated that cyclophilin $\mathrm{D}$ regulates the $\mathrm{Ca}^{2+}$ sensitivity of the MPTP, as higher cytosolic $\mathrm{Ca}^{2+}$ levels are required to induce MPTP formation in absence of cyclophilin $\mathrm{D}^{47}$. Likewise, in cyclophilin D-deficient- platelets higher $\mathrm{Ca}^{2+}$ levels are required to induce PS exposure 45. We found that inhibition of MPTP formation by cyclosporin A strongly suppresses TMEM16F-dependent phospholipid scrambling. In agreement with this, others have shown that stimulation of MPTP formation results in increased platelet PS exposure ${ }^{46}$. Together, these data point to the involvement of $\mathrm{Ca}^{2+}$-sensitive MPTP formation in the promotion of TMEM16F-dependent phospholipid scrambling. Of note, MPTP formation by itself is not sufficient to induce PS exposure, because Scott syndrome platelets do not show PS exposure despite normal cyclophilin D-mediated mitochondrial depolarisation.

Upon convulxin/thrombin-stimulation, intracellular $\mathrm{Ca}^{2+}$ levels are relatively high in the population of PS-exposing platelets ${ }^{45,48}$, and specifically these platelets show mitochondrial depolarisation. Considering that MPTP formation is a major determinant of platelet PS exposure, this may reflect a role of $\mathrm{Ca}^{2+}$ in the regulation of MPTP formation, with subsequent (downstream) PS exposure as a resultant. However, since TMEM16F also is a $\mathrm{Ca}^{2+}$ sensitive protein as described by Suzuki et al. ${ }^{34}$, it could also be proposed that MPTP formation mediates PS exposure by a secondary further elevation of cytosolic $\mathrm{Ca}^{2+}$. This idea is supported by evidence that loss of the mitochondrial membrane potential reduces the capacity of mitochondria to buffer cytosolic $\mathrm{Ca}^{2+} 49,50$, while following ATP depletion would impair the function of the plasma membrane and sarco-endoplasmic $\mathrm{Ca}^{2+}$-ATPases, thereby enhancing the $\mathrm{Ca}^{2+}$ response. However, this does not agree with the finding by Choo et al. that cyclophilin D-deficient platelet exhibit unchanged $\mathrm{Ca}^{2+}$ responses ${ }^{45}$. A limitation of the latter study, however, is that $\mathrm{Ca}^{2+}$ levels were measured only after the first minutes of platelet activation, i.e. a period in which the majority of platelets not yet shows mitochondrial depolarisation and PS exposure. Together, these data indicate that PS exposure is not exclusively determined by $\mathrm{Ca}^{2+}$ entry, but primarily depends on the (mitochondrial-dependent) elevation of cytosolic $\mathrm{Ca}^{2+}$. Still, more evidence is needed to unravel the events occurring in the late phases of platelet phospholipid scrambling.

\section{Distinct roles of TMEM16F in hematopoietic cells}

Besides a role in phospholipid scrambling, TMEM16F is also involved in the generation of $\mathrm{Ca}^{2+}$-activated ion currents ${ }^{42,51,52}$. In chapter 7 , we provide evidence that TMEM16F is responsible for both anion and cation currents in immortalised $B$ lymphocytes. Importantly, these currents were absent in B lymphocytes from a Scott patient (Scott USA $_{\text {A }}$ ), lacking TMEM16F expression due to a mutation causing a premature stop of translation. A recent paper indicates that mutation of the putative pore region of TMEM16F changes the anion selectivity of the currents ${ }^{53}$. This may indicate that TMEM16F is the pore-forming subunit of a channel or, alternatively, a channel protein with intrinsic ion-conducting properties. In the B lymphocytes derived from another Scott patient (Scott $\left.{ }_{U K}\right)$, we were able to identify a small residual $\mathrm{Cl}^{-}$current. The latter cells were low in expression of a mutant form of TMEM16F, lacking 38 amino acids in the N-terminal cytoplasmic tail of the protein ${ }^{54}$. Over-expression of this mutated TMEM16F in HEK-293 cells resulted in a detectable whole cell current in response to $\mathrm{Ca}^{2+}$-ionophore ionomycin, although weaker than observed in cells expressing wildtype TMEM16F (chapter 7). 
In spite of these differences in ion conductance, ionomycin-induced phospholipid scrambling was equally impaired in B lymphocytes from the UK and US Scott patients. As previously reported for Jurkat cells ${ }^{51}$, we found that Fas ligand was able to induce TMEM16F-assigned $\mathrm{Cl}^{-}$currents, as these were present in control B lymphocytes, but absent in Scott B-cells. Fas ligand-induced PS exposure, however, was not affected in the patient-derived cells, concordant with the earlier observation that apoptosis-induced PS exposure occurs normally in Scott B-cells ${ }^{55}$. As expected, ABT-737-induced PS exposure was normal in Scott lymphocytes.

While investigating whether TMEM16F-mediated phospholipid scrambling relies on these $\mathrm{Cl}^{-}$currents, we found that neither pharmacologic blockade of chloride channel activity nor replacement of extracellular $\mathrm{Cl}^{-}$by gluconate did affect ionomycin-induced phospholipid scrambling in control B-cells. From this, we conclude that the TMEM16F-dependent phospholipid scrambling and $\mathrm{Cl}^{-}$channel activity are not functionally linked. A limitation, though, of these experiments is, that due to the high rate of PS exposure after ionomycin treatment the annexin A5-binding assay may not detect small differences in rate of phospholipid scrambling.

A phenomenon tightly associated with PS exposure is the change in platelet morphology. Under all conditions, platelets exposing PS typically transform into blebbing, balloonshaped cells with a degraded actin cytoskeleton ${ }^{36,56}$. Strikingly, this morphological change does not appear to occur in Scott syndrome platelets ${ }^{57}$. Although not described in this thesis, similar observations have recently been made in our laboratory using Tmem16f ${ }^{/-}$ mouse platelets ${ }^{58}$. It has been speculated that such morphological changes may originate from differences in the rate of inward and outward movement between phospholipid classes, thus creating a mass imbalance between the inner and outer leaflet leading to exfoliation of the plasma membrane ${ }^{59}$. The experiments in this thesis cannot conclude on this idea. Hence, the precise mechanisms of changes in platelet morphology, ion currents and phospholipid scrambling by TMEM16F remain to be elucidated.

Chapter 6 describes that erythrocytes from heterozygous Tmem $16 f^{+/-}$mice show a diminished PS exposure upon ionomycin treatment when compared to wildtype erythrocytes, with a further reduction in Tmem $16 f^{/-}$erythrocytes. This suggests that the expression level of TMEM16F is a limiting factor in $\mathrm{Ca}^{2+}$-mediated PS exposure at least in mouse erythrocytes. In contrast, ionomycin-induced PS exposure in platelets from heterozygous Tmem $16 f^{+-}$mice was similar to that observed in wildtype platelets. This can be explained by the fact that $\mathrm{Ca}^{2+}$-induced phospholipid scrambling is much faster in platelets than in erythrocytes, implicating that the annexin A5-binding assay is insensitive for assessing differences in rate of lipid scrambling ${ }^{55}$. Previously, using a different technique, reduced rates of ionomycin-induced phospholipid scrambling were observed in platelets from two heterozygous Scott patients ${ }^{44}$, suggesting a direct link between the level of expression of TMEM16F and rate of phospholipid scrambling.

The data presented in this thesis and the current literature cannot distinguish whether TMEM16F has intrinsic scramblase activity or is a regulator of another protein with scramblase activity. If TMEM16F is a protein with intrinsic scramblase activity, other proteins with scramblase activity must exist, since apoptosis-induced phospholipid scrambling induced by ABT-737 (platelets and lymphocytes) or Fas ligand (lymphocytes) occurs inde- 
pendently of functional TMEM16F. Furthermore, with particular agonists, Scott syndrome platelets and Tmem $16 f^{--}$murine platelets, show residual phospholipid scrambling activity. Ultimate proof for TMEM16F being a scramblase protein requires purification and reconstitution in proteo-liposomes, demonstrating $\mathrm{Ca}^{2+}$-induced lipid scrambling. Recent evidence indicates that also other members of the TMEM16 family (TMEM16C, TMEM16D, TMEM16G and TMEM16J) can be implicated at least in ionomycin-induced phospholipid scrambling ${ }^{60}$. However in chapter 6 , no such role for TMEM16A was found.

\section{References}

1. Zwaginga JJ, Nash G, King MR, Heemskerk JW, Frojmovic M, Hoylaerts MF, Sakariassen KS. Flow-based assays for global assessment of hemostasis. Part 1: Biorheologic considerations. J Thromb Haemost. 2006;4:2486-2487.

2. Cosemans JM, Kuijpers MJ, Lecut C, Loubele ST, Heeneman S, Jandrot-Perrus M, Heemskerk JW. Contribution of platelet glycoprotein $\mathrm{VI}$ to the thrombogenic effect of collagens in fibrous atherosclerotic lesions. Atherosclerosis. 2005;181:19-27.

3. Nergiz-Unal R, Cosemans JM, Feijge MA, van der Meijden PE, Storey RF, van Giezen JJ, oude Egbrink MG, Heemskerk JW, Kuijpers MJ. Stabilizing role of platelet $P 2 Y_{12}$ receptors in shear-dependent thrombus formation on ruptured plaques. PLoS One. 2010;5:e10130.

4. Reininger AJ, Bernlochner I, Penz SM, Ravanat C, Smethurst P, Farndale RW, Gachet C, Brandl R, Siess W. A 2-step mechanism of arterial thrombus formation induced by human atherosclerotic plaques. J Am Coll Cardiol. 2010;55:1147-1158.

5. Heemskerk JW, Sakariassen KS, Zwaginga JJ, Brass LF, Jackson SP, Farndale RW. Collagen surfaces to measure thrombus formation under flow: Possibilities for standardization. J Thromb Haemost. 2011;9:856-858.

6. van der Meijden PE, Munnix IC, Auger JM, Govers-Riemslag JW, Cosemans JM, Kuijpers MJ, Spronk HM, Watson SP, Renne T, Heemskerk JW. Dual role of collagen in factor XII-dependent thrombus formation. Blood. 2009;114:881-890.

7. Denis CV, Dubois C, Brass LF, Heemskerk JW, Lenting PJ. Towards standardization of in vivo thrombosis studies in mice. J Thromb Haemost. 2011;9:1641-1644.

8. Bossavy JP, Thalamas C, Sagnard L, Barret A, Sakariassen K, Boneu B, Cadroy Y. A double-blind randomized comparison of combined aspirin and ticlopidine therapy versus aspirin or ticlopidine alone on experimental arterial thrombogenesis in humans. Blood. 1998;92:1518-1525.

9. Cadroy Y, Bossavy JP, Thalamas C, Sagnard L, Sakariassen K, Boneu B. Early potent antithrombotic effect with combined aspirin and a loading dose of clopidogrel on experimental arterial thrombogenesis in humans. Circulation. 2000;101:2823-2828.

10. Mendolicchio GL, Zavalloni D, Bacci M, Corrada E, Marconi M, Lodigiani C, Presbitero P, Rota L, Ruggeri ZM. Variable effect of $\mathrm{P}_{2} \mathrm{Y}_{12}$ inhibition on platelet thrombus volume in flowing blood. J Thromb Haemost. 2011;9:373-382.

11. Hosokawa K, Ohnishi T, Fukasawa M, Kondo T, Sameshima H, Koide T, Tanaka KA, Maruyama I. A microchip flow-chamber system for quantitative assessment of the platelet thrombus formation process. Microvasc Res. 2012;83:154-161.

12. Nurden AT. Qualitative disorders of platelets and megakaryocytes. J Thromb Haemost. 2005;3:17731782.

13. Varga-Szabo D, Braun A, Kleinschnitz C, Bender M, Pleines I, Pham M, Renne T, Stoll G, Nieswandt B. The calcium sensor STIM1 is an essential mediator of arterial thrombosis and ischemic brain infarction. J Exp Med. 2008;205:1583-1591.

14. Braun A, Varga-Szabo D, Kleinschnitz C, Pleines I, Bender M, Austinat M, BosI M, Stoll G, Nieswandt B. Orai1 (CRACM1) is the platelet SOC channel and essential for pathological thrombus formation. Blood. 2009;113:2056-2063.

15. Bergmeier W, Oh-Hora M, McCarl CA, Roden RC, Bray PF, Feske S. R93W mutation in Orai1 causes impaired calcium influx in platelets. Blood. 2009;113:675-678. 
16. Dachary-Prigent J, Pasquet JM, Nurden AT. Simultaneous detection of changes in cytoplasmic $\mathrm{Ca}^{2+}$, aminophospholipid exposure and micro-vesiculation in activated platelets. Platelets. 1997;8:405-412

17. Williamson P, Bevers EM, Smeets EF, Comfurius P, Schlegel RA, Zwaal RF. Continuous analysis of the mechanism of activated transbilayer lipid movement in platelets. Biochemistry. 1995;34:10448-10455

18. Ahmad F, Boulaftali Y, Greene TK, Ouellette TD, Poncz M, Feske S, Bergmeier W. Relative contributions of stromal interaction molecule 1 and CaIDAG-GEFI to calcium-dependent platelet activation and thrombosis. J Thromb Haemost. 2011;9:2077-2086.

19. Bevers EM, Comfurius P, van Rijn JL, Hemker HC, Zwaal RF. Generation of prothrombin-converting activity and the exposure of phosphatidylserine at the outer surface of platelets. Eur J Biochem. 1982;122:429-436.

20. Heemskerk JW, Bevers EM, Lindhout T. Platelet activation and blood coagulation. Thromb Haemost. 2002;88:186-193.

21. Heemskerk JW, Mattheij NJ, Cosemans JM. Platelet-based coagulation: Different populations, different functions. J Thromb Haemost. 2013;11:2-16.

22. Merritt JE, Armstrong WP, Benham CD, Hallam TJ, Jacob R, Jaxa-Chamiec A, Leigh BK, McCarthy SA, Moores KE, Rink TJ. SK\&F-96365, a novel inhibitor of receptor-mediated calcium entry. Biochem J. 1990;271:515-522.

23. Vial C, Pitt SJ, Roberts J, Rolf MG, Mahaut-Smith MP, Evans RJ. Lack of evidence for functional ADPactivated human $\mathrm{P} 2 \mathrm{X}_{1}$ receptors supports a role for atp during hemostasis and thrombosis. Blood. 2003;102:3646-3651.

24. Harper MT, Poole AW. Store-operated calcium entry and non-capacitative calcium entry have distinct roles in thrombin-induced calcium signalling in human platelets. Cell Calcium. 2011;50:351-358

25. Ramanathan G, Gupta S, Thielmann I, Pleines I, Varga-Szabo D, May F, Mannhalter C, Dietrich A, Nieswandt B, Braun A. Defective diacylglycerol-induced $\mathrm{Ca}^{2+}$ entry but normal agonist-induced activation responses in TRPC6-deficient mouse platelets. J Thromb Haemost. 2012;10:419-429.

26. Dobrydneva Y, Blackmore P. 2-aminoethoxydiphenyl borate directly inhibits store-operated calcium entry channels in human platelets. Mol Pharmacol. 2001;60:541-552.

27. Ng SW, di Capite J, Singaravelu K, Parekh AB. Sustained activation of the tyrosine kinase Syk by antigen in mast cells requires local $\mathrm{Ca}^{2+}$ influx through $\mathrm{Ca}^{2+}$ release-activated $\mathrm{Ca}^{2+}$ channels. J Biol Chem. 2008;283:31348-31355.

28. Ashmole I, Duffy SM, Leyland ML, Morrison VS, Begg M, Bradding P. CRACM/Orai ion channel expression and function in human lung mast cells. J Allergy Clin Immunol. 2012;129:1628-1635

29. Baba Y, Nishida K, Fujii Y, Hirano T, Hikida M, Kurosaki T. Essential function for the calcium sensor STIM1 in mast cell activation and anaphylactic responses. Nat Immunol. 2008;9:81-88.

30. Vig M, DeHaven WI, Bird GS, Billingsley JM, Wang H, Rao PE, Hutchings AB, Jouvin MH, Putney JW, Kinet JP. Defective mast cell effector functions in mice lacking the CRACM1 pore subunit of storeoperated calcium release-activated calcium channels. Nat Immunol. 2008;9:89-96.

31. Feske S. Immunodeficiency due to defects in store-operated calcium entry. Ann N Y Acad Sci. 2011;1238:74-90.

32. Feske S, Gwack Y, Prakriya M, Srikanth S, Puppel SH, Tanasa B, Hogan PG, Lewis RS, Daly M, Rao A. A mutation in Orai1 causes immune deficiency by abrogating crac channel function. Nature. 2006;441:179-185.

33. Schoenwaelder SM, Yuan Y, Josefsson EC, White MJ, Yao Y, Mason KD, O'Reilly LA, Henley KJ, Ono A, Hsiao S, Willcox A, Roberts AW, Huang DC, Salem HH, Kile BT, Jackson SP. Two distinct pathways regulate platelet phosphatidylserine exposure and procoagulant function. Blood. 2009;114:663-666

34. Suzuki J, Umeda M, Sims PJ, Nagata S. Calcium-dependent phospholipid scrambling by TMEM16F. Nature. 2010;468:834-838

35. Vogler M, Hamali HA, Sun XM, Bampton ET, Dinsdale D, Snowden RT, Dyer MJ, Goodall AH, Cohen $\mathrm{GM}$. Bcl-2/Bcl- $x_{\mathrm{L}}$ inhibition induces apoptosis, disrupts cellular calcium homeostasis, and prevents platelet activation. Blood. 2011;117:7145-7154.

36. Jackson SP, Schoenwaelder SM. Procoagulant platelets: Are they necrotic? Blood. 2010;116:20112018. 
37. Mason KD, Carpinelli MR, Fletcher JI, Collinge JE, Hilton AA, Ellis S, Kelly PN, Ekert PG, Metcalf D, Roberts AW, Huang DC, Kile BT. Programmed anuclear cell death delimits platelet life span. Cell. 2007;128:1173-1186

38. Saunders C, Rowe G, Wilkins K, Collins P. Impact of glucose and acetate on the characteristics of the platelet storage lesion in platelets suspended in additive solutions with minimal plasma. Vox Sang. 2013;105:1-10.

39. Brooks MB, Catalfamo JL, Friese P, Dale GL. Scott syndrome dogs have impaired coated-platelet formation and calcein-release but normal mitochondrial depolarization. J Thromb Haemost. 2007;5: 1972-1974.

40. Munnix IC, Harmsma M, Giddings JC, Collins PW, Feijge MA, Comfurius P, Heemskerk JW, Bevers EM. Store-mediated calcium entry in the regulation of phosphatidylserine exposure in blood cells from Scott patients. Thromb Haemost. 2003;89:687-695.

41. Jobe SM, Wilson KM, Leo L, Raimondi A, Molkentin JD, Lentz SR, Di Paola J. Critical role for the mitochondrial permeability transition pore and cyclophilin $\mathrm{D}$ in platelet activation and thrombosis. Blood. 2008;111:1257-1265.

42. Yang H, Kim A, David T, Palmer D, Jin T, Tien J, Huang F, Cheng T, Coughlin SR, Jan YN, Jan LY. TMEM16F forms a $\mathrm{Ca}^{2+}$-activated cation channel required for lipid scrambling in platelets during blood coagulation. Cell. 2012;151:111-122.

43. Toti F, Satta N, Fressinaud E, Meyer D, Freyssinet JM. Scott syndrome, characterized by impaired transmembrane migration of procoagulant phosphatidylserine and hemorrhagic complications, is an inherited disorder. Blood. 1996;87:1409-1415.

44. Zwaal RF, Comfurius P, Bevers EM. Scott syndrome, a bleeding disorder caused by defective scrambling of membrane phospholipids. Biochim Biophys Acta. 2004;1636:119-128.

45. Choo HJ, Saafir TB, Mkumba L, Wagner MB, Jobe SM. Mitochondrial calcium and reactive oxygen species regulate agonist-initiated platelet phosphatidylserine exposure. Arterioscler Thromb Vasc Biol. 2012;32:2946-2955.

46. Remenyi G, Szasz R, Friese P, Dale GL. Role of mitochondrial permeability transition pore in coatedplatelet formation. Arterioscler Thromb Vasc Biol. 2005;25:467-471.

47. Basso E, Fante L, Fowlkes J, Petronilli V, Forte MA, Bernardi P. Properties of the permeability transition pore in mitochondria devoid of cyclophilin D. J Biol Chem. 2005;280:18558-18561.

48. Arachiche A, Kerbiriou-Nabias D, Garcin I, Letellier T, Dachary-Prigent J. Rapid procoagulant phosphatidylserine exposure relies on high cytosolic calcium rather than on mitochondrial depolarization. Arterioscler Thromb Vasc Biol. 2009;29:1883-1889.

49. Starkov AA. The molecular identity of the mitochondrial $\mathrm{Ca}^{2+}$ sequestration system. FEBS J. 2010;277:3652-3663.

50. Rizzuto R, De Stefani D, Raffaello A, Mammucari C. Mitochondria as sensors and regulators of calcium signalling. Nat Rev Mol Cell Biol. 2012;13:566-578.

51. Martins JR, Faria D, Kongsuphol P, Reisch B, Schreiber R, Kunzelmann K. Anoctamin 6 is an essential component of the outwardly rectifying chloride channel. Proc Natl Acad Sci U S A. 2011;108:1816818172.

52. Shimizu T, lehara T, Sato K, Fujii T, Sakai H, Okada Y. TMEM16F is a component of a Ca ${ }^{2+}$-activated $\mathrm{Cl}^{-}$ channel but not a volume-sensitive outwardly rectifying $\mathrm{Cl}^{-}$channel. Am J Physiol Cell Physiol. 2013;304:C748-759.

53. Grubb S, Poulsen KA, Juul CA, Kyed T, Klausen TK, Larsen EH, Hoffmann EK. TMEM16F (Anoctamin 6), an anion channel of delayed $\mathrm{Ca}^{2+}$ activation. J Gen Physiol. 2013;141:585-600.

54. Castoldi E, Collins PW, Williamson PL, Bevers EM. Compound heterozygosity for 2 novel TMEM16F mutations in a patient with Scott syndrome. Blood. 2011;117:4399-4400.

55. Williamson P, Christie A, Kohlin T, Schlegel RA, Comfurius P, Harmsma M, Zwaal RF, Bevers EM. Phospholipid scramblase activation pathways in lymphocytes. Biochemistry. 2001;40:8065-8072.

56. Heemskerk JW, Vuist WM, Feijge MA, Reutelingsperger CP, Lindhout T. Collagen but not fibrinogen surfaces induce bleb formation, exposure of phosphatidylserine, and procoagulant activity of adherent platelets: Evidence for regulation by protein tyrosine kinase-dependent $\mathrm{Ca}^{2+}$ responses. Blood. 1997;90:2615-2625. 
57. Wielders SJ, Broers J, ten Cate H, Collins PW, Bevers EM, Lindhout T. Absence of platelet-dependent fibrin formation in a patient with Scott syndrome. Thromb Haemost. 2009;102:76-82.

58. Mattheij NJ, Braun A, van Kruchten R, Cosemans JM, van der Meijden PE, Baaten C, Ehlen HW, Schreiber R, Vortkamp A, Collins P, Bevers EM, Ousingsawat J, Kunzelmann K, Nieswandt B, Heemskerk JW. The Scott syndrome protein Anoctamin 6 (TMEM16F) regulates multiple cell death responses including membrane phospholipid scrambling in platelets. J Thromb Haemost. 2013;11 Suppl 2:112.

59. Smeets EF, Comfurius P, Bevers EM, Zwaal RF. Calcium-induced transbilayer scrambling of fluorescent phospholipid analogs in platelets and erythrocytes. Biochim Biophys Acta. 1994;1195:281-286.

60. Suzuki J, Fujii T, Imao T, Ishihara K, Kuba H, Nagata S. Calcium-dependent phospholipid scramblase activity of TMEM16 protein family members. J Biol Chem. 2013;288:13305-13316. 

Summary 
Platelets have prominent roles in thrombus formation. This involves their adherence to extracellular matrix components, co-aggregation to from a platelet plug, and stimulation of the coagulation process. Elevation of the intracellular $\mathrm{Ca}^{2+}$ level is an essential signalling event in the process of platelet activation and, hence, for thrombus formation. Storeoperated $\mathrm{Ca}^{2+}$ entry is considered to be the most important $\mathrm{Ca}^{2+}$ entry route in activated platelets. Prolonged high intracellular calcium levels activate the scrambling of membrane phospholipids, resulting in exposure of phosphatidylserine (PS) at the outer leaflet of the plasma membrane. The exposure of PS stimulates coagulation by providing a catalytic surface for the assembly of coagulation factor complexes and ensuing thrombin generation.

In chapter 1, relevant background information is given on the roles of platelets in thrombosis. The role of fluid dynamics in the process of thrombus formation is discussed, as well as the use of parallel-plate flow chambers to determine whole blood thrombus formation. Furthermore, an introduction is given into the mechanisms of platelet $\mathrm{Ca}^{2+}$ signalling, with special attention to the functions of STIM1 and Orai1, two proteins involved in platelet store-operated $\mathrm{Ca}^{2+}$ entry. Current knowledge on the mechanisms of phospholipid scrambling is discussed, with a focus on TMEM16F (also called anoctamin 6), a protein proposed to be involved in $\mathrm{Ca}^{2+}$-induced phospholipid scrambling. Apart from platelet activation, also platelet apoptosis is mentioned as another route by which platelets can expose PS.

In chapter 2 practical issues are discussed regarding the use of parallel-plate flow chambers for the assessment of in vitro whole-blood thrombus formation. The aim of this chapter is to provide new guidelines for a reproducible assessment of in vitro thrombus formation. The practical issues discussed encompass, among others, flow chamber assembly, calculation of shear rates, common experimental artefacts, and abilities of microscopic image recording. Because residual coagulation can strongly influence the outcome of the process of in vitro thrombus formation, methods are described to restrict coagulation or to allow coagulation in a controlled manner. Furthermore, a wide variety of possible substrates and possible read-out parameters are given. Although a clear role for Orai1 and STIM1 in regulating platelet store-operated $\mathrm{Ca}^{2+}$ and thrombus formation has been demonstrated, their relative contribution to platelet procoagulant activity and thrombus formation under coagulating and non-coagulating conditions remains obscure. This issue is addressed in chapter 3 . In vitro experiments, using blood from mice with platelet deficiencies in STIM1 or Orai1, showed that collagen-driven thrombus formation, platelet $\mathrm{Ca}^{2+}$ signaling, and platelet PS exposure are significantly impaired in absence of STIM1 or Orai1. Notably, these effects tended to normalize upon introduction of coagulation. Additional experiments in washed platelets confirmed that STIM1 and Orai1 became redundant in the concomitant presence of high thrombin concentrations. Also evidence for an Orai1-independent $\mathrm{Ca}^{2+}$ entry pathway in platelets is presented. This alternative pathway appeared to become prominent upon combined collagen/thrombin stimulation. In contrast to STIM1, deficiency in STIM2 did not show any effect on thrombus formation or platelet procoagulant activity, indicating that STIM2 does not play a major role in platelet activation.

Given the importance of $\mathrm{Ca}^{2+}$ entry for platelet activation and thrombus formation, potential inhibitors of Orai1 were tested for their efficacy to suppress these processes, the 
results of which are described in chapter 4. Apart from the known platelet $\mathrm{Ca}^{2+}$ entry inhibitors 2-APB and SKF96365, the novel compounds Synta66 and GSK-7975A were identified as effective inhibitors of platelet store-operated $\mathrm{Ca}^{2+}$. Subsequent experiments, measuring whole blood thrombus formation in parallel-plate flow chambers, revealed that the compounds 2-APB, Synta66 and GSK-7975A all were able to suppress platelet procoagulant activity, $\mathrm{Ca}^{2+}$ responses, and thrombus formation under flow. In addition, 2APB markedly reduced the size of brain infarctions in an in vivo murine stroke model. Experiments performed with Orai1-deficient blood pointed to Orai1 as primary target of these compounds. Altogether, the data from chapter 3 and 4 identify Orai1 as a potential target for development of novel anti-thrombotic agents.

As described, elevation of intracellular $\mathrm{Ca}^{2+}$ stimulates phospholipid scrambling in platelets. Scott syndrome is a rare bleeding disorder in which $\mathrm{Ca}^{2+}$-dependent phospholipid scrambling in platelets and other blood cells is impaired. Recently, this defect could be attributed to the absence of functional TMEM16F. In chapter 5, the involvement of TMEM16F in various pathways to platelet PS exposure was studied by in vitro experiments, using platelets from a patient with Scott syndrome. Phospholipid scrambling upon platelet apoptosis was determined by incubation of platelets with the BH3-mimetic ABT737. While platelets from Scott syndrome patients and healthy controls showed a similar percentage of PS exposure upon ABT-737-induced apoptosis, the Scott platelets failed to generate a specific, high PS-exposing population. This led to the conclusion that, although TMEM16F is not critically involved in PS exposure upon apoptosis, it does accelerate PS exposure in a subset of the apoptotic platelets. Additional experiments with the intracellular $\mathrm{Ca}^{2+}$ chelator BAPTA confirmed that the TMEM16F-mediated phospholipid scrambling is $\mathrm{Ca}^{2+}$ dependent. Regarding phospholipid scrambling, a major finding was that upon costimulation of platelets with collagen and thrombin, next to a TMEM16F-dependent pathway, also a TMEM16F-independent pathway to PS exposure is activated. The insensitivity of the latter pathway to pharmacological inhibition by either the caspase inhibitor QVD-Oph or the mitochondrial inhibitor cyclosporin A, suggested that it acts independently of caspase activity and Cyclophillin D-dependent mitochondrial depolarization.

In chapter 6 , the role of TMEM16F in phospholipid scrambling upon platelet activation and platelet apoptosis was confirmed using murine TMEM16F knockout platelets. Furthermore, the consequences of TMEM16F heterozygousity were tested. Platelet PS exposure was not affected in heterozygous TMEM16F-deficient platelets. However, $\mathrm{Ca}^{2+}$ ionomycininduced PS exposure was affected in heterozygous erythrocytes. These erythrocytes showed levels of PS exposure that were intermediate between those in wild type and homozygous TMEM16F-deficient erythrocytes. This suggests that TMEM16F expression is a limiting factor in $\mathrm{Ca}^{2+}$-induced phospholipid scrambling in mouse erythrocytes.

Recent reports indicate that TMEM16F is a calcium-activated channel that is involved in conducting anion (chloride) and cation (calcium) currents. In chapter 7, these properties were studied using immortalized B-cells from two unrelated Scott syndrome patients and healthy controls. Calcium elevation was able to stimulate large whole cell currents in control lymphocytes, but not in Scott lymphocytes, although a small residual chloride current could be identified in the B-cells from one patient. Whole cell currents were also suppressed upon knockdown of TMEM16F by siRNA, by replacement of chloride by gluconate, 
and by pharmacologic chloride channel blockade. The process of $\mathrm{Ca}^{2+}$-induced PS exposure was strongly impaired in both Scott lymphocytes cell lines, while PS exposure was not impaired in these cells in response to apoptotic stimuli, which is in line with the defect found in platelets. The $\mathrm{Ca}^{2+}$-induced PS exposure in control lymphocytes could not be inhibited by suppression of chloride currents, by pharmacological blockade or chloride replacement, suggesting that $\mathrm{Ca}^{2+}$-activated phospholipid scrambling does not rely on chloride currents.

In chapter 8, the most important findings of this thesis are discussed in view of the current literature. 
Samenvatting 
Bloedplaatjes hebben een veelzijdige rol in de vorming van een trombus. Dit behelst het aanhechten van plaatjes aan extracellulaire matrixcomponenten, het samenklonteren van plaatjes tot een plaatjesplug en het stimuleren van de bloedstolling. Stijging van het intracellulaire calciumniveau is een essentiële signaleringsstap in het proces van plaatjesactivatie en daarmee ook voor trombusvorming. De voornaamste route voor calciuminstroom in plaatjes verloopt via het mechanisme van store-operated calciuminflux. In sterk geactiveerde plaatjes wordt, door de langdurig hoge intracellulaire calciumniveaus, het proces van fosfolipiden-scrambling geactiveerd. Dit heeft de expositie van fosfatidylserine op de buitenzijde van het plaatjesmembraan als gevolg. De expositie van fosfatidylserine stimuleert vervolgens de stolling omdat het een katalytisch oppervlak vormt waarop stollingsfactoren kunnen complexeren en activeren.

In hoofdstuk 1 wordt relevante achtergrondinformatie gegeven over de veelzijdige rol van plaatjes in trombose. De rol van de stromingscondities in het proces van trombusvorming wordt besproken, evenals het gebruik van parallelplaat-flowkamers voor de bepaling van trombusvorming in volbloed. Verder worden de mechanismen beschreven van calciumsignalering in plaatjes, met de nadruk op de functies van STIM1 en Orai1, twee eiwitten betrokken bij de store-operated calciuminstroom. Tevens wordt de huidige kennis over het mechanisme van fosfolipidenscrambling geïnventariseerd, met focus op TMEM16F, een eiwit dat bepalend is voor calcium-gereguleerde fosfolipiden-scrambling. Niet alleen plaatjesactivatie, maar ook plaatjesapoptose komt aan bod, omdat dit laatste proces een andere manier is via welke plaatjes fosfatidylserine kunnen exposeren.

In hoofdstuk 2 wordt praktische informatie gegeven over het gebruik van parallelplaatflowkamers voor de bepaling van trombusvorming in geïsoleerd volbloed. Het doel van dit hoofdstuk is verbeterde voorschriften aan te dragen voor het reproduceerbaar meten van in vitro trombusvorming. Onderwerpen die in dit hoofdstuk aan bod komen omvatten onder andere de constructie van de flowkamer, het berekenen van afschuifsnelheden, experimentele artefacten en de wijze van opname van (fluorescentie)beelden. Omdat zelfs minieme trombinevorming en stolling het proces van trombusvorming sterk kan beïnvloeden, wordt uitgebreid ingegaan op methodes om ofwel de stolling te voorkomen, ofwel op een gecontroleerde manier te laten plaatsvinden. Verder bevat hoofdstuk 2 een uiteenzetting van de potentiële substraten waarop trombusvorming kan plaatsvinden, alsook van de diverse mogelijke uitkomstparameters.

Alhoewel al eerder is aangetoond dat de eiwitten STIM1 en Orai1 een voorname rol spelen bij de regulatie van store-operated calciuminstroom en trombusvorming, is hun betrokkenheid bij de procoagulante respons van plaatjes en trombusvorming onder stollende en niet-stollende condities nooit bepaald. Dit is onderzocht in hoofdstuk 3 . Uit in vitro experimenten met bloed van muizen met STIM1- of Orai1-deficiënte plaatjes bleek, dat collageen-afhankelijke trombusvorming, calciumsignalering en fosfatidylserine expositie significant onderdrukt zijn in afwezigheid van STIM1 of Orai1. Een opvallende bevinding was dat deze effecten geringer werden onder stollingscondities, dat wil zeggen met trombine. Vervolgexperimenten met gewassen plaatjes bevestigden dat STIM1 en Orai1 niet meer bepalend zijn voor collageen-geïnduceerde plaatjesactivatie in de aanwezigheid van trombine. Tevens werden aanwijzingen gevonden voor een Orai1-onafhankelijke route van calciuminstroom. Deze alternatieve route bleek vooral prominent na gecombineerde 
stimulatie van plaatjes met collageen en trombine. In tegenstelling tot de effecten van deficiëntie van STIM1, bleek STIM2-deficiëntie niet van invloed op trombusvorming of procoagulante activiteit van plaatjes. Dit impliceert dat STIM2 geen belangrijke rol speelt in de calciumsignalering van plaatjes.

Gezien het belang van calciuminstroom voor plaatjesfunctie en trombusvorming, althans onder condities waar de stolling beperkt is, werden in hoofdstuk 4 potentiële remmers van Orai1 getest. Naast de bekende calciumremmers 2-APB en SKF-96365, werden de verbindingen Synta66 en GSK-7975A geïdentificeerd als effectieve remmers van storeoperated calciuminstroom in plaatjes. Vervolgmetingen van in vitro trombusvorming in parallelplaat-flowkamers, maakten duidelijk dat 2-APB, Synta66 en GSK-7975A in staat zijn om zowel de procoagulante activiteit van plaatjes en de calciumrespons, alsook trombusvorming te onderdrukken onder stromingscondities. Tevens bleek, middels een in vivo muismodel van ischemisch herseninfarct, dat remming van Orai1 door 2APB leidt to een aanzienlijke verkleining van het infarctgebied na vasculaire occlusie. Experimenten met Orai1-deficiënt bloed gaven aan dat plaatjes-Orai1 het primaire doeleiwit is van 2APB. Samenvattend, laten de data van hoofdstuk 3 en 4 zien dat Orai1 een potentieel target is voor de ontwikkeling van nieuwe antitrombotische medicatie.

Zoals beschreven, stimuleert stijging van de intracellulaire calciumconcentratie het proces van fosfolipiden-scrambling in plaatjes. Het Scott syndroom is een zeer zeldzame bloedingsaandoening, waarbij plaatjes en andere bloedcellen niet in staat zijn tot calciumgeïnduceerde fosfolipiden-scrambling. Onlangs bleek dat de oorzaak van dit defect gelegen is in de afwezigheid of dysfunctie van het TMEM16F-eiwit, ook wel aangeduid als anoctamin 6 . In hoofdstuk 5 is de betrokkenheid van TMEM16F onderzocht in de verschillende signaleringsroutes leidend tot fosfatidylserine-expositie in plaatjes. Dit werd gedaan door in vitro experimenten, gebruikmakend van de plaatjes van een patiënt met het Scott syndroom. Fosfolipiden-scrambling als gevolg van apoptose werd bestudeerd door plaatjes te incuberen met de verbinding ABT-737, die in gezonde cellen apoptose veroorzaakt. Alhoewel het proces van fosfatidylserine-expositie onder invloed van ABT-737 in de Scott-plaatjes als zodanig optrad, bleek een plaatjespopulatie met hoge fosfatidylserineexpositie afwezig te zijn. Hieruit werd geconcludeerd dat TMEM16F weliswaar niet essentieel is voor fosfatidylserine-expositie als gevolg van apoptose, maar dat het betrokken is bij de acceleratie van dit proces in een populatie van apoptotische plaatjes. Vervolgexperimenten met de intracellulaire calcium-chelator BAPTA bevestigden de veronderstelde calciumafhankelijkheid van de TMEM16F-gemedieerde fosfolipiden-scrambling. Bij stimulatie met collageen en trombine bleek, dat er zowel een TMEM16F-afhankelijke als een TMEM16F-onafhankelijke signaleringsroute geactiveerd werd, beide leidend tot fosfolipiden-scrambling. Uit het feit dat de TMEM16F-onafhankelijke route ongevoelig was voor de caspase-remmer Q-VD-Oph en de mitochondriële remmer cyclosporine A, werd geconcludeerd dat deze route onafhankelijk verloopt van caspase-activiteit en cyclofiline Dgemediëerde depolarisatie van het mitochondriële membraan.

In hoofdstuk 6 werd met behulp van TMEM16F-deficiënte muizenplaatjes de rol van TMEM16F bestudeerd in fosfolipiden-scrambling als gevolg van plaatjesactivatie en apoptose. Uit experimenten met heterozygote TMEM16F-deficiënte muizenplaatjes bleek dat de fosfatidylserine-expositie hier niet verstoord is. Daarentegen was er wel een ver- 
minderde fosfatidylserine-expositie als gevolg van calciumverhoging in heterozygote TMEM16F-deficiënte rode bloedcellen. Deze rode cellen vertoonden intermediaire niveaus van fosfatidylserine-expositie, in vergelijking met wildtype of volledig TMEM16Fdeficiënte cellen. Deze resultaten suggereren dat TMEM16F-expressie een limiterende factor is voor calcium-geïnduceerde fosfolipiden-scrambling in muizenerytrocyten.

Behalve betrokkenheid van TMEM16F bij fosfolipiden-scrambling, is in de literatuur ook een rol van TMEM16F beschreven als eiwitkanaal voor anionen $\left(\mathrm{Cl}^{-}\right)$en kationen $\left(\mathrm{Ca}^{2+}\right)$. In hoofdstuk 7 werden deze eigenschappen van TMEM16F bestudeerd met behulp van geimmortaliseerde B-cellen, afkomstig van twee verschillende patiënten met Scott syndroom en van gezonde proefpersonen. Met de patch-clamp techniek werd een calcium-afhankelijke chloridestroom gemeten in de controle lymfocyten, maar niet in de Scott lymfocyten. Zowel uitschakeling van TMEM16F middels siRNA, vervanging van chlorideionen door andere anionen, als farmacologische blokkade van de chloride-instroom, onderdrukte deze ionenstromen. De calcium-afhankelijke fosfatidylserine-expositie was sterk verminderd in de cellijnen van beide Scott patiënten, terwijl de fosfatidylserine-expositie als gevolg van apoptose normaal verliep in deze cellen, zulks in overeenstemming met de observaties aan Scott plaatjes. Calciumafhankelijke fosfatidylserine-expositie in controle lymfocyten werd niet geremd door onderdrukking van chloridestromen middels ofwel farmacologische blokkade, ofwel vervanging van chloride-ionen door andere anionen. Dit suggereert dat calcium-geïnduceerde fosfolipiden-scrambling als zodanig niet afhankelijk is van de chloridestromen. Ten slotte zijn in hoofdstuk 8 de belangrijkste bevindingen van dit proefschrift besproken in het licht van de huidige literatuur. 
Curriculum Vitae 
Roger van Kruchten werd geboren op 13 februari 1985 te Sittard. In 1997 begon hij zijn middelbare school-opleiding aan het Bischoppelijk College Schöndeln te Roermond, waar hij in 2003 zijn VWO-diploma behaalde, met als afstudeerprofielen Natuur \& Gezondheid en Natuur \& Techniek. In 2003 begon hij met de bacheloropleiding Moleculaire Levenswetenschappen aan de transnationale Universiteit Limburg. Na het behalen van de bachelorgraad in 2006 volgde hij aan de Universiteit Maastricht de masteropleiding Clinical Molecular Sciences. Zijn afstudeerstage, naar de rol van mechanische stress op differentiatie van cardiale fibroblasten, deed hij bij de vakgroep Fysiologie van de Universiteit Maastricht, waarna hij in 2008 zijn master-diploma ontving met de onderscheiding cum laude. Op 1 september 2008 begon hij zijn PhD-onderzoek bij het Cardiovascular Research Institute Maastricht (CARIM), binnen de vakgroep Biochemie van de faculteit Health, Medicine and Life Sciences van de Universiteit Maastricht. Onder begeleiding van Prof. Dr. J.W.M. Heemskerk en Dr. E.M. Bevers voerde hij onderzoek uit in het domein van trombose in hemostase, zoals beschreven in dit proefschrift. Het onderzoek van dit proefschrift werd uitgevoerd binnen het programma INCOAG van het Center for Translational Molecular Medicine (CTMM). Tijdens zijn periode als promovendus presenteerde hij delen van zijn onderzoek op congressen in Boston (Verenigde Staten), Nürnberg (Duitsland), Kyoto (Japan), Noordwijkerhout en Maastricht. Vanaf maart 2013 is hij werkzaam als Medical Advice and Communication Specialist bij Janssen Biologics in Leiden. 


\section{Publications}




\section{Papers:}

- Wouters K, van Gorp PJ, Bieghs V, Gijbels MJ, Duimel H, Lütjohann D, Kerksiek A, van Kruchten R, Maeda N, Staels B, van Bilsen M, Shiri-Sverdlov R, Hofker MH. Dietary cholesterol, rather than liver steatosis, leads to hepatic inflammation in hyperlipidemic mouse models of nonalcoholic steatohepatitis. Hepatology. 2008;48:474-486. Impact factor: 12.00

- Gilio K, van Kruchten R, Braun A, Berna-Erro A, Feijge MA, Stegner D, van der Meijden PE, Kuijpers MJ, Varga-Szabo D, Heemskerk JW, and Nieswandt B. Roles of platelet STIM1 and Orai1 in glycoprotein VI- and thrombin-dependent procoagulant activity and thrombus formation. J Biol Chem. 2010; 285:2362923638. Impact factor: 4.65

- Cosemans JM, van Kruchten R, Olieslagers S, Schurgers LJ, Verheyen FK, Munnix IC, Waltenberger J, Angelillo-Scherrer A, Hoylaerts MF, Carmeliet P, and Heemskerk JW. Potentiating role of Gas6 and Tyro3, AxI and Mer (TAM) receptors in human and murine platelet activation and thrombus stabilization. J Thromb Haemost. 2010; 8:1797-1808. Impact factor: 6.08

- Lievens D, Zernecke A, Seijkens T, Soehnlein O, Beckers L, Munnix IC, Wijnands E, Goossens P, van Kruchten R, Thevissen L, Boon L, Flavell RA, Noelle RJ, Gerdes N, Biessen EA, Daemen MJ, Heemskerk JW, Weber C, Lutgens E. Platelet CD40L mediates thrombotic and inflammatory processes in atherosclerosis. Blood. 2010; 116:4317-4327. Impact factor: 9.06

- Nergiz-Unal R, Lamers MM, van Kruchten R, Luiken JJ, Cosemans JM, Glatz JF, Kuijpers MJ, Heemskerk JW. Signaling role of CD36 in platelet activation and thrombus formation on immobilized thrombospondin or oxidized low-density lipoprotein. J Thromb Haemost. 2011; 9:1835-1846. Impact factor: 6.08

- Van Kruchten R, Cosemans JM, Heemskerk JW. Measurement of whole blood thrombus formation using parallel-plate flow chambers - a practical guide. Platelets. 2012;23:229-242. Impact factor: 2.24

- Van Kruchten R, Braun A, Feijge MA, Kuijpers MJ, Rivera-Galdos R, Kraft P, Stoll G, Kleinschnitz C, Bevers EM, Nieswandt B, Heemskerk JW. Antithrombotic potential of blockers of store-operated calcium channels in platelets. Arterioscler Thromb Vasc Biol. 2012;32:1717-1723. Impact factor: 6.34

- Van Kruchten R, Mattheij NJ, Saunders C, Feijge MA, Swieringa F, Wolfs JL, Collins PW, Heemskerk JW, Bevers EM. Both TMEM16F-dependent and TMEM16Findependent pathways contribute to phosphatidylserine exposure in platelet apoptosis and platelet activation. Blood. 2013;121:1850-1857. Impact factor: 9.06

- Kmit A, van Kruchten R, Ousingsawat J, Mattheij NJ, Senden-Gijsbers B, Heemskerk JW, Schreiber R, Bevers EM, and Kunzelmann K. Calcium-activated and apoptotic phospholipid scrambling induced by Ano6 can occur independently of Ano6 ion currents. Cell Death Dis. 2013;4:e611. Impact factor: 6.04 
- Mattheij NJ, Gilio K, van Kruchten R, Jobe SM, Wieschhaus, AJ, Chisthi AH, Collins $P$, Heemskerk JW, Cosemans JM. Dual mechanism of integrin $\alpha_{11 b} \beta_{3}$ closure in procoagulant platelets. J Biol Chem. 2013;288:13325-13336. Impact factor: 4.65

- Van Kruchten R, Mattheij NJ, Braun A, Baaten C, van der Meijden PEJ, Baaten C, Ehlen HWA, Vortkamp A, Schreiber R, Ousingsawat J, Bevers EM, Cosemans JMEM, Kunzelmann K, Nieswandt B, Heemskerk JWM. Role of murine TMEM16F in agonist- and apoptosis-induced phospholipid scrambling in platelets and erythrocytes. Submitted.

- De Witt SM, Lamers MM, Cavill R, van Kruchten R, Swieringa F, Coort S, Mastenbroek T, Pugh N, Schulz A, Scharrer I, Jurk K, Ziegler B, Clemetson KJ, Farndale RW, Heemskerk JW, Cosemans JM. Multi-parameter assessment of thrombus formation: identifying platelet function defects. Submitted

\section{Abstracts:}

- Shiri-Sverdlov R, Bieghs, V, Wouters K, van Gorp PJ, van der Made I, Lütjohann D, Kerksiek A, van Kruchten R, Maeda N, Kathryn J, Gijbels MJ, de Winther MP, Staels, B, van Bilsen M, and Hofker MH. Chem Phys Lipids. 2008;154:S14.

- Gilio K, van Kruchten R, Braun A, Elvers M, van der Meijden PE, Feijge MA, Kuijpers MJ, Stegner D, Heemskerk JW, and Nieswandt B. Role of platelet Orai1 and STIM1 in GPVI-dependent and GPVI-independent thrombus formation and procoagulant activity. J Thromb Haemost. 2009;7:Supplement 2.

- Gilio K, Mattheij N, Feijge MA, van Kruchten R, Cosemans JM, and Heemskerk JW. Regulation of integrin closure in procoagulant platelets. Hämostaseologie. 2010;30:A92.

- Van Kruchten R, Gilio K, Feijge MA, Nieswandt B, Bevers EM, and Heemskerk JW. Inhibitors of store-operated calcium entry to target the platelet procoagulant response. Hämostaseologie. 2010;30:A93.

- Mattheij N, Gilio K, van Kruchten R, Feijge MA, Bevers EM, Jobe S, Cosemans JM, and Heemskerk JW. Regulation of integrin closure in procoagulant platelets. J Thromb Haemost. 2011; 7:Supplement 2.

- Van Kruchten R, Wolfs JL, Feijge MA, Mattheij NJ, Collins P, Heemskerk JW, and Bevers EM. Role of TMEM16F in agonist-induced but not apoptosis-induced phosphatidylserine exposure in Scott platelets. J Thromb Haemost. 2011;9: Supplement 2.

- Nergiz-Unal R, Lamers MM, van Kruchten R, Cosemans JM, Luiken J, Glatz JF, Kuijpers MJ, and Heemskerk JW. Signaling role of CD36 in platelet adhesion and spreading. J Thromb Haemost. 2011;9:Supplement 2.

- Van Kruchten R, Braun A, Feijge MA, Schmidt DE, Kraft P, Stoll G, Kuijpers MJ, Bevers EM, Nieswandt B, and Heemskerk JW. Store-operated calcium entry as a potential target to suppress arterial thrombus formation. J Thromb Haemost. 2011;9:Supplement 2.

- de Witt SM, Lamers MM, Swieringa F, van Kruchten R, Farndale RW, Clemetson $\mathrm{KJ}$, Cosemans JM, and Heemskerk JW. Synergy of platelet receptors in thrombus 
formation: a microarray approach. 58th Meeting of SSC/ISTH, Liverpool, UK, 2630 June 2012.

- Mattheij NJ, Gilio K, van Kruchten R, Jobe SM, Du X, Wieschhaus AJ, Chishti AH, Collins P, Heemskerk JW, and Cosemans JM. Dual mechanism of integrin closure in procoagulant platelets. Proc EUPLAN Conference, Maastricht, NL, 19-21 September 2012.

- De Witt SM, Lamers MM, Swieringa F, van Kruchten R, Farndale RW, Clemetson $\mathrm{KJ}$, Cosemans JM, and Heemskerk JW. Multiparameter assessment of thrombus formation: A systems biology approach. Proc EUPLAN Conference, Maastricht, NL, 19-21 September 2012.

- Van Kruchten R, Mattheij NJ, Saunders C, Feijge MA, Collins PW, Heemskerk JW, and Bevers EM. Scott syndrome platelets demonstrate presence of TMEM16Fdependent and -independent phospholipid scrambling in both platelet apoptosis and platelet activation. Proc EUPLAN Conference, Maastricht, NL, 19-21 September 2012.

- Kuijpers MJ, Nergiz-Unal R, de Witt SM, van Kruchten R, Korporaal SJ, Febbraio M, Hoylaerts M, Tjwa M, Voshol PJ, Cosemans JM, and Heemskerk JW. Subtle role of platelet thrombospondin-1 interaction with CD36 in murine thrombus formation on collagen. Proc EUPLAN Conference, Maastricht, NL, 19-21 September 2012.

\section{Oral presentations and awards:}

- Van Kruchten R: Role of platelet Orai1 and Stim1 in GPVI-dependent and GPVI-independent thrombus formation and procoagulant activity. XXIIth Congress of the International Society on Thrombosis and Haemostasis (ISTH), Boston MA, USA, June, 2009.

- Van Kruchten R: Roles of platelet STIM1 and Orai1 in glycoprotein VI- and thrombin-dependent procoagulant activity and thrombus formation. NVTH/BSTH Joint Symposium, Noordwijkerhout, NL, 23-25 June 2010.

- Van Kruchten R: Store-operated calcium entry as a potential target to suppress arterial thrombus formation. XXIIIth Congress of the International Society on Thrombosis and Haemostasis (ISTH), Kyoto, JPN, July, 2011.

- Van Kruchten R: Role of TMEM16F in agonist-induced but not apoptosis-induced phosphatidylserine exposure in Scott platelets. XXIIIth Congress of the ISTH, Kyoto, JPN, July, 2011.

- Van Kruchten R: Young investigator award 2011 of the ISTH, XXIIIth ISTH Congress, Kyoto, JPN, July 2011. 
Dankwoord 
Zonder de hulp van velen, had dit proefschrift in zodanige vorm nooit tot stand kunnen komen. Dit onderdeel van mijn thesis is dan ook bedoeld om deze mensen te bedanken voor de hulp en support tijdens mijn promotie-onderzoek.

Allereerst wil ik Johan en Edouard, mijn promotor en co-promotor, bedanken voor de kans die ze mij hebben geboden. Ik had dit proefschrift nooit kunnen afronden zonder jullie inzet, kennis, creativiteit en motiverende kracht. Het was een voorrecht om gebruik te kunnen maken van jullie enorme expertise op het gebied van calciumsignalering en fosfolipidenscrambling. De deur stond bij jullie altijd open en ik heb mij gedurende het promotietraject altijd volledig gesteund gevoeld door jullie beiden. Ik ben er dan ook trots op dat mijn proefschrift zo duidelijk jullie beider handtekening draagt.

A great part of the studies described in thesis, could not be performed without the help of international collaborators. Dear Prof. Bernhard Nieswandt, Dr. Attila Braun and all other (former) colleagues of your group, I would like to express my gratitude for your constant willingness and enthusiasm to collaborate. I have always felt very welcome at your lab, as we always got excellent support for our experiments. Moreover I would like to thank Prof. Kleinschnitz, Prof. Stoll, Prof. Kunzelmann, Prof. Collins, Prof. Vortkamp and their coworkers for their willingness to collaborate on various projects.

Het grootste deel van promotie-onderzoek vond natuurlijk gewoon in Maastricht plaats. Ik heb het geluk gehad dat ik daar in een geweldig leuke groep heb mogen werken. Het is zoveel makkelijker om de onvermijdelijke tegenslagen die een promotietraject met zich meebrengt te overwinnen, als je kan rekenen op de support van zulke fijne collega's. Niet alleen hebben jullie mij geholpen in mijn onderzoek middels het meehelpen aan experimenten en met jullie waardevolle adviezen, maar ook hebben we samen veel plezier gehad. Susanne, Nadine, Frauke, Moniek, Karen, Paola, Marion, Marijke, Judith, Reyhan, Siamack, Tom, Roosje, Constance en Jilke, ik wens jullie dan ook al het beste voor de toekomst en ik hoop dat we nog lang contact mogen houden.

David en Bart wil ik bedanken voor hun bijdrage aan mijn onderzoek tijdens hun stages. Ook Jef ben ik erkentelijk voor zijn hulp bij enkele experimenten. Ook een woord van dank aan de overige werknemers van de afdeling Biochemie, voor hun behulpzaamheid, de leuke sfeer, en waardevolle adviezen die ik heb mogen ontvangen. Tevens een bedankje aan alle vrijwilligers die middels het doneren van bloed hebben bijgedragen aan mijn onderzoek.

Het promotietraject was waarschijnlijk heel wat zwaarder en vooral saaier geweest, zonder de leuke momenten die ik heb mogen delen met mijn vrienden. Raymond en Pieter, het is fijn om te weten dat ongeacht de woonafstand, ik altijd kan rekenen op jullie vriendschap. Jeroen, al vroeg in de studie zijn we bevriend geraakt en het is mooi dat (ondanks dat ik inmiddels in de randstad woon), we elkaar nog altijd geregeld weten te vinden. Tevens wil ik mijn overige studievrienden bedanken, die ik verspreid over de vele afdelingen van de universiteit kon vinden. Het was altijd leuk om met jullie bij te kletsen en 
prettig om de ergernissen van een promotietraject te kunnen delen. Ook mijn Posterholtse (voetbal)vrienden wil ik bedanken voor al de leuke stapavonden en uitstapjes die we samen hebben beleefd. Ook al woon ik nu niet meer in de buurt, ik weet zeker dat met onze geweldige groep, er nog vele mooie uitstapjes en stapavonden zullen volgen. Dank ook aan de mannen van PSV'35, voor de gezellige sfeer tijdens het broodnodige stukje ontspanning in het weekend.

Graag maak ik hier ook gebruik van de mogelijkheid om mijn (schoon)familie te bedanken voor alle steun die zij mij hebben gegeven bij het afronden van mijn promotie. Ondanks dat het vrijwel onmogelijk was om inhoudelijk bij te dragen aan mijn onderzoek, leefden jullie wel mee met het hele promotietraject. Daarnaast stelden jullie mij bij momenten in staat, middels bijvoorbeeld het tijdelijk overnemen van de zorg voor Mads, om te kunnen werken aan de afronding van deze thesis. Dus pap, mam, Suzan, Yvonne, Erik, en ook Patty en Chris, bedankt voor al jullie support.

Natalie, dit laatste deel van mijn dankwoord gebruik ik om nog eens te benadrukken hoe blij ik ben dat ik mijn leven met jou mag delen. Na een jaar veel reizen, heb jij de grote stap genomen om naar Limburg te verhuizen. Daar hebben we heerlijk samengewoond, met natuurlijk de geboorte van onze lieve, grote kleine vent Mads als hoogtepunt. Vooral sinds onze verhuizing naar Nootdorp, heb ik veel taken op jou afgeschoven om zelf te kunnen werken aan de afronding van dit proefschrift. Zonder jouw hulp was dit dan ook nooit zo voorspoedig gelukt, en ik ben je dan ook enorm dankbaar voor al jouw begrip, steun en liefde gedurende deze periode. 
